\title{
ANALYTICAL AND EXPERIMENTAL EVALUATION OF JOINING CERAMIC OXIDES TO CERAMIC OXIDES AND CERAMIC OXIDES TO METAL FOR ADVANCED HEAT ENGINE APPLICATIONS
}

J. Ahmad, B. Majumdar, A. R. Rosenfield, S. L. Swartz, J. Cawley, E. Park, D. Hauser, and A. T. Hopper

Date Published-April 1992

\author{
FINAL REPORT
}

Prepared by Battelle Columbus Laboratories

$50 j$ King Avenue

Columbus, Ohio 43201-2693

$86 \mathrm{X}-\mathrm{SB} 046 \mathrm{C}$

\author{
Funded by \\ Office of Transportation Materials \\ Office of Transportation Technologies \\ the Assistant Secretary for Conservation and Renewable Energy \\ U.S. Department of Energy \\ EE 5101000
}

for

OAK RIDGE NATIONAL LABORATORY

Oak Ridge, Tennessee 37831

managed by

MARTIN MARIETTA ENERGY SYSTEMS, INC.

for the

U.S. DEPARTMENT OF ENERGY

under Contract DE-AC05-84OR21400

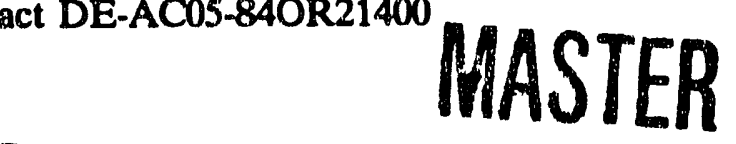

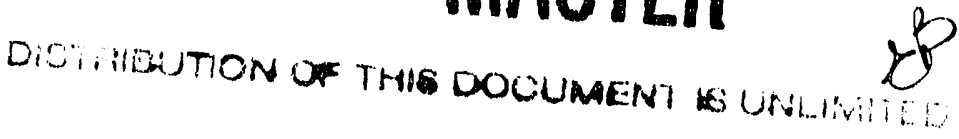


CONTENTS

Page

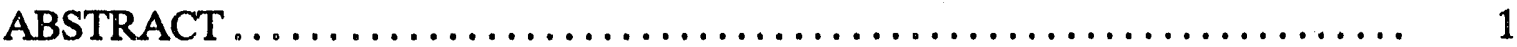

EXECUTIVE SUMMARY. . . . . . . . . . . . . .

ANALYTICAL DESIGN METHODOLOGY $\ldots \ldots \ldots \ldots \ldots \ldots \ldots \ldots, 2$

JOINT FABRICATION $\ldots \ldots \ldots \ldots \ldots \ldots \ldots \ldots \ldots \ldots \ldots \ldots \ldots, 4$

Materials Selection ................................ 5

Zirconia/Zirconia Joint Fabrication ..................... 5

Zirconia/Nodular Cast Iron Joint Fabrication $\ldots \ldots \ldots \ldots \ldots \ldots \ldots .5$

Joint Scale-Up $\ldots \ldots \ldots \ldots \ldots \ldots \ldots \ldots \ldots \ldots \ldots \ldots \ldots \ldots, 6$

CHARACTERIZATION AND ANALYSIS OF JOINTS

AND MONOLITHIC MATERIALS $\ldots \ldots \ldots \ldots \ldots \ldots \ldots \ldots \ldots \ldots, 6$

VALIDATION OF JOINT ASSESSMENT AND

DESIGN METHODOLOGY $\ldots . \ldots \ldots \ldots \ldots \ldots \ldots \ldots \ldots \ldots \ldots, \quad 7$

1.0 CERAMIC OXIDE JOINT DESIGN METHODOLOGY $\ldots \ldots \ldots \ldots \ldots, 7$

1.1 JOINT ASSESSMENT AND DESIGN

MODEL FORMULATION $\ldots . \ldots \ldots \ldots \ldots \ldots \ldots \ldots \ldots \ldots, \quad 7$

1.2 ZIRCONIA/ZIRCONIA BEND SPECIMEN ............... 11

1.3 ZIRCONIA/NODULAR CAST IRON BEND

SPECIMEN $\ldots . \ldots \ldots \ldots \ldots \ldots \ldots \ldots \ldots \ldots \ldots \ldots, 15$

1.4 ZIRCONIA/ZIRCONIA DISK SPECIMEN $\ldots \ldots \ldots \ldots \ldots \ldots \ldots, 16$

1.5 ZIRCONIANNODULAR CAST IRON DISK

SPECIMEN $\ldots \ldots \ldots \ldots \ldots \ldots \ldots \ldots \ldots \ldots \ldots \ldots \ldots, 18$

1.6 DISCUSSION OF THE JAD MODEL $\ldots \ldots \ldots \ldots \ldots \ldots \ldots \ldots, 19$

$2.0 \quad$ JOINT FABRICATION $\ldots \ldots \ldots \ldots \ldots \ldots \ldots \ldots \ldots \ldots \ldots \ldots \ldots \ldots . \ldots \ldots, 21$

$2.1 \quad$ MATERIALS SELECTIONS $\ldots \ldots \ldots \ldots \ldots \ldots \ldots \ldots \ldots \ldots . \ldots \ldots$

2.1.1 Zirconia .................................... 21

2.1.2 Nodular Cast Iron $\ldots \ldots \ldots \ldots \ldots \ldots \ldots \ldots \ldots \ldots \ldots, 21$ 
CONTENTS (cont.)

Page

2.2 ZIRCONIA/ZIRCONIA JOINTS $\ldots \ldots \ldots \ldots \ldots \ldots \ldots \ldots \ldots, 23$

2.2.1 Sol-gel Zirconia Interlayer $\ldots \ldots \ldots \ldots \ldots \ldots \ldots \ldots \ldots \ldots, 23$

2.2.2 CTS and CAS Interlayers ......................... 25

2.2.3 MASZ Interlayers $\ldots \ldots \ldots \ldots \ldots \ldots \ldots \ldots \ldots \ldots \ldots, 25$

2.3 Zirconia/Nodular Cast-Iron Joints $\ldots \ldots \ldots \ldots \ldots \ldots \ldots \ldots \ldots, \quad 30$

3.0 CHARACTERIZATION AND ANALYSIS OF JOINTS

AND MONOLITHIC MATERIALS $\ldots \ldots \ldots \ldots \ldots \ldots \ldots \ldots \ldots, \quad 35$

3.1 OBJECTIVES OF CHARACTERIZATION $\ldots \ldots \ldots \ldots \ldots \ldots . . \ldots$

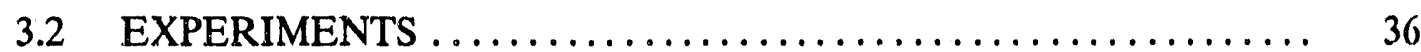

3.2.1 Materials Characterized $\ldots \ldots \ldots \ldots \ldots \ldots \ldots \ldots \ldots \ldots . \quad 36$

3.2.2 Specimen Design ................................ 39

3.2.3 Key Properties Characterized $\ldots \ldots \ldots \ldots \ldots \ldots \ldots \ldots \ldots, 45$

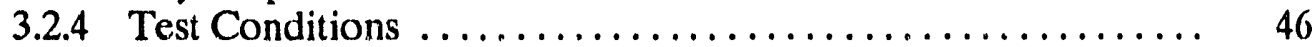

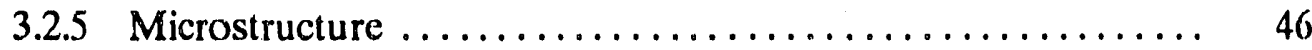

3.2 .6 Fractography $\ldots \ldots \ldots \ldots \ldots \ldots \ldots \ldots \ldots \ldots \ldots \ldots, \quad 47$

3.2.7 Preliminary Analysis of Data $\ldots \ldots \ldots \ldots \ldots \ldots \ldots \ldots \ldots, 57$

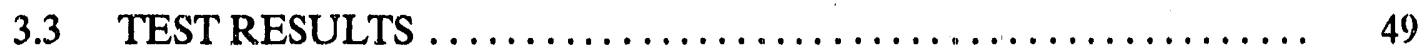

3.3.1 Properties of Constituent Materials $\ldots \ldots \ldots \ldots \ldots \ldots \ldots \ldots$........ 49

3.3.2 Preliminary Validation Results .................... 65

3.3.3 Microstructure and Fractography of Joints ............ 76

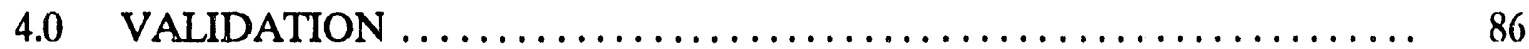

5.0 CONCLUSIONS AND RECOMMENDATIONS $\ldots \ldots \ldots \ldots \ldots \ldots \ldots, 89$

ACKNOWLEDGEMENTS $\ldots \ldots \ldots \ldots \ldots \ldots \ldots \ldots \ldots \ldots \ldots \ldots \ldots, \quad 91$

REFERENCES $\ldots \ldots \ldots \ldots \ldots \ldots \ldots \ldots \ldots \ldots \ldots \ldots \ldots \ldots \ldots \ldots \ldots \ldots \ldots \ldots, \quad 92$ 


\section{FIGURES}

$\underline{\text { Page }}$

Figure 1. Schematic of joint design methodology development $\ldots \ldots \ldots \ldots$

Figure 2. Test specimen geometries studied by finite element analysis ...... 9

Figure 3. Graphical representation of assessment vector and failure curve $\ldots 10$

Figure 4. Assessment diagram for zirconia/zirconia bend specimen $\ldots \ldots \ldots 15$

Figure 5. Assessment diagram for zirconia/cast iron bend specimen $\ldots \ldots \ldots 16$

Figure 6. Assessment diagram for zirconia/zirconia disk specimen $\ldots \ldots \ldots \ldots 18$

Figure 7. Assessment diagram for zirconia/cast iron disk specimen . . . . . . 19

Figure $8 . \quad$ Variation in failure curve shape $\ldots \ldots \ldots \ldots \ldots \ldots \ldots \ldots \ldots$

Figure 9. Summary of joint types and fabrication techniques $\ldots \ldots \ldots \ldots \ldots 21$

Figure 10. Optical micrographs of zirconia joint produced by hotforging at $1500 \mathrm{C}$ with a sol-gel zirconia interlayer .......... 24

Figure 11. Optical micrographs of small-scale zirconia joints produced by hot-forging with calcia-titania-silica CTS interlayers ......... 27

Figure 12. Optical micrographs of small-scale zirconia joints produced by hot-forging with calcia-alumina-silica (CAS) interlayers $\ldots \ldots \ldots 28$

Figure 13. Optical micrograph of large-scale zirconia joint produced by hot-forging with the CTS-3 interlayer composition and SEM micrograph of the fractured surface of a bend-test specimen produced from the above joint $\ldots \ldots \ldots \ldots \ldots \ldots \ldots \ldots \ldots \ldots 28$

Figure 14(a). Backscattered electron image of the interlayer region of an active filler metal joint fabricated using as-ground $\mathrm{NCI}$ polished, zirconia, and Incusil-ABA filler metal ........... 32

Figure 14(b). WDS element map for $\mathrm{Ti} \ldots \ldots \ldots \ldots \ldots \ldots \ldots \ldots \ldots \ldots \ldots \ldots$

Figure $14(\mathrm{c}) . \quad$ WDS element $\operatorname{map}$ for $\mathrm{In} \ldots \ldots \ldots \ldots \ldots \ldots \ldots \ldots \ldots \ldots$

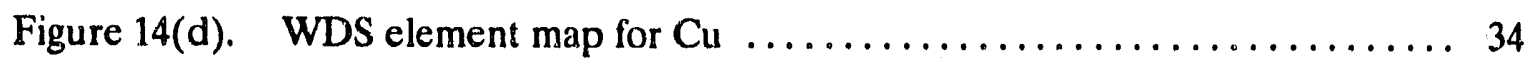

Figure $14(\mathrm{e}) . \quad$ WDS element map for $\mathrm{Ag} \ldots \ldots \ldots \ldots \ldots \ldots \ldots \ldots \ldots \ldots \ldots$ 


\section{FIGURES (cont.)}

Page

Figure 15. Diagram of characterizations and analyses of materials 37

Figure 16(a). Bend test geometry for evaluation of the bend strength of joints and of constiuent materials. Displacement, , 8 , was measured between the upper loading pins and the center of the compression face of the bend bar, using a high-resolution LVDT . .......... 40

Figure 16(b). Notched bend test geometry for evaluating the fracture toughness of constituent materials, and for preliminary validation testing of joints

Figure 17. Experimental setup for bend iesting of constituent materials and joints. The LVDT core-rod is located at the center, above the specimen $\ldots \ldots \ldots \ldots \ldots \ldots \ldots \ldots \ldots \ldots \ldots \ldots, 41$

Figure 18(a). Un-notched disk specimen for measuring the shear strength of joints

Figure 18(b). Chevron-notched cracked disk specimen used in final validation testing of joints . . . . . . . . . . . . . . . . . . . . . . . . . . . . 43

Figure 19. Photograph of zirconia/NCI cracked disk specimen $\ldots \ldots \ldots \ldots .44$

Figure 20. Experimental setup used in final validation testing of joints using cracked disk specimens

Figure 21. Thermal expansion trace of base zirconia from room

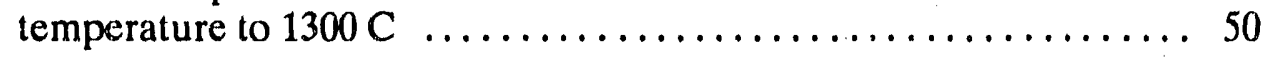

Figure 22. Thermal expansion trace of base zirconia from room

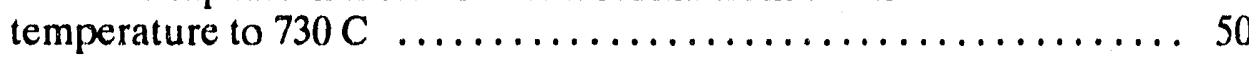

Figure 23. Thermal expansion of MASZ-67 material from room temperature to $1300 \mathrm{C} \ldots \ldots \ldots \ldots \ldots \ldots \ldots \ldots \ldots \ldots \ldots \ldots$

Figure 24. Thermal expansion of zirconia/NCI joint $\ldots \ldots \ldots \ldots \ldots \ldots \ldots .51$

Figure 25. Room temperature stress-strain behavior of as-received zirconia

Figure 26. Room temperature stress-strain behavior of heat-treated zirconia 


\section{FIGURES (cont.)}

Page

Figure 27. Room temperature stress-strain behavior of nodular cast iron $\ldots \ldots \ldots \ldots \ldots \ldots \ldots \ldots \ldots \ldots \ldots \ldots \ldots \ldots, 54$

Figure 28. Room temperature stress-strain behavior of Incusil ABA braze metal .................................. 54

Figure 29. Room temperature stress-strain behavior of MASZ-67 material . . . 55

Figure 30. Room temperature stress-strain behavior of MASZ-80 material . ... 55

Figure 31. Source of specimens machined from the joined 2 -inch billets .....63

Figure 32. Weibull plot showing comparison of strength of zirconia/zirconia joints and bulk constituent materials $\ldots \ldots \ldots \ldots \ldots \ldots \ldots \ldots .65$

Figure 33. Weibull plot showing comparison of zirconia/zirconia joints and constituent materials as a function of percent zirconia powder in interlayer $\ldots \ldots \ldots \ldots \ldots \ldots \ldots \ldots \ldots \ldots, 66$

Figure 34. Weibull plot for zirconia/NCI joints $\ldots \ldots \ldots \ldots \ldots \ldots \ldots \ldots, 67$

Figure 35. Load versus displacement plots for bend bars fabricated with MASZ-67 interlayer and its constituent materials .......... 68

Figure 36. Load versus displacement plot for zirconia/NCI joint ......... 68

Figure 37. Strain energy release rate as a function of mode mixity for zirconia/zirconia specimens $\ldots \ldots \ldots \ldots \ldots \ldots \ldots \ldots \ldots \ldots \ldots, 73$

Figure 38. Strain energy release rate as a function of mode mixity for zirconia/NCI specimens $\ldots \ldots \ldots \ldots \ldots \ldots \ldots \ldots \ldots \ldots \ldots, 73$

Figure 39. Load versus crack opening displaciment plot for a zirconia/zirconia cracked disk specimen. Specimen loaded

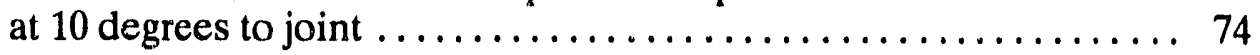

Figure 40. Load versus disk crack opening displacement plot for zirconia/zirconia cracked disk specimen $\ldots \ldots \ldots \ldots \ldots \ldots \ldots \ldots, 75$

Figure 41. Load versus disk crack opening displacement plot for zirconia/NCI cracked disk specimen. Specimen loaded at 0 degrees to joint 


\section{FIGURES (cont.)}

Figure 42. Load versus disk crack opening displacement plot for zirconia/NCI cracked disk specimen. Specimen loaded at 15 degrees to joint

Figure 43. Microprobe BSE image of a large scale zirconia/zirconia joint fabricated using a MASZ-67 interlayer $\ldots \ldots \ldots \ldots \ldots \ldots \ldots, 77$

Figure 44. SEM micrograph of fracture surface of as-received zirconia ...... 78

Figure 45. SEM micrograph and corresponding EDS trace of a zirconia/zirconia joint fabricated withMASZ-67interlayer. The micrograph and EDS trace indicate that the crack propagated through the MASZ-67 interlayer $\ldots \ldots \ldots \ldots \ldots \ldots \ldots$

Figure 46. Microprobe BSE image and elemental maps for a zirconia/NCI joint. (a) low magnification micrograph with NCI on left side, braze in the middle, and zirconia on the right side; (b) BSE image of the braze/zirconia interface at a high magnification; (c) and (c) are Ti and Cu maps, respectively, of the samie region as (b)

Figure 47. Fracture surfaces of a zirconia/NCI joint for a notched bend bar. (a) NCI side of the fracture surface; (b) zirconia side of the fracture surface $\ldots \ldots \ldots \ldots \ldots \ldots \ldots \ldots \ldots \ldots . . .63$

Figure 48. Microstructure of the NCI (left) and zirconia (right) immediately adjacent to the fracture surface. The cross-sections are not matching halves of the fracture surface $\ldots \ldots \ldots \ldots \ldots \ldots \ldots . .6$

Figure 49. Fracture surfaces of a zirconia/NCl joint for a cracked disk specimen, with the crack at an angle of 20 degrees ( $\Psi=80.4$ degrees) with respect to the load line. (a) NCI side of the fracture surface; (b) zirconia side of the fracture surface $\ldots \ldots \ldots \ldots \ldots \ldots \ldots \ldots . . .65$

Figure 50. Results of validation analyses and testing with zirconia/zirconia and zirconia/NCI joints. Bend bars were used for preliminary validation. Disk specimens were used for final validation $\ldots \ldots \ldots \ldots 86$

Figure 51. Role of JAD model: (a) structural integrity assessment and (b) joint design 


\section{TABLES}

Page

Table 1. Parameters used in assessment diagram calculations ........... 15

Table 2. $\quad \mathrm{CaO}^{-\mathrm{TiO}_{2}} \mathrm{SiO}_{2}(\mathrm{CTS})$ interlayer compositions $\ldots \ldots \ldots \ldots \ldots \ldots 26$

Table 3. $\quad \mathrm{CaO}-\mathrm{Al}_{2} \mathrm{O}_{3}-\mathrm{SiO}_{2}(\mathrm{CAS})$ interlayer compositions $\ldots \ldots \ldots \ldots \ldots \ldots 26$

Table 4. $\quad \mathrm{MgO}-\mathrm{Al}_{2} \mathrm{O}_{2}-\mathrm{SiO}_{2}-\mathrm{TiO}_{2}-\mathrm{ZrO}_{2}$ (MASZ) interlayer compositions .... 30

Table 5. Stress-strain parameters for constituent materials used in zirconia/zirconia and zirconia/NCI joining $\ldots \ldots \ldots \ldots \ldots \ldots \ldots, 56$

Table 6. Bend-test results of constituent materials and joints .......... 57

Table 7. Fracture toughness test results of constituent materials and joints ...61

Table 8. Fracture toughness test results of constituent materials ........ 64

Table 9. Average bend strength of zirconia/zirconia and zirconia/NCI

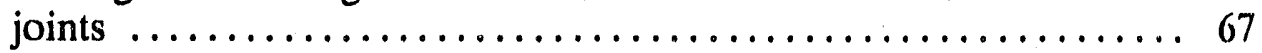

Table 10. Average toughness values of constituent materials ........... 70

Table 11. Results of fracture tests on cracked and uncracked disk specimens $\ldots \ldots \ldots \ldots \ldots \ldots \ldots \ldots \ldots \ldots \ldots \ldots \ldots \ldots \ldots, 72$

Table 12. $\quad$ Preliminary and final validation calculations $\ldots \ldots \ldots \ldots \ldots \ldots . .68$ 


\section{LIST OF SYMBOLS}

coefficient of linear thermal expansion

constant appearing in Equation (25)

contour of integration

constant appearing in Equation (25)

Kronecker delta

difference between joining temperature and test temperature

Bimaterial constant

strain

logarithmic term in stress field

angle measured from disk-bond line to compressive loading direction

measure of thermal stress singularity at the specimen edge

shear modulus

Poisson's ratio

stress

yield strength

critical stress value

uniform compressive residual stress

residual stress

nominal residual stress

stress component in the $\mathrm{x}$-direction

angle that assessment vector makes with the strength axis

distance between center of interlayer and crack location

phase angle measuring degree of mode I and mode II fracture toughness

mixity

one half the total crack length

dimensionless crack length, a/W

a

A

assessment vector magnitude

A assessment vector

B specimen thickness

C parameter in failure criterion on page 39

c denotes ceramic when used as subscript

C geometry dependent factor in asymptotic residual stress solution

D coefficient in Ramberg-Osgood relation

$\mathrm{E} \quad$ Young's modulus

$F_{\mathrm{R}} \quad$ rational function of $\mathrm{a} / \mathrm{W}$ used in calculating the residual stress load

parameter $\mathbf{P}_{\mathrm{A}}$

$f_{s} \quad$ shielding factor due to mismatches in Young's modulus

crack driving force

G total (elastic-plastic) energy release rate

$\mathrm{G}_{\mathrm{c}} \quad$ critical crack driving force

$G_{\theta} \quad$ elastic crack tip energy release rate

$\mathrm{G}_{\mathrm{r}} \quad$ dimensionless crack driving force parameter

i

denotes interlayer when used as subscript 


\section{LIST OF SYMBOLS (cont.)}

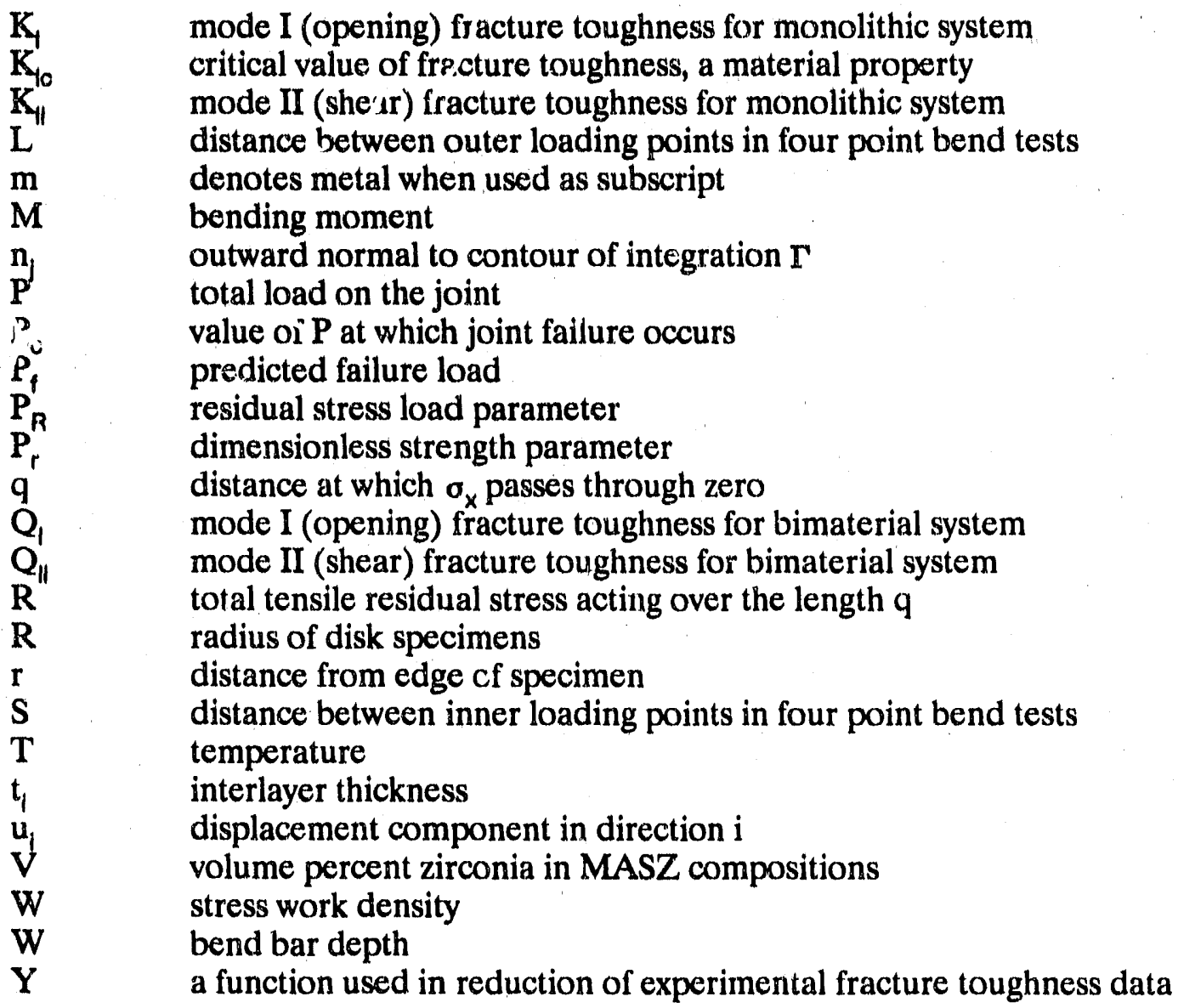


FINAL REPORT

on

\title{
ANALYTICAL AND EXPERIMENTAL EVALUATION OF JOINING CERAMIC OXIDES TO CERAMIC OXIDES AND CERAMIC OXIDES TO METAL FOR ADVANCED HEAT ENGINE APPLICATIONS
}

December 31, 1990

J. Ahmad, B. Majumdar, A. R. Rosenfield, S. L. Swartz, J. Cawley, E. Park, D. Hauser, and A. T. Hopper

\begin{abstract}
The problem of designing reliable, high strength zirconia-to-zirconia and zirconia-tonodular cast iron joints is addressed by developing a general joint design and assessment methodology. A joint's load carrying capability is predicted in terms of its material strength and fracture toughness characteristics. The effects of joint constituent properties and joining process variables are included. The methodology is verified in a two step process by applying it first to notched bend bars and then to a notched disk specimen loaded in compression.

Key technical accomplishments in the program include the development of a joint design and assessment methodology which predicts failure based on a combination of strength and toughness, the development of a new method of hot forging magnesia partially stabilized zirconia to itse'f, and the development of a bimaterial disk-shaped specimen notched along the diametral bond line and compressively loaded to generate both shear and tensile loadings on the bond line.

Mechanical and thermal characterization of joints, adherents, and interlayer materials were performed to provide data for input to the design methodology. Results from over 150 room temperature tests and 30 high temperature tests are reported. Extensive comparisons of experimental results are made with model predictions of failure load.

The joint design and assessment model, as applied to the materials and test specimens of this program, has been programmed for a $\mathrm{PC}$ and is available to interested researchers.
\end{abstract}

\section{EXECUTTVE SUMMARY}

The research discussed in this report was funded by the U.S. Department of Energy under Subcontract No. 86X-SB046C to Martin Marietta Energy Systems. The program was one of three similar contracts dealing with developing a validated design methodology for improving the strength of joints made by joining tough ceramic oxides to either ceramic 
oxides or to metals. This project deals with the development of procedures necessary for the design of reliable, high strength zirconia-to-zirconia and zirconia-to-nodular cast iron joints. The objectives were met by implementing a combined program of analysis and experimentation.

Figure 1 is a schematic of the program showing the relationships between the various tasks and milestones in the joint design methodology. It involved finite element analyses of the joint configurations based on joint geometry, properties of constituent materials (adherents and joint interlayers) and the joining temperature; reduction of the finite element analysis results to a simplified engineering joint assessment and design model; experimental evaluation of the failure load of notched and unnotched bend bars containing joints; using the preliminary validation results to fine tune the joint assessment and design model by incorporating factors which were previously not accounted for; and finally, testing cracked disk specimens and comparing measured and predicted fracture loads as part of the final validation of the methodology.

The joint assessment methodology, as it is currently formulated, can be used in two ways. First, it can be used in the machine design of components containing joints, where the processing conditions and interlayer constituents are already prescribed. Second, the methodology can be used for improving joint performance. In this latter mode, processing temperatures and constituent properties can be altered within limits and the model will provide a quantitative assessment of how those changes affect the load bearing capability of the joint relative to the load bearing capability of the monolithic ceramic of the same geometry.

\section{ANALYTICAL DESIGN METHODOLOGY}

An analytically based joint design methodology has been developed. The methodology has been applied to the particular materials and geometries studied in this program and the results incorporated into a PC code.

The essence of the methodology is that for a given specimen geometry and the manner in which it is loaded, a joint's load carrying capacity is determined by its strength and ıoughness properties. Which of the two properties dictates how and at what load failure occurs depends on their relative magnitude and residual stresses in the joint. Joint constituent properties influence the load carrying capacity of a joint through their inherent strength and toughness. Joining process variables influence the load bearing capacity through their effect on residual stresses, local stress-strain behavior and their effects on interlayer and joint constituent properties.

A key difference in this approach and other available formulations is the way failure depends on a combination of toughness and strength. The current approach represents a synergism of applied stress, crack length, toughness, residual stress, and strength in a selfconsistent manner.

Stress analysis and fracture mechanics based models were developed for determining the stress field, $\sigma$, crack driving force, $G$, and residual stresses $\sigma_{R}$, for the test specimen geometries being tested in this program. These computations used linear and nonlinear finite element analyses which accounted for the physical properties of the joint constituents as well as the joining temperature and interlayer thickness. Other processing variables were 


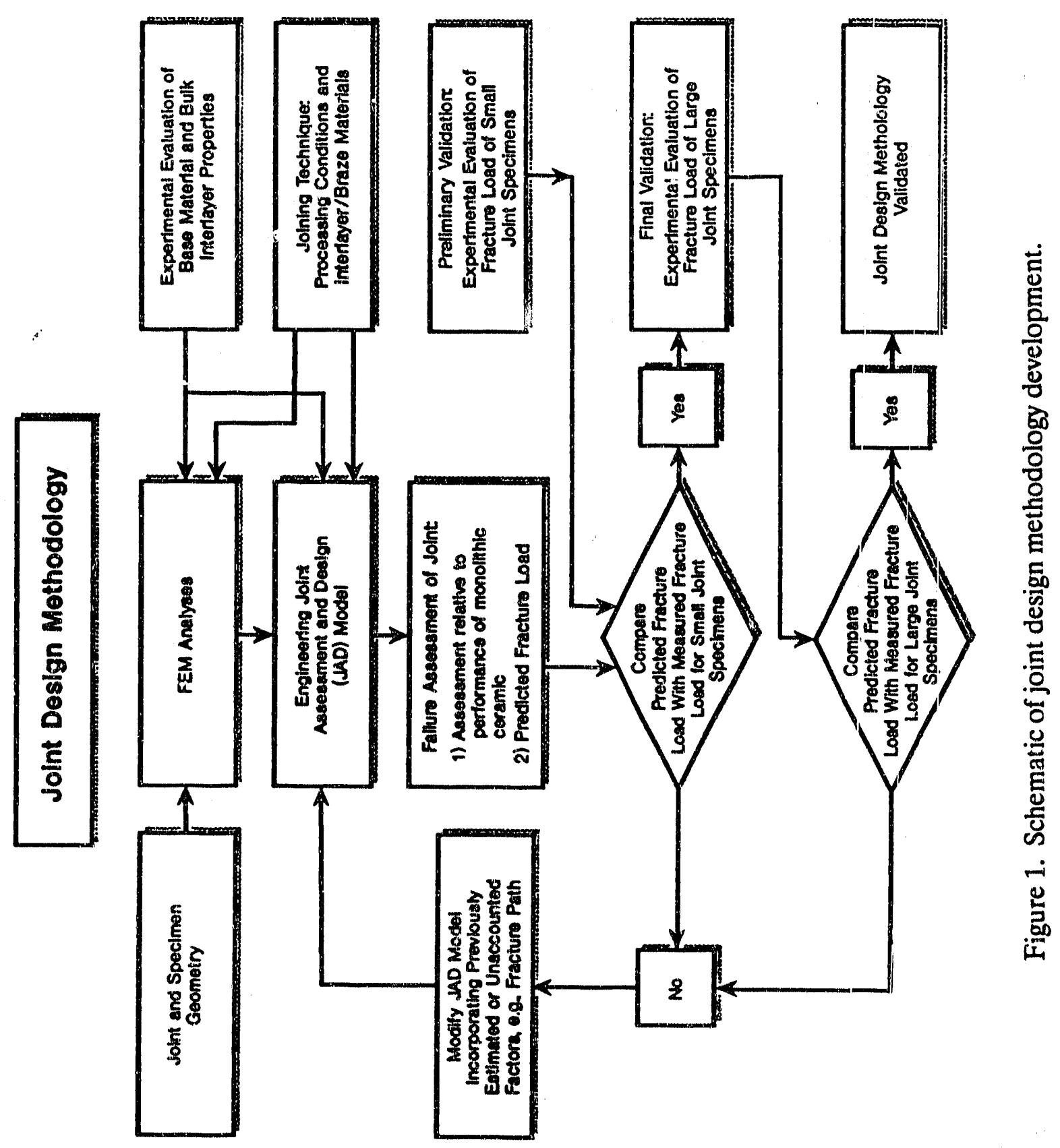


handled empirically. The results of the detailed analyses were used to develop simpler engineering models for estimating the factors which influence joint performance.

A joint assessment and design model (JAD model) which unifies the three primary factors $\left(\sigma, G\right.$ and $\left.\sigma_{R}\right)$ embodies the simplified analysis. The simplicity resides in the fact that the engineering model is fashioned after a homogeneous material. The complexity of the joint constituents and process conditions are handled by incorporating algebraic factors which account for thermal expansion mismatch effects (residual stresses) and shielding effects (arising from elastic modulus mismatch). A joint assessment vector $\AA$ with components depending on strength, crack driving force, residual stress, and load was derived. It has the property that the smaller its magnitude, the less the propensity for failure of the joint. Another aspect of the design model is a failure curve which depends on the joint type and geometry. The conditions for which the vector extends to the failure curve for a given joint type and geometry define failure.

The area enclosed by the failure curve (or a fraction thereof) represents a design space for the joint. So long as $\AA$ is within this space the joint is not predicted to fail under the prescribed load. For failure prediction, both the assessment vector and the failure curve are needed. A different application in which joint improvement is sought only requires the assessment vector. Here, at some specified reference or design load one would try to minimize the length of $\AA$ with respect to suitably constrained values of the constituent properties and process variables.

\section{JOINT FABRICATION}

To validate the methodology and provide input data to the analyses, joints were fabricated by bonding blocks of ceramic and iron materials. Specimens were machined from the resulting billets. All bonds were geometrically simple butit joints to facilitate both analysis and experiment. While smaller joints (typically $1.0-1.6 \mathrm{~cm}^{2}$ ) were produced for initial screening, the strength and fracture test specimens were cut from large $\left(220 \mathrm{~cm}^{2}\right)$ bonded areas.

Since bonded joints are likely to contain measurable flaws, it is essential to measure both strength and fracture toughness, either of which property can control the load-carrying capacity of a joint. Furthermore, because joints composed of dissimilar materials have an inherent mixed mode nature arising from elastic property mismatch between constituents, it is important to assess any design and predictive methodology by imposing various combinations of tensile and shear loads on the joints.

Two geometries were used for mechanical testing: bend bars and disks. The bend bar is the most common specimen for measuring ceramic strength in tension. It is also well established as a fracture-toughness specimen. The disk specimen, developed as part of this research, consists of two D-shaped pieces bonded together and loaded in compression. By varying the angle between the bond line and the loading line, desired proportions of tensile and shear stresses were exerted on the bond line. This design was used for both strength and toughness measurements. 


\section{MATERIALS SELECTION}

Zirconia. Specification of zirconia involved first deciding whether to use one grade for both ceramic/ceramic and ceramic/metal bonds or to tailor the grade to the sond. The choice of a single grade for both bonds provided for the most efficient use of resources in that more effort was devoted to modeling and less to routine material characterization. The magnesia-stabilized grade (Zircoa Zycron L Mg-PSZ) was chosen over a yttria-stabilized grade because it is a more well-established material, a fully-dense ceramic can be more readily produced, and it is easier to machine. It also has good strength and fracture toughness as well as an acceptably low coefficient-of-therma!-expansion mismatch with cast iron.

Nodular Cast Iron. The nodular cast iron (NCI) chosen for this program had a ferritic microstructure, corresponding both to SAE D4018 and to ASTM A536, Grade 60-40-18. The main reason for this choice was that it was the most metallurgically stable grade. It may be noted that significant microstructural changes can occur when $\mathrm{NCI}$ is heated to around $760 \mathrm{C}$, which is only slightly above the temperature range in which brazing is normally carried out. As a result, the mechanical properties of the NCI after brazing can be significantly different from those of the as-received iron and can vary from bond-to-bond, masking the effects of bonding variables and complicating the application of the design model. The major drawback to the chosen grade w'as that it is weaker than the grade used previously in the Oak Ridge National Laboratories (ORNL) bonding studies (D5506) and much weaker than the one currently being used there $(8003)$.

Zirconia/Zirconia Joint Fabrication. Zirconia/zirconia joints were fabricated using a ceramic interlayer that became molten at the joining temperature. Metallic brazes were rejected due to their limited high-temperature capabilities since the goal was to obtain acceptable strength and toughness of joints at temperatures up to $1000 \mathrm{C}$. Initially, two ternary eutectic oxides (calcia-titania-silica and calcia-alumina-silica) were evaluated because they become liquid at a bonding temperature of $1420 \mathrm{C}$ where no phase changes were expected in the base zirconia. These eutectic materials proved to be too weak at room temperature, despite good wetting and minimal influence on residual stresses. The eventual choice of interlayer materialwas magnesia-alumina-silica-zirconia (MASZ) which had acceptable strength and toughness. In order to allow validation of the joint design and assessment methodology over a range of process variables, the composition of the MASZ interlayers was altered by changing the zirconia content.

In addition to fabricating joints with MASZ interlayers, bulk interlayer blocks were fabricated by sintering, and these allowed the determination of thermal expansion coefficients, deformation characteristics, and inherent strength and toughness of bulk MASZ materials.

Zirconia/NCI Joint Fabrication. Brazing of zirconia to NCI was investigated using both the active-substrate and active-filler-metal methods. Attempts to join these materials using the active-substrate brazing method were generally unsuccessful, except when the joint area was small. However, large-area strong bonds were obtained using Incusil- $\mathrm{ABA}$, an active-filler-metal braze (Ag-27.5Cu-12In-1.2Ti), in which the relative amounts of silver, copper, and titanium were nearly the same as produced in the active-substrate brazing 
method. In contrast to the active substrate process, no surface coatings were applied to either the zirconia or the NCI in the active filler metal process and no significant voids were observed in the resulting joint.

\section{Joint Scale-up}

Although initial fabrication using small joints $(2 \mathrm{sq} . \mathrm{cm}$.) with a goal of scaling up to $20 \mathrm{sq} . \mathrm{cm}$. was envisioned, rescarch during the course of the project showed that the larger joints could be fabricated without any additional difficulty. For this reason, the size objective for the joints was achieved.

\section{CHARACTERIZATION AND ANALYSIS OF JOINTS AND MONOLITHIC MATERIALS}

Mechanical and thermal characterization of joints, adherents, and interlayer materials were performed. Specifically, stress-versus-strain curves were measured for the zirconia, MASZ interlayer materials, Incusil-ABA, and the cast iron. In the case of the zirconia, stress-strain behavior for both as received material and material heat treated at $1350 \mathrm{C}$ was measured. Thermal expansion cur ves were obtained over appropriate temperature ranges for each of these materials for use in residual stress calculations. Based on these results and the published literature, estimates were obtained for the flow stress, ultimate tensile strength, elastic modulus, and Poisson's ratio of the adherents as a function of temperature.

Five different specimen types were used to characterize the materials and joints. Unnotched bend specimens were loaded in 4-point bending to determine the bend strength and stress-strain behavior of monolithic materials and specimens containing joints. Notched bend specimens were loaded in 4-point bending to determine the fracture toughness of monolithic materials and specimens containing joints. The notched bend specimens containing joints were used in the preliminary validation procedure. Tensile specimens were used to evaluate the stress-strain behavior of nodular cast iron and Incusil ABA. Uncracked disk specimens were loaded in diametral compression to evaluate the shear strength of zirconia/zirconia joints. Cracked disk specimens were loaded in diametral compression for final validation of the joint design methodology. The disk specimens had bond areas that were approximately 20 times that of the bend bars used in the preliminary validation.

Approximately 160 room temperature tests and 30 high temperature tests were performed to generate material data and validation results. For the zirconia/zirconia joints high temperature tests were performed at $1000 \mathrm{C}$; for zirconia/ $\mathrm{NCI}$ joints high temperature tests were performed at $400 \mathrm{C}$.

Fracture surfaces were examined optically and using a scanning electron microscope. Failure of zirconia/zirconia joints occurred primarily through the ceramic interlayer, although in a few cases the crack also propagated partly through the rcaction zone of the base material. The propensity of the crack to propagate through the interlayer provided a good opportunity to predict the failure load of these joints based on the strength and toughness of the bulk interlayer; this was the approach used in failure load predictions. For the zirconia/NCI joints, however, failure occurred partly through the reaction zone of the 
zirconia and partly through the Ti interface of the braze-metal/zirconia interface. In this system, the fracture toughness associated with the failure location had to be estimated indirectly.

\section{VALIDATION OF JOINT ASSESSMENT AND DESIGN METHODOLOGY}

Two kinds of validation experiments were conducted to compare with the JAD model analyses. Bend bars, both notched and unnotched, were used in preliminary validation experiments. These experiments were conducted to fine tune the model and provide some degree of assurance that the predictions made by the methodology were reasonably accurate. The second type of experiments were termed final validation experiments and were conducted on disk specimens. Because the geometry of the oisk specimens was significantly different than that of the bend bars, these experiments provided a challenging validation of the design methodology developed on this program.

In all of the comparisons made between computations and experiments the parameter used for comparison was the failure load. During preliminary validation the model was used to calculate the failure load of notched bend bars fabricated from zirconia/zirconia joints and zirconia/nndular cast iron joints. Final validation computations were made on disk specimens of a similar variety; zirconia/zirconia disks and zirconia/nodular cast iron disks.

For several tests of zirconia/zirconia bend bars with a notch the measured failure loads had an average value of $211 \mathrm{~N}$. The design model predicted a failure load of $260 \mathrm{~N}$. For zirconia/cast iron bend bars an average failure load of $514 \mathrm{~N}$ was measured. This compares with a calculated value of $505 \mathrm{~N}$. In an example of a zirconia/zirconia disk with a chevron notch and loaded in compression in line with the joint, the measured failure load was $1442 \mathrm{~N}$ while the calculated failure load was $1600 \mathrm{~N}$. A final example is supplied by a metal-ceramic disk loaded in compression with the crack and bond line at an angle of 15 degrees to the load line. The specimen failed at $6631 \mathrm{~N}$ and was predicted to be able to withstand $7100 \mathrm{~N}$. The degree of difference between experiment and theory cited in these examples was typical for all of the validation experiments. A master plot comparing measured and predicted failure loads is presented in Section 4.0 Validation.

\subsection{CERAMIC OXIDE JOINT DESIGN METHODOLOGY}

\subsection{JOINT ASSESSMENT AND DESIGN MODEL FORMULATION}

In this section a predictive model that can be used in design and structural integrity assessments of ceramic to ceramic and metal to ceramic joints for advanced gas turbine and internal combustion engine applications is developed.

In the modeling effort, the measure of joint performance was taken to be its ability to withstand monotonically applied load. A pragmatic, continuum mechanics-based approach was adopted which links joint performance with joining process variables and physical properties of the constituents. The approach was based on the notion that for a given joint configuration, its ability to withstand load is dictated by strength $\left(o_{c}\right)$ and toughness $\left(G_{c}\right)$ properties at the potential failure location and the residual stress $\left(\sigma_{R}\right)$ induced by the joining 
process. Physical properties of the joint constituents (ceramic, metal and joining material) and joint process variables (e.g., interlayer thickness and joining temperature) influence joint performance indirectly by changing $\sigma_{c}, G_{c}$, and $\sigma_{R}$. Also, it was assumed that a micromechanical defect population and distribution associated with a joining process affects joint performance indirectly by changing the apparent strength and toughness properties. The influence of joining area on performance was dealt with empirically by testing specimens with significantly different joint dimensions.

With strength, toughness, and residual stress being the primary factors influencing performance, effort was focussed on developing stress analysis and fracture mechanics based models which would determine the stress field $(o)$, crack driving force $(G)$ and residual stress $\left(\sigma_{R}\right)$ for the test specimen geometries shown in Figure 2. Only cracked/notched specimens with crack lengths significantly larger than the interlayer thickness were included in the JAD model calculations. However, the same methodology can easily be extended to macroscopically uncracked geometries, where any crack would typically have dimensions less than the dimensions of the interlayer thickness. As discussed in Appendix A, this modeling effort involved detailed linear and nonlinear finite element analyses whose results were subsequently used to develop simpler and easier-to-use engineering models for estimating $\sigma, G$ and $\sigma_{\mathrm{R}}$. Input to these stress and fracture mechanics models included physical properties of the joint constituent materials as well as two joining process variables-joining temperature $\left(T_{J}\right)$ and interlayer thickness $\left(t_{i}\right)$. The affect of other joining process variables could only be included empirically. For ceramic/ceramic joints, this was done by developing an empirical relation between joining material (MASZ) composition and the interlayer's elastic modulus, yield strength and toughness.

Following the development of engineering models capable of estimating $\sigma, G$, and $\sigma_{A}$ corresponding to all the loads, specimens and material combinations included in the experimental part of the project, the focus shifted to developing a joint assessment and design model. The objective was to formulate a methodology in which the three primary factors $\left(\sigma_{c}, G_{c}\right.$, and $\left.\sigma_{R}\right)$ would be represented in a synergistic and unified manner. This objective was achieved by invoking concepts in engineering nonlinear fracture mechanics ${ }^{[1,2]}$ to derive an expression for a joint assessment vector $(\bar{A})$ as follows:

$$
\bar{A}=\left(\frac{G_{o}}{G_{c}}\right)^{\frac{1}{2}} i+\left(\frac{P}{P_{c}}\right) j
$$

in which $i$ and $j$ denote orthogonal unit vectors, $P$ is a load parameter (related to joint stresses due to applied loads and residual stresses) and $P_{c}$ is the critical load parameter (related to strength, $\sigma_{c}$ ). The quantity $G_{\theta}$ is the elastic crack tip energy release rate for the cracked joint geometry of interest, corresponding to the combined action of residual stresses and applied load. The magnitude of the vector,

$$
A=\left[\frac{G_{e}}{G_{C}}+\left(\frac{P}{P_{c}}\right)^{2}\right]^{\frac{1}{2}}
$$




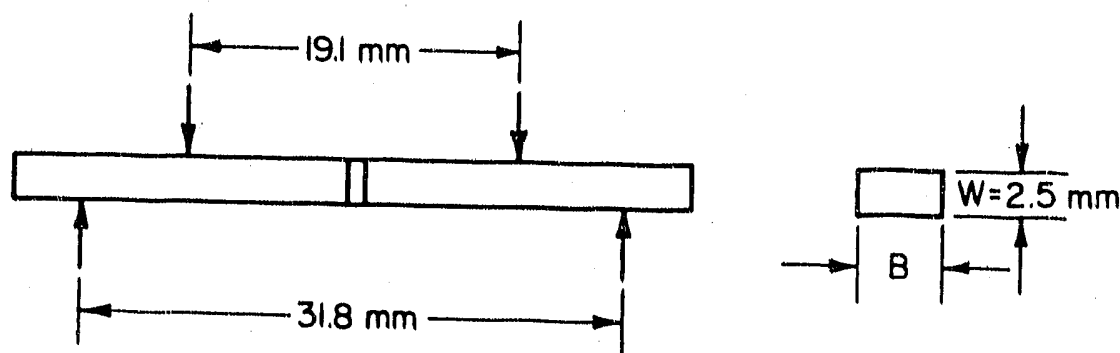

Unnotched Bend Bor, B=5.1 mm

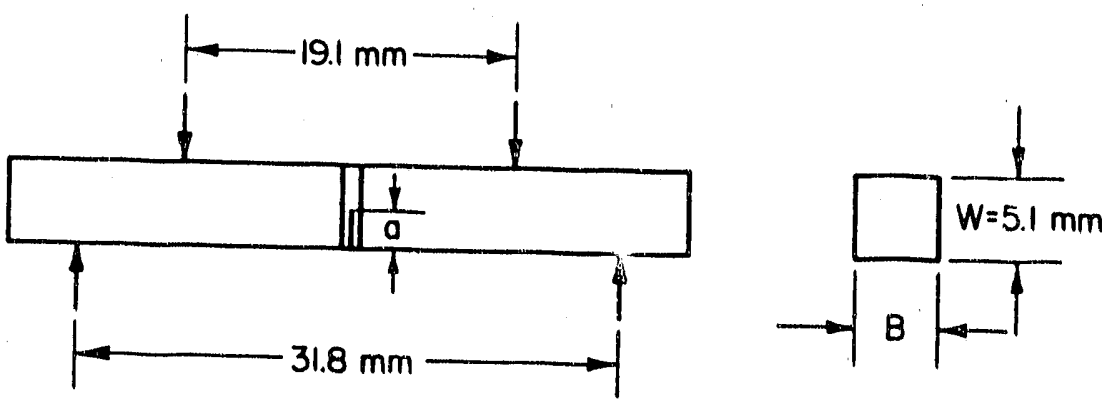

Notched Bend Bar, $A / W=0.30 \mathrm{~mm}, B=5.1 \mathrm{~mm}$

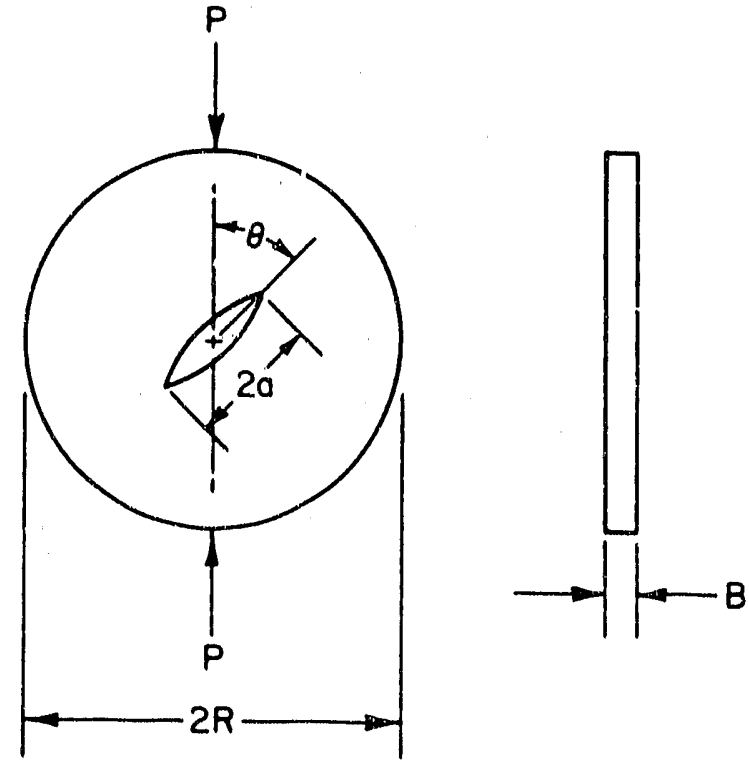

Disk Specimen

Figure 2. Test specimen geometries studied by finite element analysis. 
represents the propensity for joint failure in the direction in G-P space given by

$$
\phi=\tan ^{-1}\left[\frac{\sqrt{G_{\mathrm{e}} / G_{\mathrm{c}}}}{\left(P / P_{c}\right)}\right]
$$

The smaller the magnitude of $\mathrm{A}$, the smaller is the propensity for joint failure. For a given joint type and geometry, failure would occur when the vector intersects the following failure curve

$$
\sqrt{G_{x}}=\frac{\sqrt{G_{e}\left(a, P_{x}\right)}}{G\left(a, P_{x}\right)}
$$

in which $a$ is crack length dimension, $G_{r}=G_{e} / G_{c}, P_{r}=P / P_{c}$ and $G$ represents the total (elastic-plastic) energy release rate. Note that equation (4) defines the failure curve and is not the definition of $G_{r}$. For $P<<P_{o}$, the plastic deformation contribution to $G$ is small, $G$ approaches $G_{e}$, and the right hand side of Equation (4) approaches unity. For $P$ approaching $P_{c}, G>>G_{e}$, and the right hand side of Equation (4) approaches zero.

A graphical representation of the assessment vector [Equation (1)] and the failure curve [Equation (4)] is shown in Figure 3. Using the dimensionless quantities $G_{r}$ and $P_{r}$, the assessment vector can be expressed as follows:

$$
\bar{A}=\left(G_{x}\right)^{\frac{1}{2}} i+\left(P_{x}\right) j
$$

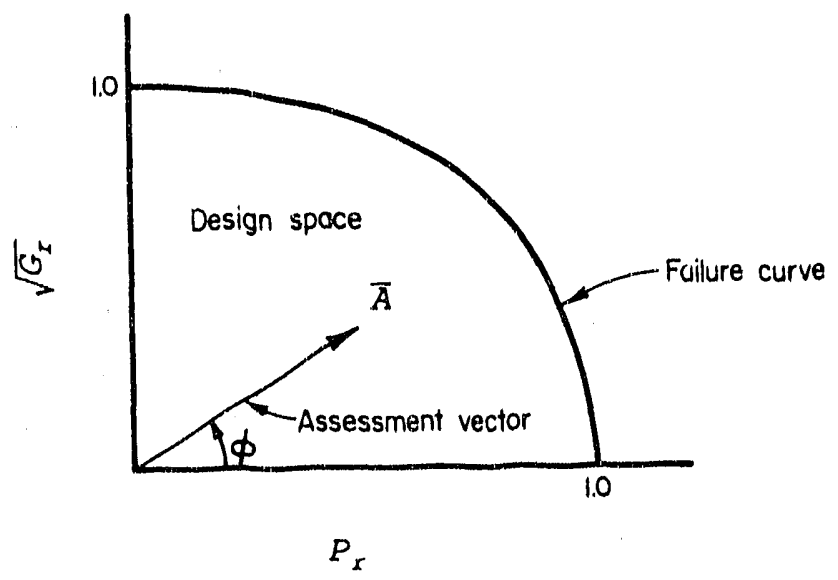

Figure 3. Graphical respresentation of assessment vector and failure curve. 
In the graphical representation of the JAD model, the space enclosed by the failure curve (or a fraction thereof) may be defined as the design space within which the assessment vector $\AA$ would be required to reside. At a reference or anticipated service applied load $\left(P_{A}\right)$, one would try to minimize $A$ with respect to joint constituent properties and process variables to improve joint performance. To predict failure, one would find the applied load $\left(P_{f}\right)$ such that the vector $\AA$ intersects the failure curve. Thus, for failure prediction one needs both the failure curve [Equation (4)] and the assessment vector [Equation (5)]. For improving design, only the assessment vector is needed.

For joint design one needs to specify a reference load $\left(P_{A}\right)$ which is used to find the total load, $\mathrm{P}$, on the joint

$$
P=P_{A}+P_{R}
$$

in the evaluation of $A$. In Equation (6), $P_{B}$ represents a load parameter due to residual stress in the joint. From a practical viewpoint $P_{A}$ should be chosen such that $P_{A}<<P_{A}<\left(S_{F} \cdot P_{f}\right)$ where $S_{F}$ is a safety factor and $P_{i}$ is the failure load. For the present work, we choose $P_{A}$ to be the minimum of the failure loads corresponding to a monolithic specimen of the materials being joined. For example, in designing a nodular cast iron/zirconia bend bar joint, $\mathrm{P}_{\mathrm{A}}$ would be the failure load corresponding to a monolithic zirconia bend bar of the same dimensions and subjected to the same type of loading, knowing that the failure load corresponding to a cast iron bend bar would be higher. This particular choice of $P_{A}$ is, of course, not mandatory. But it may have practical significance if it is argued that a component containing a joint need not withstand any more load than a monolithic component of either of the two materials being joined.

Based on the stress and fracture mechanics engineering models mentioned earlier, expressions for $A$ and $\sqrt{G}_{r}$ for the four joint types and specimen geometry combinations are given in the following paragraphs. Details and justifications for the assumptions involved in their derivation are given in Appendix A.

\subsection{ZIRCONIAVZIRCONIA BEND SPECIMEN}

For cracked zirconia/zirconia bend specimens, the failure curve is given by the following equation:

$$
\sqrt{G_{r}}=\frac{\pi f g}{2 \sqrt{2}} P_{r}\left[\ln \left\{\sec \left(\frac{\pi}{2} \cdot f \cdot g \cdot P_{Y}\right)\right\}\right]^{-\frac{1}{2}}
$$

where

$$
g=1-\sqrt{P_{r}}+\frac{P_{r}}{f}
$$


The assessment vector for this specimen type (for $P_{R}<<P_{c}$ ) is given by the following equation:

$$
\bar{A}=\left\lfloor\frac{3 f(S-L) P}{2 W^{2} t}\left(\frac{\pi a}{E_{1}^{\prime} G_{c 1}}\right)^{\frac{1}{2}}\right] i+P_{r} j
$$

In Equations (7), (8), and (9)

$$
\begin{aligned}
& E_{1}^{\prime}=E_{1} /\left(1-v_{1}^{2}\right) \\
& f=f_{H} \cdot f_{s} \\
& f_{H}=1.12-1.39 \bar{a}+7.32 \bar{a}^{2}-13.1 \bar{a}^{3}+14.0 \bar{a}^{4} \\
& \bar{a}=a / w \\
& f_{s}=1.0+\left(0.376+2.34 \frac{t_{1}}{2 a}\right)\left(1-\frac{\mu_{1}}{\mu_{c}}\right)- \\
& -\left(2.504+3.87 \frac{t_{1}}{2 a}\right)\left(1-\frac{\mu_{1}}{\mu_{c}}\right)^{2} \\
& P_{x}=P_{A} \frac{1.5(S-L) \bar{\sigma}}{W^{2} t \sigma_{O 1}} \\
& P_{A} \approx \frac{W^{2} t}{1.5(S-L) f_{H}}\left(\frac{G_{C C} E_{c}^{\prime}}{\pi a}\right)^{\frac{1}{2}}
\end{aligned}
$$




$$
\begin{gathered}
P=P_{A}+\frac{2 W^{2} t F_{R} \sigma_{R T}}{3(S-L) f} \\
\bar{\sigma}=1.0+\left(\frac{t i}{w}\right)\left(1-\frac{\mu_{1}}{\mu_{G}}\right)\left[177 \frac{t i}{W}-10.9\right] \\
F_{R}=\frac{f_{R}}{\pi \bar{a}-f_{R}^{\prime}} \\
f_{R}=\frac{3.52}{(1-\bar{a})^{\frac{3}{2}}}-\frac{4.35}{(1-\bar{a})^{\frac{1}{2}}+2.13(1-\bar{a})} \\
f_{R}^{\prime}=0.265(1-\bar{a})^{4}+\frac{0.857+0.265(\bar{a})}{(1-\bar{a})^{\frac{3}{2}}}
\end{gathered}
$$

The symbols $v, \mu, E$, and $\sigma_{0}$ represent Poisson's Ratio, the shear modulus, Young's Modulus and yield strength, respectively, with subscripts $i$ and $c$ denoting interlayer (MASZ) and ceramic (zirconia) materials. Geometric dimensions ( $a, W, t, S, L$. and $\mathrm{t}_{\mathrm{t}}$ ) used in Equations (9) to (21) are shown in Figure 2. In Equations (11) and (14) the term $\mathrm{f}_{\mathrm{g}}$ is a shielding factor and accounts for modulus mismatch effects on joint stresses. The word "shielding", in this context, has ben coined because the interlayers used in this investigation (as well as in most other ceramic joining processes) had lower moduli than the adherents, and acted to reduce the local stresses and crack driving forces compared with corresponding values calculated based on a homogeneous material. The quantity $\sigma_{\mathrm{AT}}$ is related to the residual stress across the bond line which occurs close to the specimen edges. At the ceramic-interlayer interface,

$$
\sigma_{R T}=\frac{2 t_{1} \sigma_{t}(\lambda-1)}{\lambda\left(W-2 t_{1}\right)}\left[\left(\frac{\sigma_{t}}{\sigma_{Y}+\sigma_{t}}\right)^{\frac{\lambda}{1-\lambda}}-1\right]
$$

where

$$
\sigma_{t}=\left|\frac{E_{1}^{\prime} E_{c}^{\prime}}{E_{1}^{\prime}+E_{c}^{\prime}}\left[\left(1+v_{1}\right) \alpha_{1}-\left(1+v_{c}\right) \alpha_{c}\right] \cdot \Delta T\right|
$$


$\Delta T=$ Difference between joining temperature $\left(T_{p}\right)$ and test temperature $\left(T_{1}\right)$

$\sigma_{Y}=$ minimum of $\sigma_{o l}$ and $\sigma_{o o}$

$\boldsymbol{\alpha}_{1,0}=$ coefficients of linear thermal expansion corresponding to interlayer (i) and ceramic (c)

$\lambda=1.0+$ power of thermal stress singularity at the specimen edge. For a zirconia/zirconia joint with an MASZ interlayer, $\lambda=0.97$.

For the parameters given in the third line of 'Table 1, a graphical representation of the JAD model application to a zirconia/zirconia bend bar joint is shown in Figure 4. The reference load, which is much higher than the predicted and measured failure load for the joint, is the load whict. would be needed to cause fracture in a geometrically identical monolithic specimen made of zirconia. The predicted failure load correspunds to the intersection of the vector with the curve at $P / P_{0}-0.493$, and is somewhat lower than the measured value of $260 \mathrm{~N}$. To improve joint design one would need to increase $G_{i j \mid}$ and $\sigma_{0}$ (e.g. by increasing zirconia content in the interlayer material) which would reduce the assessment vector length. As discussed later in the report, empirical relations belween $\sigma_{\text {ol }}$ $\mathrm{G}_{\mathrm{cl}}, \mathrm{E}_{1}$ and volume percent $(\mathrm{V})$ of zirconia in the interlayer material (MASZ) are as follows:

$\begin{array}{llll}o_{\text {ol }}=41.4+2.35(\mathrm{~V}-50) & \mathrm{MPa} & \\ \mathrm{E}_{1}=109+0.1588(\mathrm{~V}-50) & \mathrm{GPa} & 50 \leq \mathrm{V}<67 \\ \mathrm{G}_{\mathrm{cl}}=[1.52+0.03(\mathrm{~V}-50)]^{2} / 10^{3} \mathrm{E}_{1} & \mathrm{~N} / \mathrm{m} & \\ \mathrm{o}_{\text {ol }}=74.0+2.13(\mathrm{~V}-67) & \mathrm{MPa} & \\ \mathrm{E}_{1}=111.7+2.2692(\mathrm{~V}-67 & \mathrm{GPa} & 67 \leq \mathrm{V}<80 \\ \mathrm{G}_{\mathrm{cl}}=[2.04+0.06(\mathrm{~V}-67)]^{2} / 10^{3} \mathrm{E}_{1} & \mathrm{~N} / \mathrm{m} & \\ & & & \\ \boldsymbol{o}_{\text {ol }}=101.7+1.95(\mathrm{~V}-80) & \mathrm{MPa} & \\ \mathrm{E}_{1}=141.2+3.04(\mathrm{~V}-80) & \mathrm{GPa} & 80 \leq \mathrm{V} \\ \mathrm{G}_{\mathrm{cl}}=[2.82+0.0125(\mathrm{~V}-80)]^{2} / 10^{3} \mathrm{E}_{1} & \mathrm{~N} / \mathrm{m} & \end{array}$

As an example, using 80 percent zirconia (instead of 67 percent) would reduce the assessment vector length by approximately 37 percent. Further reduction may also be effected by reducing interlayer thickness of the joint. 
Table 1. Parameters used in assessment diagram calculations.

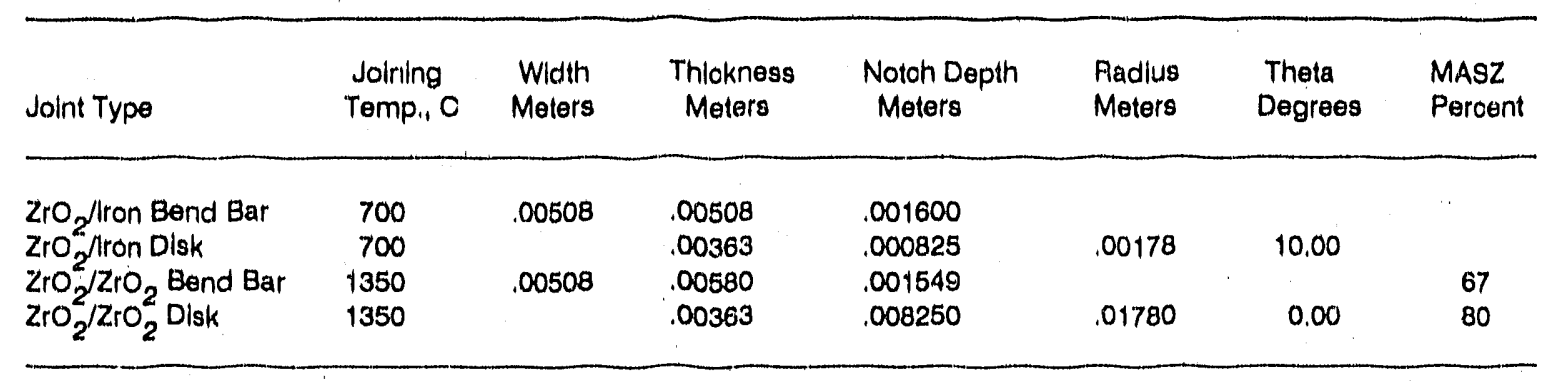

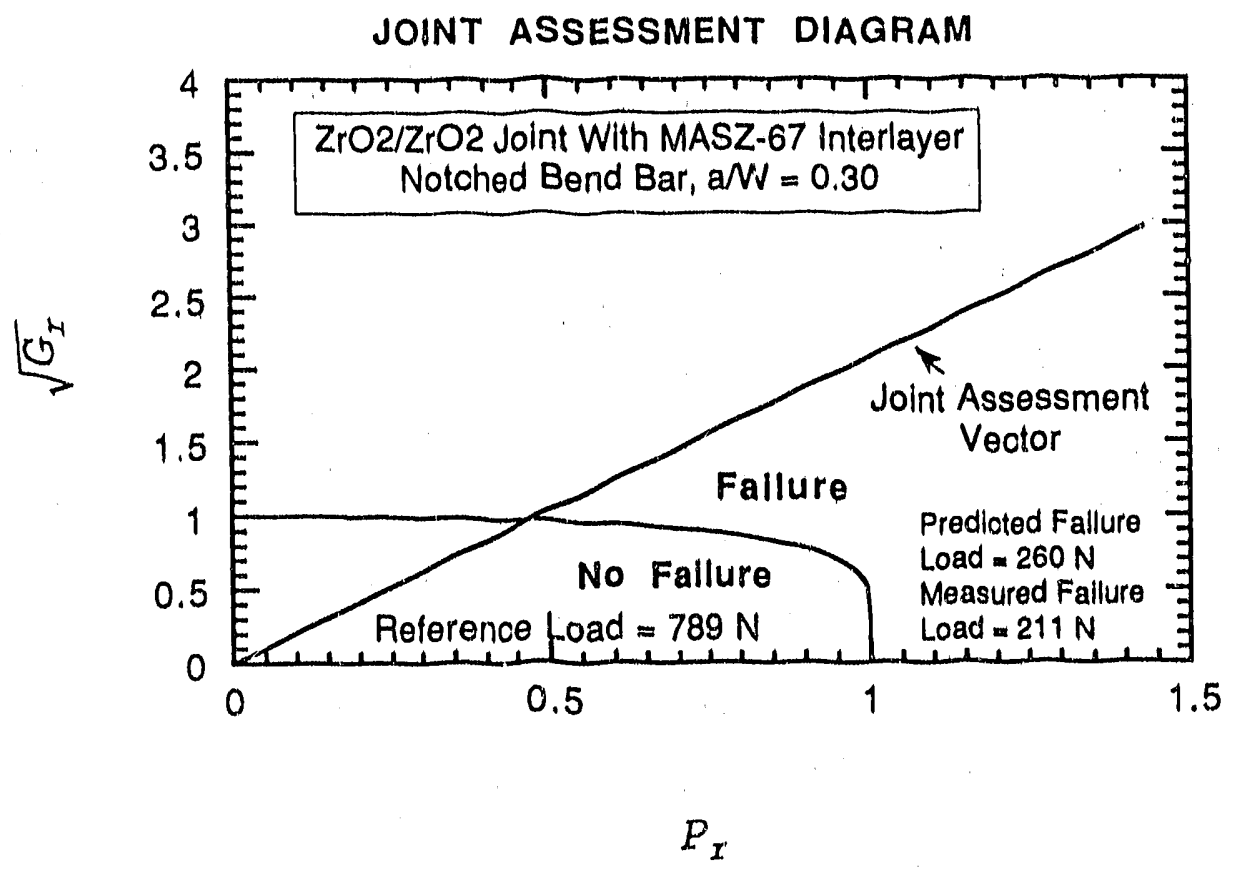

Figure 4. Assessment diagram for zirconia/zirconia bend specimen.

\subsection{ZIRCONIAVNODULAR CAST IRON BEND SPECIMEN}

For ceramic/metal bend specimens (with appropriate material property changes) all the equations from (7) to (23), with the exception of Equations (14) and (18), still apply. The dimensionless quantities $\mathrm{f}_{\mathrm{s}}$ and $\overline{\boldsymbol{\sigma}}$ are now redefined as:

$$
f_{s}=0.4766+1.0468\left(\frac{\mu_{1}}{\mu_{m}+\mu_{c}}\right)
$$




$$
\begin{gathered}
\bar{\sigma}=\left\{1.0+\frac{t_{1}}{W}\left(1-\frac{2 \mu_{1}}{\mu_{m}+\mu_{c}}\right)\left[177 \frac{t_{1}}{W}-10.9\right]\right\} . \\
\cdot\left[0.98+\beta\left(\frac{2 x}{t_{1}}\right)+\gamma\left(\frac{2 x}{t_{1}}\right)^{2}\right]
\end{gathered}
$$

where $\beta=0.0389, \gamma=0.0949$, and $x$ denotes the distance from the enter of the interlayer to the crack location. For the cast iron/zirconia joints in the present program, the crack location was at the ceramic-interlayer interface. Thus, $x=1,2$. As before $\mu$ represents shear modulus and subscript $m$ represents metal (cast iron).

For the parameters given in Table 1, a graphical representation of the JAD model application to a metal-ceramic bend specimen geometry is shown in Figure 5.

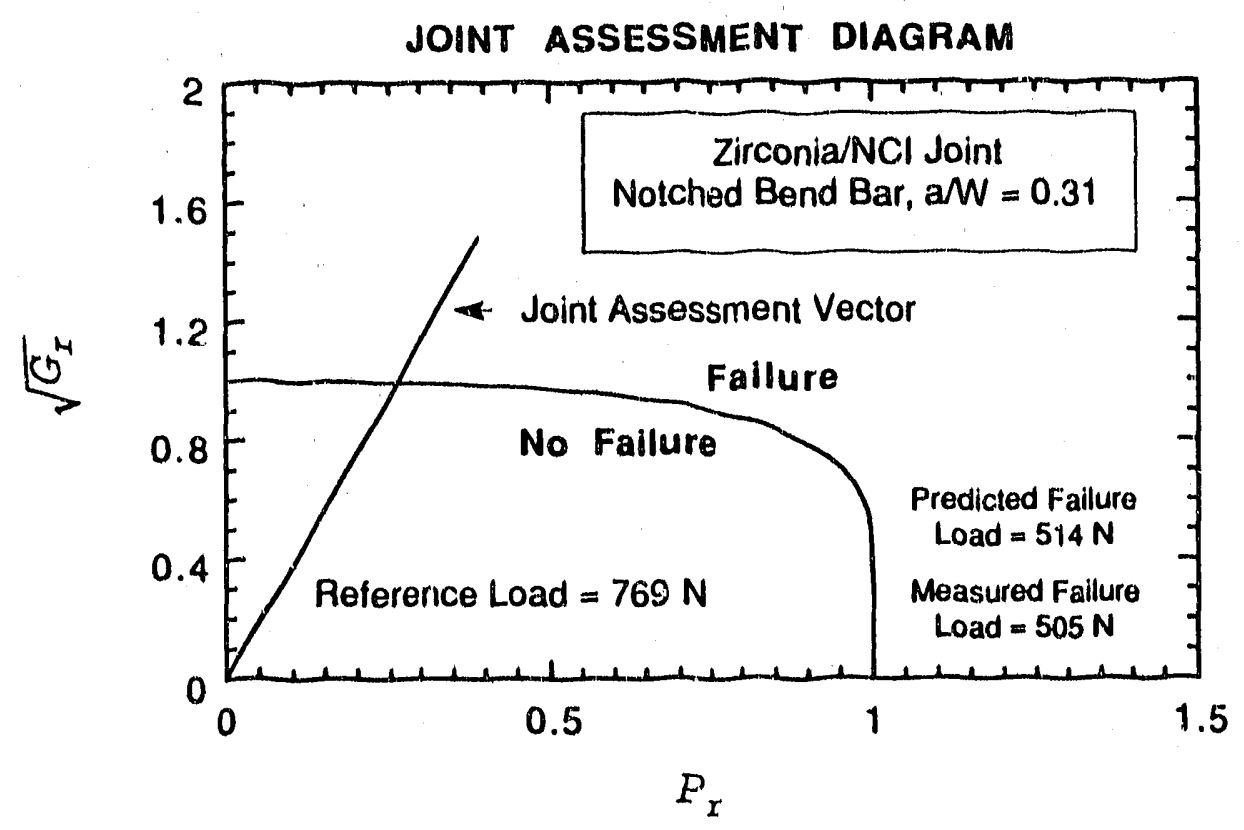

Figure 5. Assessment diagram for zirconia/cast iron bend specimen.

\subsection{ZIRCONIA/ZIRCONIA DISK SPECIMEN}

For a zirconia/zirconia disk specimen with load angle $\theta$ between the bond line and load line in the range $0.0 \leq \theta \leq 22.5$ degrees and $\mathrm{a} / \mathrm{R}=0.5$ the failure curve is given by the following equation

$$
\sqrt{G_{r}}=\frac{\pi f g}{2 \sqrt{2}} P_{r}\left[\ln \left\{\sec \left(\frac{\pi}{2} f g P_{r}\right)\right\}\right]^{-\frac{1}{2}}
$$


where

$$
g=1-\sqrt{P_{x}}+\frac{P_{x}}{f}
$$
equation

The assessment vector for this specimen type (for $P_{R}<<P_{c}$ ) is given by the following

$$
\bar{A}=\left[\frac{f P}{R t}\left(\frac{a}{\pi E_{1}^{\prime} G_{c i}}\right)^{\frac{1}{2}}\right] i+P_{x} j
$$

In Equations (26), (27), and (29)

$$
\begin{aligned}
& f=f_{H} \cdot f_{s} \\
& f_{H}=62.755-43.316 \sin \theta-65.257 \cos \theta+ \\
& +21.883 \sin 2 \theta+4.485 \cos 2 \theta \\
& f_{s}=\left(\cos ^{2} \theta\right) \text {. } \\
& \cdot\left[\frac{\mu_{1}\left(1-v_{c}\right)}{\mu_{c}\left(1-v_{1}\right)}\left\{1.0-0.224\left(1-\frac{\mu_{1}}{\mu_{c}}\right)+0.375\left(1-\frac{\mu_{1}}{\mu_{c}}\right)^{2}\right\}^{\frac{1}{2}}\right. \\
& P_{x}=P_{A} \bar{\sigma} /\left(\begin{array}{llll}
\pi & R & t & \sigma_{0.1}
\end{array}\right) \\
& P_{A}=\frac{R t}{f_{H}}\left[\frac{\pi E_{c} G_{c c}}{\left(1-v_{c}^{2}\right) a}\right]^{\frac{1}{2}} \\
& P=P_{\Lambda}-\pi R t \sigma_{R T}
\end{aligned}
$$


The quantity $\sigma_{R T}$ is the same as defined in Equations (23) and (24), and for the disk specimen, the dimensionless quantity ö appearing in Equation (33) is approximately unity.

For the parameters given in Table 1, a graphical representation of the JAD model application to a zirconia/zirconia disk specimen geometry is shown in Figure 6.

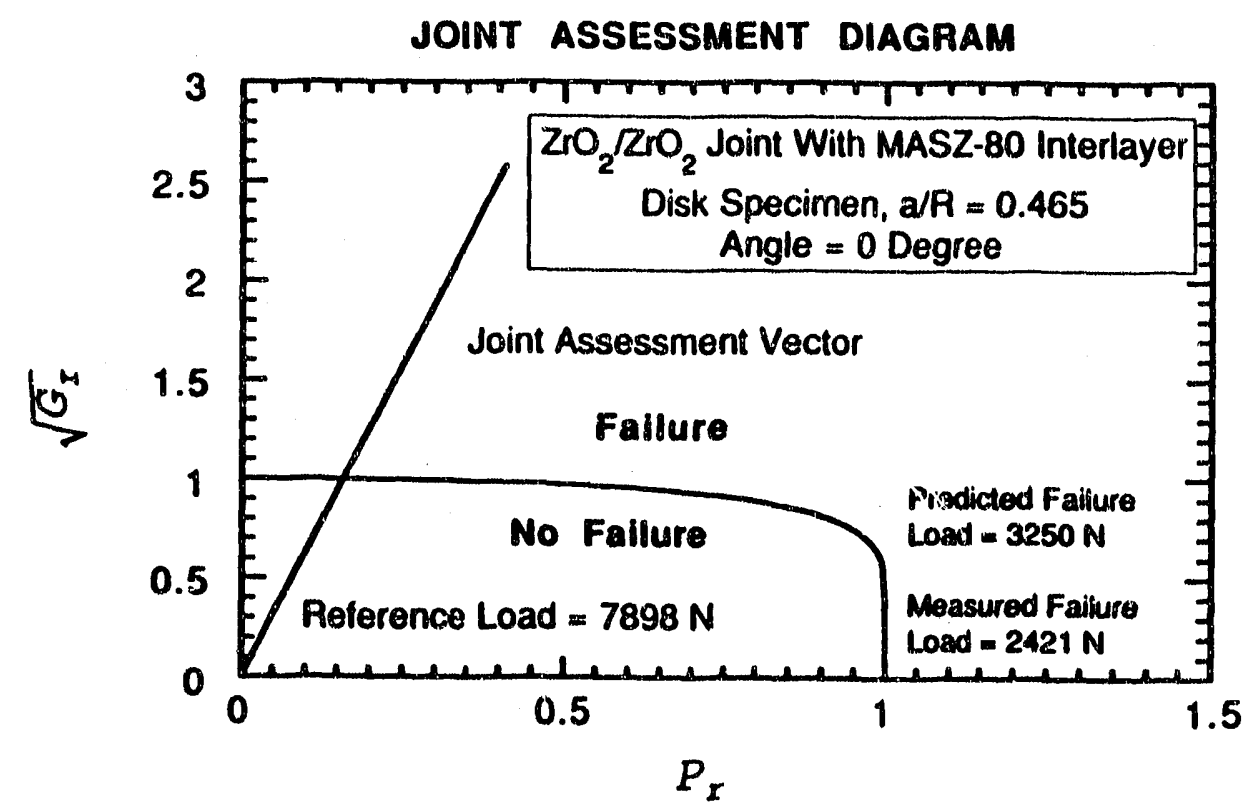

Figure 6. Assessment diagram for zirconia/zirconia disk specimen.

\subsection{ZIRCONIANODULAR CAST IRON DISK SPECIMEN}

For a zirconia/nodular cast iron disk specimen with load angle $\theta$ in the range $0.0 \leq \theta$ $\leq 22.5$ degrees and $\mathrm{a} / \mathrm{R}=\mathbf{0 . 5}$, the failure curve and assessment vector are given by Equations (26) to (30). The dimensionless quantities $f_{H}$ and $f_{s}$ are for this case defined as follows:

$$
\begin{aligned}
f_{H}= & {[62.493-42.935 \sin \theta-65.112 \cos \theta+} \\
& +21.765 \sin 2 \theta+4.587 \cos 2 \theta]^{\frac{1}{2}} \\
f_{s}= & {\left[0.4766+1.0468\left(\frac{\mu_{1}}{\mu_{m}+\mu_{c}}\right)\right] \cos ^{2} \theta }
\end{aligned}
$$

Equations (33), (34), and (35) remain applicable to metal-ceramic disk specimens with $\dot{\sigma}=1.0$ and $\sigma_{\mathrm{AT}}$ defined by Equations (23) and (24). 
For the parameters given in Table 1, a graphical representation of the JAD model application to a cast iron/zirconia disk specimen geometry is shown in Figure 7.

JOINT ASSESSMENT DIAGRAM

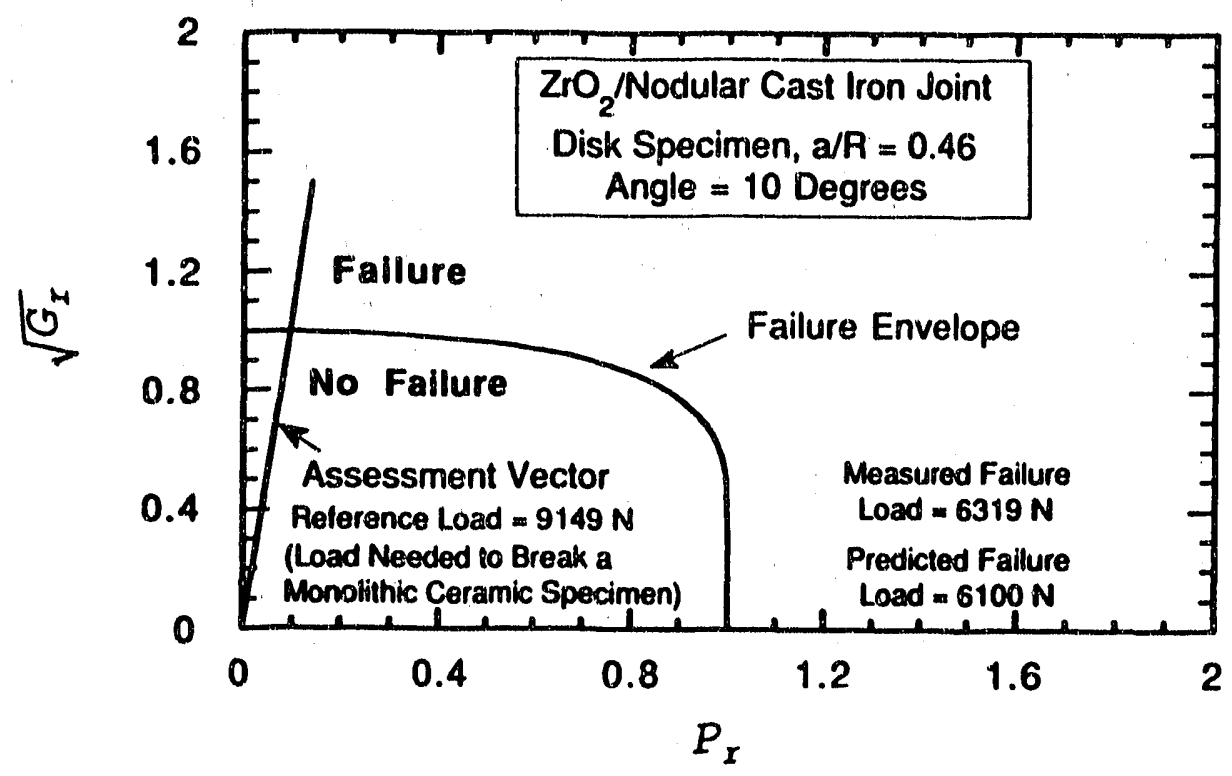

Figure 7. Assessment diagram for zirconia/cast iron disk specimen.

\subsection{DISCUSSION OF THE JAD MODEL}

The JAD model developed in the present work represents an attempt to provide a link between the structural performance of ceramic/ceramic and metal/ceramic joints with the fracture, mechanical and thermal expansion properties of the joint constituents (ceramic, metal and interlayer). For the materials and joint geometries sclected for material property data generation and model validation, the JAD model was found to provide reasonahly accurate results. The bend bar and disk specimens tested in the project represent significantly different geometries, giving rise to widely different stress distributions across the joint. The fact that the model provided reasonably good results for both geometrics and for both material bonds, suggests that the modeling approach may provide a useful tool for design and assessment of joints.

While model validation was performed on only bend bar and disk (with varying load angles) specimens, the modeling approach adopted in the present work is quite general. It can be readily extended to other joint configurations as well as other material combinations. To do so, one would need to find (probably numerically) appropriate expressions for $G_{e}, G$, and $P_{r}$ appearing in Equations (4) and (5) for the failure curve and assessment vector. If it is found (by numerical analysis of other material and geometry combinations) that the equation for the failure curve [see Equations (7) and (26)] is a reasonably good representation for other geometries as well, one would need to find only the dimensionless factors $f$ and $g$ for the new geometry and material. Figure 8 shows the variation in the failure curve shape using the extreme values of $f$ [ with $g$ as defined by Equation (8)] encountered in the present work. The smaller value of $f$ corresponds to a bend specimen and the larger value 
corresponds to a disk specimen with load angle ( $\theta)$ of 22.5 degrees. The figure suggests that the failure curve shape does not change drastically by varying $\mathrm{f}$. Thus, for other geometries a fixed value of $f(s a y, f=1.0)$ may be appropriate. If both $f$ and $g$ are taken to be unity, the curve shape, also shown in Figure 8, becomes specimen geometry independent.

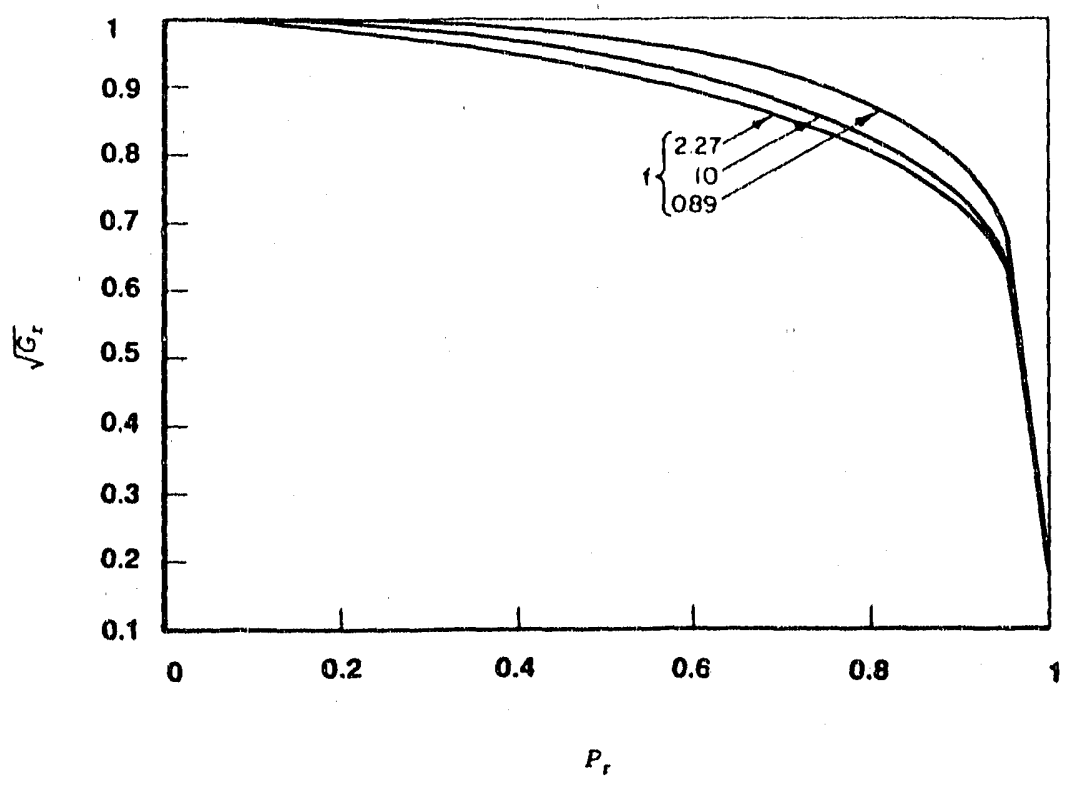

Figure 8. Variation in failure curve shape.

From a design view point, it is desirable that joining process variables (and not only constituent material properties) can also be linked to joint performance. Two of the process variables (joining temperature and interlayer thickness) are directly represented in the JAD model. For ceramic/ceramic joints with an MASZ interlayer, the zirconia content in the MASZ is also included in the model using empirical relations between percent zirconia and $E_{i,} \sigma_{o i}$, and $G_{c i}$, as discussed in Section 3.0 Characterization and Analysis of Joints and Monolithic Materials.

The JAD model has been programmed in BASIC for use on an IBM- compatible personal computer. Instructions for obtaining a copy of the code can be found in Appendix D. The code (which contains the material property data base generated in the present project) represents a first step toward a potentially much more general and useful design tool for ceramic/ceramic and ceramic metal joints. A more general code would encompass a wider range of geometry configurations, material combinations, joining methods and service load and environmental conditions. 


\subsection{JOINT FABRICATION}

Figure 9 summarizes the joint types and fabrication techniques used in this investigation. The adherents were magnesia partially stabilized zirconia and nodular cast iron. Small scale joints with bond areas approximately $12.5 \mathrm{~mm} \times 12.5 \mathrm{~mm}$ were used for preliminary screening of the joining techniques. Later, large scale joints were fabricated using disks $51 \mathrm{~mm}$ in diameter and $19 \mathrm{~mm}$ thick and joining them along their flat faces. Mechanical test specimens used for preliminary and final validation were machined from these large scale joints. As illustrated in Figure 9 a number of techniques were tried for fabricating zirconia/zirconia and zirconia/NCI joint. Among these, the magnesia-aluminasilica-zirconia system was selected for fabricating zirconia/zirconia joints for validation testing. The active filler metal approach was finally selected for joining zirconia and cast iron. The details of material selection and fabrication techniques are discussed in the paragraphs that follow.

\subsection{MATERIALS SELECTION}

\subsubsection{Zirconia}

Type Zycron-L magnesia partially stabilized zirconia (PSZ) was purchased from Zircoa Products, Inc.. This grade was selected to obtain optimal strength and toughness up to temperatures of $400 \mathrm{C}$. It is chemically inert to molten metals, minimizing hot corrosion problems during brazing. Finally, a good thermal-expansion match to nodular cast iron minimizes residual stresses and a good elastic-modulus match minimizes interface stresses under load. Two other types of zirconia were used in the development stages of the joining process. These included an yttria zirconia which was fabricated by vacuum hot pressing at Ohio State and a magnesia zirconia, Nielsen grade MS, with an electron-beam PVC titanium coating supplied by ORNL. However, all of the joints used in validation testing were fabricated using the Zircoa Zycron-L material.

\subsubsection{Nodular Cast Iron}

A piece of nodular cast iron measuring $203 \mathrm{~mm} \times 203 \mathrm{~mm} \times 25 \mathrm{~mm}$ was supplied by Sandia National Laboratory and used in metal/ceramic joints. The material is of ferritic microstructure and close to SAE D4018 (equivalent to ASTM A536, Grade 60-40-18). (a) $^{\text {(a) }}$ However, it is weaker than the grade used previously in the ORNL bonding studies (D5506) and much weaker than the one currently being used there (8003).

(a) The SAE designation code for nodular iron is DXXOO, where $\mathrm{XX}=$ Yield Strength and $00=$ Elongation. 


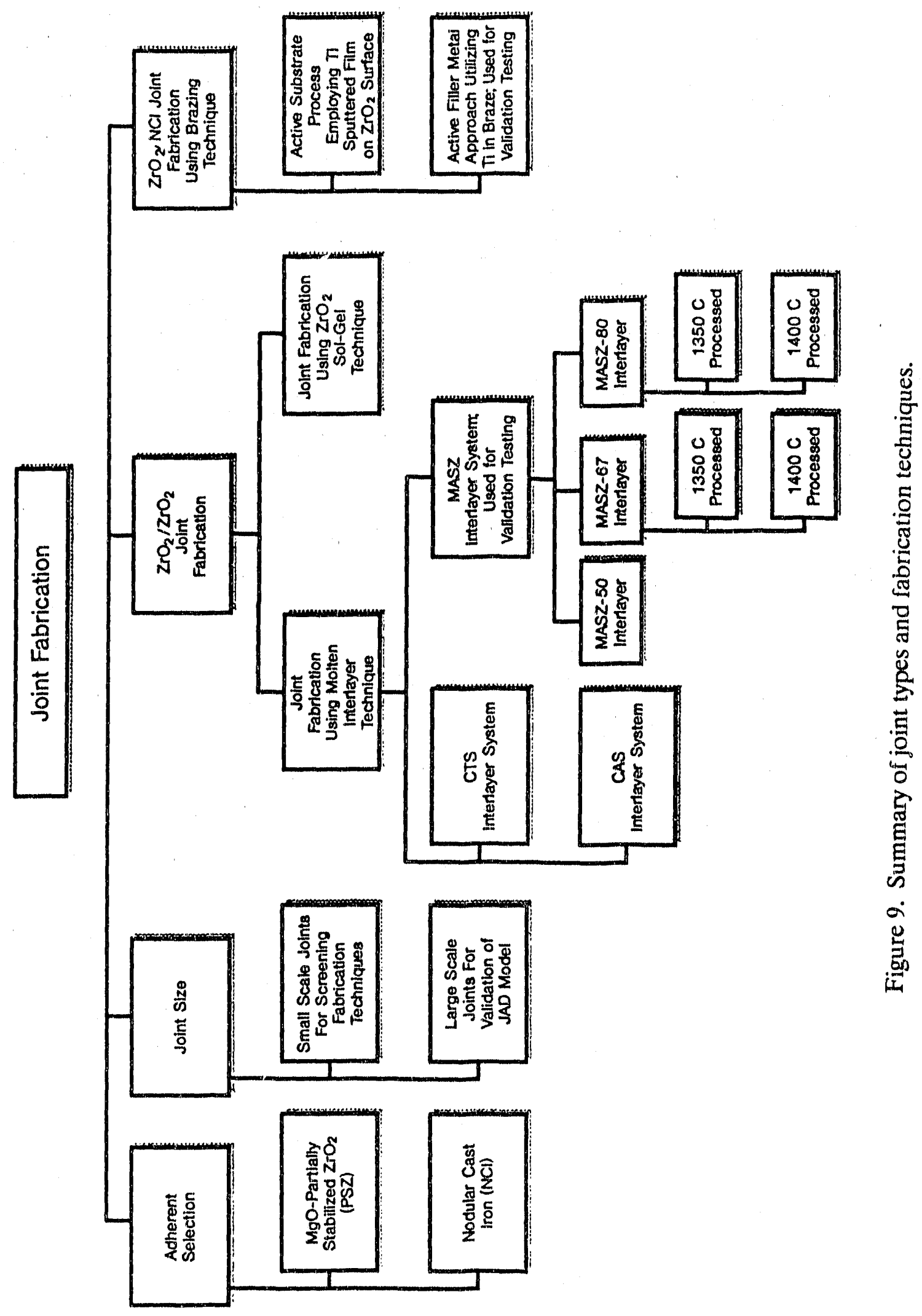


The reasons for choosing this material were:

1. It has the most stable microstructure in this alloy system. Significant metallurgical changes can occur when these alloys are heated to around $760 \mathrm{C}$, which is only slightly above the temperature range in which brazing is normally carried out. As a result, there is concern that the mechanical properties of the iron after brazing will not only be significantly different from those of the asreceived material, but also will vary from bond-to-bond, which would mask the effects of bonding variables. To compound the problem, some of the physical properties become erratic when these changes occur, complicating the model verification. Therefore, use of the ferritic material was expected to minimize problems associated with possible phase and microstructural changes.

2. The physical and mechanical properties of this grade of nodular cast iron have been charac:erized in great detail. For example, Sandia is doing extensive work on the same block that was used in this investigation.

\subsection{ZIRCONIA/ZIRCONIA JOINTS}

A literature survey indicated that there was no established technique that provided zirconia/zirconia joints of acceptable strengths at temperatures up to $1000 \mathrm{C}$. A brazing technique was ruled out because the braze metal is molten below that temperature. Accordingly, various ceramic interlayers were evaluated for joining zirconia to itself. Results on experiments performed with various interlayer materials are discussed below and also in the papers ${ }^{[3,4,5]}$ provided in Appendix B.

\subsubsection{Sol-gel Zirconia Interlayer}

The use of a zirconia interlayer would be ideal because the thermal expansion match would be good and because of the inherent strength of zirconia ceramics. However, a bond could be formed with a zirconia interlayer only through solid-state diffusion. It was felt that this would be possible with a highly reactive, fine-particle-size zirconia powder produced by sol-gel processing. A sol-gel method for the preparation of an $\mathrm{MgO}$-doped zirconia powder was developed. This powder was used as an interlayer for a joining experiment with $12.5 \mathrm{~mm}$ diameter zirconia disks. The zirconia powder was dispersed in methanol and applied to the mating faces. Sintering of the zirconia sandwich in air at a temperature of $1500 \mathrm{C}$ resulted in a bond that survived several drop-tests before failing. Observation of the fracture surface indicated that the bond was porous and that the interlayer exhibited lateral shrinkage during sintering. It was clear that the application of pressure during bonding would be required for a sol-gel zirconia interlayer to be effective for joining.

An air-ambient hot-forging apparatus was built at Battelle for this program, and two joining experiments were performed with the sol-gel zirconia interlayer. In the first experiment, two $12.5 \mathrm{~mm}$ diameter zirconia disks were joined by the application of $13.8 \mathrm{MPa}$ at a temperature of $1600 \mathrm{C}$. A good bond was formed although the specimen size was too antall for a bond strength measurement. Optical micrographs (Figure 10) showed that the as-iormed bond region was very dense, although some porous regions were present. A bonding experiment was then repeated using $51 \mathrm{~mm}$ diameter zirconia billets. 

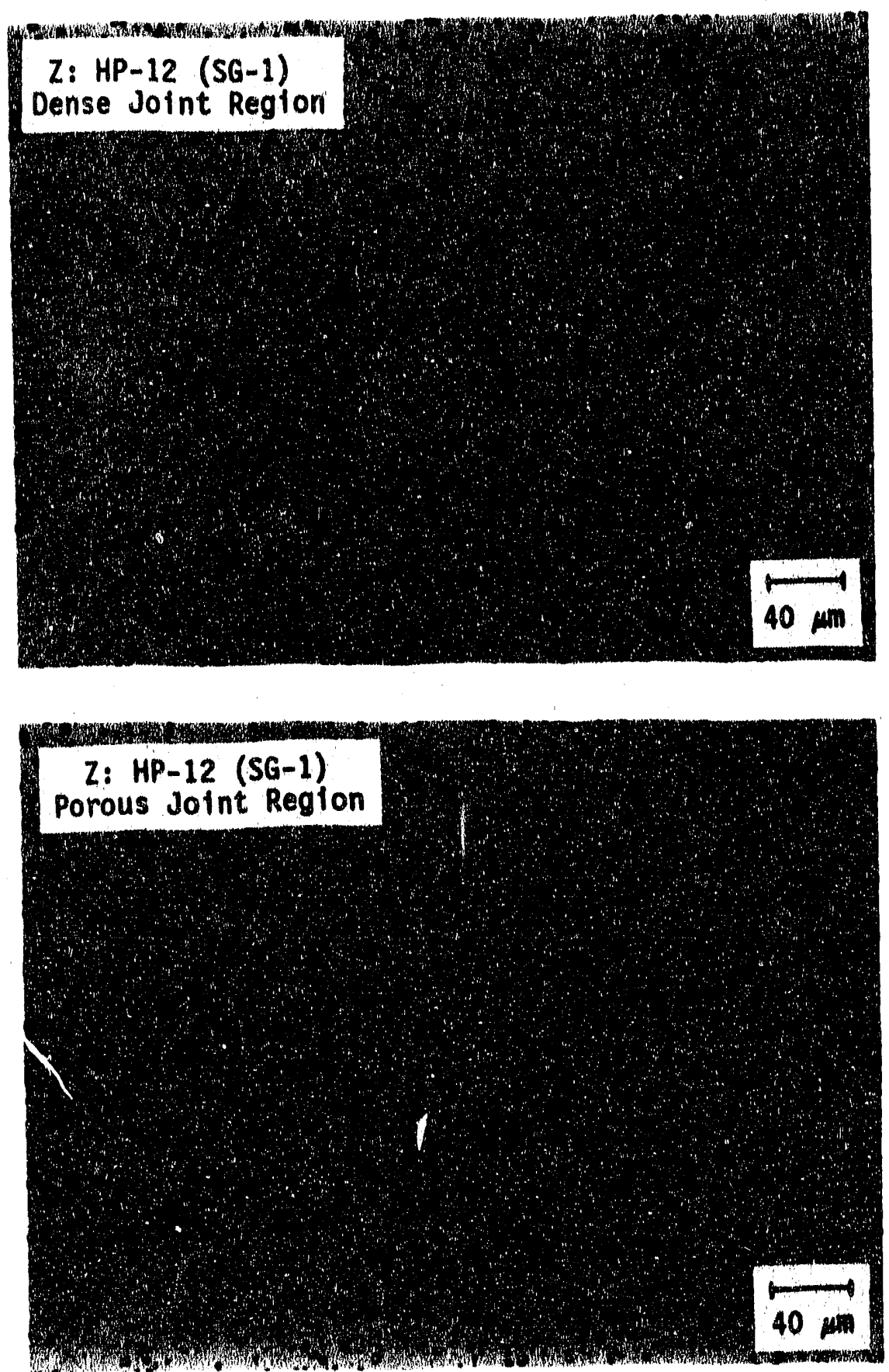

Figure 10. Optical micrographs of zirconia joint produced by hot-forging at $1600 \mathrm{C}$ with a sol-gel zirconia interlayer. Both dense (top) and porour (bottom) joint regions are shown. 
Unfortunately, this experiment ended in catastrophic failure of the alumina forging rams. It became clear that hot forging was a promising approach but that lower joining temperatures were required.

\subsubsection{CTS and CAS Interlayers}

The use of Battelle's air-ambient hot-forging apparatus for joining zirconia ceramics was limited to below about $1450 \mathrm{C}$. Since solid-state diffusional bonding with zirconia interlayers was not feasible at these low temperatures, a molten interlayer technique was considered to reduce the bonding temperatures for hot-forging. A temperature of $1420 \mathrm{C}$ was selected as the bonding temperature, because it was thought that this temperature would minimize degradation of the base zirconia material (although this assumption was not evaluated). Two possible molten-interlayer systems were identified by searching through various phase diagrams. These were the $\mathrm{CaO}-\mathrm{TiO}_{2}-\mathrm{SiO}_{2}(\mathrm{CTS})$ and $\mathrm{CaO}-\mathrm{Al}_{2} \mathrm{O}_{3}-\mathrm{SiO}_{2}(\mathrm{CAS})$ systems, each of which has eutectic compositions below $1400 \mathrm{C}$.

Interlayer powders of three CTS compositions and three CAS compositions were prepared by milling the oxide/carbonate raw materials, followed by calcination at $1100 \mathrm{C}$, and sieving to below $200 \mathrm{mesh}$. Compositions of CTS and CAS interlayer powders are given in Tables 2 and 3, respectively. Both small-scale (15 mm diameter disks) and large-scale (51 $\mathrm{mm}$ diameter disks) joining experiments were performed. Interlayers were applied to the zirconia disks through a methanol slurry, and disks were joined by hot-forging at 1420 $\mathrm{C}$ under pressures of 3.4 to 13.8 MPa. Both CTS and CAS interlayers provided successful small-scale bonds. Optical micrographs of small-scale zirconia joints produced with CTS and CAS interlayers are provided in Figures 11 and 12, respectively. Scale-up problems were encountered, related to thermal expansion mismatch and to "squeeze-out" of the interlayer material during hot forging. This was addressed by adding $30 \mathrm{wt} \%$ zirconia powder to the CAS and CTS interlayer material. The zirconia powder increased the viscosity of the interlayer during hot-forging, thus preventing "squeeze out", and also provided for a better expansion match between the interlayer and the zirconia base material. The best large-scale joint was produced by hot-forging with the CTS-3 interlayer composition, containing 30 weight percent zirconia. The average joint strength (four-point bending) was $67 \mathrm{MPA}$, with a Weibull modulus of 6.1. An optical micrograph of this joint, and an SEM micrograph of the fractured surface of a bend-test specimen, are shown in Figure 13.

Electron microprobe results obtained during initial CTS joining experiments were published ${ }^{[3]}$. Additional work describing zirconia joints formed using interlayers in both CTS and CAS systems was also published ${ }^{[4]}$. These two papers are reproduced in Appendix B. 
Table 2. $\mathrm{CaO}-\mathrm{TiO}_{2}-\mathrm{SiO}_{2}(\mathrm{CTS})$ interlayer compositions.

\begin{tabular}{llcccl}
\hline & \multicolumn{4}{c}{ Composition (wt\%) } & \\
\cline { 2 - 5 } & $\mathrm{CaO}$ & $\mathrm{TiO}_{2}$ & $\mathrm{SiO}_{2}$ & $\mathrm{ZrO}_{2}$ & \multicolumn{1}{c}{ Comments } \\
\hline CTS-1 & 35.0 & 50.0 & 15.0 & & $\mathrm{Tm}=1372 \mathrm{C}$ (DTA) \\
CTS-2 & 25.0 & 57.0 & 18.0 & & $\begin{array}{l}\text { eutectic composition } \\
\mathrm{Tm}=1356 \text { C (DTA) }\end{array}$ \\
CTS-3 & 17.5 & 39.9 & 12.6 & 30.0 & $\begin{array}{l}70 \text { wt\% CTS-2 + 30 wt\% Zro2 } \\
\mathrm{Tm}=1357 \text { C (DTA) }\end{array}$ \\
\hline
\end{tabular}

Table 3. $\mathrm{CaO}-\mathrm{Al}_{2} \mathrm{O}_{3}-\mathrm{SiO}_{2}$ (CAS) Interlayer compositions.

\begin{tabular}{|c|c|c|c|c|c|}
\hline & \multicolumn{4}{|c|}{ Composition (wt\%) } & \multirow[b]{2}{*}{ Cornments } \\
\hline & $\overline{\mathrm{CaO}}$ & $\mathrm{Al}_{2} \mathrm{O}_{3}$ & $\mathrm{SiO}_{2}$ & $\mathrm{ZrO}_{2}$ & \\
\hline CAS-4 & 49.7 & 43.4 & 7.0 & & $\begin{array}{l}\text { eutectic composition } \\
\mathrm{Tm}=1323 \mathrm{C} \text { (DTA) } \\
\alpha=8.4 \mathrm{ppm} / \mathrm{C}\end{array}$ \\
\hline CAS-5 & 41.0 & 11.8 & 47.2 & & $\begin{array}{l}\text { eutectic composition } \\
\mathrm{Tm}=1308 \mathrm{C} \text { (DTA) } \\
\alpha=8.9 \mathrm{ppm} / \mathrm{C}\end{array}$ \\
\hline CAS-6 & 28.7 & 8.3 & 33.0 & 30.0 & $70 w t \%$ CAS-5 + 30 wt $\%$ Zro2 \\
\hline
\end{tabular}

\subsubsection{MASZ Interlayers}

The low joint strengths achieved in the CTS and CAS systems required consideration of alternative molten-interlayer materials. One possibility was the use of a glass-ceramic material that was molten during joining but would crystallize, providing high strength to the joint, during cooling. Glass-ceramics in the $\mathrm{MgO}-\mathrm{Al}_{2} \mathrm{O}_{3}-\mathrm{SiO}_{2}$ (MAS) system are used for certain structural applications, and Battelle's experience with these materials suggested reasonable high-temperature $(1000 \mathrm{C})$ strength. One such glass-ceramic material is Zircoa 9606 glass-ceramic, which contains $\mathrm{MgO}_{2} \mathrm{Al}_{2} \mathrm{O}_{3}, \mathrm{SiO}_{2}$, and $\mathrm{TiO}_{2}$ (MAST). An initial, rather 

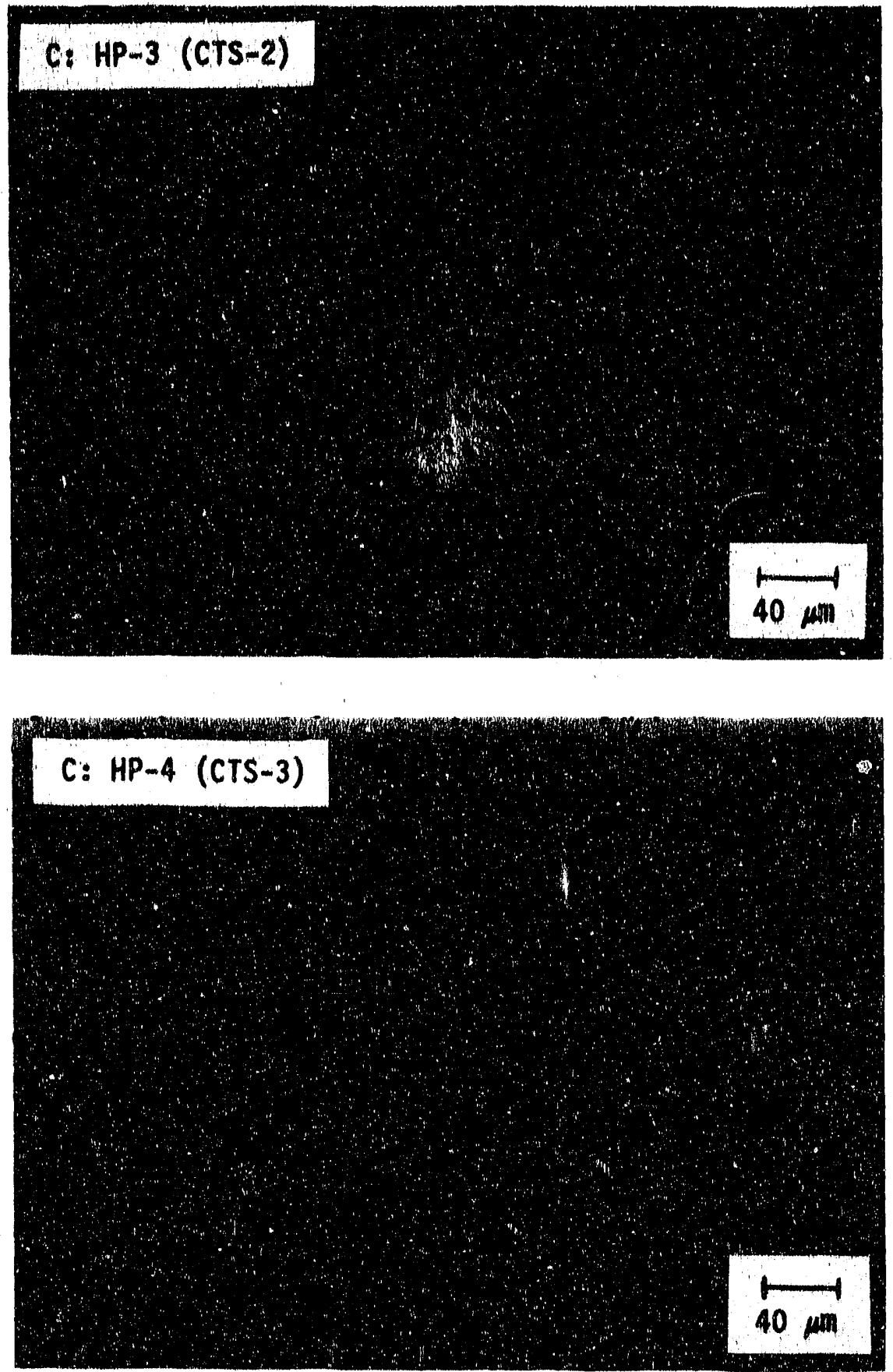

Figure 11. Optical micrographs of small scale zirconia joints produced by hotforging with calcia-titania-silica CTS interlayers. 

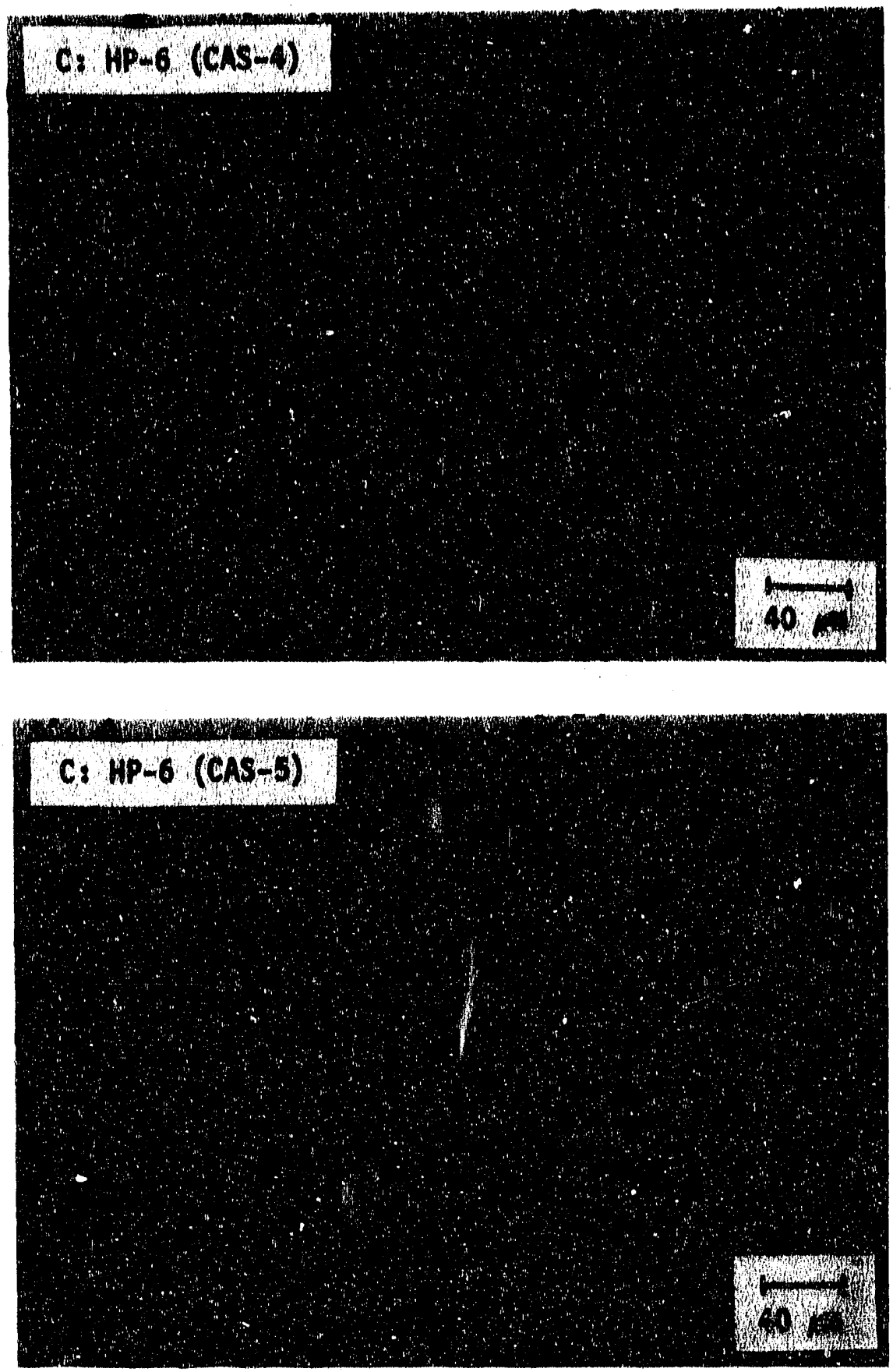

Figure 12. Optical micrographs of small scale zirconia joints produced by hotforging with calcia-alumina-silica (CAS) interlayers. 

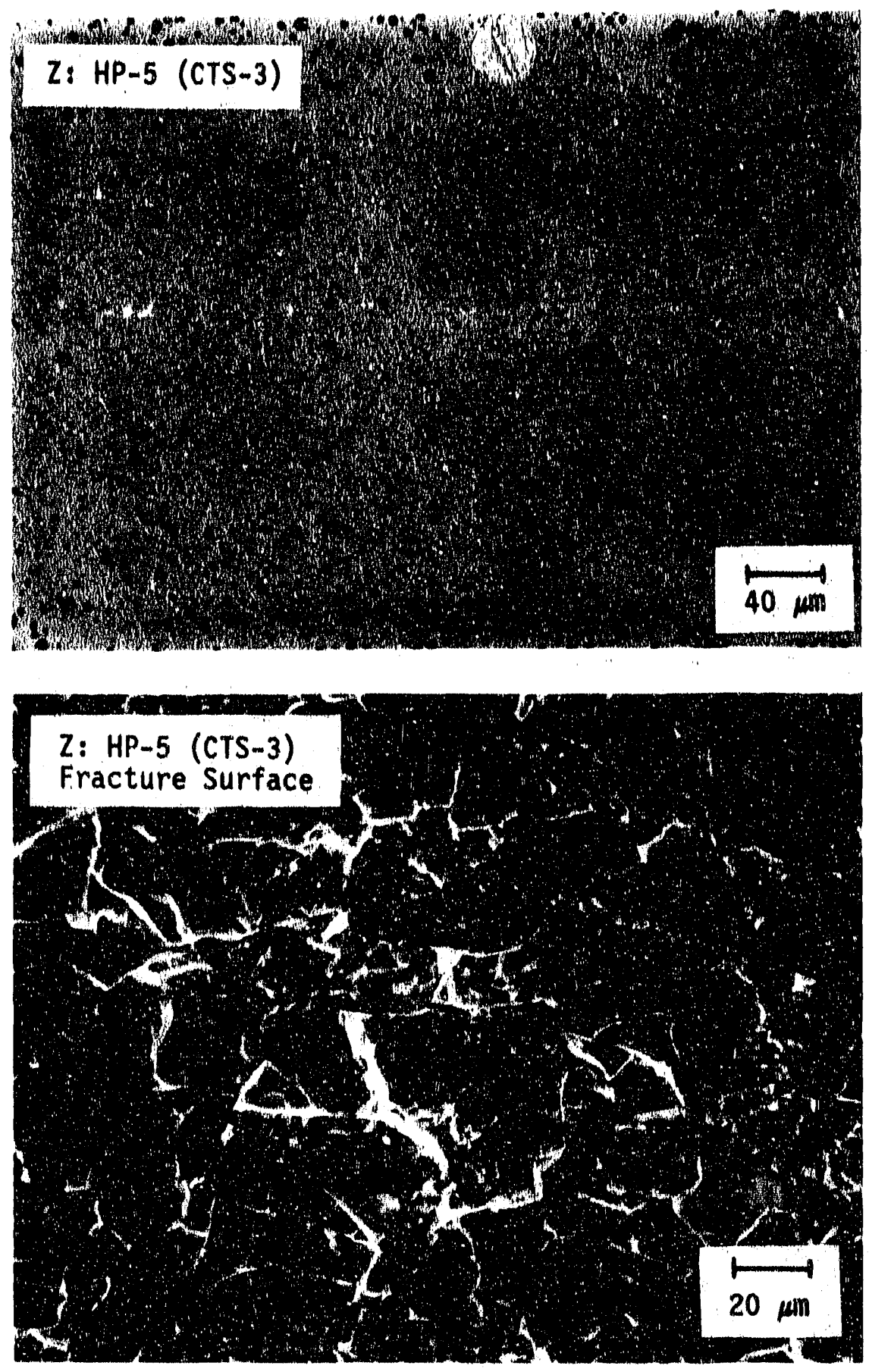

Figure 13. Top: Optical micrograph of large scale zirconia joint produced by hotforging with the CTS-3 interlayer composition. Bottom: SEM micrograph of the fractured surface of a bend-test specimen produced from the above joint. 
crude experiment was conducted to determine whether this material would be useful for joining. Some 9606 glass-ceramic material was crushed into a powder and applied as an interlayer between two pieces of zirconia, which were then heated (without pressure) to a temperature of $1300 \mathrm{C}$. The two pieces stuck together and survived drop tests.

More controlled joining experiments then were conducted with MAS interlayer powders with the 9606 glass-ceramic composition. Initial experiments with crushed 9606 glass-ceramic powder gave similar results to interlayer powders produced by milling and calcination at $1100 \mathrm{C}$. The use of MAST interlayers reduced the joining temperature to the range of 1320 to $1365 \mathrm{C}$. The best joining results were obtained when large amounts of zirconia powder (up to 80 weight percent) were added to the MAS interlayer powder. The family of magnesia-alumina-silica-zirconia interlayers are henceforth referred to as MASZ interlayers. MASZ interlayers with 67 and 80 weight percent zirconia were studied in detail in validation experimentation. The compositions of MASZ interlayers are provided in Table 4. The joining of zirconia ceramics using the MASZ interlayer powders required joining pressures of less than $2 \mathrm{MPa}$, much lower than those used for the CTS and CAS interlayers. This apparently was due to good wettability and high reactivity of the interlayer with the base zirconia material. The joint strengths achieved with MASZ interlayers also were much improved over CTS and CAS interlayers. For example, the best bend strength obtained for the CTS system was $66 \mathrm{MPa}$ while the average strength of the MASZ-80 system was $158 \mathrm{MPa}$.

Table 4. $\mathrm{MgO}-\mathrm{Al}_{2} \mathrm{O}_{3}-\mathrm{SiO}_{2}-\mathrm{TiO}_{2}-\mathrm{ZrO}_{2}(\mathrm{MASZ})$ interlayer composition.

\begin{tabular}{lcccll}
\hline Powder No. & $\mathrm{MgO}$ & $\mathrm{Al}_{2} \mathrm{O}_{3}$ & $\mathrm{SiO}_{3}$ & $\mathrm{TiO}_{2}$ & $\mathrm{ZrO}_{2}$ \\
\hline MASZ-0 & 14.9 & 19.9 & 56.1 & 9.1 & 0 \\
MASZ-33 & 10.0 & 13.3 & 37.6 & 6.1 & 33.0 \\
MASZ-50 & 7.5 & 10.0 & 28.0 & 4.5 & 50.0 \\
MASZ-67 & 4.9 & 6.6 & 18.5 & 3.0 & 67.0 \\
MASZ-80 & 3.0 & 4.0 & 11.2 & 1.8 & 80.
\end{tabular}

The results of a detailed study of the joining of zirconia ceramics produced using MASZ interlayers were reported in two manuscripts which we show reproduced in Appendix B.

\subsection{ZIRCONIA/NODULAR CAST IRON JOINTS}

Two brazing processes were used in the fabrication of the zirconia/NCI joints. The active-substrate process developed at ORNL was initially selected because of the reported ability to form joints at temperatures sufficiently low to avoid degradation of the $\mathrm{NCI}^{\text {(a) }}$.

(a) Metals and Ceramics Information Center: Structural Alloys Handbook, 1989 ed., Vol. 1. 
Repeated attempts to fabricate joints with contact areas on the order of $20 \mathrm{~cm}^{2}$ using this process failed; these are described in Appendix C. At the suggestion of Dr. M. Santella of ORNL, the active-filler metal process was then employed in the fabrication of the successful joints used for validation studies. The active filler metal had the composition $59.18 \mathrm{Ag}, 27.50$ $\mathrm{Cu}, 12.13 \mathrm{In}$, and $1.18 \mathrm{Ti}$ all in weight percent.

The surfaces of the billets were made flat and uniform by grinding to a 220 grit finish using standard machining practices for the NCI and a resin bonded diamond wheel for the zirconia. The NCI was used in the as-ground state, while (in latter experimentation) the zirconia was polished using a vibratory polisher to a specular finish using successive grades of diamond paste, typically to $9 \mu \mathrm{m}$. Prior to assembly, or film deposition, all of the specimens were cleaned using acetone followed by a methanol rinse, typically using an ultrasonic bath. In most cases, filler-metal foils were lightly abraded to remove or break up any native oxide.

Brazing was arried out at OSU in a graphite resistance-heated vacuum hot press. The specimens were placed on a pedestal and brazing was carried out without an applied load. Typical vacuums were in the range of $2 \times 10^{-5}$ to $1 \times 10^{-4}$ torr. The heating schedule used with the active filler metal process was: $10-12 \mathrm{C} / \mathrm{min}$ to $650 \mathrm{C} ; 3$ to $5 \mathrm{C} / \mathrm{min}$ to $7315 \mathrm{C}$; and cooling at about $7 \mathrm{C} / \mathrm{min}$ to room temperature. Power was typically cut off when the temperature reached $735 \mathrm{C}$. It was found empirically that due to the thermal mass of the samples and the radiant properties of the graphite element, this procedure resulted in a maximum temperature very close to $750 \mathrm{C}$.

All efforts involving the active filler metal process resulted in strong joints. Ultrasonic scanning examination showed that the joints were free of microscopic defects; correspondingly, the unsuccessful joints fabricated using the active substrate process indicated a brain-like structure of the joint composed of large segregated regions of bonds and no bonds. Four large scale joints were brazed and used in the validation studies.

Microstructural analysis was performed on specimens taken from the first active filler metal process braze, using an electron microprobe using a wavelength dispersion spectroscopic (WDS) analyzer. Figure 14 shows a backscattered electron irmage and WDS element maps of the joint. Ti segregation to the region near the surface of the zirconia is evident (Figure 14b). Interestingly, a two-layer structure involving $\mathrm{Ti}$ is observed which is qualitatively very similar to that observed in the microstructure of the $2.0 \mu \mathrm{m}$ thick Ti-layer active substrate joint. This is reasonable since the relative weight percentages of $\mathrm{Ti}, \mathrm{Ag}$ and $\mathrm{Cu}$ are nearly the same for these systems (see Appendix $\mathrm{C}$ ). Some differences, however, are apparent. The active substrate process employs $\mathrm{Sn}$, and this element is found in significant proportion in the second Ti enriched region. In the active filler metal process in is replaced with In and careful examination of the element maps in Figure 14 reveals that the In is distributed in the Ag-rich phase and the outer Ti enriched region appears to be a Ti-Cu alloy. Also, the Ti-Sn-Cu phase in the active substrate joint is coarse relative to the $\mathrm{Ti}-\mathrm{Cu}$ phase in the active filler metal joint.

Ti segregation appears to have had other beneficial aspects. Ellectron microprobe analysis identified a thin Ti enriched phase adjacent to exposed graphite nodules, perhaps involving carbide formation, and several isolated iron bearing particles, presumably milling debris, were encapsulated with a thin layer of Ti enrichment. 


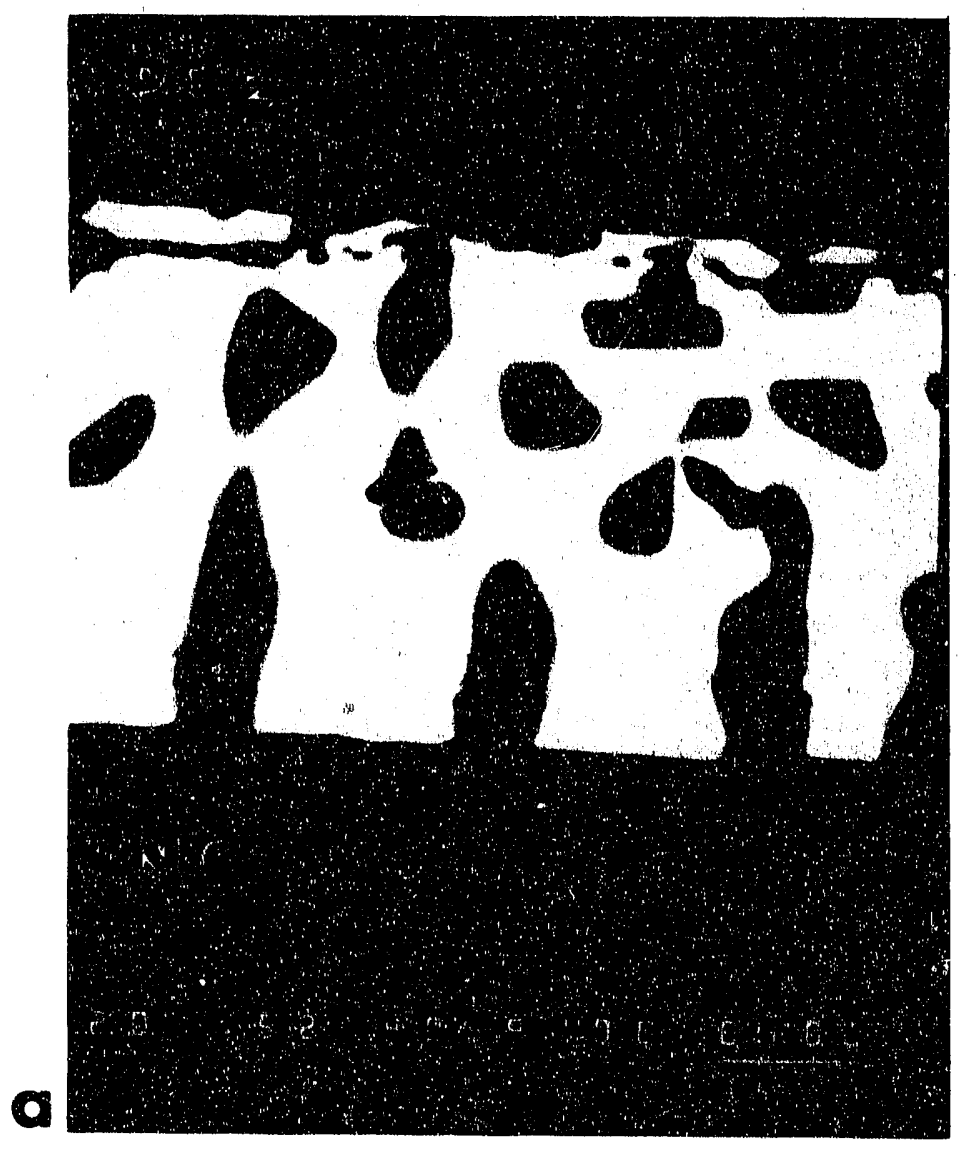

Figure 14a. Backscattered electron image of the interlayer region of an active filler metal joint fabricated using as-ground NCI, polished zirconia, and Incusil-ABA filler metal. 

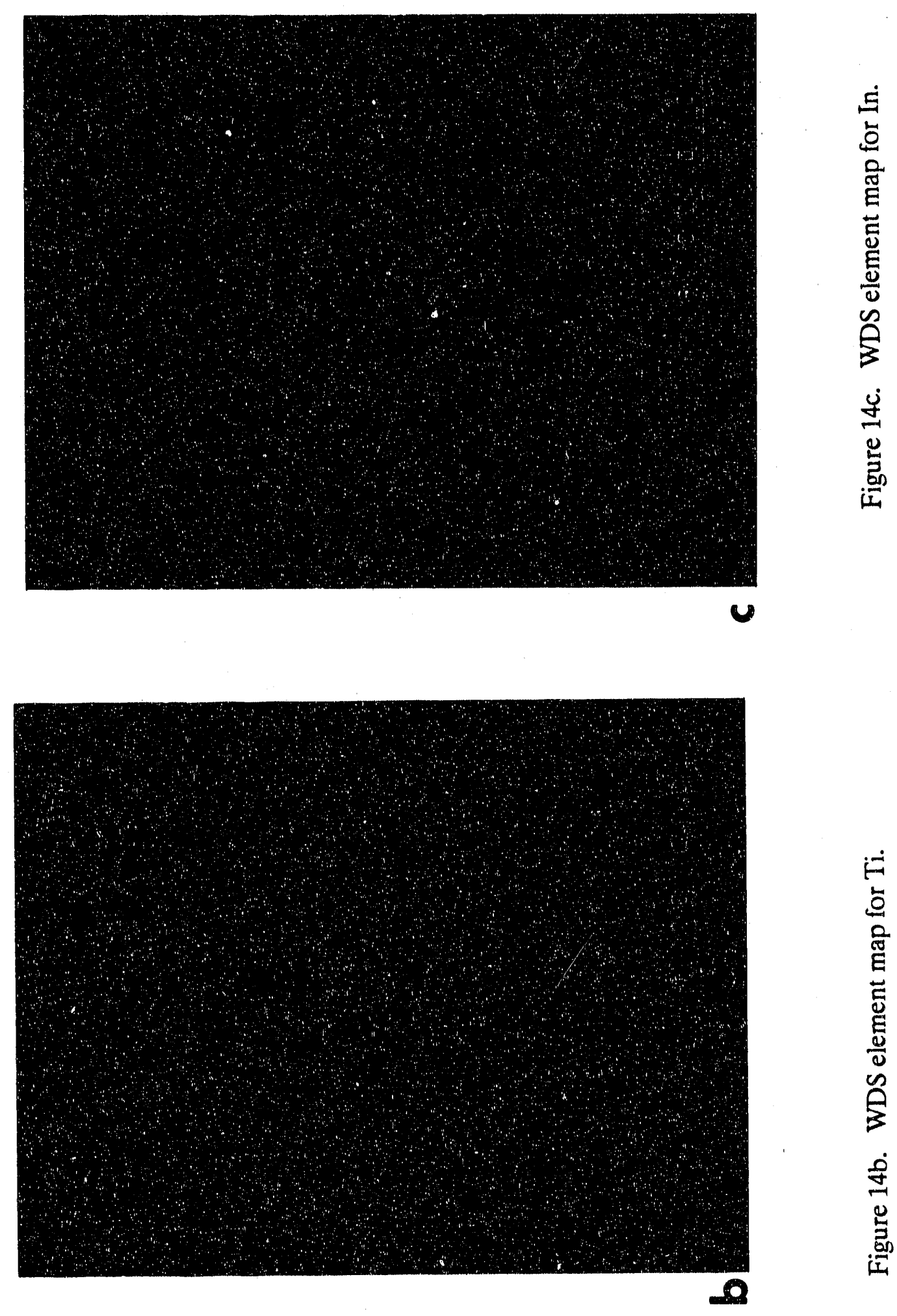

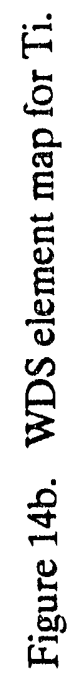



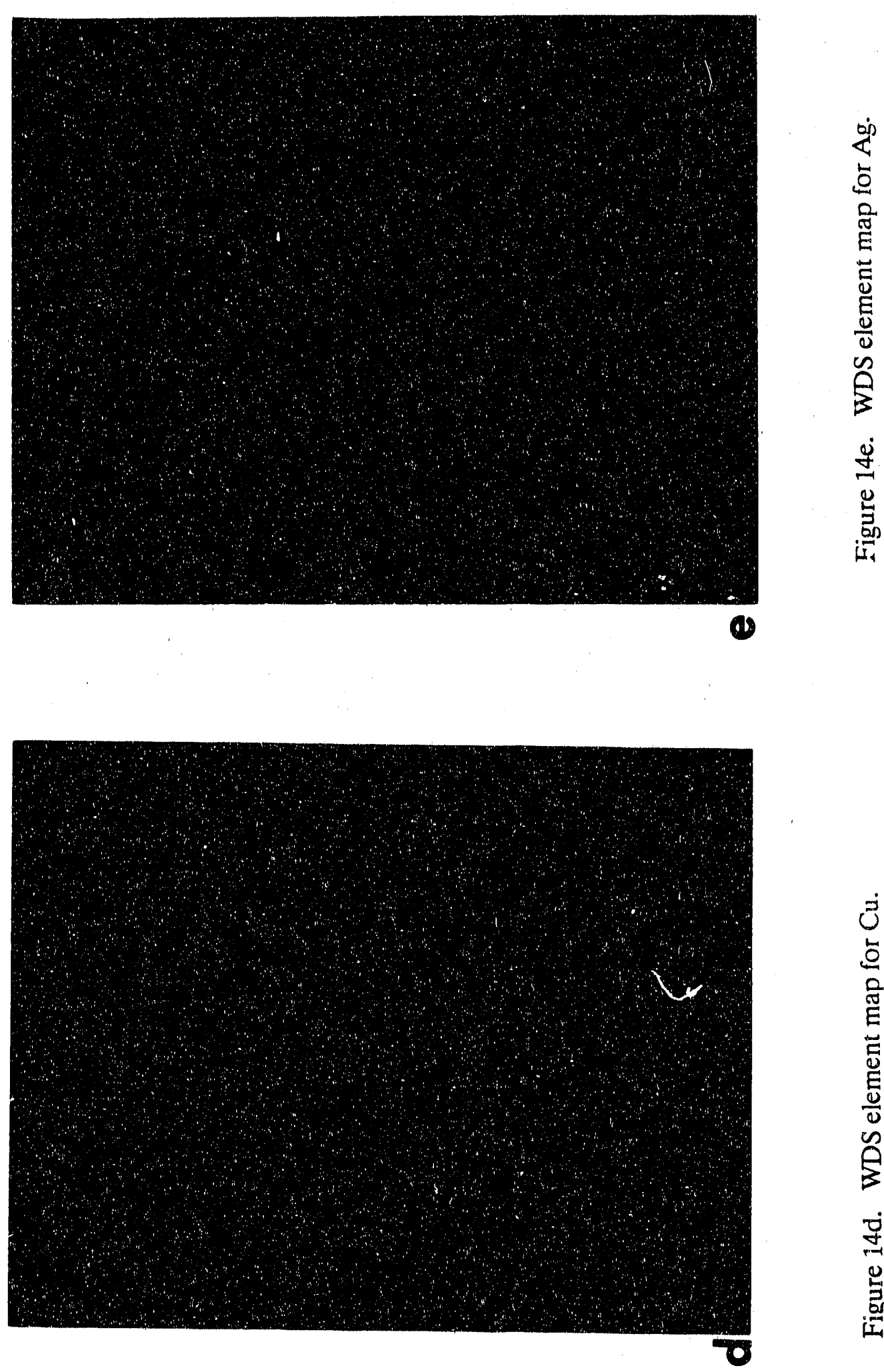

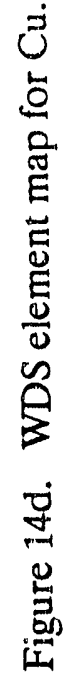




\subsection{CHARACTERIZATION OF JOINTS AND CONSTTTUENT MONOLTHIC MATERIALS}

\subsection{OBJECTIVES OF CHARACTERIZATION}

Mechanical and thermal characterizations of materials (adherents and interlayers) were performed in support of the joint assessment and design model. The following were the three primary objectives:

1. To obtain constitutive properties of base materials and interlayer materials as input data to the JAD model.

2. To measure the load-bearing capability of small joint specimens (4-point notched/unnotched bend bars) for preliminary validation of the JAD model, and for incorporating appropriate modifications to the model to suit experimental results.

3. To measure the load bearing capability of large joint specimens (cracked disks) as part of the final validation procedure for establishing the JAD model.

The data generated included stress-strain relations and thermal expansion characteristics of base materials (adherents) and interlayer materials for input to the finite element analysis of the joints. Stress-strain data were obtained primarily at room temperature although a few experiments were also performed at elevated temperatures. Based on these results as well as data on the adherents in the published literature, estimates were obtained for the flow stress, ultimate tensile strength, elastic modulus, and Poisson's ratio of the materials as a function of temperature. The higher temperature data were needed primarily for calculating residual stresses, and it is envisaged that for more accurate residual stress estimates it would be necessary to actually perform additional tensile and bend tests at elevated temperatures.

Preliminary validation procedures involved determining the fracture strength and load-displacement behavior of small sized joints, and comparing the results with predictions of the JAD model. Notched bend bars, loaded in 4-point bending, were used for preliminary validation while unnotched 4-point bend bars were used for estimating the efficiency of the joints; efficiency is defined as the ratio of strength of the joint to strength of the monolithic ceramic. Experiments on unnotched specimens also helped in determining the preferred fracture path, namely, whether a crack propagated in the interlayer, the reaction zone of the base material, or through the base material. This served as an input to the JAD model. In this context, it may be noted that although strengths and toughnesses of adherents and interlayer materials can be determined separately, there is currently no straight-forward route for estimating apriori the corresponding properties of the reaction zone, or properties of the interface between the interlayer and adherents. Thus, unless the strength of these regions is greater than the adherent or the interlayer, or there is a convenient way of determining separately the strength and toughness of these regions, it is not possible to predict apriori the location of fracture, which is needed for the JAD model. Fortunately, as will be discussed later, failure of zirconia/zirconia joints occurred primarily through the interlayer, which coincided with the fact that the strength and toughness of the bulk 
interlayer (either MASZ-67 or MASZ-80) was always less than the base heat-treated zirconia. On the other hand, in the case of zirconia/NCI joints, failure occurred partly through the reaction zone of the zirconia and partly through the Ti-rich region immediately adjacent to the zirconia. This fracture path could not be predicted based on bulk measurements, nor could the fracture load of notched bend bars be predicted based on data of braze metal or as-received zirconia. Such experiments further confirmed the importance of performing small-scale validation experiments as part of establishing a joint design methodology.

Final validation was performed by testing cracked disk specimens subjected to diametral compression, with the crack (along the joint plane) rotated at various angles to the loading direction. This specimen had a joint area that was 20 times that of the bend bars used in preliminary validation, and served to evaluate the JAD model for a scaled up joint. The disk specimen served two additional purposes. First, because the specimen geometry differed significantly from that of the bend bar, testing of the disk specimen helped in establishing geometry independence of the design methodology. Second, it helped in validating the joint model over a considerable mixed-mode (different combinations of opening and sliding modes) loading domain. This aspect, although not as significant in the fracture of monolithic materials, assumes considerable importance for joints, because of the inherent mixed-mode nature of loading of bimaterial interfaces.

The details of the characterization and analysis task are illustrated by the chart in Figure 15. As shown in the figure, the task has been grouped under the following headings:

1. Materials

2. Specimen designs

3. Key properties characterized

4. Test conditions

5. Microstructure

6. Fractography, particularly for determining the fracture path

7. Preliminary analysis

\subsection{EXPERIMENTS}

\subsubsection{Materials Characterized}

The bulk constituent materials characterized for input to the JAD model consisted of the following:

1. As-received partially stabilized zirconia. The data for this material were used for assessing the zirconia/NCI joints, since the thermal cycle associated with the brazing cycle (maximum temperature of $750 \mathrm{C}$ ) did not involve any phase 


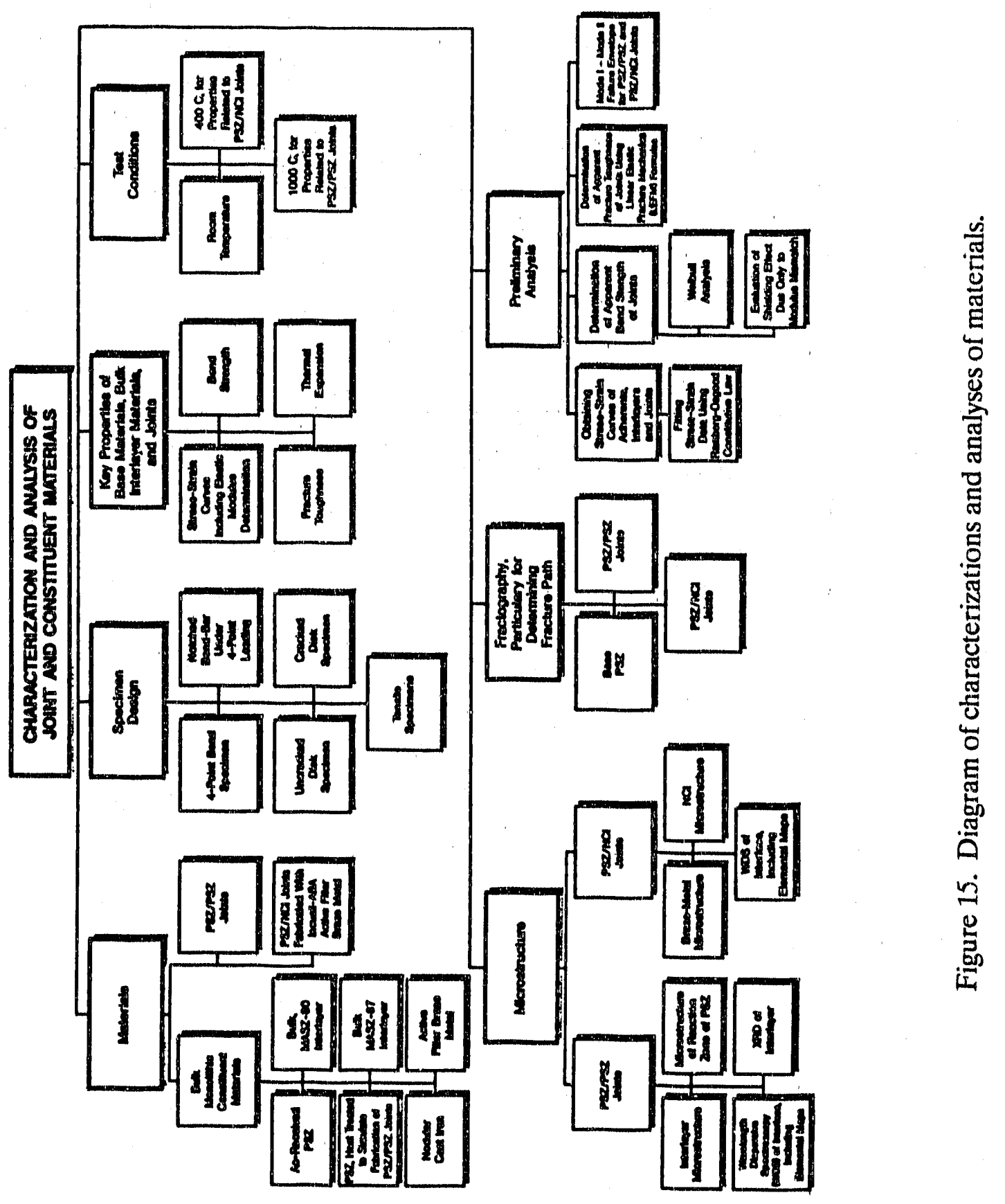


transformation, and was found not to significantly affect the bulk properties ${ }^{(a)}$ of the zirconia.

2. Heat-treated zirconia, involving a soak at $1350 \mathrm{C}$ for 2 hours in air. The heat treatment was used to simulate the thermal cycle involved in the zirconia/zirconia joints. Although the thermal cycle (it involved phase transformations of the zirconia) was found to have negligible effect on the elastic properties of the zirconia it had significant effect on the flow strength, bend strength, and fracture toughness of the material as well as on the overall thermal expansion coefficient. For this reason it was believed appropriate that properties of the heat treated zirconia be used in the JAD model when analyzing zirconia/zirconia joints.

3. Nodular cast iron which was used for the zirconia/ $\mathrm{NCI}$ joints. No heat treatment was applied to the $\mathrm{NCI}$ since the brazing temperature was too low to have any effect on this material.

4. Bulk MASZ-67 and bulk MASZ-80 interlayers. It may be recalled from the previous section that these magnesia-alumina-silica-zirconia interlayers were used for fabricating zirconia/zirconia joints.

5. Incusil-ABA active filler braze metal, used in fabricating zirconia/ $\mathrm{NCI}$ joints. The active filler metal incorporated $\mathrm{Ti}$, which was found to impart excellent wettability to the zirconia.

In addition to the bulk constituent materials, zirconia/zirconia and zirconia/NCI joints were characterized for validating the JAD model, and also for incorporating modifications as necessary in the model to account for observed phenomena. For example, preliminary validation experiments helped to identify the fracture path, and also to estimate an appropriate strain energy release rate value for zirconia/NCI joints.

The zirconia/zirconia joints that were characterized included joints fabricated using the following interlayer materials at the bonding temperature indicated:

1. Zirconia/zirconia joints fabricated using MASZ-50 interlayer and fabricated at $1350 \mathrm{C}$.

2. Zirconia/zirconia joints fabricated using MASZ-67 interlayer and fabricated at $1350 \mathrm{C}$.

(a) However, as will be indicated later, the brazing process involved formation of a reaction zone in the zirconia immediately adjacent to the braze metal. Because it was not possible to obtain bulk specimens from the reaction zone, in the JAD model it was assumed that the reaction zone had the same elastic and thermal properties as the bulk material. The toughness value was obtained by testiig a notched bend bar with the crack located in the reaction zone but at a slight distance from the braze-metal/reaction zone interface. This toughness was found to be lower than that of the bulk zirconia. 
3. Zirconia/zirconia joints fabricated using MASZ-67 interlayer and fabricated at $1400 \mathrm{C}$.

4. Zirconia/zirconia joints fabricated using MASZ-80 interlayer and fabricated at $1350 \mathrm{C}$.

5. Zirconia/zirconia joints fabricated using MASZ-80 interlayer and fabricated at $1400 \mathrm{C}$.

The zirconia/ $\mathrm{NCI}$ joint that was characterized was fabricated using Incusil-ABA active filler braze metal at a joining temperature of approximately $750 \mathrm{C}$.

In addition to the above joint types, many zirconia/zirconia joints such as those fabricated using calcia-titania-silica (CTS) interlayer, or zirconia/ $\mathrm{NCI}$ joints fabricated using the active substrate process, were characterized but they were not included for further analysis because of poor joint strengths. Those data are not included in this report, although some of the data are available as part of the published papers ${ }^{[3,4]}$ reproduced in Appendix $B$.

\subsubsection{Specimen Design}

As illustrated in Figure 15, a number of different specimen geometries were used for characterizing the mechanical behavior of bulk monolithic materials and joints. The specimen types were:

1. Unnotched rectangular bars (Figure 16a), loadød in 4-point pure bending, for determining the bend strength and stress-strain behavior of monolithic ceramic specimens and specimens containing joints.

2. Notched bend specimen (Figure 16b), loaded in 4-point bending, for determining the fracture toughness of monolithic ceramic specimens and specimens containing joints. The machined notch was alligned along the mid-plane of the bond. This specimen geometry was used as part of the preliminary validation procedure.

3. Tensile specimen, used for evaluating the stress-strain behavior of nodular cast iron and braze metal.

4. Uncracked disk specimen, loaded in diametral compression, with the bond plane rotated at an angle of $\mathbf{3 0}$ degrees to the load axis. This specimen design was used for evaluating the shear strength of zirconia/zirconia joints.

5. Cracked disk specimen, loaded in diametral compression, with the machined notch/crack at various angles to the loading axis. This specimen geometry was used as part of the final validation procedure, and it had a bond area that was approximately 20 times that of the bend bar used in preliminary validation of the joint assessment model. 

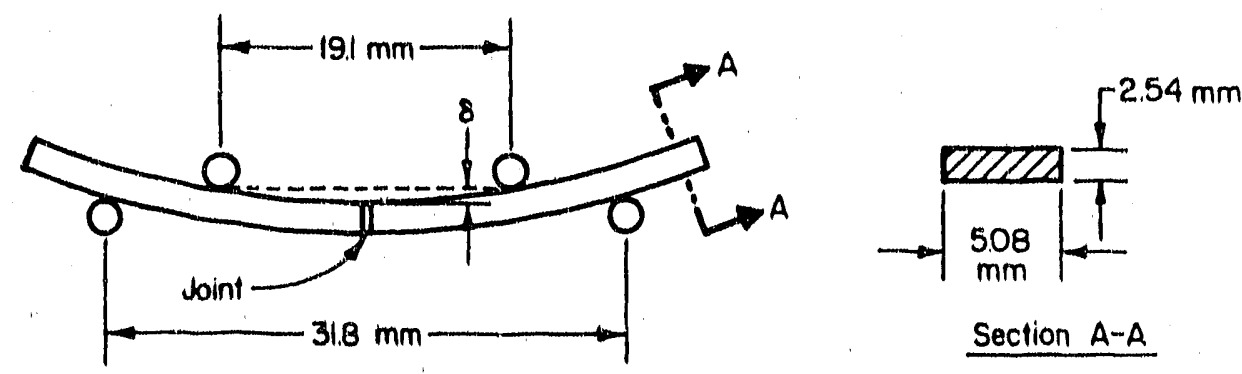

Figure 16a. Bend test geometry for evaluation of the bend strength of joints and of constituent materials. Displacement, 8, was measured between the upper loading pins and the center of the compression face of the bend bar, using a high-resolution LVDT.
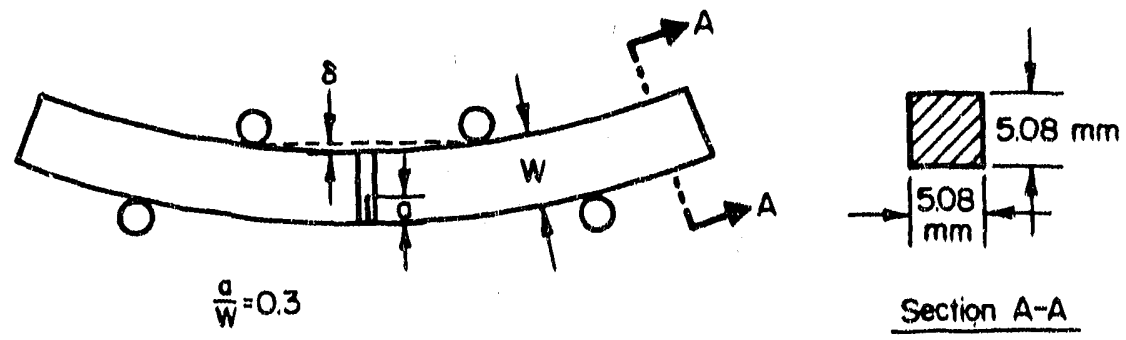

Figure 16b. Notched bend test geometry for evaluating the fracture toughness of constituent materials, and for preliminary validation testing of joints. 
The 4-point bend specimen (Figure 16), was of nominal width $5.08 \mathrm{~mm}$, thickness $2.54 \mathrm{~mm}$, and length $38.1 \mathrm{~mm}$. The specimen was finish ground using a 110-grit diamond wheel and was loaded under 4-point bending using a self-alligning fixture that allowed for free rotation in two direstions. Figure 17 is a photograph of the experimental setup. The lower loading pins were $31.75 \mathrm{~mm}$ apart, while the upper loading pins were $19.05 \mathrm{~mm}$ apart. A high accuracy displacement measuring fixture was used to determine the center displacement of the bend bar with respect to the upper loading pins; a displacement of 0.1 $\mu \mathrm{m}$ was easily resolved by the LVDT assembly' and calibration procedure. For some of the specimens that were used for generating stress-strain curves, the strain on the tension face of the bend bar was monitored using a strain gage bonded to that face. In this way, it was possible to determine the true stress-strain curve from the measured stress-strain and loaddisplacement plots.

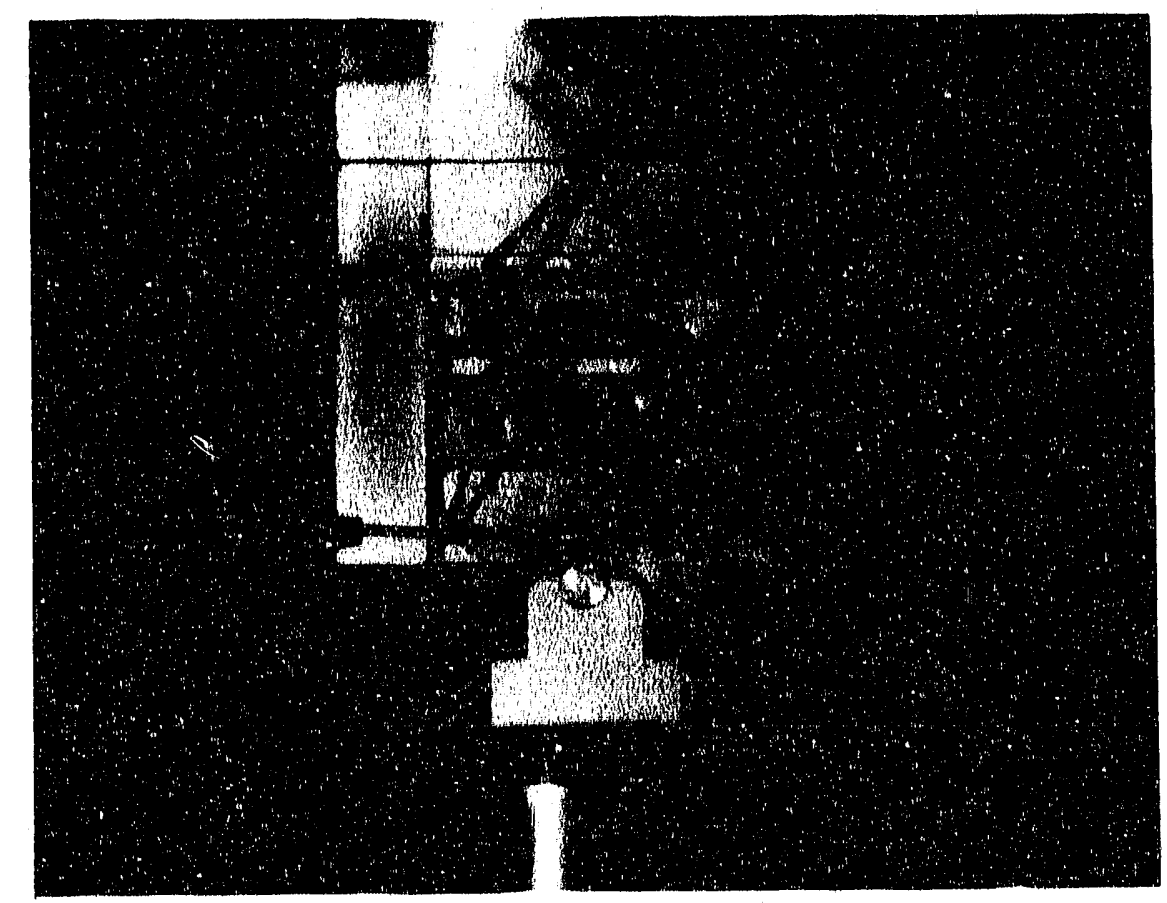

Figure 17. Experimental setup for bend testing of constituent materials and joints. The LVDT core-rod is located at the center, above the specimen.

The notched bend bar specimen is illustrated in Figure 16b. A fine slitting saw was used to make the notch, which was approximately $0.3 \mathrm{~mm}$ wide. The ratio $(\mathrm{a} / \mathrm{W})$ of crack length (a) to specimen depth (W) was approximately 0.3. Fatigue precracking was not attempted since earlier experiments, involving toughness evaluation of the as-received zirconia using straight notched and chevron notched bend bars as well as chevron-notched disk specimens, indicated that the straight-notched bend specimen provided fracture toughness data that were in excellent agreement with those generated using other specimen geometries. 
The machined notch was centered along the mid-plane of the bond in the case of zirconia/zirconia bonds. However, for zirconia/NCI joints it was not always possible to maintain the notch along the mid-plane of the bond. Rather, because of softness of the braze metal, there was always a tendency for the fine slitting saw to deviate into the reaction zone of zirconia, although the extent of deviation was extremely small (typically less than $50 \mu \mathrm{m})$. Preliminary experiments indicated that this did not have any significant effect on the fracture toughness value. This was in agreement with the observed fracture path for unnotched bend specimens, which showed that crack propagation occurred partly through the reaction zone of the zirconia and partly through the Ti-interface next to the zirconia. Hence, for consistency purposes, the machined notch was cut in the reaction zone, and within $50 \mu \mathrm{m}$ of the zirconia/braze interface. Fractographic evidence indicated that this did not prevent the crack from partly weaving through the Ti-rich zone of the braze metal.

The geometries of the uncracked disk and cracked disk specimens are illustrated in Figures $18 \mathrm{a}$ and $18 \mathrm{~b}$, respectively. The specimens were loaded in compression, with paper cards used to prevent crushing the specimens at the loading points. The uncracked disk specimen was used to determine the shear strength of joints by orienting the crack plane and bond at an angle of 30 degrees to the compression loading axis. For such an angle, the normal stress is zero at the center, and the shear stress (assuming homogeneous material and no residual stresses) is given by:

$$
t=\sqrt{3} P / \pi R B
$$

In the case of the cracked disk specimen, a fine slitting saw was also used to cut the notch, approximately $0.3 \mathrm{~mm}$ wide. Figure 19 is a photograph showing the fine slit in a disk specimen. The slit is located well within the dark band which is the reaction zone of the zirconia, although in this particular case the slit is not exactly centered on the bond-line; in some of the specimens, the tip of the notch did coincide with the center-line of the bond, but these specimens did not indicate any significant difference in fracture load compared with slits machined in the manner shown in Figure 19.

The ratio of half-notch length (a) at the specimen faces to the radius ( $R$ ) of the disk was nominally 0.5 , while the ratio of half-length of the chevron notch at mid-thickness to the radius was typically 0.41 . For the chevron-notched disk specimen, a stable crack is generally formed that propagates through the entire chevron notch prior to fast fracture. However, it was observed that when the crack angle was large (typically greater than 15 degrees), there was a sharp deviation of the crack from the bond and notch plane even before the crack had propagated through the entire chevron notch. Therefore, in all cases, the crack length at fast fracture was estimated from the fracture surface; i.e., $a / R$ that was used for calculation purposes was obtained from observations of the fracture surface. The crack opening displacements (COD) were measured in a direction perpendicular to the crack plane using a COD gage with strain-gage arms. The knife edges were located on the specimen at equal distances of $3.81 \mathrm{~mm}$ on either side of the slit. Figure 20 is a photograph of the experimental setup. The extensometer was calibrated over a maximum span of $25 \mu \mathrm{m}$, and this provided a resolution of better than $0.1 \mu \mathrm{m}$ for monitoring crack opening displacements. 

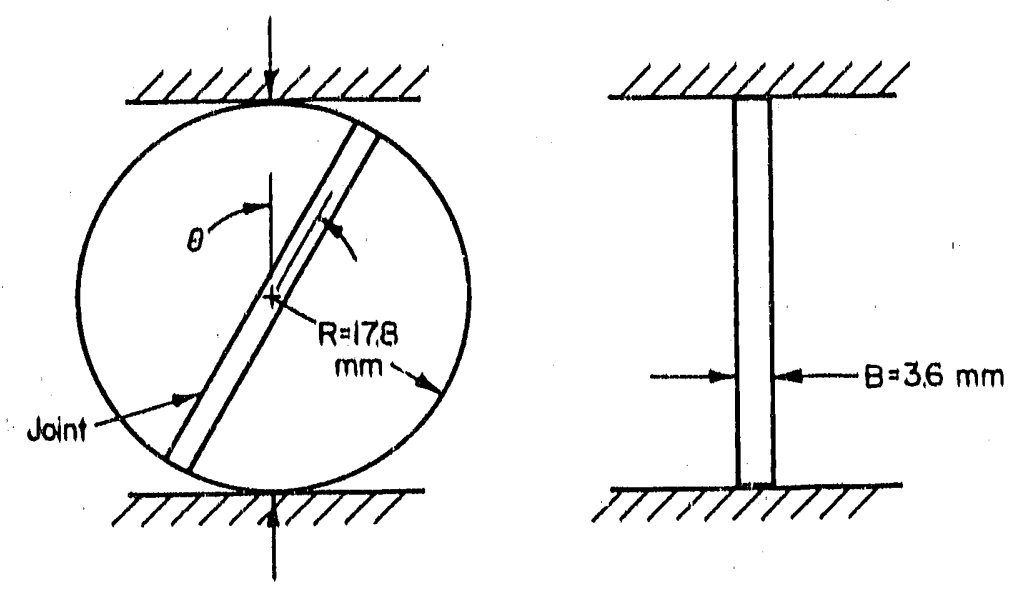

Figure 18a. Un-notched disk specimen for measuring the shear strength of joints.
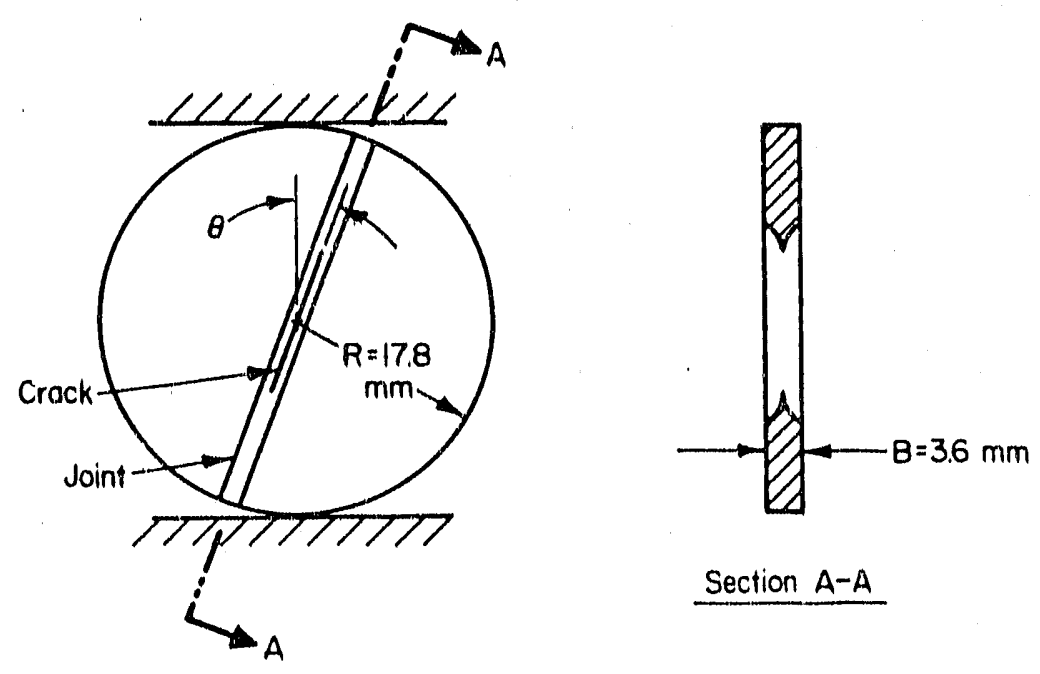

Section A-A

Figure 18b. Chevron-notched cracked disk specimen used in final validation testing of joints. 


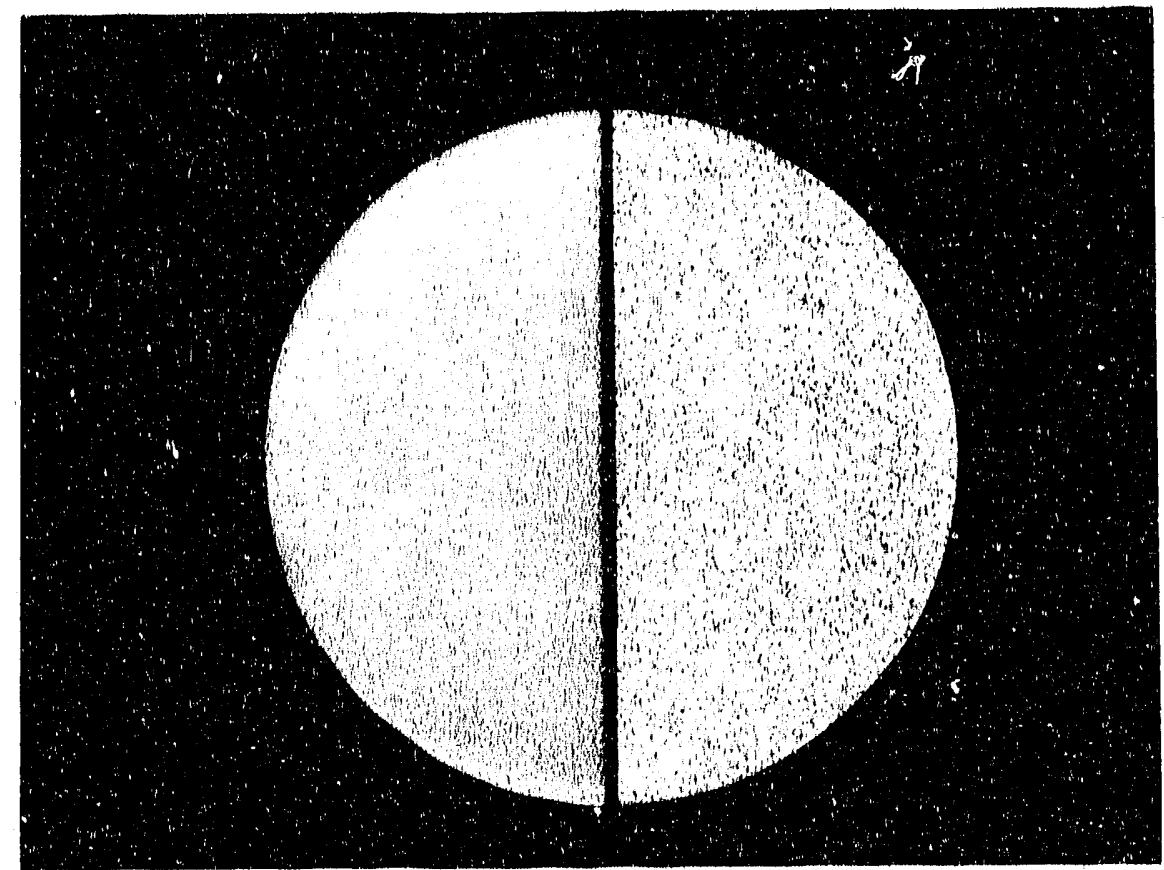

Figure 19. Photograph of zirconia/NCI cracked disk specimen. The zirconia is on the left and NCI is on the right.

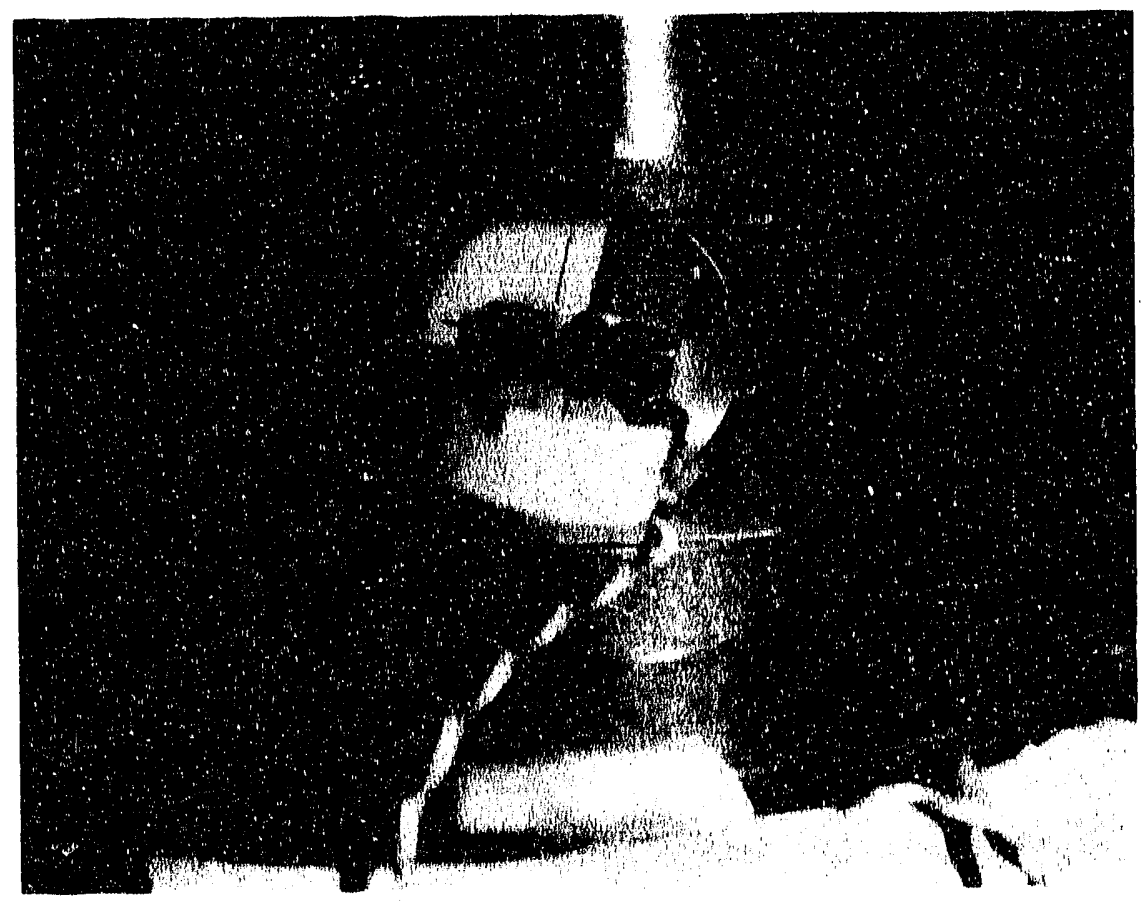

Figure 20. Experimental setup used in final validation testing of joints using cracked disk specimen. 
Tensile sheet specimens were used for evaluating the stress-strain behavior of the braze metal and nodular cast iron. These were pulled to failure in a servo-hydraulic testing machine. Strain was monitored with an extensometer employing strain gages.

\subsubsection{Key Properties Characterized}

Thermal Expansion. The only physical property that was measured was the thermal expansion behavior of adherents and interlayers, and they served as input to the FEM code for evaluating residual stresses. The thermal expansion of as-received zirconia, NCI, and braze metal were determined from room temperature (RT) to $730 \mathrm{C}$, which was near the processing temperature for zirconia/ $/ \mathrm{NCI}$ joints. The thermal expansion trace was essentially linear, and did not indicate any phase transformation over the temperature domain. The thermal expansion behavior of heat-treated zirconia was determined over the temperature range $\mathrm{RT}$ to $1350 \mathrm{C}$. The thermal expansion behavior of the ceramic interlayers, namely MASZ-67 and MASZ-80 interlayers, were only evaluated over the temperature range RT to $1200 \mathrm{C}$, since they were molten at temperatures above $1300 \mathrm{C}$. These iriterlayers indicated phase transformations over the temperature domain of interest.

Stress-Strain Behavior. The stress-strain behavior of adherents, bulk interlayer materials, and specimens containing joints were determined primarily at room temperature. The stress-strain curves of the constituent materials were then fit to a non-linear RambergOsgood constitutive relation. Significant non-linear deformation was observed for the base zirconia material, NCI and braze metal. Even the ceramic interlayer materials indicated some non-linear deformation; for example, the proportional limit for MASZ-67 interlayer was only 63 percent of the material's bend strength. That is why inealstic fracture mechanics principles were used in the JAD model to account for the non-linear deformation response of the constituent materials.

Elevated temperature tests consisted of experiments perforrned at $200 \mathrm{C}$ and $400 \mathrm{C}$ for braze material and NCI, and at temperatures of $400 \mathrm{C}, 750 \mathrm{C}$, and $1000 \mathrm{C}$ for the zirconia material. These results, along with those available in the published literature were used for estimating the stress-strain response at intermediate temperatures.

Bend Strength. Bend strengths of base materials and joints were obtained from 4point bend tests. Standard mechanics of material formulas for a homogeneous continuum were used to evaluate the bend strength of the joint from the gecometry of the specimen and the failure load. Although this provided only the apparent bend strength of the joint, the error was estimated to be less than 8 percent, because the elastic modulus mismatch of the materials was small for both the zirconia/zirconia and zirconia/NCI systems, and also because of small differences in the thermal expansion coefficient of the constituent materials. Nevertheless, it is useful to keep this point in mind when assessing the joint strengths in the tables listed later in this section.

A sufficient number of specimens were tested to obtain the Weibull modulus of the base materials and joints. This parameter is useful for assessing the variability of data, with a high number indicating lower scatter in strength compared with a material with a low Weibull modulus value. The efficiency of the joint was obtained from the ratio of the average bend strength of the joint with respect to the strength of the base zirconia. In all cases, efficiency was less than unity with the worst efficiency observed for zirconia/zirconia joints fabricated using the MASZ-50 interlayer. 
For zirconia/zirconia joints, it was observed that the preferred fracture path was the interlayer material. Because of this crack path, it was possible to relate the bend strength of zirconia/zirconia joints with the bend strength of the corresponding interlayer. For zirconia/NCI joints, failure occurred partly through the reaction zone of the zirconia and partly through the Ti-rich layer of the braze metal. Accordingly, it was not possible to relate the bend strength of the constituent bulk materials to that of the joint.

Fracture Toughness. The fracture toughnesses of base materials and joints were evaluated using notched bend bar and cracked disk specimens. Appropriate formulas were used to determine fracture toughness from the applied load and specimen geometry. The fracture toughness data cf constituent materials (adherents and interlayers) were used as input to the JAD model. Mixed-mode fracture toughness data were used for evaluating the dependence of strain energy release rate on mode mixity, expressed in terms of the phase angle $\Psi, \tan ^{-1}\left(Q_{\|} / Q_{1}\right)^{(a)}$.

\subsubsection{Test Conditions}

Mechanical properties of adherents and interlayer materials, and the load-bearing capability of joints were determined at RT, $400 \mathrm{C}$ and at $1000 \mathrm{C}$. However, most of the experiemnts were performed at room temperature. The $400 \mathrm{C}$ tests were used for evaluating the performance of zirconia/ $\mathrm{NCI}$ joints at that temperature. $1000 \mathrm{C}$ tests were used for evaluating the performance of zirconia/zirconia joints at that temperature. All tests were performed in air.

\section{$\underline{3.25 \text { Microstructure }}$}

The microstructures of zirconia/zirconia and zirconia/NCI joints were observed using optical and scanning electron microscopy (SEM) techniques. Chemical analysis, using wavelength dispersive spectroscopy (WDS) on a JEOL 733 microprobe, was performed to determine the chemical species responsible for good wetting between interlayer and adherents, and also for evaluating any undesirable reaction product that may have formed as a result of the joining process. In addition, limited $\mathrm{X}$-ray diffraction was performed on the MASZ interlayer materials to understand the source of $\mathrm{R}$-curve behavior that was observed for notched zirconia/zirconia joint specimens. Details of some of the microstructures obtained for zirconia/zirconia joints, fabricated either with a CTS interlayer or an MASZ interlayer are provided in the papers ${ }^{[3,4,5]}$ in Appendix B.

Most of the microstructural examinations were performed at the begining of this program, while developing appropriate bonding interlayers and joining conditions for reliable joints. During the validation stage, microstructural examination was limited to determining the thickness of the bonds. For zirconia/zirconia joints, interlayer thickness ranged between 100 and $150 \mu \mathrm{m}$, while for zirconia/NCI joints, the interlayer thickness ranged between 50 and $80 \mu \mathrm{m}$.

(a) For bimaterial systems, the counterpart to the monolithic fracture toughness parameter $\mathrm{K}$ is denoted by $\mathrm{Q}$. 


\subsubsection{Fractography}

The fracture surfaces of representative specimens were examined optically and by using SEM. Limited energy dispersive X-ray analysis (EDS) was conducted to obtain estimates of the chemistry in different regions of the fractue surface. Such observations and measurements helped in identifying the preferred fracture path, namely, whether a crack propagated through the adherents, or through the bonding interlayer, or through the interface between the interlayer and adherent. Additional confirmation of the fracture path was obtained by sectioning fractured samples perpendicular to the fracture surface, metallographically polishing those sections, and observing such polished sections using optical and scanning electron microscopy techniques.

\subsubsection{Preliminary Analysis of Data}

A preliminary analysis of the data included the following:

1. Reducing the load-versus-displacement data and load-versus-strain-gage data to determine the stress-strain behavior of the constituent materials. All the constituent materials showed some degree of non-linearity at room temperature, and the stress-strain results were mathematically expressed using the elastic-plastic Ramberg-Osgood relation:

$$
\epsilon / \epsilon_{0}=\left(\sigma / \sigma_{0}\right)+D\left(\sigma / \sigma_{0}\right)^{n}
$$

where o denotes stress, $e$ denotes strain, $\sigma_{0}$ yield stress, $\varepsilon_{0}$ yield strain, $\sigma_{0} / \varepsilon_{0}$ represents the elastic modulus, $\mathrm{E}$, and $\mathrm{D}$ is a constant.

2. Determination of apparent bend strengths of the joints from the load at failure, using the standard bend-bar formula for a homogeneous material. Although such a procedure neglects residual stresses from thermal expansion mismatch and shielding stresses from modulus mismatch, it provides a basis for comparing the strength of the joint with respect to the strength of the base ceramic. This is similar to the JAD model procedure used for notched specimens, where the distance measured, in the direction of the joint assessment vector, from the origin to the failure envelope is compared with the reference load, which is the load required to break a monolithic ceramic specimen.

The bend strengths of constituent materials and joints were expressed in the form of Weibull plots. The data were arranged in increasing values of strength, and the probability of failure was expressed through the relation:

$$
\mathrm{P}=\mathrm{i} /(\mathrm{N}+1)
$$


where $\mathrm{i}$ is the rank ( $\mathrm{i}=1$ corresponding to the lowest strength), and $\mathrm{N}$ is the number of samples tested. The Weibull modulus was obtained by plotting $\ln (1 /(1-\mathrm{P}))$ versus strength on a log-log plot, and determining the slope of the best fit straight line.

Additional analytical efforts associated with bend strengths of unnotched specimens involved predicting the stength of joints from the strength of the bulk interlayer material. This procedure was feasible for zirconia/zirconia joints because it was observed that failure occurred preferentially in the interlayer. The predictive effort had to incorporate shielding effects, since the modulus of the interlayer was consistently less than the surrounding zirconia, thereby reducing the local stress at the failure location with respect to the far-field applied stress. These shielding effects are discussed in the attached paper ${ }^{[6]}$. In the case of zirconia/ $\mathrm{NCI}$ joints, such a predictive procedure could not be used because failure occurred partly through the reaction zone of the zirconia and partly through the Ti-rich zone of the braze metal. In this case, a predictive methodology for bend strength would require measurement of the bend strength of the reaction zone. Although this could be performed in principle, by depositing a Ti-film on the surface of an as-received zirconia bend bar, and then subjecting the sample to a $750 \mathrm{C}$ heat treatment, such experiments were not performed in this program.

3. Evaluating the fracture toughness of notched bend bars using the following LEFM formula for a homogeneous material:

$$
\mathrm{K}_{\mathrm{Y}}=6 \mathrm{MY}(\mathrm{a} / \mathrm{W}) \sqrt{\mathrm{a}} / \mathrm{BW^{2 }}
$$

where $K_{1}$ is the mode $I$ stress intensity factor, $M$ is the magnitude of a pure bending moment, $a$ is the crack length, $W$ is the beam depth, $B$ is the beam thickness, and $\mathrm{Y}$ is a function of a/ $\mathrm{W}$ given by:

$$
\mathrm{Y}(\mathrm{a} / \mathrm{W})=1.99-2.47(\mathrm{a} / \mathrm{W})+12.97(\mathrm{a} / \mathrm{W})^{2}-23.17(\mathrm{a} / \mathrm{W})^{3}+24.80(\mathrm{a} / \mathrm{W})^{4}
$$

The fracture toughness of constituent materials and the apparent fracture toughness of joints were calculated using the above formulas. Of course, the apparent fracture toughness of joints is denoted by $Q_{1}$. The reason that the above formulas provide only apparent fracture toughness of joints is that the formulas do not take into account the elastic and thermal mismatch of the constituents, although the latter was small for the constituent materials considered in this investigation. Nevertheless the apparent toughness values provide an approximate means for comparing the fracture toughness of joints with those of the constituent materials, and are tabulated in Section 3.3. It may be noted, in this context, that the local $Q$ of zirconia/zirconia joints, fabricated with MASZ 67 interlayer material, at failure locations inside the interlayer were calculated to be approximately 68 percent of the apparent $Q$ value; for joints 
fabricated with MASZ-80 interlayer material, the local Q was approximately 90 percent of the apparent $Q$ value.

The apparent mixed-mode stress intensity factors for zirconia/zirconia joints were obtained using Atkinson's solution ${ }^{[7]}$ for a cracked disk specimen of a homogeneous material, with the crack oriented at various angles to the compression load line. For the zirconia/NCI disk specimens, the current FEM results for a bimaterial disk specimen provided by Professor C. F. Shih were used for determining the Mode I-Mode II stress intensity factors; Atkinson's analytical results were within 5 percent of the current FEM values, primarily because the modulus mismatch between zirconia and NCI was quite small. The apparent mixed-mode data were reduced using the current analytical results to compute the local $Q_{1}$ and $Q_{\|}$values at failure. These local $Q$ values were then plotted in the form of $\mathrm{G}$ versus mode mixity, $(\Psi),\left(\Psi=\tan ^{-1}\left(Q_{\|} / Q_{1}\right)\right)$. Such plots were helpful in developing and assessing an appropriate function which related strain energy release rate to $\Psi$. Currently there does not exist a universal functional form of $G$ versus $\Psi$, and the form suggested by Evans and Hutchinson ${ }^{[8]} \mathrm{G}(\Psi)=G_{0} \operatorname{Sec}^{2} \Psi$, had to be modified based on data from monolithic ceramics which suggested that the form $G(\Psi)=G_{0} \operatorname{Sec}^{2}\left(\Psi / \Psi_{0}\right)$, where $\Psi_{0}$ is a constant, was more appropriate.

\subsection{TEST RESULTS}

The presentation of the test results is divided into three sections:

1. Results of mechanical and thermal property measurements that were used for generating baseline data for constituent material properties. These results were used as input data to the FEM code and JAD model.

2. Results of mechanical tests on unnotched and notched bend bars that were used as part of preliminary validation of the JAD model.

3. Results of mechanical tests on cracked disk specimens that were used as part of the final validation of the JAD model.

\subsubsection{Properties of Constituent Materials}

Thermal Expansion. Figure 21 provides the thermal expansion trace of the base zirconia material over the temperature range $100 \mathrm{C}$ to $1300 \mathrm{C}$; measurements were made over a gage length of $38.1 \mathrm{~mm}$. The expansion trace provided an average thermal expansion $\left(\alpha_{\mathrm{th}}\right)$ coefficient of approximately $10.3 \times 10^{-6} / \mathrm{C}$, and this value was used in the analysis of zirconia/zirconia joints. Figure 22 is a thermal expansion trace of the base zirconia over a narrower temperature range, $\mathrm{RT}$ to $730 \mathrm{C}$. The plot shows minimum hysterisis, and here too the average thermal expansion coefficient is $10.3 \times 10^{-6} / \mathrm{C}$. For $\mathrm{NCI}$ an $\alpha_{\text {th }}$ of $14.9 \times 10-6 / \mathrm{C}$ was obtained. For the Incusil-ABA braze metal, a thermal expansion coefficient of $18.2 \times 10-6 / C$ was obtained from the material supplier.

The thermal expansion trace of bulk MASZ-67 interlayer material, that was used in zirconia/zirconia joining, is shown in Figure 23. In this case significant non-linear expansion may be observed; in particular, the volumetric expansion and contraction that are observed 
in the temperature range $550 \mathrm{C}$ to $900 \mathrm{C}$ can be ascribed to a monoclinic to tetragonal (and vice versa) phase transformation mechanism most likely involving the retained zirconia particles in the interlayer material. A similar thermal expansion trace was obtained for the MASZ-80 interlayer. Because of the complexity of the thermal expansion trace, the actual data were used in the computation of residual stresses in the FEM model.

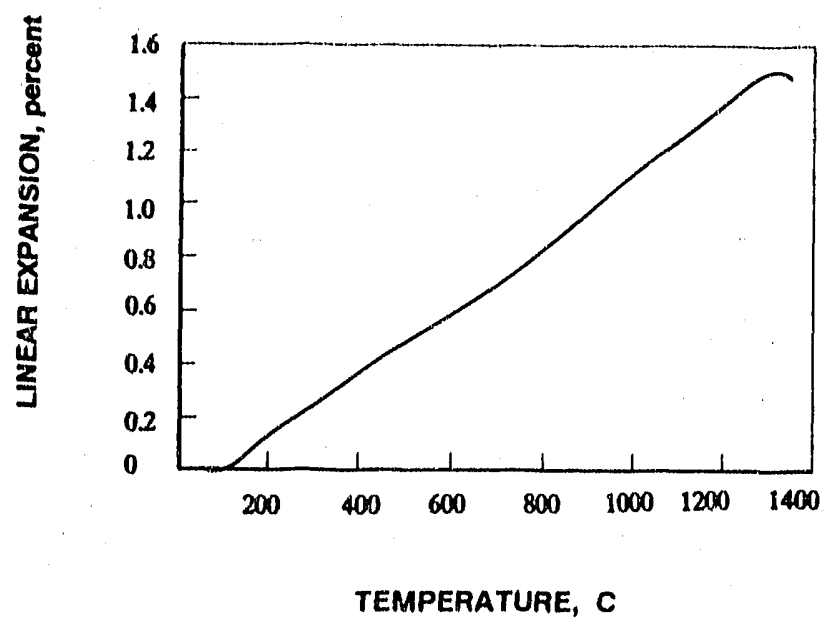

Figure 21. Thermal expansion trace of base zirconia from room temperature to $1300 \mathrm{C}$.

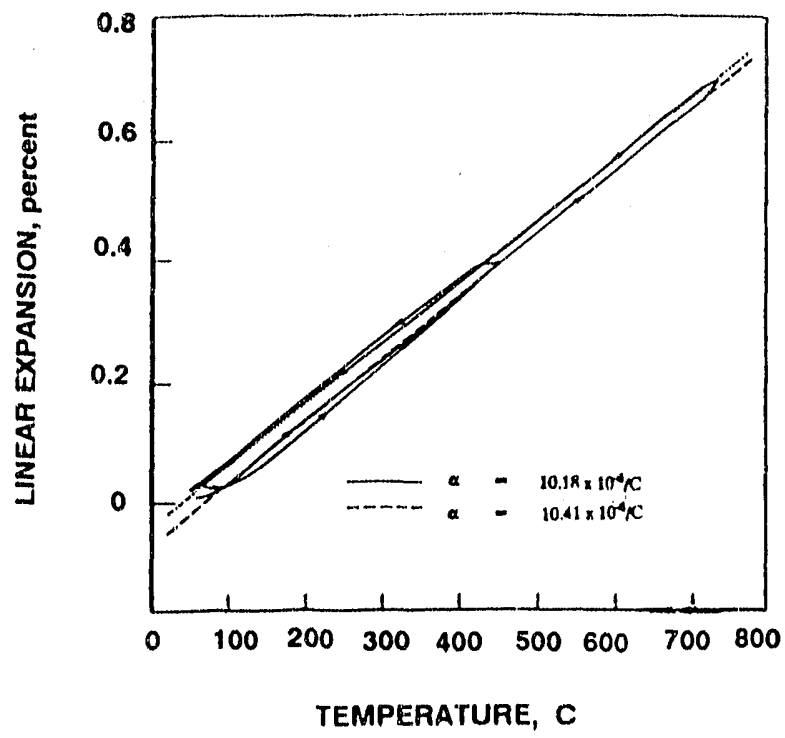

Figure 22. Thermal expansion of base zirconia material from room temperature to $730 \mathrm{C}$. 


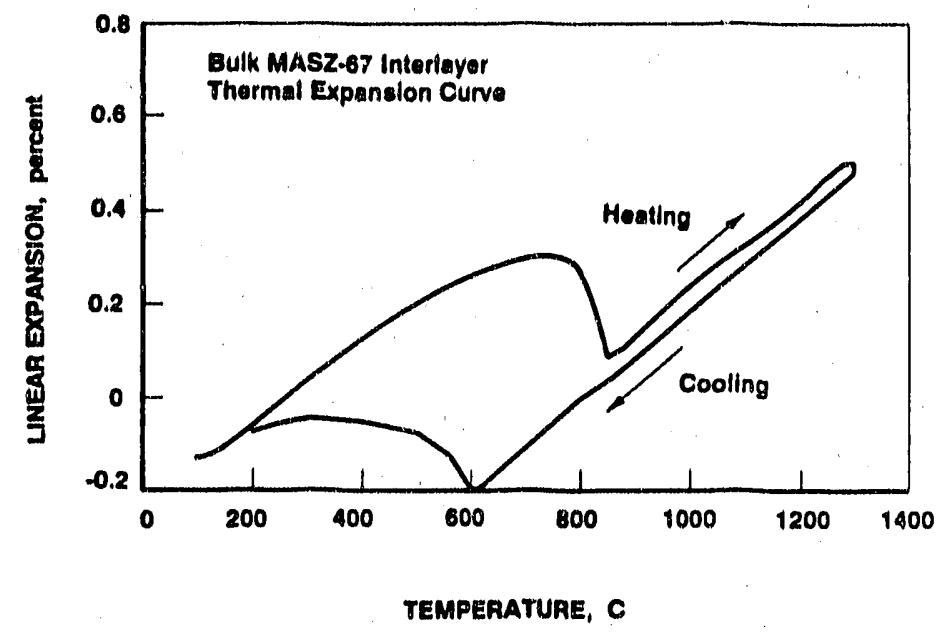

Figure 23. Thermal expansion of MASZ-67 material from room temperature to $1300 \mathrm{C}$.

For completeness, the thermal expansion trace of a zirconia/NCI joint is shown in Figure 24. The specimen was a bend bar of length $38.63 \mathrm{~mm}$, and the expansion was measured in a direction perpendicular to the joint plane (braze metal thickness was approximately $70 \mu \mathrm{m}$ ). An average $\alpha_{\text {th }}$ of $11.84 \times 10-6 / C$ was obtained. This value may be compared with $\alpha_{\mathrm{th}}$ of $10.3,14.9$, and $18.2 \mathrm{ppm} / \mathrm{C}$ for the zirconia, $\mathrm{NCI}$, and braze metal, respectively.

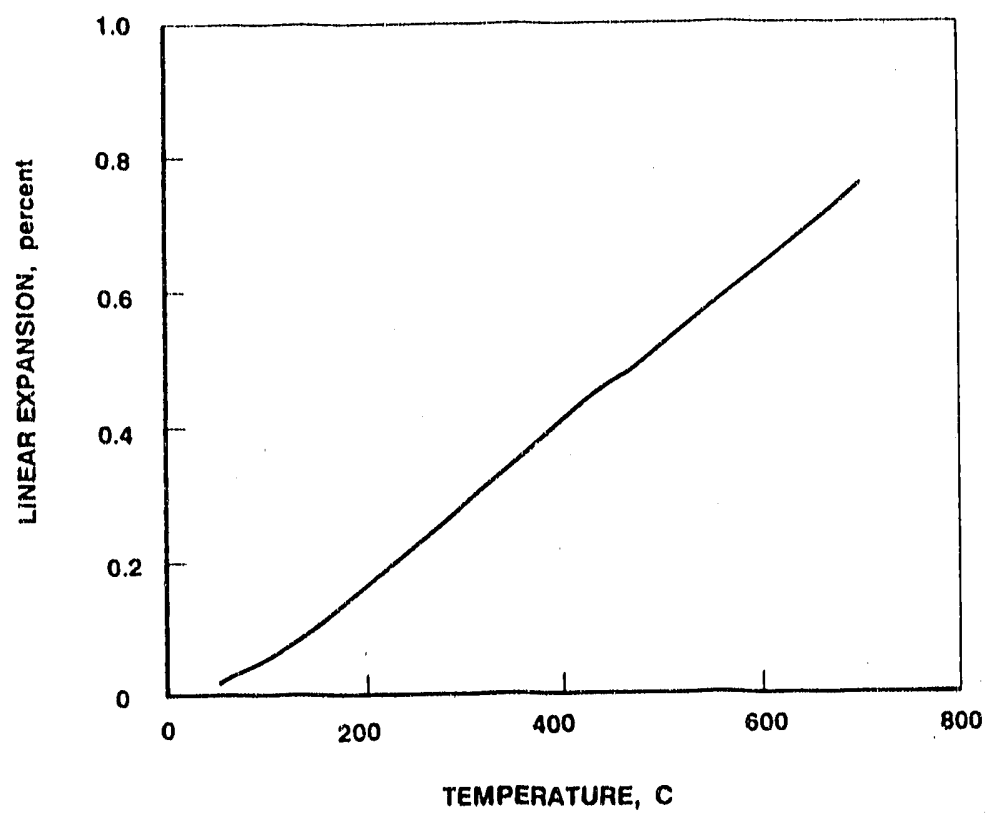

Figure 24. Thermal expansion of zirconia/NCI joint. 
Stress-Strain Behavior of Constitutive Materials. Figures 25-30 illustrate the true stress-strain behavior of the following constituent materials at room temperature:

1. As-received zirconia (Figure 25),

2. Heat-treated zirconia, heat treated at $1350 \mathrm{C}$ (Figure 26),

3. Nodular cast iron (Figure 27),

4. Incusil- $\mathrm{ABA}$ (Figure 28),

5. Bulk MASZ-67 ceramic interlayer, sintered at $1350 \mathrm{C}$ (Figure 29),

6. Bulk MASZ-80 ceramic interlayer, sintered at $1350 \mathrm{C}$ (Figure 30).

The true stress-strain data were fit using the Ramberg-Osgood relation given earlier in this section. Table 5 provides appropriate parameters used for fitting the stress-strain curves. The Poisson's ratios that are provided in the table were not measured but were obtained from the literature. The table also includes parameters for elevated temperature behavior. Among these latter results, the complete stress-strain behavior was experimentally measured at $400 \mathrm{C}$ for the braze metal and $\mathrm{NCI}$, and at $200 \mathrm{C}$ for the braze metal; wire specimens were used in measuring the stress-strain property of braze metal, since thicker sections were not available. The stress-strain behavior of zirconia at elevated temperature was estimated based on the room temperature results confirmed with data available in the literature; only the elastic modulus and bend strength were measured for zirconia at temperatures of $400 \mathrm{C}, 750 \mathrm{C}$ and $1000 \mathrm{C}$.

The average bend strength of ceramic specimens are also tabulated in Table 5. Bend test results of individual specimens are provided in the master Table 6 . Weibull moduli of constituent materials were determined, and they are summarized in a table provided later in this report.

In Tables 6 and 7 the individual specimens are identified by a key which indicates the billet, the specimen type, and location of specimen in the billet prior to machining. The first four characters of the specimen number correspond to the particular joined billet. Thus, a specimen number such as HP22-B13 is a specimen that was machined from joined billet number HP22. The letter identifiers B, F, UD, and CD indicate specimen type; bend bar, notched bend bar (fracture), uncracked disk, and notched disk. The last two digits of the specimen number provide an approximate idea of the specimen location within the billet, with the first digit corresponding to the row number and the second digit corresponding to the column number. This is illustrated in Figure 31, and, except for the as-received zirconia, bulk interlayer materials, and the HP22 block (where row numbering was started with 0 rather than 1), this convention was followed for all the specimens.

Fracture Toughness of Constituent Materials. The fracture toughness of constituent materials and apparent fracture toughness of joints are tabulated in Table 7. Table 8 is based on Table 7 , and provides average $Q_{10}$ and corresponding $G_{10}$ values for the various constituent materials. In this table, the toughness of the reaction zone of zirconia/NCI joints was evaluated from a notched-bend bar test, where the crack propagated entirely through the reaction zone of the zirconia, away from the Ti-rich interface of the braze metal. 


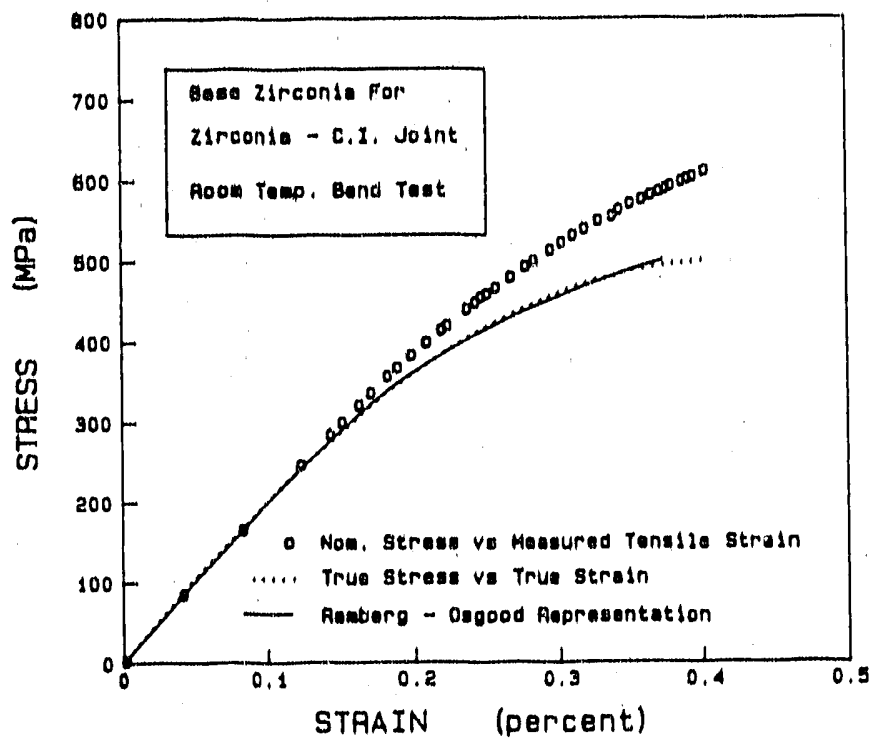

Figure 25. Room temperature stress-strain behavior of as-received zirconia.

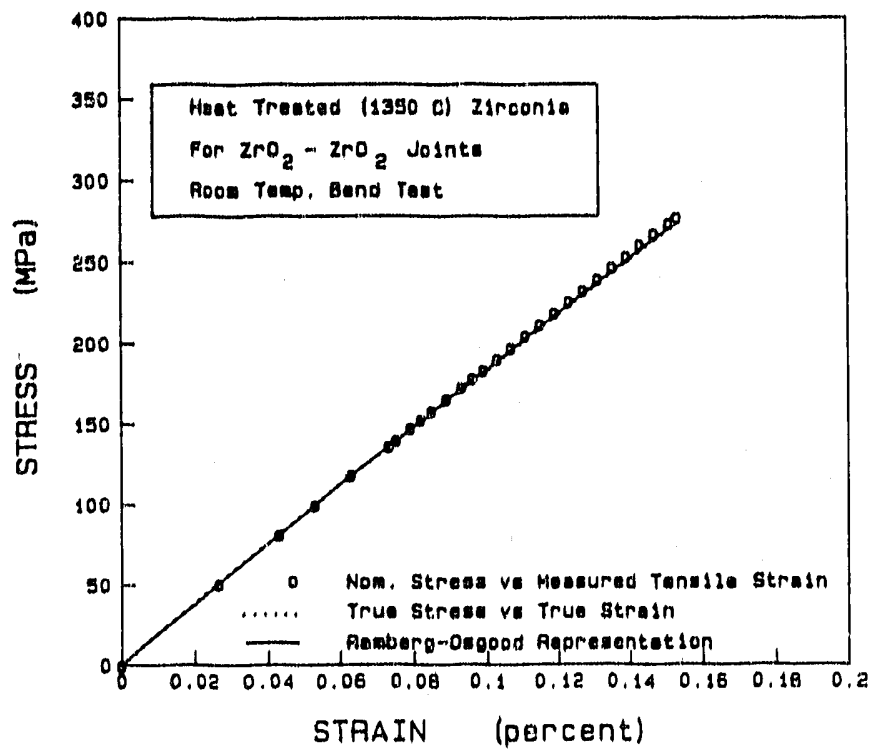

Figure 26. Room temperature stress-strain behavior of heat treated zirconia. 


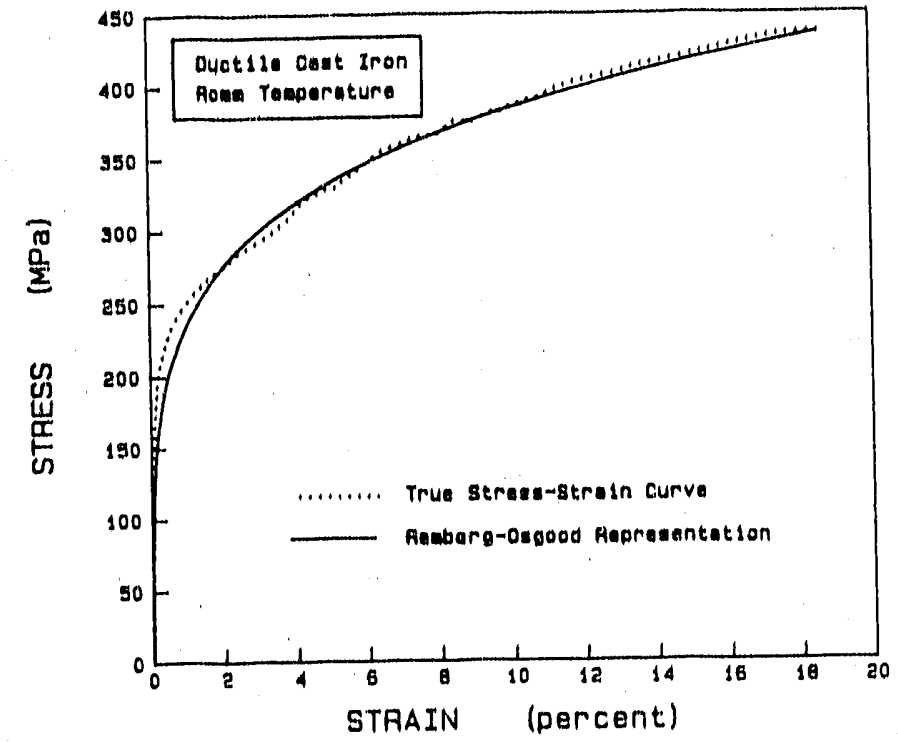

Figure 27. Room temperature stress-strain behavior of nodular cast iron.

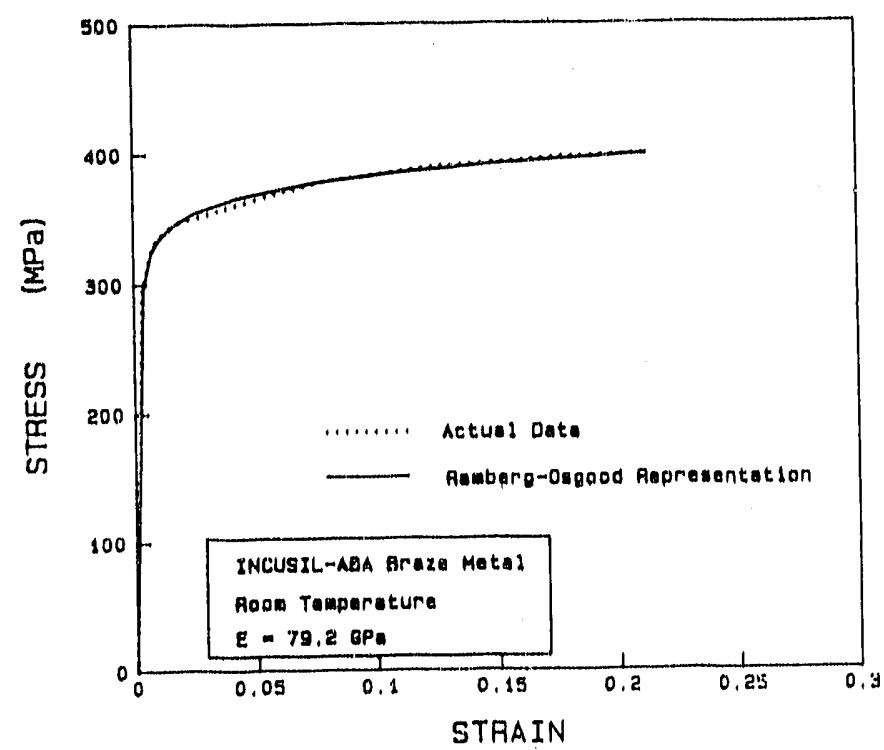

Figure 28. Room temperature stress-strain behavior of Incusil ABA braze metal. 


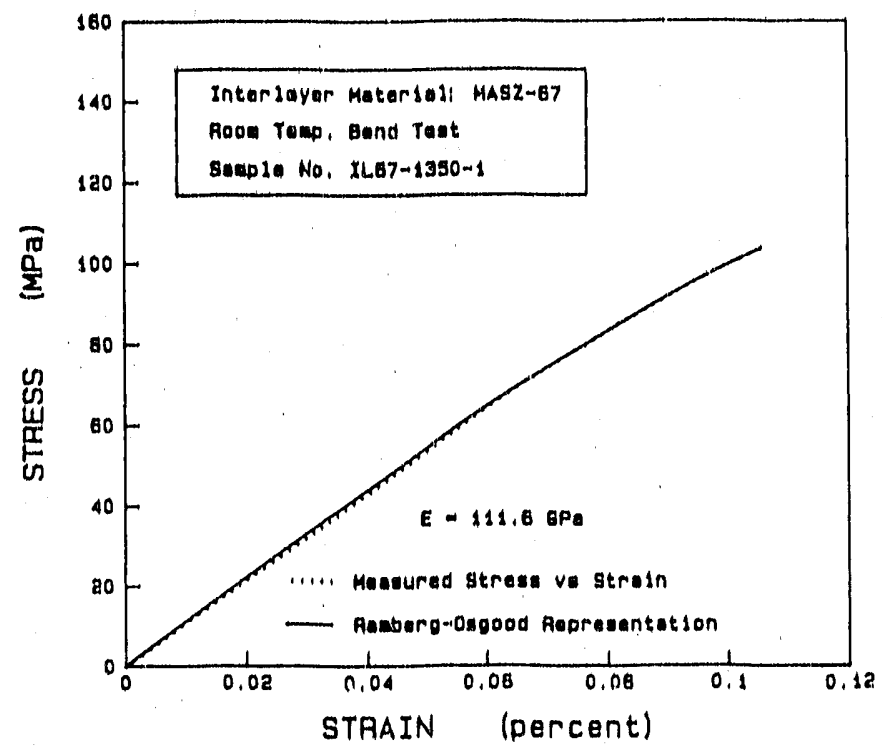

Figure 29. Room temperature stress-strain behavior of MASZ-67 material.

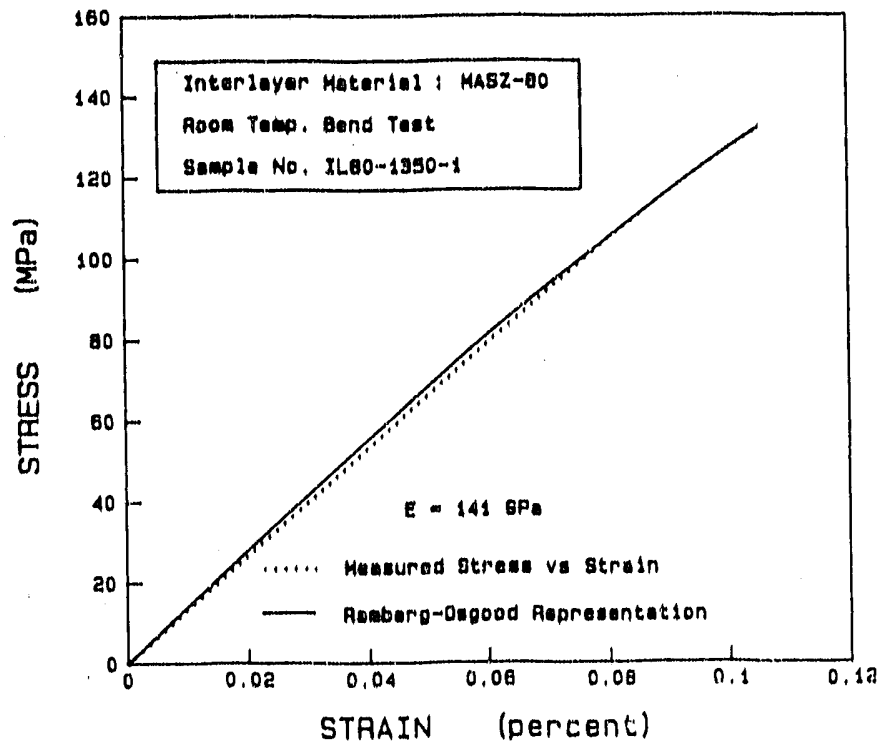

Figure 30. Room temperature stress-strain behavior of MASZ-80 material. 
Table 5. Stress-strain parameters for constituent materials used in zirconia/zirconia and zirconia/NCI joining.

\begin{tabular}{cccccccc}
$\begin{array}{c}\text { Constituent } \\
\text { Materiai }\end{array}$ & oo & E, & Fracture & & \multicolumn{2}{c}{ Poissun's } \\
MPa & so & GPa & Strongth, MPa & $n$ & $\alpha$ & Ratlo \\
\hline
\end{tabular}

\section{Roem Temperature Data}

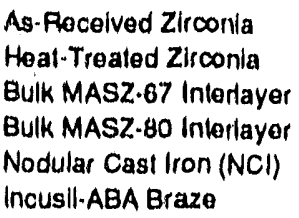

Elevated Tomperature Data

$\mathrm{NCl}, 260 \mathrm{C}$ (a)

$\mathrm{NCl}, 400 \mathrm{C}$

$\mathrm{NCl}, 538 \mathrm{C}(\mathrm{a})$

$\mathrm{NCl}, 607 \mathrm{C}(\mathrm{a})$

$\mathrm{NCl}, 716 \mathrm{C}$ (a)

Incusil-ABA, $200 \mathrm{C}$

Incus II.ABA, $400 \mathrm{C}$

As-received ZrO2, $200 \mathrm{C}$ (b)

As-recelved $\mathrm{ZrO2}, 400 \mathrm{C}$ (b)

As-recelved $\mathrm{Z} \mathrm{HO}^{2}, 600 \mathrm{C}$ (b)

As-received Z $\mathrm{rO2}, 800 \mathrm{C}$ (b)

As-received ZrO2, $1000 \mathrm{C}$ (b)

As-received $\mathrm{ZrO2}, 1200 \mathrm{C}$ (b)

As. received ZrO2, $1400 \mathrm{C}$ (b)

$\begin{array}{ccc}301.8 & 0.000150 & 202.0 \\ 140.6 & 0.000698 & 201.4 \\ 74.0 & 0.000662 & 111.7 \\ 101.7 & 0.000720 & 141.2 \\ 221.9 & 0.000136 & 163.4 \\ 295.6 & 0.000373 & 079.3\end{array}$

199.2

159.2

122.3

90,6

45.3

0.001245

0,001010

0.000870

0.000686

0.000380

160.0
157.5
140.0
132.0
116.0

048.2
013.8

197.0
$191.4(c)$
183.5
173.2
$160.5(d)$
145.4
127.9

0.007510

0.007340

0.001368

0.001213

0.001063

0.000910

0.000753

0.000575

0.000363

589
291
122
158
437
402

5.66

\subsection{6}

$\begin{array}{lll}3.93 & 0.05 & 0.22\end{array}$

$\begin{array}{lll}3.15 & 0.07 & 0.22\end{array}$

$4.99 \quad 4.61 \quad 0.28$

$19.58 \quad 0.15 \quad 0.36$

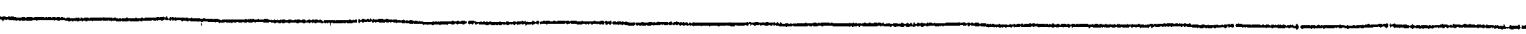

(a) E and sigma-o estimatod from Structural Alloys Handbook |H-188|, modifled to account for curront room tomporaluro results. Rost of torms are bost estimatos.

|1-188): Structural Alloys Handbook, Vol. 1, Ed. J.8. Hallowall, MCIC, Battollo (1988)

\footnotetext{
(b) Estimates, basod on curront data and data in the litorature, partlcularly, "Engineering Proporty Data on Solocted Ceramics, Vol. 3, Single Oxides", MCIC Report No. MCIC.H13-07, Battolle Momorial Instituto, Columbus, Ohio (1982)

(c) Moasured modulus and bend strongth wore 176.5 CPa and $249 \mathrm{MPa}$ respectivaly,

(d) Measured modulus and bend strength wore 142 Cipa and $225 \mathrm{MPa}$, respectively.
} 
Table 6. Bend test results of constituent materials and joints.

\begin{tabular}{|c|c|c|c|c|c|}
\hline $\begin{array}{l}\text { Specimen } \\
\text { Number }\end{array}$ & $\begin{array}{c}\text { Temperature } \\
\mathrm{C}\end{array}$ & $\begin{array}{l}\text { Width, } \mathrm{B} \\
\text { inm }\end{array}$ & $\begin{array}{c}\text { Holght, W } \\
\mathrm{mm}\end{array}$ & $\begin{array}{c}\text { Load, Pl } \\
N\end{array}$ & $\begin{array}{c}\text { Strength" } \\
\text { MPa }\end{array}$ \\
\hline \multicolumn{6}{|c|}{ As-fiecelved zircenta } \\
\hline BZ-BO & 25 & 6.01 & 2.85 & 989,5 & 676 \\
\hline BZ.B2 & 25 & 4.98 & 2.56 & 1041,3 & 610 \\
\hline BZ.BY & 26 & 5.01 & 2.56 & 1001,3 & 581 \\
\hline 82-88 & 25 & 5.03 & 2.58 & 1014,6 & 593 \\
\hline$B Z \cdot B 4$ & 100 & 8.00 & 2.86 & 235.9 & 248 \\
\hline BZ.B5 & 760 & 5,09 & 2.54 & 224.7 & 237 \\
\hline B2.-83 & 1000 & 4.98 & 2.56 & 200.0 & 220 \\
\hline BZ-69 & 1000 & 5.08 & 2.56 & 220.3 & 230 \\
\hline
\end{tabular}

\section{Zirconla/zarconla doint With MAsz-6Z interinver 1350 C Processed}

\begin{tabular}{|c|c|c|c|c|c|}
\hline HP22-BO1 & 25 & 5.87 & 3.08 & 360.5 & 128 \\
\hline HP22-EO2 & 25 & 5.87 & 3,02 & 397.2 & 138 \\
\hline HP22-803 & 25 & 8.86 & 9,04 & 849.4 & 130 \\
\hline HP22.BO4 & 25 & 6.87 & 2.05 & 369.4 & 138 \\
\hline HP22-B0S & 26 & 5.85 & 2.00 & 276.0 & 107 \\
\hline HP22-B11 & 26 & 5.32 & 2.72 & 222.5 & 108 \\
\hline HP22-B12 & 25 & 5.51 & 2.72 & 231.4 & 108 \\
\hline HP22-B13 & 25 & 8.69 & 2.73 & 233.8 & 107 \\
\hline HP22.814 & 25 & 6.36 & 2.73 & 264.6 & 126 \\
\hline HP22-91s & 25 & 6.52 & 2.73 & 247.0 & 123 \\
\hline HP22-816 & 25 & 5.30 & 2.73 & 244.8 & 110 \\
\hline HP22-821 & 26 & 5.15 & 2.68 & 214.0 & 121 \\
\hline HP22.820 & 26 & 5.16 & 2.56 & 242.6 & 137 \\
\hline HP22-B25 & 26 & 5.16 & 2.50 & 182.6 & 103 \\
\hline HP22-826 & 26 & 5.16 & 2,56 & 284.8 & 149 \\
\hline HP22-Q27 & 28 & 5.15 & 2.56 & 174.4 & 98 \\
\hline HP22-828 & 25 & 8.13 & 2.55 & $24,4,8$ & 140 \\
\hline HPas-B22 & 25 & 5.08 & 2.51 & 213.6 & 127 \\
\hline HP23.B11 & 1000 & 5.06 & 2.55 & 59.7 & 62 \\
\hline HP24-811 & 1000 & 5.00 & 2.55 & 51,6 & 64 \\
\hline HP24-013 & 1000 & 5.00 & 2.65 & 65.2 & 68 \\
\hline HP24-814 & 1000 & 5.07 & 2.62 & 62.3 & 67 \\
\hline HP24-815 & 1000 & 6.09 & 2.66 & 60.1 & 63 \\
\hline
\end{tabular}

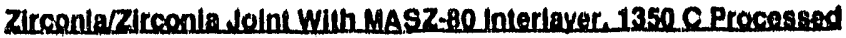

\begin{tabular}{|c|c|c|c|c|c|}
\hline HP25.811 & 25 & 6.09 & 2.63 & 240.3 & 140 \\
\hline HP26-B12 & 25 & 5.08 & 2.56 & 294.8 & 163 \\
\hline HP25-B13 & 25 & 5.08 & 2.55 & 204.7 & 118 \\
\hline HP25.B17 & 26 & 5.00 & 2.56 & 282.6 & 161 \\
\hline HP26-B21 & 25 & 5,08 & 2.52 & 329.3 & 194 \\
\hline HP25-822 & 25 & 5.08 & 2.55 & 293.7 & 170 \\
\hline HP25.828 & 25 & 6.08 & 2.55 & 195.8 & 113 \\
\hline HP25-B23 & 25 & 5.08 & 2.62 & 329.3 & 194 \\
\hline HP25-B29 & 25 & 5.07 & 2.65 & 316.0 & 182 \\
\hline HP25.B24 & 1000 & 5.00 & 2.56 & 71.6 & 76 \\
\hline HP25-B15 & 1000 & 5.06 & 2.55 & 76.8 & 80 \\
\hline HP25-B18 & 1000 & 5.07 & 2.55 & $\theta 2.3$ & 87 \\
\hline
\end{tabular}

\footnotetext{
- For foints, thase strengths are apparent bend strengths.
} 
Table 6. (continued)

\begin{tabular}{|c|c|c|c|c|c|}
\hline $\begin{array}{l}\text { Specimen } \\
\text { Number }\end{array}$ & $\begin{array}{c}\text { Temperafure } \\
\mathrm{C} \\
\end{array}$ & $\begin{array}{c}\text { Width, B } \\
\mathrm{mm}\end{array}$ & $\begin{array}{l}\text { Helght, W } \\
\text { mim }\end{array}$ & $\begin{array}{c}\text { Load, Pf } \\
N\end{array}$ & $\begin{array}{c}\text { Strengith" } \\
\mathrm{MPa}\end{array}$ \\
\hline \multicolumn{6}{|c|}{ Zirconlarzirconiadalat with MASZ-5e Interlayec 1350 e provessed } \\
\hline HP2\%.813 & 25 & 6.07 & 2.84 & 83,6 & 54 \\
\hline HP27.日14 & 25 & 5.07 & 2.84 & 69,0 & 82 \\
\hline HPa7.817 & 25 & 6.07 & 2.64 & 80,0 & 52 \\
\hline HP27.821 & 25 & 8.00 & 2.85 & 77.0 & 45 \\
\hline HP27-B22 & 25 & 5.09 & 2.64 & 102.4 & 59 \\
\hline
\end{tabular}

Base Zirconla Heatirreated at 1350 c te simulate Eabrloatlon ol zirconla/zircenled Joints

\begin{tabular}{|c|c|c|c|c|c|}
\hline HP20.811 & 25 & 5.00 & 2.56 & 449.5 & 268 \\
\hline HP26-B12 & 28 & 5.07 & 2.56 & 491.7 & 282 \\
\hline HP28-B14 & 26 & 5.07 & 2.55 & 404.0 & 286 \\
\hline HP28.817 & 25 & 8.07 & 2.57 & 520.7 & 290 \\
\hline HP26-Q10 & 25 & 5.07 & 2.56 & 408.4 & 205 \\
\hline HP26.B2t & 25 & 5.08 & 2.57 & $\$ 42,8$ & 300 \\
\hline HP26-B22 & 25 & 5.10 & 2.67 & $\$ 60.7$ & 318 \\
\hline HP26-B23 & 25 & 6.09 & 2.57 & 528.1 & 298 \\
\hline HP26.B24 & 1000 & 6.09 & 2.57 & 212.7 & 220 \\
\hline HP20.026 & 1000 & 5.07 & 2.65 & 195.8 & 206 \\
\hline
\end{tabular}

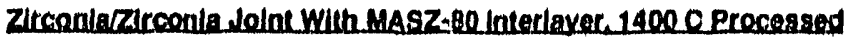

$\begin{array}{llllll}\text { HP29.811 } & 25 & 5.06 & 2.53 & 173.6 & 102 \\ \text { HP29.811 } & 25 & 5.06 & 2.53 & 182.5 & 107 \\ \text { HP29.813 } & 25 & 5.06 & 2.53 & 186.8 & 109 \\ \text { HP29.814 } & 25 & 5.06 & 2.53 & 160.2 & 94 \\ \text { HP29.821 } & 25 & 5.09 & 2.53 & 204.7 & 119 \\ \text { HP29.822 } & 25 & 5.09 & 2.53 & 191.4 & 112 \\ \text { HP29.823 } & 25 & 5.09 & 2.54 & 184.7 & 107 \\ \text { HP29.824 } & 25 & 5.09 & 2.53 & 173.6 & 101 \\ \text { HP29.825 } & 25 & 5.09 & 2.53 & 178.0 & 104\end{array}$

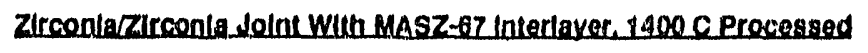

$\begin{array}{llllll}\text { HP30.811 } & 25 & 5.09 & 2.52 & 104.6 & 62 \\ \text { HP30.B12 } & 25 & 5.09 & 2.53 & 93.5 & 55 \\ \text { HP30.814 } & 25 & 6.09 & 2.53 & 93.5 & 65 \\ \text { HP30.B15 } & 25 & 5.09 & 2.53 & 111.3 & 65 \\ \text { HP30.B23 } & 25 & 5.09 & 2.54 & 102.4 & 59 \\ \text { HP30.B24 } & 25 & 5.10 & 2.53 & 135.7 & 79 \\ \text { HP30.825 } & 25 & 5.10 & 2.53 & 102.4 & 60\end{array}$

Bulk MASZ-5e Interlaver Materlal. 1350 C Processed

$\begin{array}{llllll}\text { IL.50.1350-1 } & 25 & 6.08 & 2.52 & 104.1 & 62 \\ \text { IL } 50.1350 .2 & 25 & 6.06 & 2.53 & 87.9 & 58\end{array}$

Bulk MASZ-6Z Interlaver Materlal, 1350 C Processed

\begin{tabular}{|c|c|c|c|c|c|}
\hline $16.67 \cdot 1350.1$ & 25 & 5.06 & 2.54 & 173,0 & 101 \\
\hline IL67.1350.2 & 25 & 5.07 & 2.55 & 104.7 & 95 \\
\hline
\end{tabular}

\footnotetext{
- For Joints, these strengths are apparent bend strengths.
} 
Table 6. (continued)

\begin{tabular}{cccccc}
\hline $\begin{array}{c}\text { Specimen } \\
\text { Number }\end{array}$ & $\begin{array}{c}\text { Temperature } \\
\text { C }\end{array}$ & $\begin{array}{c}\text { Width, B } \\
\mathbf{m m}\end{array}$ & $\begin{array}{c}\text { Height, W } \\
\mathbf{m m}\end{array}$ & $\begin{array}{c}\text { Load, PI } \\
\mathbf{N}\end{array}$ & $\begin{array}{c}\text { Strength* } \\
\text { MPa }\end{array}$ \\
\hline IL67-1350-3 & 25 & 5.07 & 2.55 & 158.0 & 92 \\
IL67-1350-4 & 25 & 5.03 & 2.55 & 160.2 & 93 \\
IL67-1350-5 & 25 & 5.01 & 2.54 & 160.2 & 94 \\
IL67-1350-6 & 25 & 5.06 & 2.54 & 142.4 & 93 \\
IL67-1350-7 & 1000 & 5.07 & 2.55 & 65.4 & 69 \\
IL67.1350-8 & 1000 & 5.07 & 2.54 & 65.9 & 70
\end{tabular}

Bulk MASZ-67 merlayer Materiah 1400 C Processed

$\begin{array}{llllll}1 L 67-1400-1 & 25 & 5.09 & 2.55 & 124.6 & 72 \\ 1167-1400-2 & 25 & 5.09 & 2.55 & 112.4 & 82 \\ 1167-1400-3 & 25 & 5.07 & 2.55 & 138.0 & 80 \\ 1167-1400-4 & 25 & 5.09 & 2.55 & 1215.8 & 73 \\ 1 L 67-1400-5 & 25 & 5.09 & 2.52 & 135.7 & 60 \\ 1167-1400-6 & 25 & 5.09 & 2.55 & 142.4 & 82\end{array}$

Buk MASZ-00 mentaver Matertal, 1350 C Procesesed

\begin{tabular}{|c|c|c|c|c|}
\hline $\begin{array}{l}1180-1350-1 \\
11500-1350-2\end{array}$ & $\begin{array}{l}25 \\
25\end{array}$ & $\begin{array}{l}5.09 \\
5.07\end{array}$ & $\begin{array}{l}2.51 \\
2.52\end{array}$ & $\begin{array}{l}218.1 \\
224.7\end{array}$ \\
\hline $11200-1350-3$ & 25 & 5.07 & 2.52 & 235.8 \\
\hline $1280-1350-4$ & 25 & 5.08 & 2.55 & 211.4 \\
\hline $1200-1350-5$ & 25 & 5.07 & 2.53 & 234.5 \\
\hline $1100-1350-6$ & 25 & 5.07 & 2.54 & 249.2 \\
\hline $1400-1350-8$ & 1000 & 5.07 & 2.54 & 65.0 \\
\hline
\end{tabular}

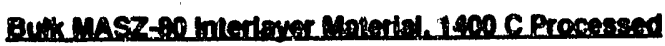

$\begin{array}{cccccc}11.80-1400-1 & 25 & 5.05 & 2.54 & 191.4 & 112 \\ 1 L 80-1400-2 & 25 & 5.06 & 2.53 & 219.6 . & 125 \\ 1180-1400-3 & 1000 & 5.04 & 2.54 & 65.0 & 69\end{array}$

\section{Zlrconia/Nodular Cast tron doints}

\begin{tabular}{|c|c|c|c|c|c|}
\hline LMC3-B21 & 25 & 5.08 & 2.57 & 471.1 & 267 \\
\hline LMCO3-B22 & 25 & 5.00 & 2.34 & $3 c 9.3$ & 212 \\
\hline LMCS-B23 & 25 & 5.00 & 2.54 & 4:17.2 & 248 \\
\hline LMC3-B24 & 25 & 5.00 & 2.53 & $3: 6.0$ & 185 \\
\hline LMCS-827 & 25 & 5.09 & 2.52 & $3: 6 ; 0$ & 210 \\
\hline$\angle M C 3-831$ & 25 & 5.06 & 2.56 & 2139,3 & 166 \\
\hline LMCO3-B32 & 25 & 5.07 & 2.56 & 373.8 & 215 \\
\hline LMCO3-833 & 25 & 5.07 & 2.56 & 471.7 & 272 \\
\hline LMCS3-834 & 25 & 5.00 & 2.56 & 445.0 & 256 \\
\hline LACA-BII & 25 & 5.09 & 2.34 & 3111.5 & 214 \\
\hline LMCA-B12 & 25 & 5.76 & 3.28 & 10613.0 & 328 \\
\hline LMCA-B21 & 25 & 5.07 & 2.57 & $\$ 71.6$ & 211 \\
\hline LMCA-822 & 25 & 5.07 & 2.57 & 3481.7 & 185 \\
\hline LAC4-B24 & 25 & 5.07 & 2.57 & $\$ 9911.6$ & 223 \\
\hline LMCA-B28 & 25 & 5.07 & 2.57 & 611.3 & 267 \\
\hline LMCA-B31 & 25 & 5.09 & 2.51 & 331.5 & 106 \\
\hline LMCA-B32 & 25 & 5.10 & 2.51 & $49 i 3.4$ & 295 \\
\hline LMCA-833 & 25 & 5.09 & 2.52 & 252.8 & 149 \\
\hline LMCA4-836 & 25 & 5.10 & 2.51 & 369.4 & 218 \\
\hline LMC5-813 & 25 & 5.08 & 2.50 & 218.1 & 130 \\
\hline
\end{tabular}

- For joints, these stiengths are apparent bend strerigt/is. 
Table 6. (continued)

\begin{tabular}{cccccc}
\hline $\begin{array}{c}\text { Specimen } \\
\text { Number }\end{array}$ & $\begin{array}{c}\text { Teinperature } \\
\text { C }\end{array}$ & $\begin{array}{c}\text { Width, B } \\
\mathbf{m m}\end{array}$ & $\begin{array}{c}\text { Helght, W } \\
\mathbf{m m}\end{array}$ & $\begin{array}{c}\text { Load, Pt } \\
\mathbf{N}\end{array}$ & $\begin{array}{c}\text { Strength" } \\
\text { MPa }\end{array}$ \\
\hline & & & & & \\
LMC5-B14 & 25 & $5.0 B$ & 2.50 & 436.1 & 261 \\
LMC5.B25 & 25 & 5.08 & 2.51 & 319.5 & 191 \\
LMC3-B35 & $400 \mathrm{C}$ & 5.07 & 2.56 & 104.1 & 109 \\
LMC5-B12 & $400 \mathrm{C}$ & 5.09 & 2.55 & 97.0 & 102 \\
LMC5.B16 & $400 \mathrm{C}$ & 5.07 & 2.55 & 100.1 & 105 \\
\hline
\end{tabular}

- For foints, these strengths ate apparent bend strengths. 
Table 7. Fracture toughness test results of constituent materials and joints.

\begin{tabular}{|c|c|c|c|c|c|c|c|}
\hline $\begin{array}{l}\text { Specimen } \\
\text { Number }\end{array}$ & $\begin{array}{l}\text { Temper- } \\
\text { ature, } \mathrm{C}\end{array}$ & $\begin{array}{l}\text { Width, B } \\
\mathrm{mm}\end{array}$ & $\begin{array}{l}\text { Helght, } w \\
\mathrm{~mm}\end{array}$ & $\begin{array}{c}\text { Crack Length, a } \\
\mathrm{mm}\end{array}$ & $\begin{array}{c}\text { Fracture Load, } \\
\mathrm{Pf}_{1} \mathrm{~N} \\
\end{array}$ & $Y(a) W)$ & $\begin{array}{l}\text { Q1c*, } \\
\text { MPadm }\end{array}$ \\
\hline \multicolumn{8}{|c|}{ Zirconia/Zircenia Joint Wilh MASZ.67 Interlayer. 1350 C Processed } \\
\hline $\begin{array}{l}\text { HP22.F15 } \\
\text { HP23.F18 } \\
\text { HP23-F27 } \\
\text { HP24.F15 } \\
\text { HP24-F14 } \\
\text { HP24-F23 }\end{array}$ & $\begin{array}{c}\text { RT } \\
\text { RT } \\
\text { RT } \\
\text { RT } \\
1000 \\
1000\end{array}$ & $\begin{array}{l}2.56 \\
5.08 \\
5.09 \\
5.08 \\
5.08 \\
5.10\end{array}$ & $\begin{array}{l}5.14 \\
5.10 \\
5.09 \\
5.07 \\
5.09 \\
5.07\end{array}$ & $\begin{array}{l}1.53 \\
1.54 \\
1.54 \\
1.63 \\
1.57 \\
1.56\end{array}$ & $\begin{array}{c}140.2 \\
209.2 \\
213.6 \\
173.6 \\
80.5 \\
69.9\end{array}$ & $\begin{array}{l}1.99 \\
2.00 \\
2.00 \\
2.03 \\
2.01 \\
2.01\end{array}$ & $\begin{array}{l}3.07 \\
2.36 \\
2.42 \\
2.07 \\
1.69 \\
1.46\end{array}$ \\
\hline \multicolumn{8}{|c|}{ Zirconia/Zircenia Joint Wilth MASZ-Be Interlayer, 1350 C Processed } \\
\hline $\begin{array}{l}\text { HP25.F16 } \\
\text { HP25.F26 } \\
\text { HP25.F14 }\end{array}$ & $\begin{array}{l}\text { AT } \\
\text { RT } \\
1000\end{array}$ & $\begin{array}{l}5.09 \\
5.08 \\
5.09\end{array}$ & $\begin{array}{l}5.09 \\
5.07 \\
5.07\end{array}$ & $\begin{array}{l}1.63 \\
1.63 \\
1.61\end{array}$ & $\begin{array}{l}264.8 \\
268.3 \\
82.3\end{array}$ & $\begin{array}{l}2.03 \\
2.03 \\
2.02\end{array}$ & $\begin{array}{l}3.14 \\
3.19 \\
1.77\end{array}$ \\
\hline \multicolumn{8}{|c|}{ Zirconia/Zircenia doint With MASZ-67 Interlayer. 1400 C Processed } \\
\hline $\begin{array}{l}\text { HP30.F16 } \\
\text { HP30.F27 }\end{array}$ & $\begin{array}{l}\text { PT } \\
\text { RT }\end{array}$ & $\begin{array}{l}5.09 \\
5.09\end{array}$ & $\begin{array}{l}5.08 \\
5.08\end{array}$ & $\begin{array}{l}1.63 \\
1.63\end{array}$ & $\begin{array}{l}107.7 \\
160.2\end{array}$ & $\begin{array}{l}2.03 \\
2.03\end{array}$ & $\begin{array}{l}1.28 \\
1.90\end{array}$ \\
\hline \multicolumn{8}{|c|}{ Zirconia/Zircenia doint With MASZ-80 Interlaver 1400 C Processed } \\
\hline $\begin{array}{l}\text { HP29-F26 } \\
\text { HP29-F27 }\end{array}$ & $\begin{array}{l}\text { RT } \\
\text { AT }\end{array}$ & $\begin{array}{l}5.08 \\
5.06\end{array}$ & $\begin{array}{l}5.09 \\
5.10\end{array}$ & $\begin{array}{l}1.60 \\
1.63\end{array}$ & $\begin{array}{l}195.8 \\
200.3\end{array}$ & $\begin{array}{l}2.02 \\
2.03\end{array}$ & $\begin{array}{l}2.28 \\
2.37\end{array}$ \\
\hline \multicolumn{8}{|c|}{$\begin{array}{l}\text { Basezirconla Heac Treated at } 1350 \text { c le Simulate } \\
\text { Eabrication of Zirconia-Zirconin doints }\end{array}$} \\
\hline $\begin{array}{c}\text { HP26.F16 } \\
\text { HP26.F21 } \\
\text { Bulk MASZ-50 }\end{array}$ & $\begin{array}{l}\text { RT } \\
\text { RT } \\
\text { arial. } 135 \text {. }\end{array}$ & $\begin{array}{c}5.10 \\
5.05 \\
\text { Processer }\end{array}$ & $\begin{array}{l}5.08 \\
5.08\end{array}$ & $\begin{array}{l}1.71 \\
1.63\end{array}$ & $\begin{array}{l}458.8 \\
458.4\end{array}$ & $\begin{array}{l}2.06 \\
2.03\end{array}$ & $\begin{array}{l}5.67 \\
5.47\end{array}$ \\
\hline $1450.1350 . F 1$ & RT & 5.07 & 5.05 & 1.71 & 122.4 & 2.07 & 1.54 \\
\hline
\end{tabular}

\footnotetext{
- Q1c=K1c for monolithic materials, and Q1c corresponds to apparent Mode I fracture roughness for joints.
} 
Table 7. (continued)

\begin{tabular}{|c|c|c|c|c|c|c|c|}
\hline $\begin{array}{l}\text { Specimen } \\
\text { Number }\end{array}$ & $\begin{array}{l}\text { Temper- } \\
\text { ature, } \mathrm{C}\end{array}$ & $\begin{array}{c}\text { Width, } \theta \\
\mathrm{mm}\end{array}$ & $\begin{array}{c}\text { Height, w } \\
\mathrm{mm}\end{array}$ & $\begin{array}{c}\text { Crack Length, } \\
\mathrm{mm}\end{array}$ & $\begin{array}{c}\text { Fracture Load, } \\
\mathrm{PH}_{1} \mathrm{~N}\end{array}$ & $Y(a / W)$ & $\begin{array}{l}\text { O1c", } \\
\text { MPaلm }\end{array}$ \\
\hline \multicolumn{8}{|c|}{ Bulk MAS7.67 Interlayer. 1350 C Processed } \\
\hline $\begin{array}{l}\text { IL67.1350.F1 } \\
\text { IL67.1350.F3 } \\
\text { IL67.1350.F2 }\end{array}$ & $\begin{array}{l}\text { RT } \\
\text { RT } \\
1000\end{array}$ & $\begin{array}{l}5.09 \\
5.11 \\
5.10\end{array}$ & $\begin{array}{l}5.07 \\
5.05 \\
5.07\end{array}$ & $\begin{array}{l}1.70 \\
1.70 \\
1.60\end{array}$ & $\begin{array}{c}169.1 \\
160.2 \\
68.1\end{array}$ & $\begin{array}{l}2.06 \\
2.06 \\
2.02\end{array}$ & $\begin{array}{l}2.10 \\
1.99 \\
1.46\end{array}$ \\
\hline \multicolumn{8}{|c|}{ Bulk MASz-80 Interlayer. 1350 C Processed } \\
\hline $\begin{array}{l}\text { IL80.1350.F1 } \\
\text { IL80.1350.F3 } \\
\text { IL80.1350.F2 }\end{array}$ & $\begin{array}{l}\text { RT } \\
\text { RT } \\
1000\end{array}$ & $\begin{array}{l}5.12 \\
5.12 \\
5.09\end{array}$ & $\begin{array}{l}5.08 \\
5.09 \\
5.09\end{array}$ & $\begin{array}{l}1.71 \\
1.65 \\
1.63\end{array}$ & $\begin{array}{c}235.9 \\
231.4 \\
73.9\end{array}$ & $\begin{array}{l}2.06 \\
2.04 \\
2.03\end{array}$ & $\begin{array}{l}2.89 \\
2.75 \\
1.59\end{array}$ \\
\hline \multicolumn{8}{|c|}{ Bulk MASZ-67 Interlaver, 1400 C Processed } \\
\hline $\begin{array}{l}\text { IL } 67.1400 . F 1 \\
\text { IL } 67.1400 . F 2\end{array}$ & $\begin{array}{l}\text { RT } \\
\text { RT }\end{array}$ & $\begin{array}{l}5.12 \\
5.09\end{array}$ & $\begin{array}{l}5.11 \\
5.08\end{array}$ & $\begin{array}{l}1.63 \\
1.63\end{array}$ & $\begin{array}{l}146.9 \\
149.1\end{array}$ & $\begin{array}{l}2.02 \\
2.03\end{array}$ & $\begin{array}{l}1.71 \\
1.77\end{array}$ \\
\hline \multicolumn{8}{|c|}{ Bulk MAS7-80 Interlaver 1400 C Processed } \\
\hline $1 L 80 \cdot 1400 . F 1$ & RT & 5.09 & 5.09 & 1.63 & 445.0 & 2.03 & 5.27 \\
\hline \multicolumn{8}{|c|}{ Zirconia/Nodular Cast Iron Joint } \\
\hline $\begin{array}{l}\text { LMC2.F25 } \\
\text { LMC3.F25 } \\
\text { LMC3.F36 } \\
\text { LMC4.F25 } \\
\text { LMC4.F26 } \\
\text { LMC4.F34 } \\
\text { LMC5.F18 } \\
\text { LMC5.F26 }\end{array}$ & $\begin{array}{l}\text { RT } \\
\text { RT } \\
\text { RT } \\
\text { RT } \\
\text { RT } \\
\text { RT } \\
\text { RT } \\
\text { RT }\end{array}$ & $\begin{array}{l}5.00 \\
5.07 \\
5.12 \\
5.11 \\
5.07 \\
5.09 \\
5.09 \\
5.08\end{array}$ & $\begin{array}{l}5.09 \\
5.11 \\
5.11 \\
5.07 \\
5.08 \\
5.09 \\
5.09 \\
5.09\end{array}$ & $\begin{array}{l}1.17 \\
1.63 \\
1.63 \\
1.63 \\
1.60 \\
1.63 \\
1.63 \\
1.60\end{array}$ & $\begin{array}{l}529.6 \\
445.0 \\
429.4 \\
600.8 \\
547.4 \\
534.0 \\
422.8 \\
596.3\end{array}$ & $\begin{array}{l}1.89 \\
2.03 \\
2.02 \\
2.03 \\
2.02 \\
2.03 \\
2.03 \\
2.02\end{array}$ & $\begin{array}{l}5.03 \\
5.23 \\
5.00 \\
7.12 \\
6.42 \\
6.31 \\
5.00 \\
6.97\end{array}$ \\
\hline
\end{tabular}

- Q1cak1c for monolithic materials, and Q1c corresponds to apparent Mode 1 fracture loughness for foints. 

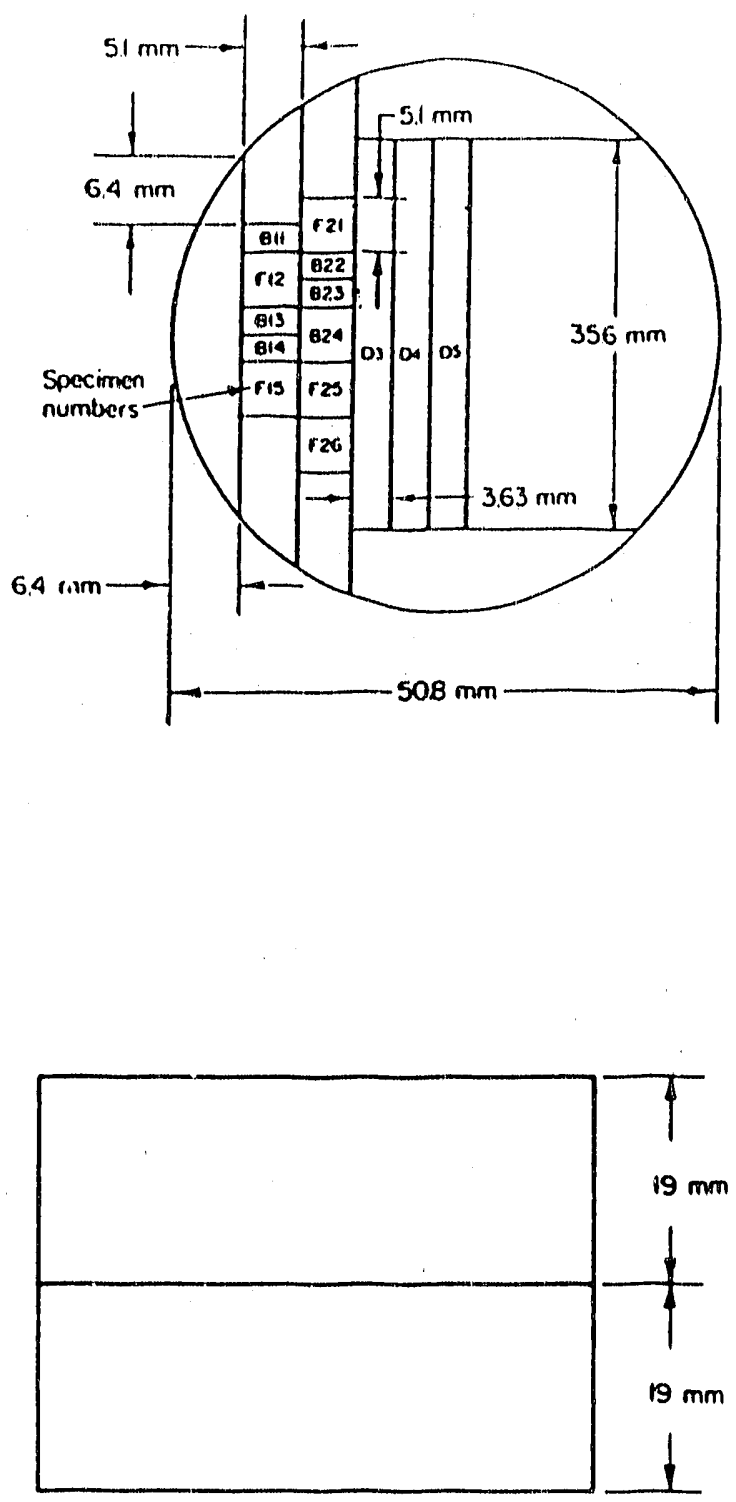

B: Uncracked bend bar, $2.54 \times 5.08 \times 38.1 \mathrm{~mm}$

F: Notched bend bar, $5.08 \times 5.08 \times 38.1 \mathrm{~mm}$

D: Cracked or uncracked disk specimen, $35.6 \mathrm{~mm}$ dia. $\times 3.63 \mathrm{~mm}$ thick

Figure 31. Source of specimens machined from the joined 2-inch billets. 
Table 8. Fracture toughness test results of constituent materials.

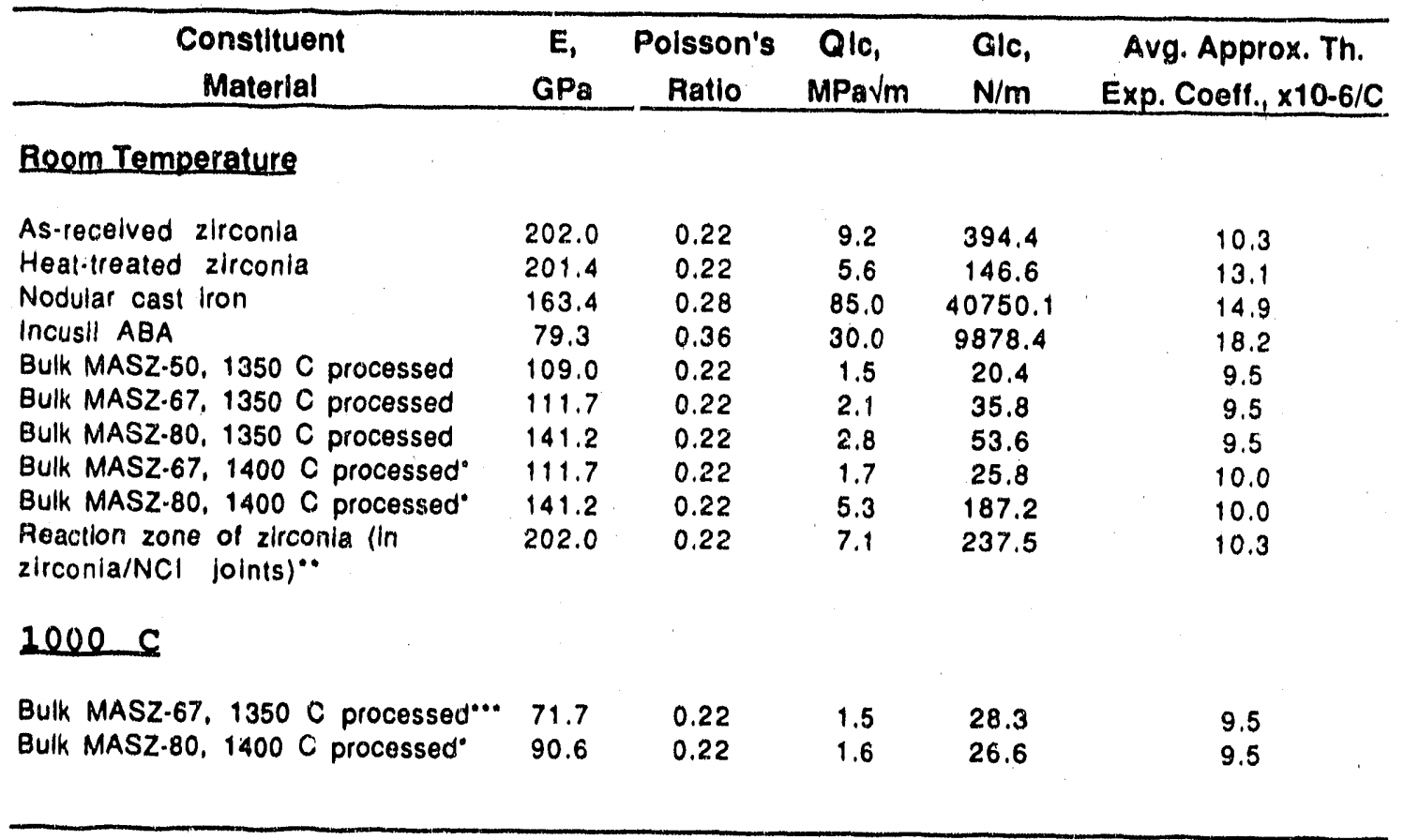

- E and Poisscri's ratio are only estimates, based on present data. Klc actually measured.

*. Data obtained by testing a notched bend bar containing a zirconia/ $\mathrm{NCl}$ joint, where the crack propagated only in the reaction zone of the zirconia.

*** Poisson's ratio was estimated. 


\subsubsection{Preliminary Validation Results}

Bend Test Results. Table 6 provides bend test results of constituent materials as well as zirconia/zirconia and zirconia/NCI joints. No significant correlation was found between the specimen strength and its location within the joined billet, suggesting uniformity of bonding, and small residual stress effects (after machining) at least at a distance of $6.5 \mathrm{~mm}$ from the billet periphery.

Table 6 includes data generated at room temperature as well as those generated at elevated temperatures; namely, $400 \mathrm{C}$ for zirconia/NCI joints and $1000 \mathrm{C}$ for zirconia/zirconia joints. Test results obtained with different processing temperatures, namely $1350 \mathrm{C}$ and $1400 \mathrm{C}$ for zirconia/zirconia joints, are also included in the table.

Figure 32 is a Weibull plot which provides a comparison of the room temperature bend strengths of zirconia/zirconia joints fabricated using MASZ-67 interlayer with those of the constituent materials. Although the average strength of the joint is less than that of the heat-treated zirconia, it is higher than the strength of the bulk MASZ-67 interlayer. Nevertheless, failure of zirconia/zirconia joints occurred primarily in the ceramic interlayer. As shown in reference ${ }^{[6]}$, this behavior can be rationalized in terms of shielding of the joint interlayer by the surrounding higher modulus zirconia adherent.

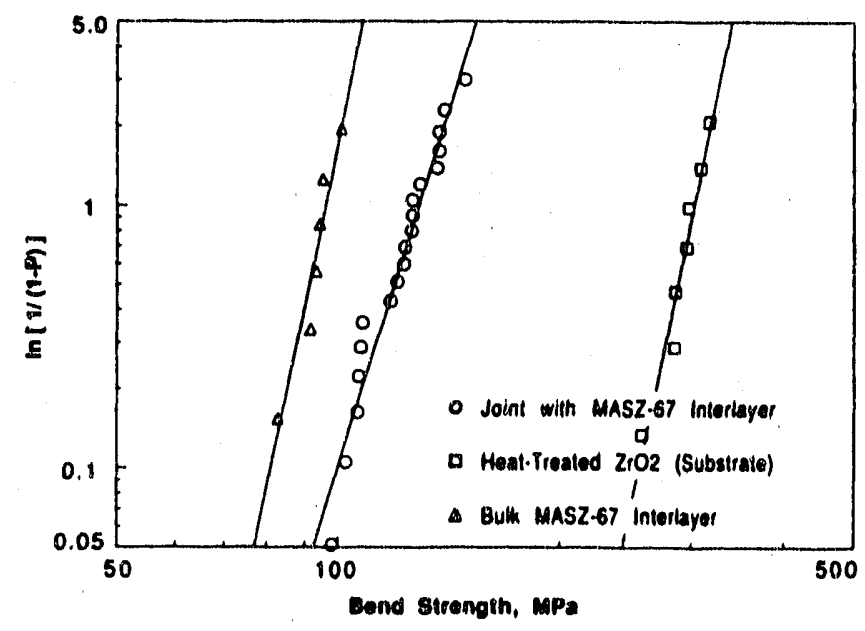

Figure 32. Weibull plot showing comparison of strength of zirconia/zirconiajointsandbulkconstituent materials.

Figure 33 is a Weibull plot comparing bend strengths of various zirconia/zirconia joints with their corresponding interlayer materials. The actual data points are not included in the plot for the purpose of clarity. This plot indicates that for both the MASZ-67 and MASZ-80 interlayer systems, joints perform better than their corresponding interlayer materials. 


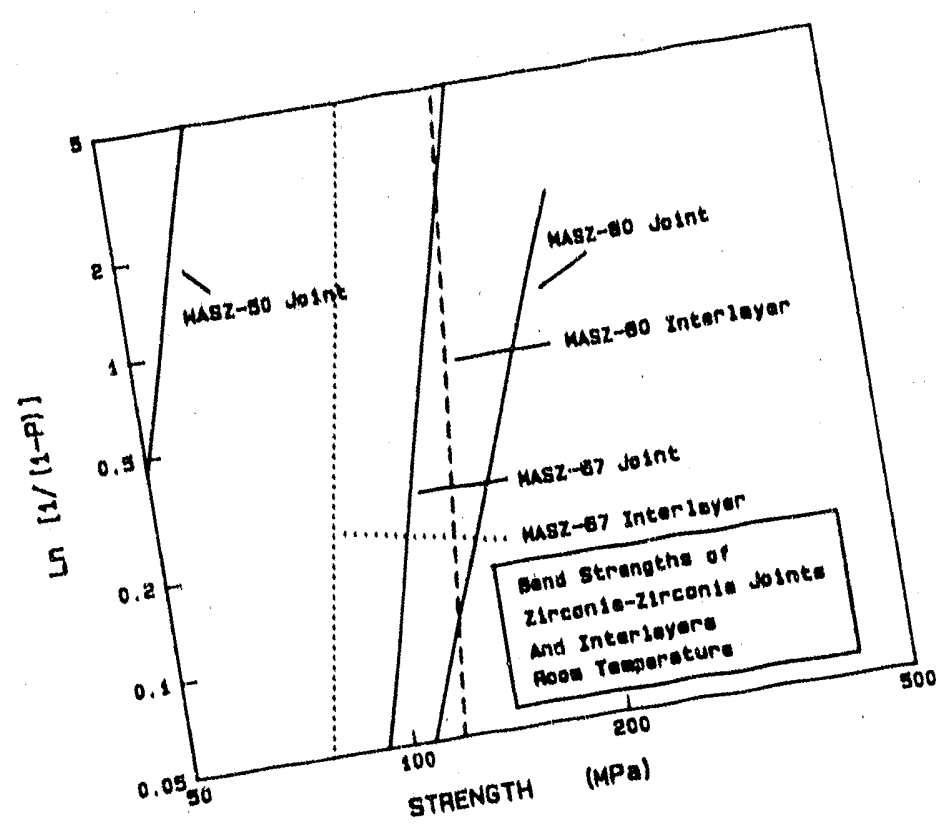

Figure 33. Weibull plot showing comparison of zirconia/zirconia joints and constituent mater in interlayer.

Conia/ NCl joints. The averagc

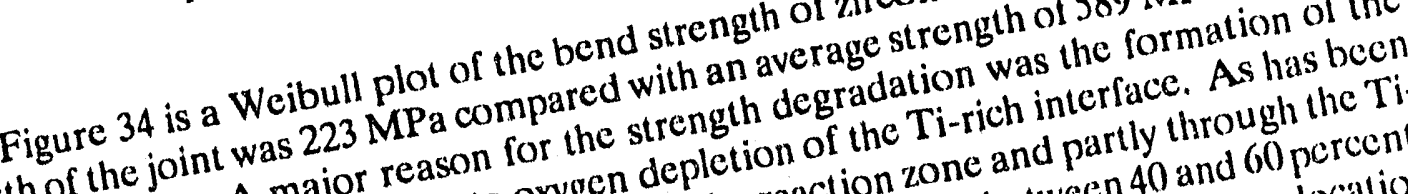
strength of the join. A major reason for the sexpletion of the Ti-rich and partly throught the $T$ receiven zone in the zirconia was partly through the each ranging betwat the fracture location noted above, the crack paximate percentage arcassed later, indicated to be discuss atcly $9.2 \mathrm{MPaVm}$ ). rich interface with approxurements, to be than the base 7.1 reone decrease in strength for the joily at the Fracture toughness mess (6 to $7 \mathrm{MPa}$ m) int for the large dectroduced defects phith of the joint. had lower toughnessence cannot ace the joining process to reduce the stre Weibull modulus However, this dither, it is believed hese larger defects acthe observation hallus of 9.5 ; in fact, our bend bar. Rathe interface, and th in agreement with

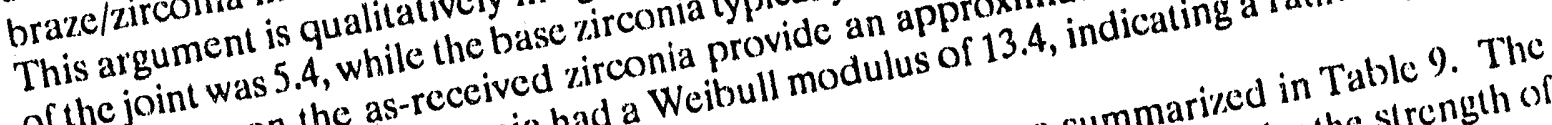
of the joint was on the as-received had a Weibull modulus of

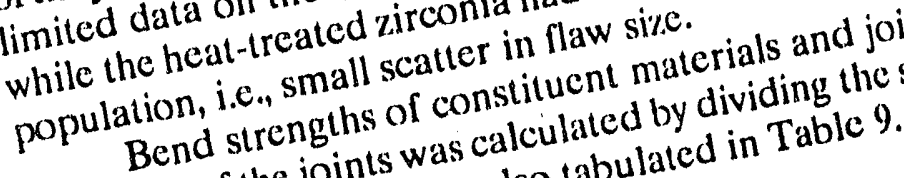

efficiency of the joints was calculated tabulated in Table

the adherent, and they are 


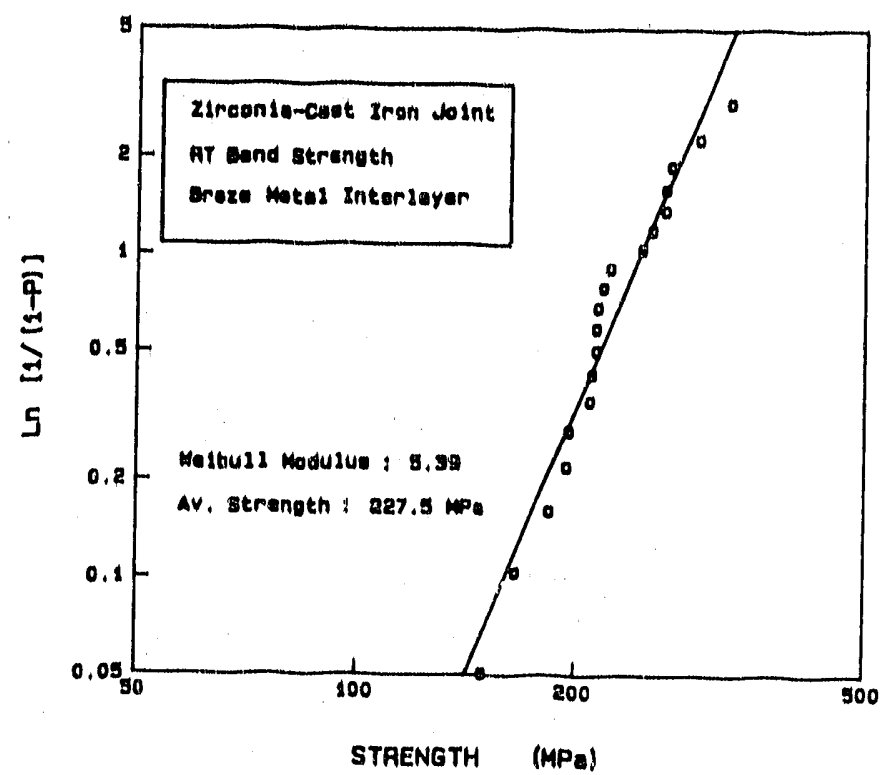

Figure 34. Weibull plot for zirconia/NCI joints.

Table 9. Average bend strength of zirconia/zirconia and zirconia/NCI joints.

\begin{tabular}{|c|c|c|c|c|c|}
\hline \multirow[b]{2}{*}{ Material } & \multicolumn{2}{|c|}{ Bulk Material } & \multicolumn{3}{|c|}{ Joints } \\
\hline & $\begin{array}{l}\text { Average } \\
\text { Strength, } \\
\mathrm{MPa}\end{array}$ & $\begin{array}{l}\text { Weibull } \\
\text { Modulus }\end{array}$ & $\begin{array}{l}\text { Average } \\
\text { Strength, } \\
\mathrm{MPa}\end{array}$ & $\begin{array}{l}\text { Weibull } \\
\text { Modulus }\end{array}$ & $\begin{array}{l}\text { Efficiency", } \\
\text { percent }\end{array}$ \\
\hline $\begin{array}{l}\text { Heat-Treated } \\
\mathrm{ZrO}_{2} \text { Substrate }\end{array}$ & 293 & 13.4 & - & - & . \\
\hline MASZ $\cdot 80$ & 134 & 2.0 .8 & 158 & 6.0 & 54 \\
\hline MASZ - 67 & 93 & 13.6 & 122 & 9.0 & 42 \\
\hline MASZ - 50 & 59 & - & 52 & - & 18 \\
\hline Zirconia/NCI & - & - & 223 & 5.4 & $38^{* *}$ \\
\hline
\end{tabular}

" Joint Efficiency $=$ Strength of Joint / Strength of Substratc

** Efficiency of zirconia/NCI joint based on strength of 589 MPa for as-reccived zirconia. 
The load versus displacement data for a joint fabricated with MASZ-67 interlayer, and those of the constituent materials are illustrated in Figure 35. As expected, the load versus displacement plot for the joint agrees very well with that of the heat-Ireated zirconia, since the thickness of the interlayer was negligible compared with the adherent. Figure 36 is a similar plot for a zirconia/NCI joint. This plot indicates significant non-linearity before fracture and the observed non-linearily is consistent with the fact that the specimen failed at a stress of $261 \mathrm{MPa}$, while the flow stress of zirconia was only 221.9 MPa. FEM calculations were not performed to check whether there was agreement between the observed load-displacement behavior and calculated elastic-plastic results.

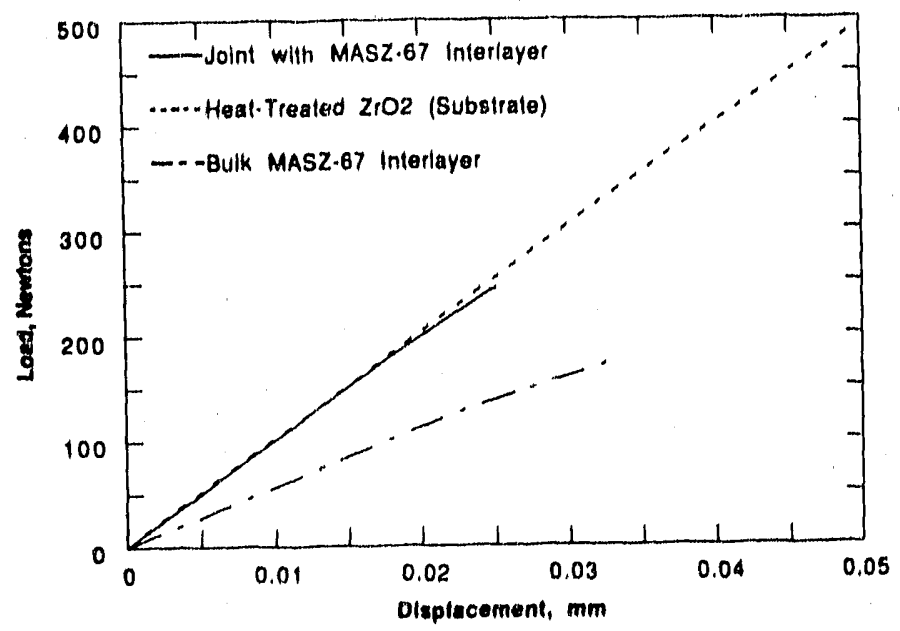

Figure 35. Load versus displacement plots for bend bars fabricated with MASZ-67 interlayer and its constituent materials.

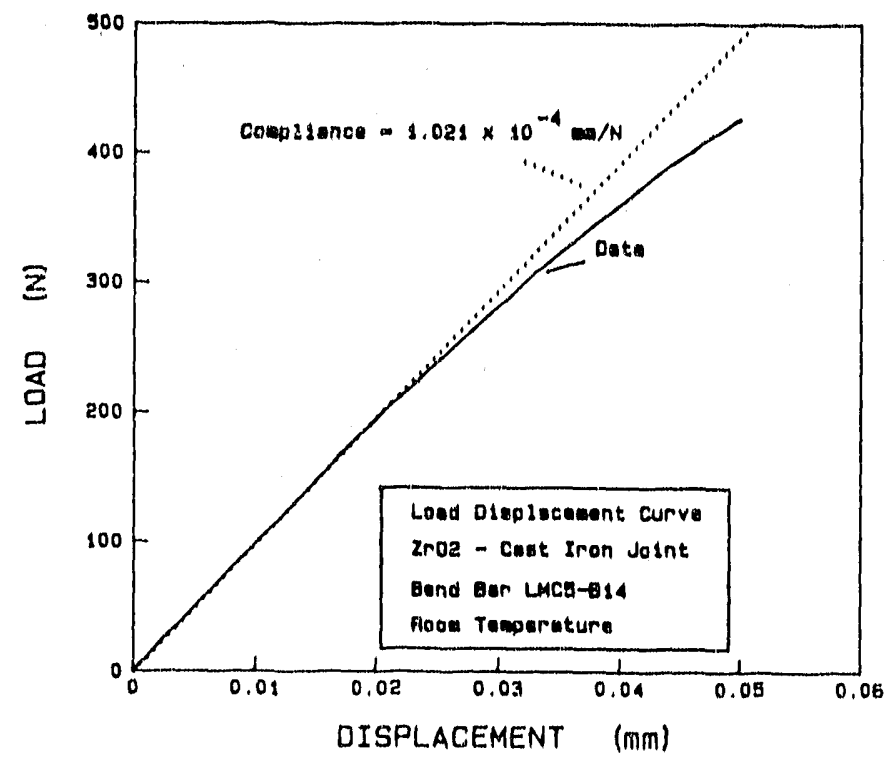

Figure 36. Load versus displacement plot for a zirconia/NCI joint. 
Notched Bend Bars and Disk Specimens. The apparent fracture toughnesses corresponding to notched bend bars with joints have already been presented in Table 7. Table 10 provides comparisons of average fracture toughness results of zirconia/zirconia joints, and it has been arranged to show a comparison of the joint apparent toughness with that of the corresponding interlayer material. Similar to unnotched bend bars, there is a slight increase in the toughnesses of zirconia/zirconia joints (fabricated at $1350 \mathrm{C}$ ) compared with those of the corresponding interlayer materials. Although the higher toughness of the joint compared with the bulk interlayer can partly be explained ${ }^{(\theta)}$ by a shielding effect, it appears that there was degradation of the interlayer material for zirconia/zirconia joints fabricated with MASZ-67 interlayer. For this material system, the apparent toughness of the joint was $2.5 \mathrm{MPa} \sqrt{\mathrm{m}}$, and analytical results indicate that this would correspond to a local stress intensity of $1.7 \mathrm{MPa} \sqrt{ } \mathrm{m}$ at the interlayer location of the joint. On the other hand, the bulk interlayer had a toughness of $2.1 \mathrm{MPa} / \mathrm{m}$; this would imply a 19 percent loss in toughness of the interlayer material due to the joining process. In the case of the MASZ-80 system, however, there did not appear to be any degradation in toughness of the interlayer material due to the joining process.

Table 10 indicates that the zirconia/zirconia joints fabricated at $1400 \mathrm{C}$ behaved differently, in that joint toughnesses were lower than bulk interlayer toughnesses. This was particularly true for the MASZ-80 interlayer fabricated at $1400 \mathrm{C}$, which has potential as a good structural material by itself. The lower joint toughnesses compared with interlayers can probably be explained by the observation that the crack propagated primarily through the reaction zone of the zirconia; i.e., the reaction zone was the weakest link rather than the ceramic interlayer material. Use of the $\mathrm{JAD}$ model indicated that the measured failure load for those specimens would require a $G_{10}$ that lay between 10 and $30 \mathrm{~N} / \mathrm{m}$ for the reaction zone, and these $G_{10}$ values would correspond to a toughness between $1.46 \mathrm{MPa} / \mathrm{m}$ and 2.1 $\mathrm{MPa} \vee \mathrm{m}$ for the reaction zone of the base zirconia (significantly lower than $5.6 \mathrm{MPa} / \mathrm{m}$ for the heat-treated zirconia). Thus, $1400 \mathrm{C}$ was obviously too high a temperature for zirconia/zirconia joining in that it caused intensive degradation of the base zirconia material.

For zirconia/NCI joints, the toughness of the joint was much less compared with either the base zirconia, NCI, or the braze metal. The explanation lies in the fact that the crack propagated partly through the reaction zone of the zirconia and partly through the 'Ti-rich interface at the braze-metal/zirconia interface. These locations were not available as bulk materials for independent toughness measurements. Because of this problem, it was recognized that the toughness of the braze metal or the base zirconia was not suitable for incorporation in the JAD model, because they did not represent local fracture energies. Therefore, an indirect approach was followed in that the load to failure of zirconia/NCI notched bend bars was used for back-calculating the local $G_{0}$ at the failure location. It was understood that because of this approach, the JAD model could not utilize the results of notched bend bar tests, performed on zirconia/NCI joints, for validation purposes. However, the approach allowed for validation using the cracked disk specimen for zirconia/ $\mathrm{NCl}$ joints. The fracture energy of the zirconia/ $\mathrm{NCI}$ joint was determined as $184.5 \mathrm{~N} / \mathrm{m}$ using the above procedure. This value was in good agreement with a test where failure in a notched zirconia/NCI specimen occurred entirely through the reaction zone of the zirconia; this particular specimen indicated a $G_{10}$ of $237.5 \mathrm{~N} / \mathrm{m}$ for the reaction zone. 
Table 10, Average toughness valucs of constituent materials.

\begin{tabular}{|c|c|c|}
\hline Material & Specimen Geometry & Qlc*, MPaVm \\
\hline \multicolumn{3}{|l|}{ Zirconia/Zirconia Joints } \\
\hline $\begin{array}{l}\text { Joint (MASZ-67, } 1350 \mathrm{C} \text { ) } \\
\text { Joint (MASZ-67, } 1350 \mathrm{C} \text { ) } \\
\text { Bulk MASZ-67, } 1350 \mathrm{C}\end{array}$ & $\begin{array}{l}\text { Notched Bend Bar } \\
\text { Cracked Dlsk } \\
\text { Notched Bend Bar }\end{array}$ & $\begin{array}{l}2.48 \\
2.12 \\
2.05\end{array}$ \\
\hline $\begin{array}{l}\text { Jolnt (MASZ-80, } 1350 \text { C prooessed) } \\
\text { Jolnt (MASZ-80, } 1350 \text { C processed) } \\
\text { Bulk MASZ-80, } 1350 \mathrm{C} \text { processed }\end{array}$ & $\begin{array}{l}\text { Notched Bend Bar } \\
\text { Oracked Disk } \\
\text { Notched Bend Bar }\end{array}$ & $\begin{array}{l}3.17 \\
2.46 \\
2.82\end{array}$ \\
\hline $\begin{array}{l}\text { Joint (MASZ-67, } 1400 \text { C processed) } \\
\text { Bulk MASZ-67, } 1400 \text { C processed }\end{array}$ & $\begin{array}{l}\text { Notohed Bend Bar } \\
\text { Notched Bend Bar }\end{array}$ & $\begin{array}{l}1.59 \\
1.74\end{array}$ \\
\hline $\begin{array}{l}\text { Jolnt (MASZ-80, } 1400 \mathrm{C} \text { processed) } \\
\text { Bulk MASZ-80, } 1400 \mathrm{C} \text { processed }\end{array}$ & $\begin{array}{l}\text { Notched Bend Bar } \\
\text { Notched Bend Bar }\end{array}$ & $\begin{array}{l}2.33 \\
5.27\end{array}$ \\
\hline $\begin{array}{l}\text { Heat-Treated Zlrconia, } 1350 \mathrm{C} \\
\text { processed }\end{array}$ & Notched Bend Bar & 5.57 \\
\hline \multicolumn{3}{|l|}{ Zirconia/NCI Joints } \\
\hline $\begin{array}{l}\text { Zirconla/NCl Jolnt } \\
\text { Zirconla/NCl Jolnt }\end{array}$ & $\begin{array}{l}\text { Notched Bend Bar } \\
\text { Cracked Dlsk, O-degree }\end{array}$ & $\begin{array}{l}5.89 \\
6.63\end{array}$ \\
\hline $\begin{array}{l}\text { As-Received Zirconla } \\
\text { As-Received Zirconla }\end{array}$ & $\begin{array}{l}\text { Nolched Bend Bar" } \\
\text { Cracked Dlsk, O-degree }\end{array}$ & $\begin{array}{l}9.70 \\
8.60\end{array}$ \\
\hline
\end{tabular}

-. Qle $=$ Klc for monollthic materials, and it corrosponds to apparent Modo I fracturo toughnoss for foints.
Chevron-notchod bond bar. 
For predicting mixed-mode fracture conditions, it is important to determine the variation of the critical strain energy release rate, $G_{0}$ as a function of mode mixity, $\Psi$. Evans and Hutchinson ${ }^{[8]}$ have suggested a function of the form,

$$
\sigma_{0} /\left(\operatorname{Cos}^{2} \psi+k \sin ^{2} \psi\right)
$$

for joints, where $G_{0}$ is the critical strain energy release rate under pure Mode I loading and $k$ is a material constant. The analysis of data on monolithic ceramic materials indicated that a function of the form

$$
G_{c}=G_{0} \operatorname{Sec}^{2}\left(\psi / \Psi_{0}\right)
$$

represents the monolithic data very well, where $\Psi_{0}$ is a constant depending upon the material. Based on this evaluation, the functional form given by Equation (39) was selected apriori for the JAD model. The value of $\mathrm{G}_{0}$ was determined from testing bulk interlayer cracked bend bars (for zirconia/zirconia joints), and from the preliminary validation results

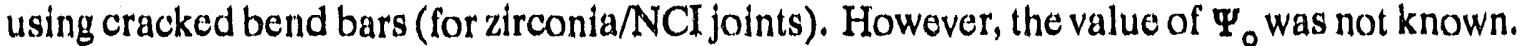

It was decided that the data from cracked disk specimens would be used for determining $\Psi_{0}$. Because the cracked disk specimen data were also used for validation of the JAD model, it was decided that only one data-point from the disk specimens would be used for evaluating $\Psi_{0}$, and then the rest of the disk data would be used for comparing predicted and measured fracture loads.

Table 11 provides the apparent mixed-mode fracture toughness data for the cracked disk specimens. The analytical results of Atkinson et al., ${ }^{[7]}$ for homogeneous material were used for computing the apparent stress-intensity factors from the failure loads. As already indicated, Atkinson's results were within 3 percent of the FEM results on zirconia/NCI cracked specimens, primarily because of the good matching of the elastic constants of zirconia and NCI. From the apparent stress-intensity values, the local stress intensity factors and $G$ at the interlayer location were calculated using the JAD model calculations, and these local $G$ values were plotted versus $\Psi$. Figures 37 and 38 are plots of local $G(\Psi)$ versus $\Psi$ for zirconia/zirconia and zirconia/NCI joints, respectively. Although there is only one datapoint corresponding to each value of non-zero $\Psi$, the results at $\Psi=0$ show a degree of scatter in the joint toughness. The solid curves in Figures 37 and 38 were obtained by using the data at $\Psi=72.3$ degrees, and equating $G_{0}$ with the average of $G$ at $\Psi=0$ degree $(G(0)$ $=20.9 \mathrm{~N} / \mathrm{m}$ for zirconia/zirconia joints, and $237.7 \mathrm{~N} / \mathrm{m}$ for zirconia/ $\mathrm{NCI}$ joints), thereby calculating $\Psi_{\circ}$ according to Equation (39) above. An angle of 72.3 degrees was selected for determining $\Psi_{\circ}$ because it was a sufficiently large angle to estimate mixed-mode effects, and also because it was sufficiently removed from 90 degrees, where crack-face rubbing could mask out true toughness values. However, any other angle could in principal be chosen (such as, say, 45 degrees), although an angle between 65 and 80 degrees is desirable because it spans a reasonably large range of $\Psi$.

Using the above approach, values of $\Psi_{0}$ of 1.14 and 1.49 were obtained for the zirconia/zirconia and zirconia/NCI joints, respectively. These values, together with the $\mathrm{G}(0)$ data, were substituted into Equation (39) to obtain the solid curves in Figures 37 and 38. Figure 37 shows that the solid curve appears to repi sent the data trend quite well, except at conditions approaching 90 degrees. The lack of agreement may partly be due to the fact 
Table 11. Results of fracture tests on cracked anci uncracked disk specimons.

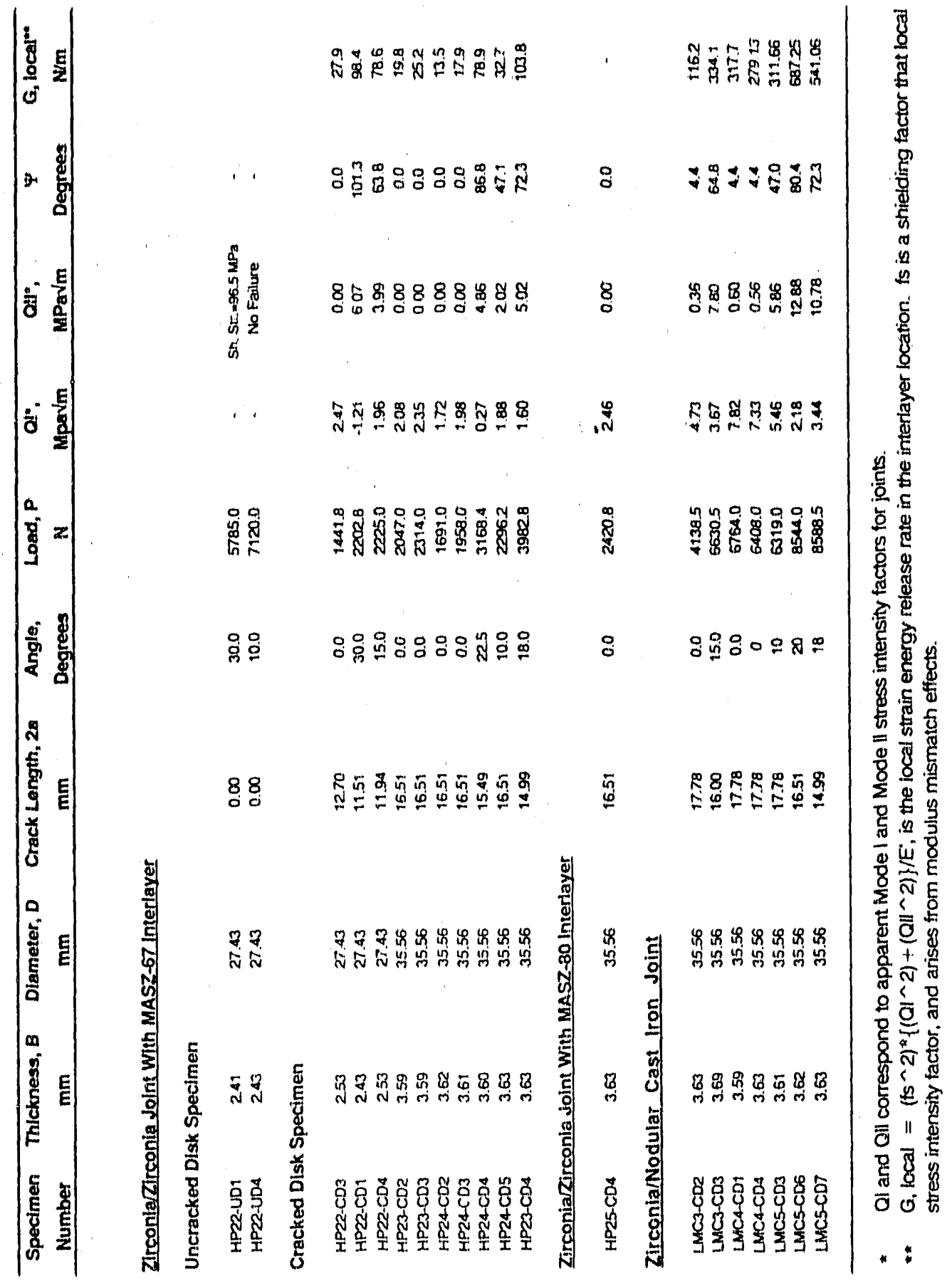




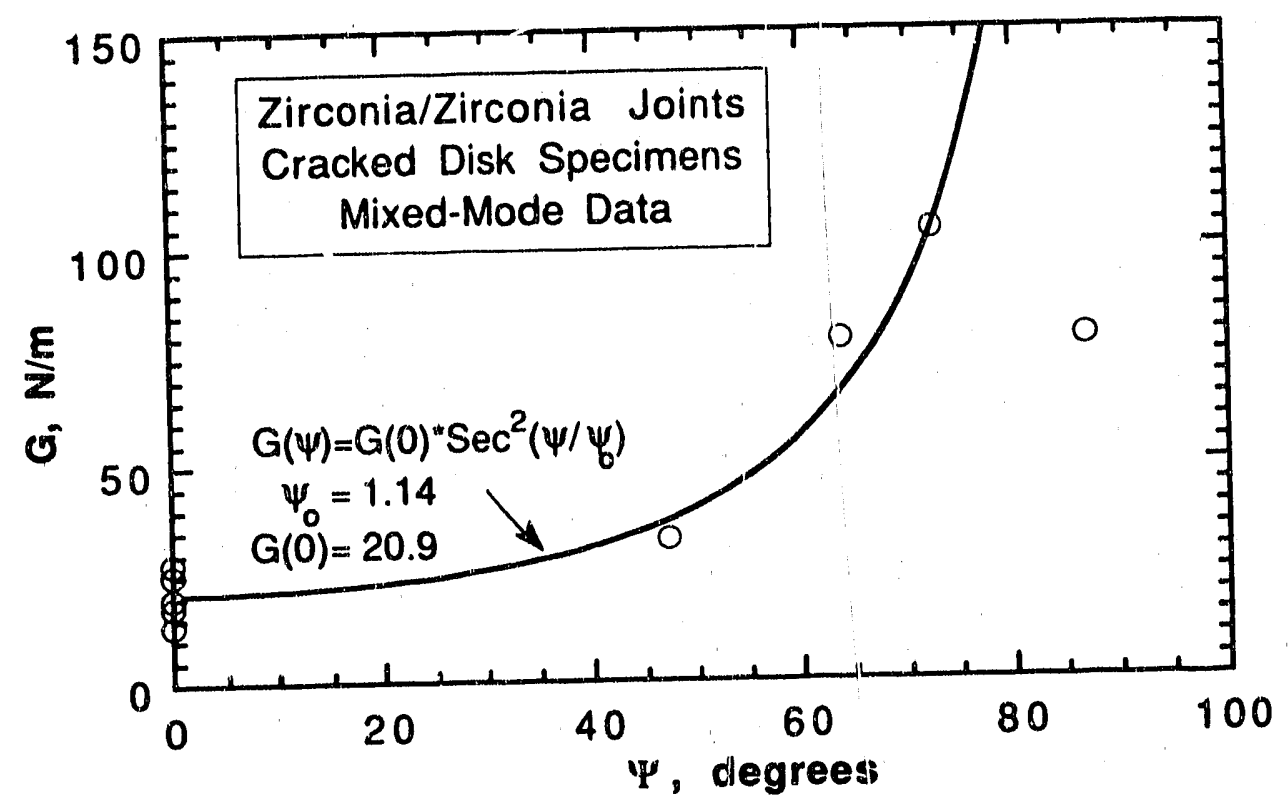

Figure 37. Strain energy release rate as a function of mode mixity for zirconia/zirconia specimens.

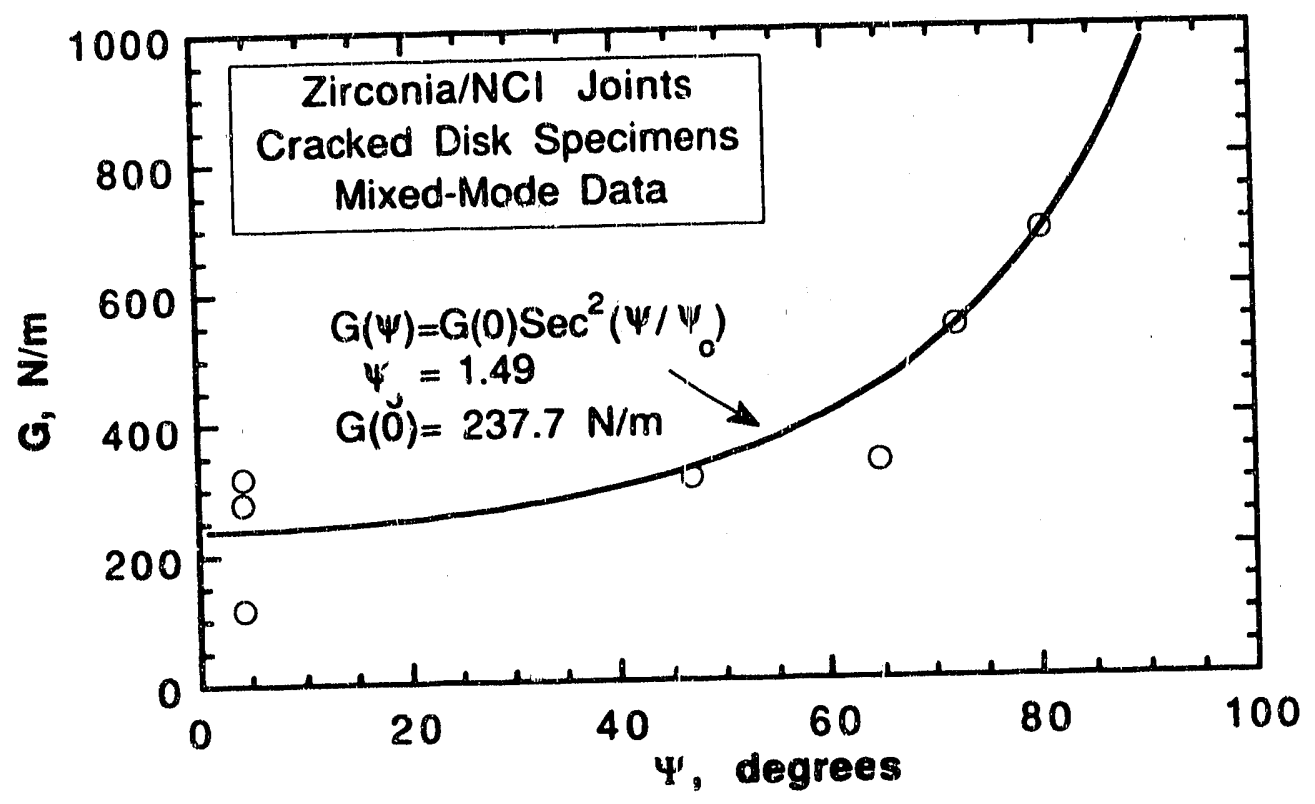

Figure 38. Strain energy release rate as al function ofl mode mixity for zirconia/NCI specimens. 
that at angles approaching 90 degrees, closure of crack surfaces can provide erroneous results. More likely, a larger data base is necessary to evaluate whether the data at 86.8 degrees is indeed an outlier or whether the functional form shown in Equation (39) needs to be modified. For the zirconia/NCI joints, the solid curve provided excellent correlation with most of the data.

In the final validation of the JAD model, the above values of $\Psi_{0}$, together with values of $\mathrm{G}_{0}$ obtained earlier from experiments on bulk interlayer material, were used for assessing fracture under mixed-mode conditions; note that average $G(0)$ (at $\Psi=0$ degrec) for disk specimens were not used in the final validation of the JAD model.

Figures 39 to 42 are load-displacement plots of zirconia/zirconia and zirconia/NCI disk specimens. The COD displacements were measured across the crack mouth at a distance of $3.81 \mathrm{~mm}$ on either side of the slit. Some amount of non-linearity is observed for the zirconia/NCI joint (Figure 42), and may have been the result of small scale plasticity prior to fast fracture. The experimental and predicted load-displacement plots were not compared in this program. However, the experimental traces are provided for future reference and for further validation of the JAD analysis.

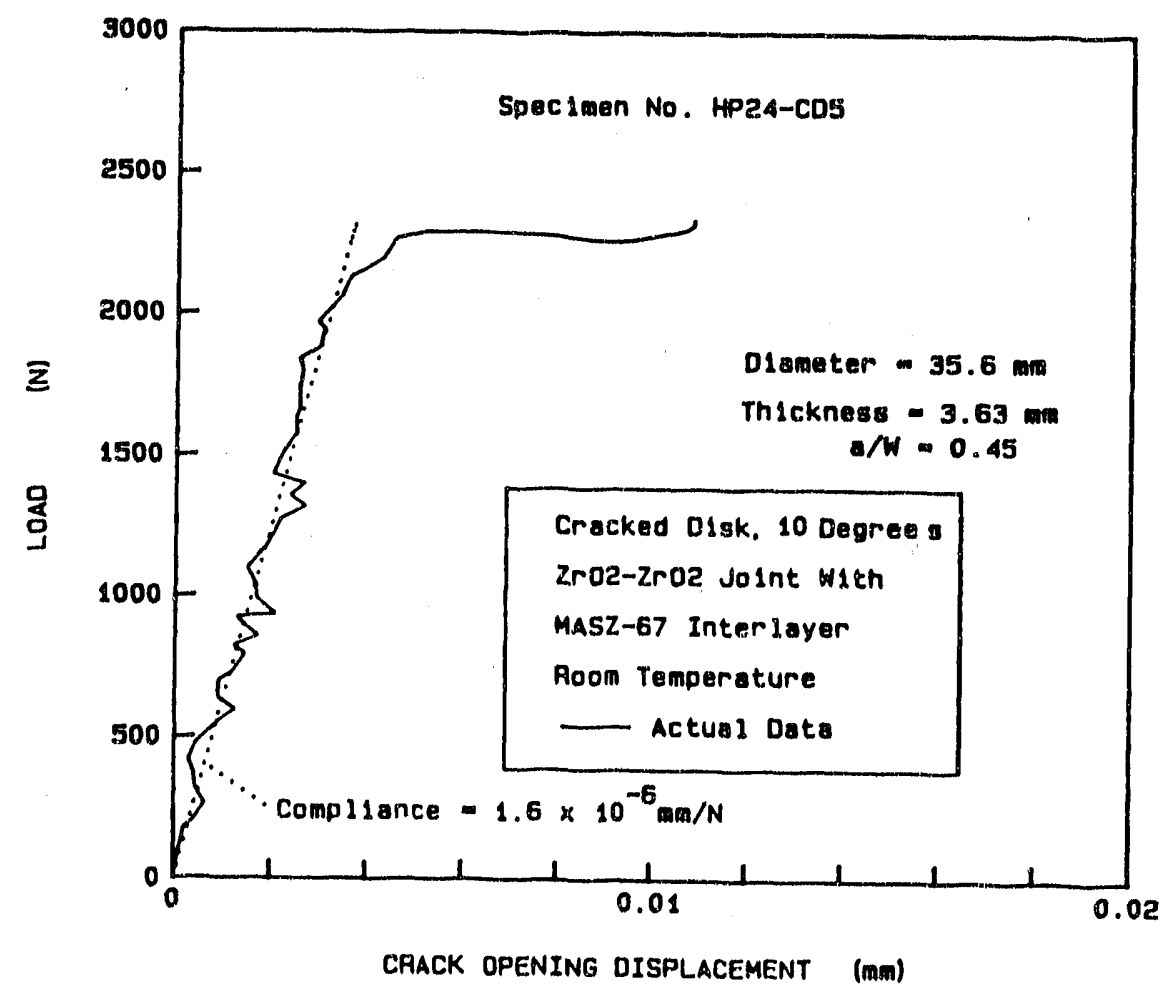

Figure 39. Load versus crack opening displacement plot for a zirconia/zirconia cracked disk specimen. Specimen loaded at 10 degrees to joint. 


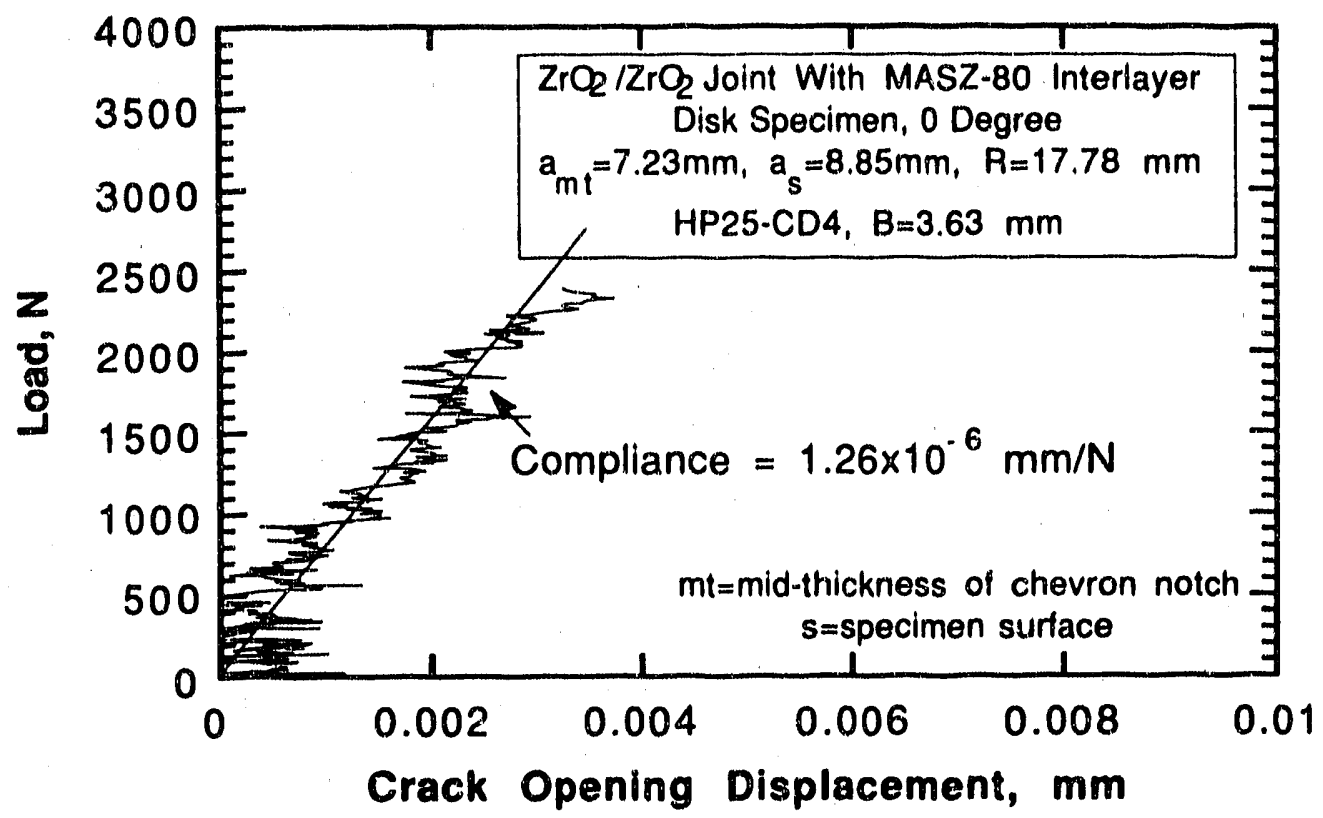

Figure 40. Load versus disk crack opening displacement plot for a zirconia/zirconia disk specimen.

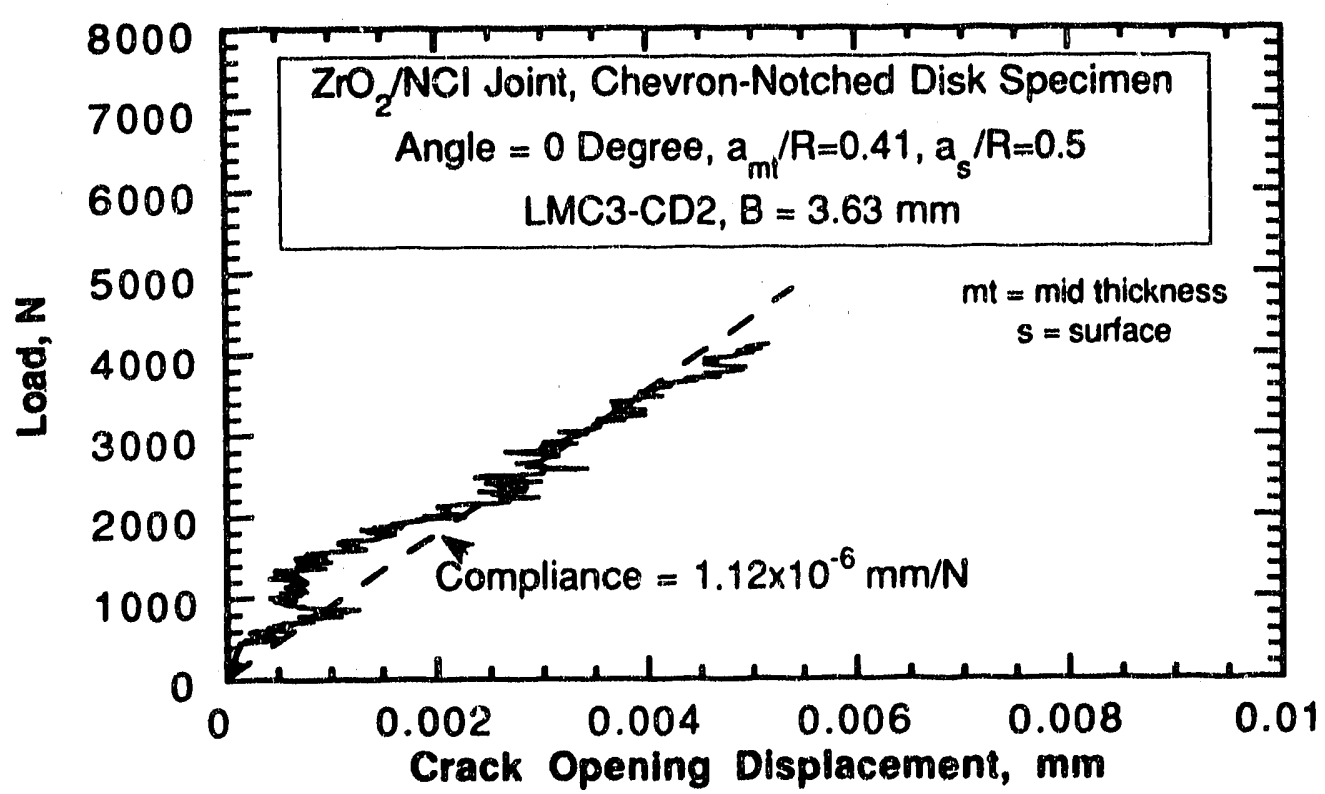

Figure 41. Load versus disk crack opening displacement plot for a zirconia/NCI cracked disk specimen. Specimen loaded at 0 degrees to joint. 


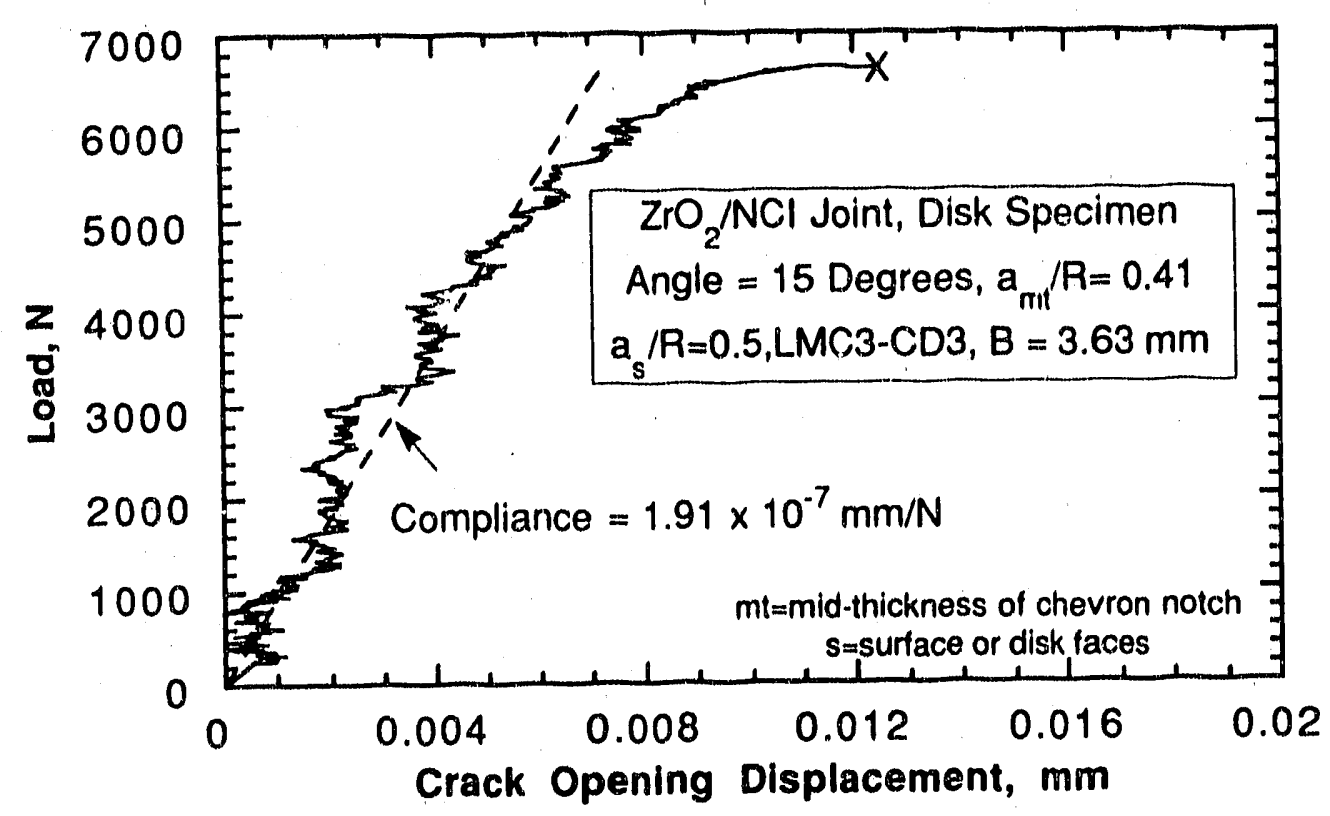

Figure 42. Load versus disk crack opening displacement plot for a zirconia/NCI cracked disk specimen. Specimen loaded at 15 degrees to joint.

\subsubsection{Microstructure and Fractography of Joints}

Zirconia/Zirconia Joints. Figure 43 is a microprobe back scaltered electron (BSE) image of a joint fabricated with MASZ-67 interlayer at $1350 \mathrm{C}$. The figure shows that the joint had a thickness of approximately $150 \mu \mathrm{m}$, and the diffused reaction zones extended approximately $50 \mu \mathrm{m}$ from the joint surfaces. The three largest dark areas in Figure 43 correspond to pores or joint defects, but the smaller dark regions are not pores. Those regions appear dark in the figure because of the higher concentration of lighter atomicweight elements.

Higher magnification micrographs ${ }^{[5]}$ indicated that the bright white circular particles in the figure were retained zirconia particles. X-ray diffraction results ${ }^{[6]}$ showed that the particles were primarily tetragonal zirconia rather than monoclinic zirconia, although nominally pure zirconia powder was used in preparing the MASZ interlayer. These retained tetragonal zirconia particles explain why improved joint properties were observed with increased zirconia concentration in the interlayer. The dark phase in Figure 43 contained a high concentration of magnesia, and the blocky grey phase was evaluated to be zircon $\left(\mathrm{ZrSiO}_{4}\right)$, most likely produced by the reaction of zirconia with silica. The undesirable formation of zircon reduced the bond properties, and explains why a minimum of 67 weightpercent zirconia was needed in the interlayer material for producing acceptable bond strengths. Microprobe investigations also indicated that $\mathrm{Mg}$ and $\mathrm{Si}$ were primarily responsible for good wettability between the interlayer and the substrate. 


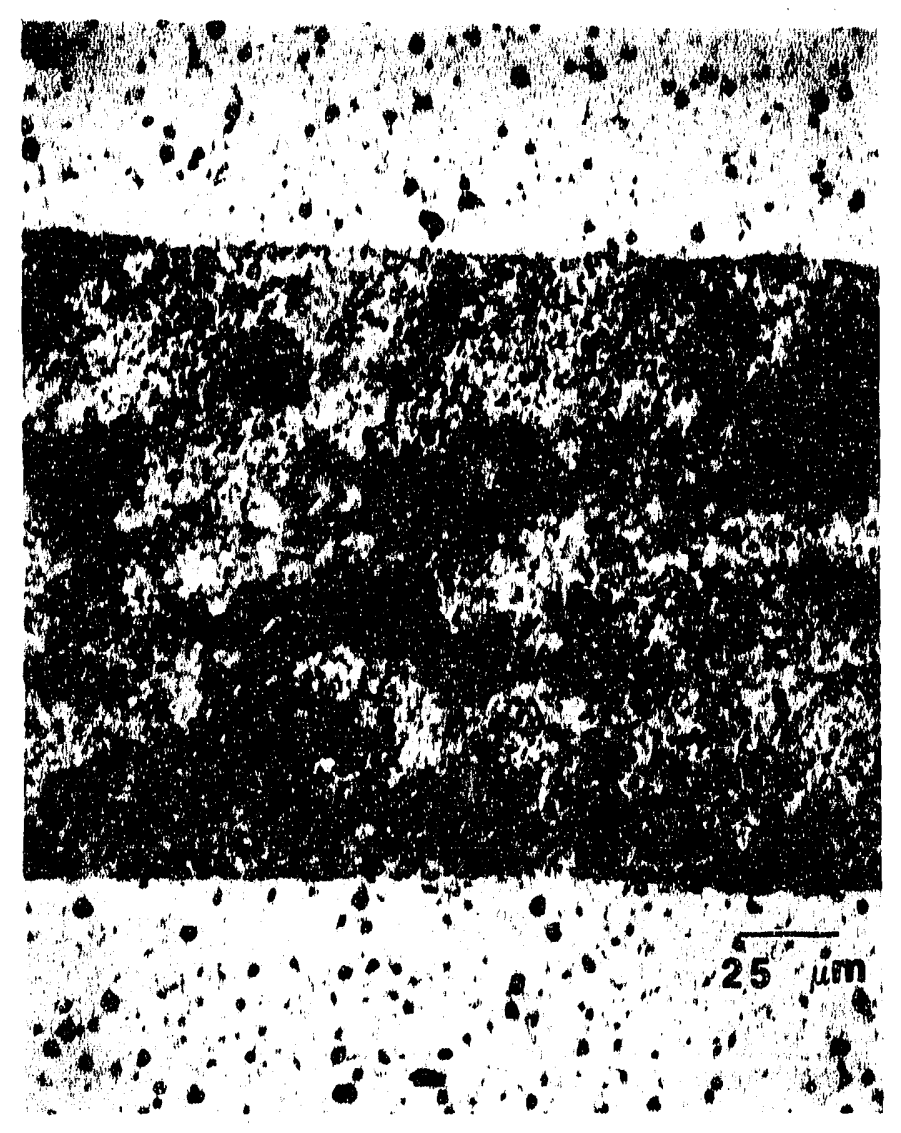

Figure 43. Microprobe BSE image of a large scale zirconia/zirconia joint fabricated using MASZ-67 interlayer.

Figure 44 is a fractograph of the base zirconia, and it shows that the base material had a substantial concentration of pores. These pores were located primarily at grain boundary triple points. For the joining experiments, the pores acted as preferential sites for accumulation of $\mathrm{Mg}$ and $\mathrm{Si}$, since high concentrations of those elements were observed in metallographic specimens in the broad reaction zones on either side of the joint. 


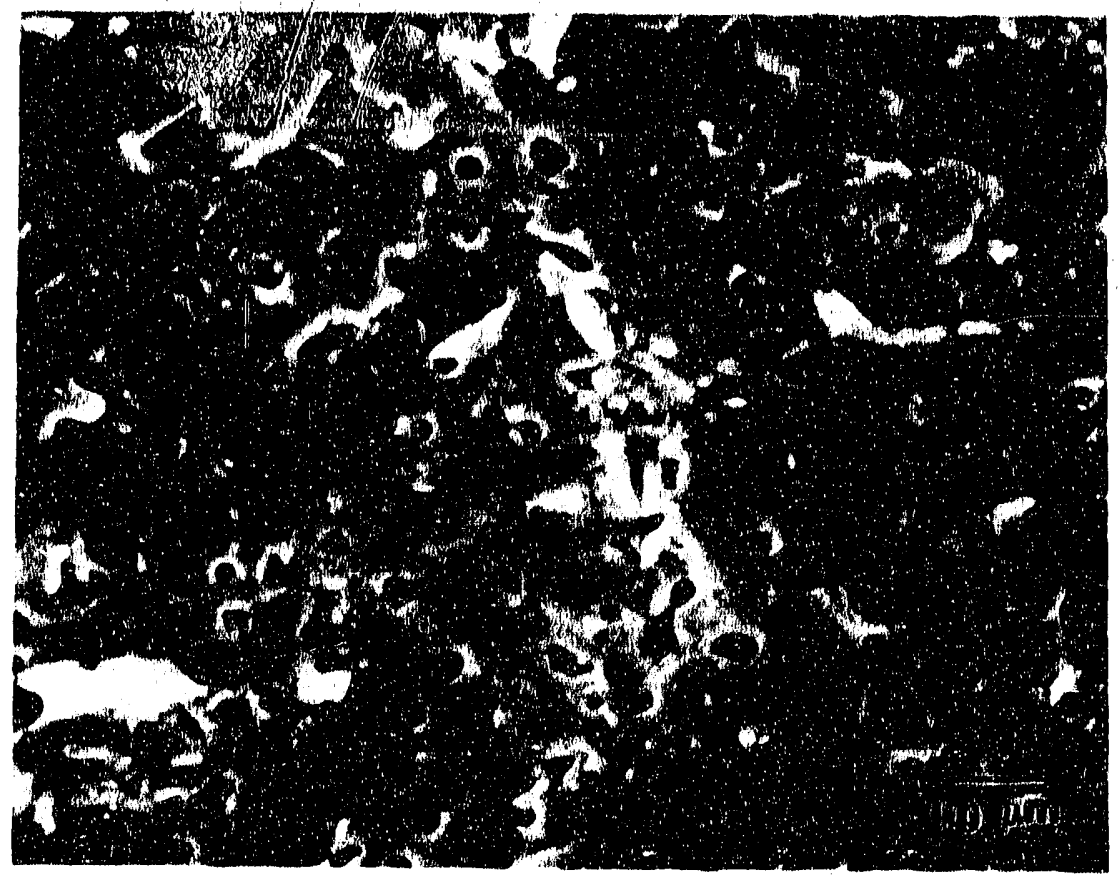

Figure 44. SEM micrograph of fracture surface of as-received zirconia.

On a macroscopic scale, the fracture surfaces of zirconia/zirconia joints were quite rough, indicating good fracture toughness. Figure 45 illustrates the fracture surface of a joint fabricated with the MASZ-67 interlayer. The fracture surface has a close resemblance to the microstructure of the interlayer material in that fine particles can be observed in a smoothtextured matrix. Energy dispersive spectroscopic (EDS) analyses provided the following approximate elemental composition (weight percent) of the fracture surface: $5.6 \mathrm{Mg}, 7.1 \mathrm{Al}$, 14.4 Si, 5.7 Ti, 67.2 Zr. From the elemental composition, and the fracture surface morphology, it was concluded that the failure propagated primarily through the $\mathrm{i}$ iterlayer material.

Although most of the bend bars showed that the preferred fracture path was through the interlayer, there were a few instances where the crack appeared to propagate partly through the reaction zone. However, the bend strengths in these instances were not 


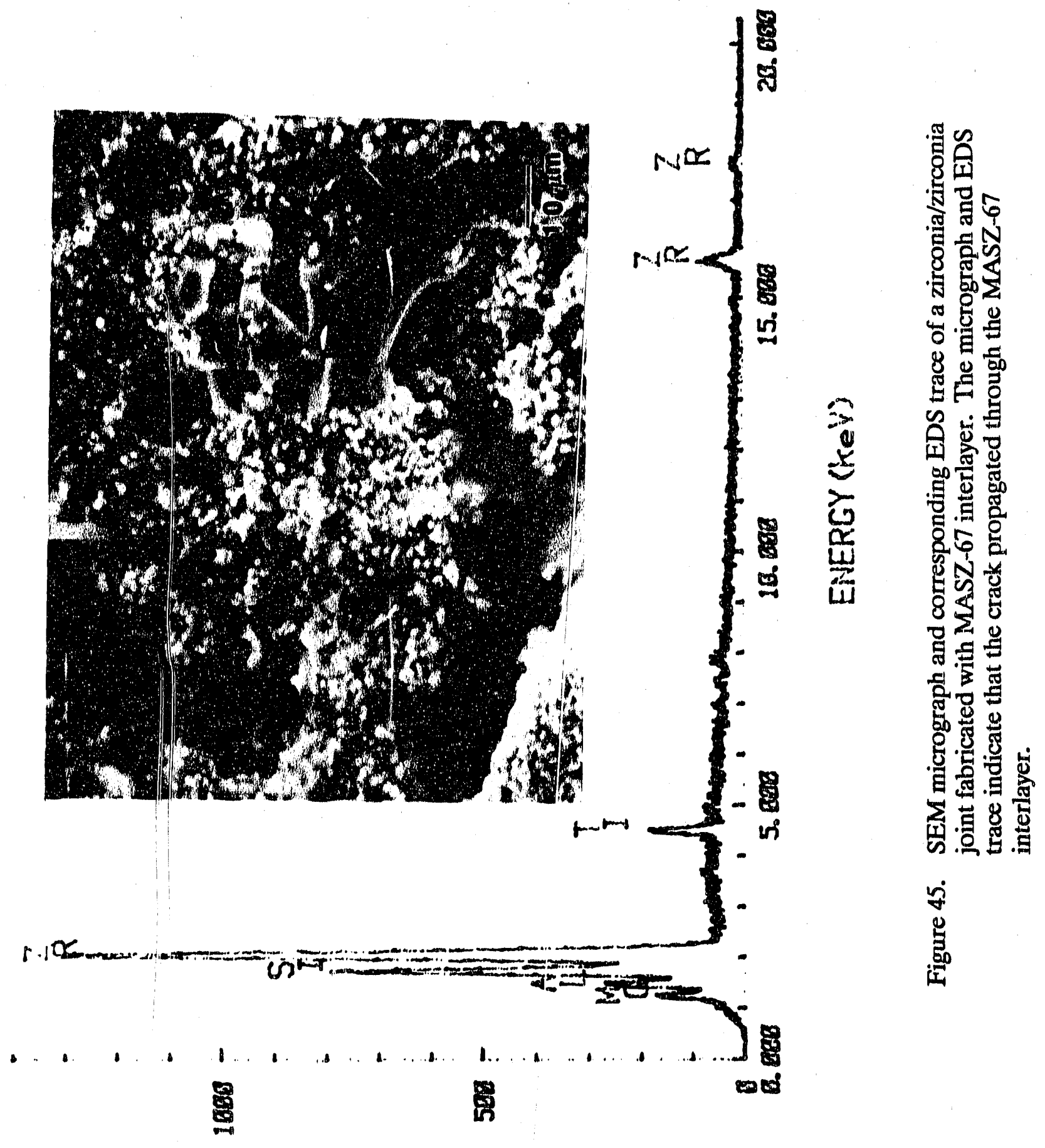


significantly different compared with the case where the crack propagated completely through the interlayer, indicating that the reaction zone had a strength that was similar to the interlayer. In the particular case of a zirconia/zirconia joint fabricated with MASZ-80 interlayer at $1400 \mathrm{C}$, the failure propagated completely through the reaction zone rather than the interlayer. This behavior was consistent with the fact that the bulk interlayer fabricated at that temperaiure had a toughness of greater than $5 \mathrm{MPa} / \mathrm{m}$, whereas the reaction zone was estimated to a have a toughness of only $2.4 \mathrm{MPa} \sqrt{\mathrm{m}}$ (much less than the heat treated zirconia, 5.6 MPa $\sqrt{\mathrm{m}}$ ).

Zirconia/NCI Joints. Figure 46 contains electron microprobe images of a zirconia/NCI joint. Figure $46 \mathrm{~b}$ is a BSE image based on Figure 46a, and shows the brazemetal/zirconia interface at a high magnification. The white region in this figure is primarily $\mathrm{Ag}$, although $\mathrm{Cu}$ and $\mathrm{In}$ are also present. Figures $46 \mathrm{c}$ and $46 \mathrm{~d}$ are $\mathrm{Ti}$ and $\mathrm{Cu}$ elemental maps, respectively, corresponding to Figure 46b. These figures indicate that there is primarily a pure Ti-layer (may contain oxygen) at the zirconia interface, followed by a $\mathrm{Cu}-\mathrm{Ti}$ layer immediately adjacent to the pure Ti-layer. Clearly $\mathrm{Ti}$ was responsible for good bonding between the zirconia and the braze metal. Although the zirconia next to the braze metal did not appear to be microstructurally different from the as-received zirconia, a dark-brown band (0.3-0.4 mm wide) could easily be observed in the zirconia next to the braze metal; the as-received zirconia had a yellow color. This region corresponded to the reaction layer, and work done at ORNL indicated that the reaction zone corresponds to non-stoichiometric zirconia $\left(\mathrm{ZrO}_{2-x}\right)$ with depleted oxygen content.

Figures $47 \mathrm{a}$ and $47 \mathrm{~b}$ are fractographs of the NCI side and the zirconia side, respectively, of a zirconia/NCI joint broken under Mode I loading. EDS analyses indicated that the void containing projections (region A3) in Figure 47a were composed of pure zirconia, indicating that the propagating crack dug into the reaction zone of the zirconia. The flatter regions, such as $\mathrm{A} 4$, contained primarily $\mathrm{Ti}$ and $\mathrm{Cu}$, with $\mathrm{Ti}$ being the dominant element. On the zirconia side (Figure 47b), regions such as A2 corresponded to some braze metal pockets held back by the zirconia. The smooth regions (such as Ala) corresponded to the zirconia surface, but it was found to contain $\mathrm{Ti}$ and $\mathrm{Cu}$, with $\mathrm{Ti}$ again being the dominant element. On the other hand, regions such as AlB corresponded to pure zirconia, being exact counterparts of the projected regions shown in Figure $47 \mathrm{a}$. Thus, these fractographs indicate that the crack propagated partly through the reaction zone of the zirconia and partly through the extremely fine Ti-rich layer between the braze metal and the zirconia. Based on an examination of a number of fracture surfaces, the reaction-zone and Ti-rich layer each occupied between 40 and 60 percent of the area of the fracture surface.

Figure 48 illustrates the microstructure of a surface obtained by sectioning perpendicular to the fracture plane. The left side contains the NCI and braze metal, the central region corresponds to a space, and the right side corresponds to zirconia. The fracture halves were not correctly positioned when preparing the metallurgical sample, so that the fracture regions are not matching halves. Nevertheless, the micrographs illustrate the general fracture morphology. The micrograph shows that the crack propagated partly through the reaction zone of the zirconia and partly through the Ti-rich zone of the brazemetal/zirconia interface. 

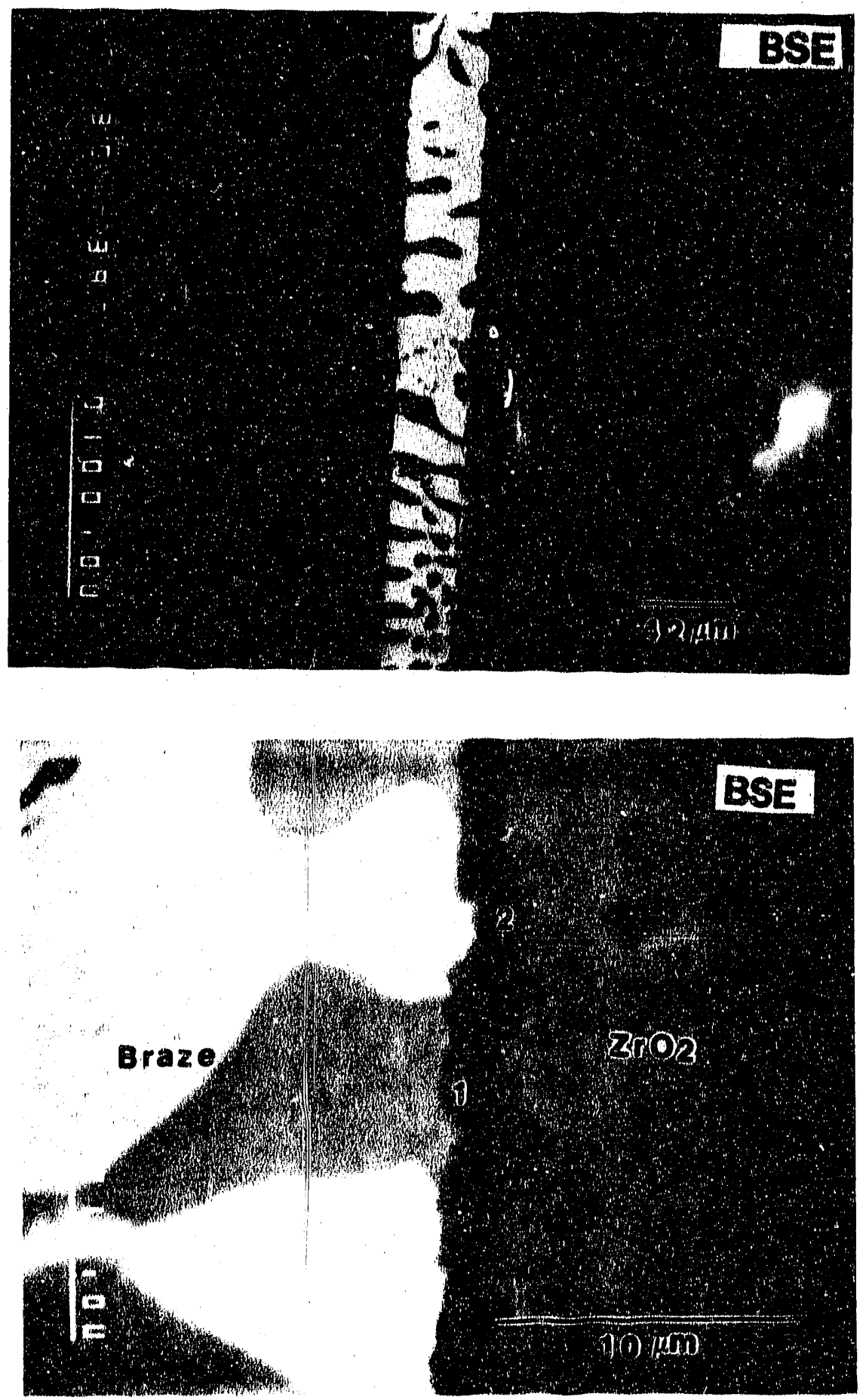

Figure 46. Microproje BSE image and elemental maps for a zirconia/NCI joint. (a) low magnification micrograph with NCI on left side, braze in the middle, and zirconia on the right side. (b) BSE image of the braze/zirconia interface at a high magnification. (c) and (d) are $\mathrm{Ti}$ and $\mathrm{Cu}$ maps, respectively, of the same region as (b). 

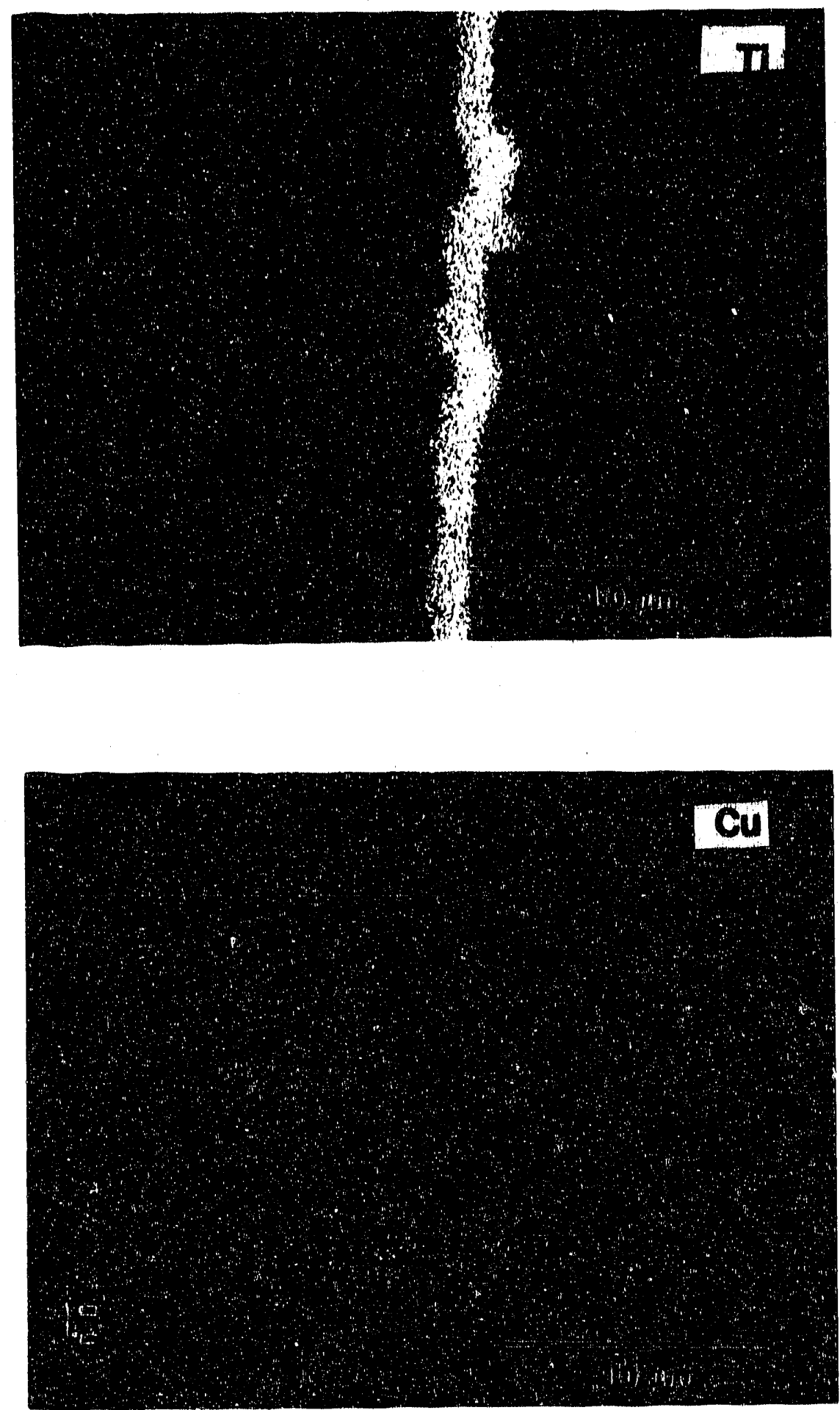

Figure 46. Cont. 
NCI Side

(a)

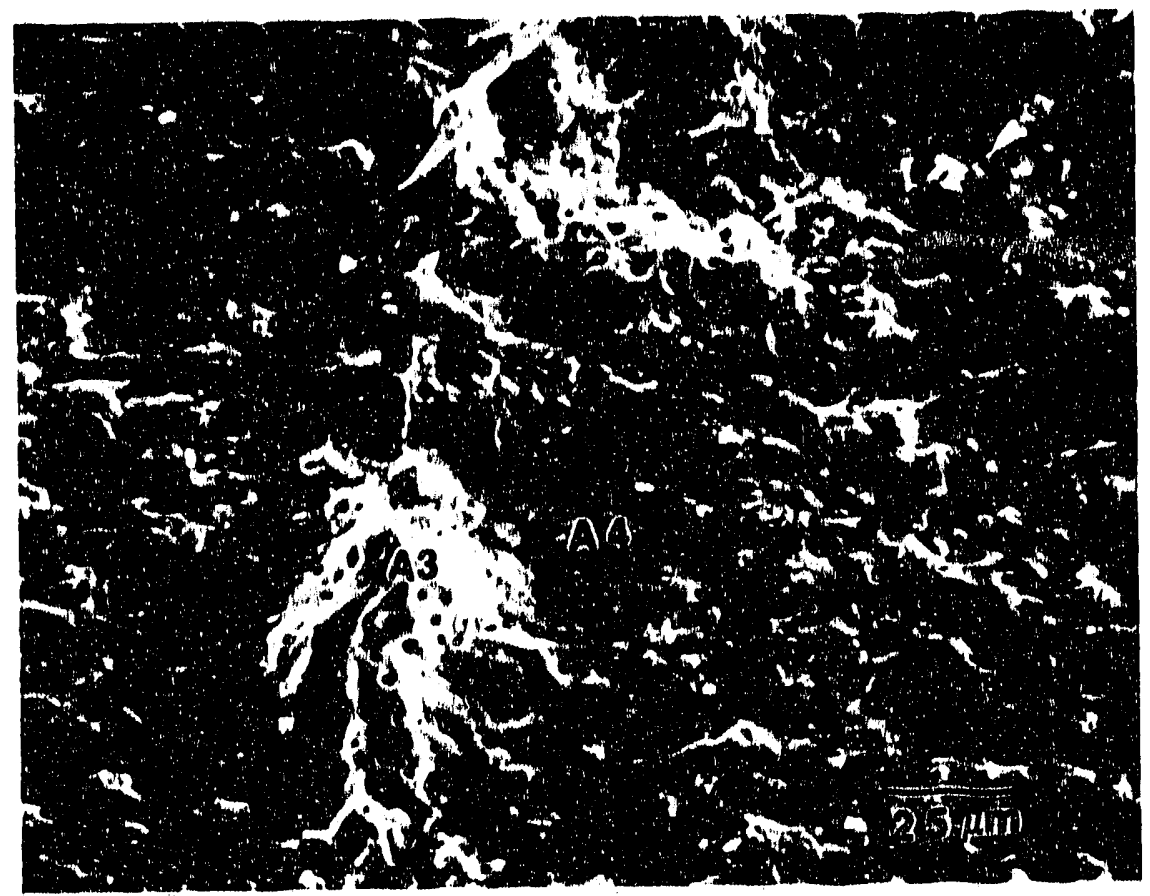

1139

$\mathrm{ZrO}_{2}$ Side

(b)

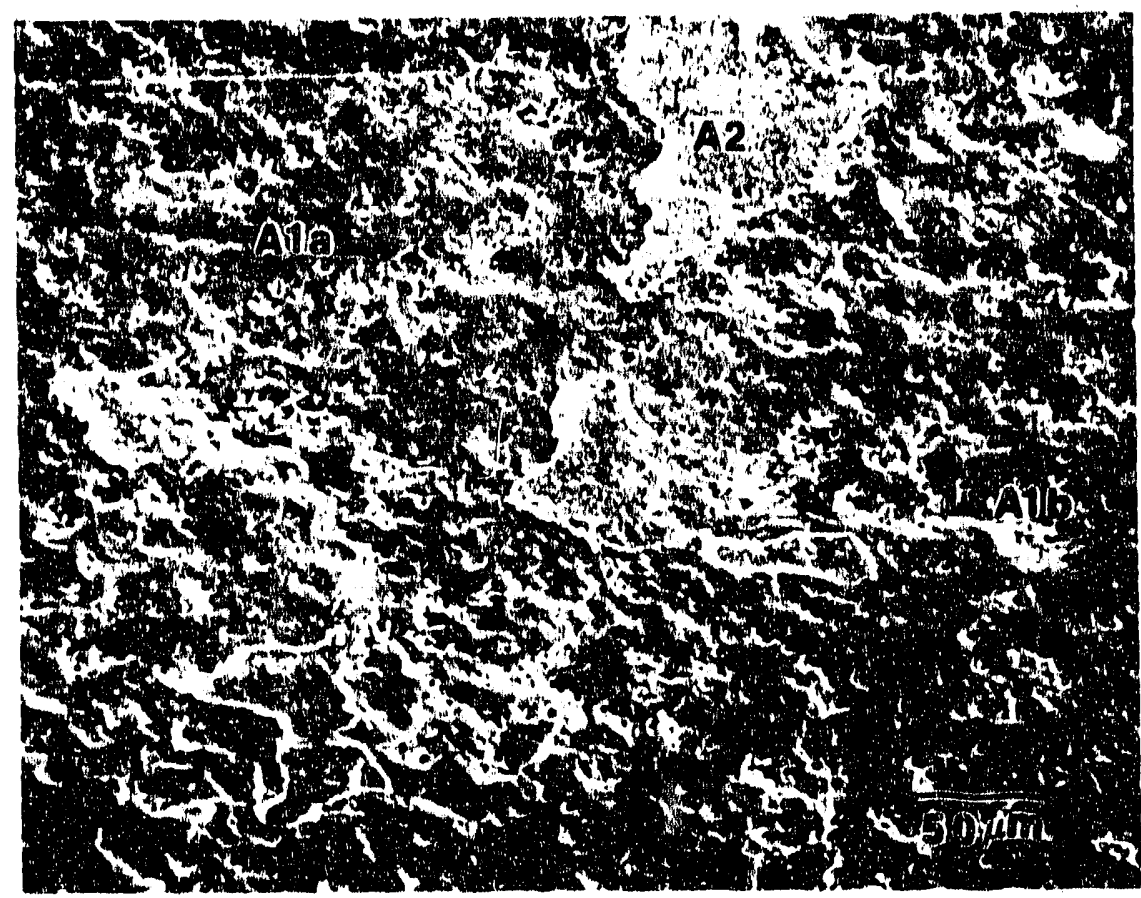

84141

Figure 47. Fracture surfaces of a zirconia/NCI joint for a notched bend bar. (a) NCI side of the fracture surface. (b) zirconia side of the fracture surface. 
84

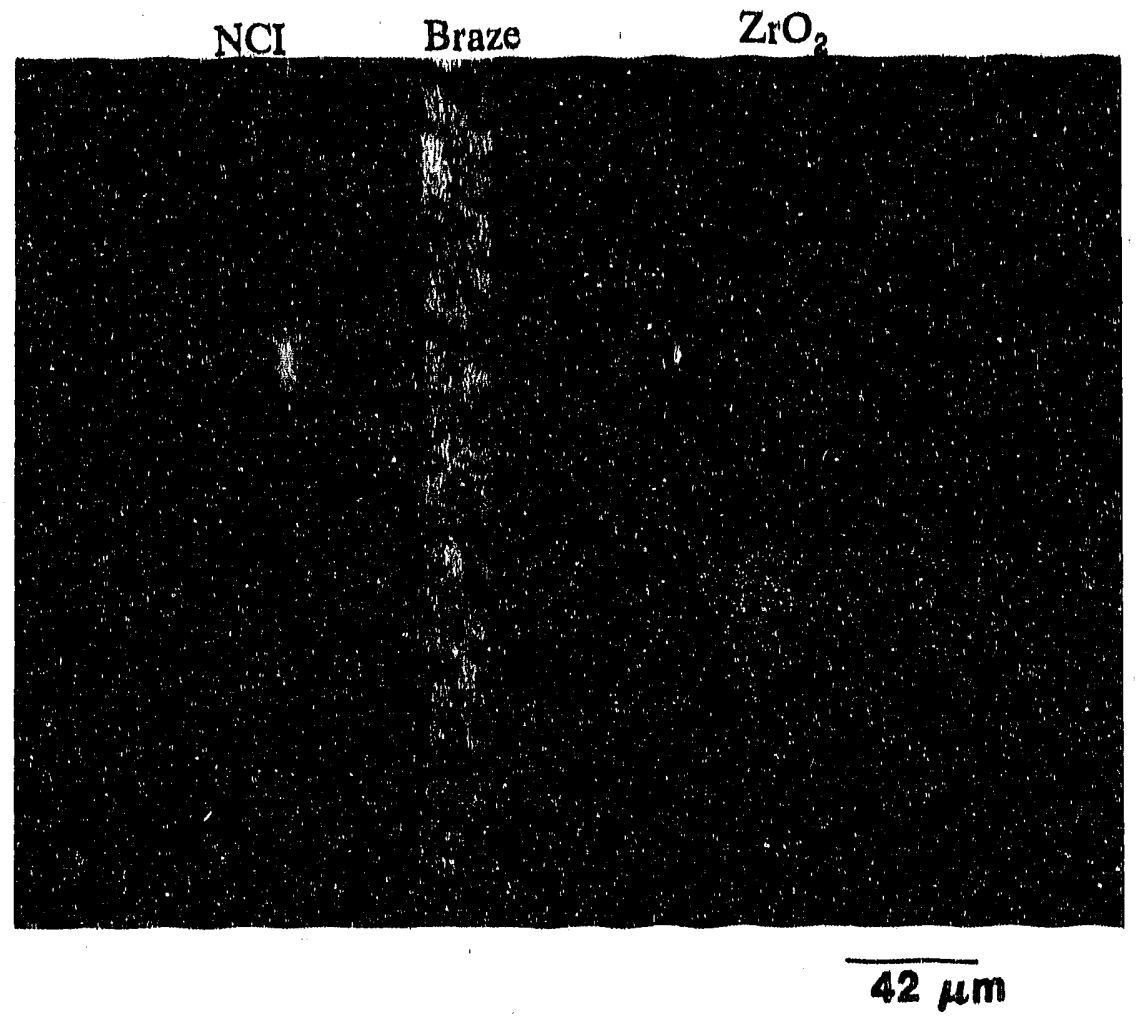

Figure 48. Microstructure of the NCI (left) and zirconia (right) immediately a. Jjacent to the fracture surface. the cross-sections are not matching halves of the fracture surface.

With increased mixity of loading (increasing $\psi$ ), there was a gradual change in the fracture path and fracture morphology. On the zirconia side of the disk specimen, the crack deviated from the notch plane and propagated towards the loading point. This behavior was similar to what has been observed for monolithic ceramic specimens. The extent of crack growth along the bond-line prior to crack deviation (for zirconia side) depended on the loading angle, being approximately $6 \mathrm{~mm}$ for an angle of 10 degrees, and being less than $1 \mathrm{~mm}$ above 15 degrees. On the NCI side, however, the crack could not propagate into the NCI; rather the crack propagated all along the bond line. Figures $49 \mathrm{a}$ and $49 \mathrm{~b}$ correspond to the $\mathrm{NCI}$ side and zirconia side, respectively, of the fracture surfaces of a disk specimen where the crack propagated through the bond line. The sample was loaded with the notch at an angle of 20 degrees with respect to the load line ( $\psi=80.4$ degrees). EDS analysis indicated that on the NCI side the surface layer was rich in Ti and $\mathrm{Cu}$, with Ti being the dominant element. However, contrary to Mode I fracture, hardly any zirconia was found on the fracture surface. The wavy structure seen in Figure 49a probably corresponds to shear deformation of the Ti-rich layer and of the braze metal beneath it. On the zirconia side, the primary elements detected were $\mathrm{Zr}$ and $\mathrm{Ti}$ and $\mathrm{Cu}$. Here too, unlike Figure 47b, very little zirconia appeared to have been pulled out by the braze metal during fracture. Overall, it appeared that under shear loads there was significant plastic shear deformation of the braze metal, including the Ti-rich layers, and these resulted in shear failure of the interface without any significant accompanying failure of the reaction zone of the interlayer. Such fracture morphology differences with the. Mode I loading probably were responsible for elevating the $\mathrm{G}_{\mathrm{c}}$ with increasing $\psi$. 
(a)

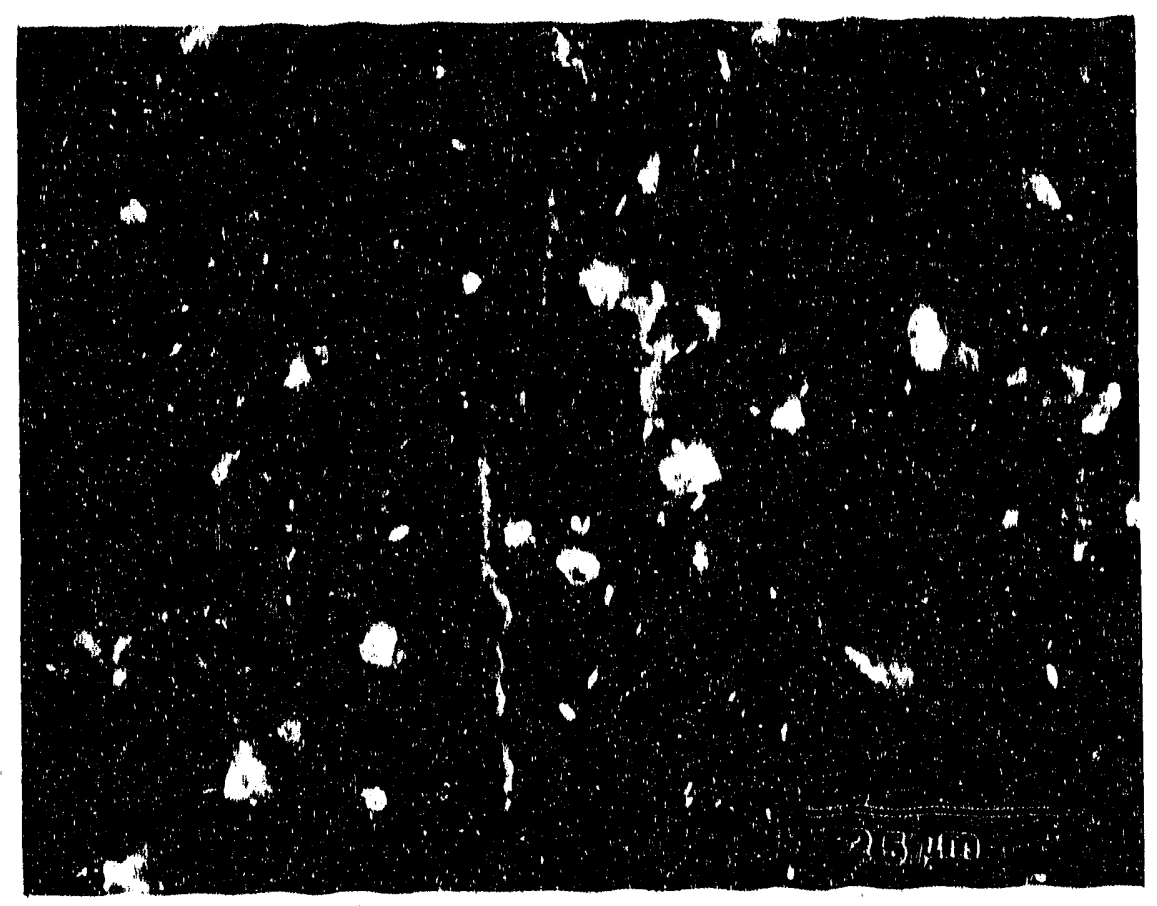

86172

(b)

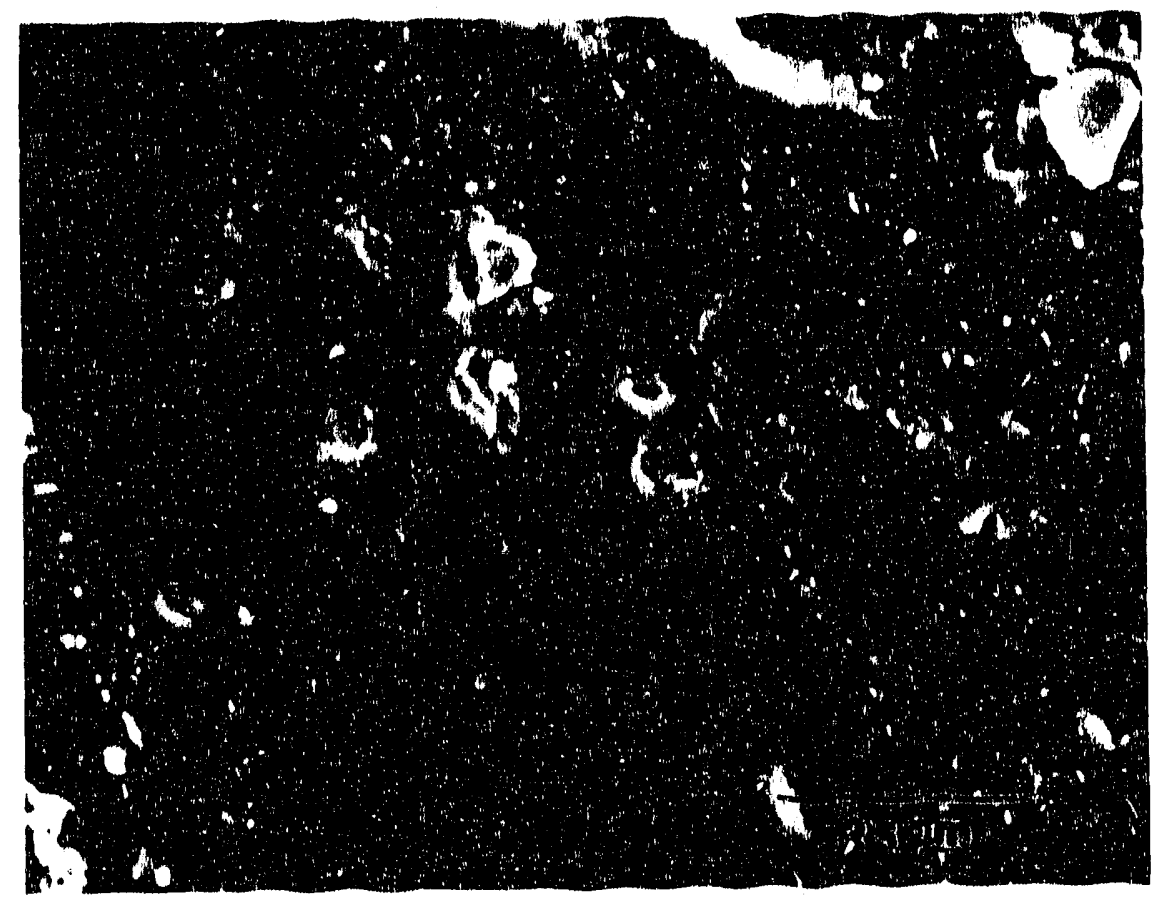

\section{7}

Figure 49. Fracture surfaces of a zirconia/NCI joint for a cracked disk specimen, with the crack at an angle of 20 degrees ( $\Psi=80.4$ degrees) with respect to the load line. (a) NCI side of the fracture surface. (b) Zirconia side of the fracture surface. 


\subsection{VAIIIDATION}

Validation of the JAD model was performed in two steps:

1. Preliminary validation, where the model predictions were compared with measured failure loads of notched and unnotehed bend bars.

2. Final validation using cracked disk specimens that contained 20 times more bonding area than bend bars, and comparing the predicted failure loads with measured failure loads.

The joint assessment diagrams for four representative specimens were presented carlicr. Calculations like those were conducted to predict the failure loads of cracked disk and bend bar specimens. Predictions of the strength of unnotched bend bars were performed only on zirconia/zirconia joints and they were based on the strength of the ceramic interlayer, appropriately modified to account for shiclding effects due to moduli mismatch.

Figure 50 provides comparisons of measured and predicted failure loads and is a plot of the data displayed in Table 12. The ligure includes data from zirconia/zirconia and zirconia/NCI joints, unnotched and notched bend bars, and cracked disk specimens loaded at various angles to the crack. Each data point is an average of several readings, particularly for the bend bar specimens. Thus, the plot contains an extensive database.

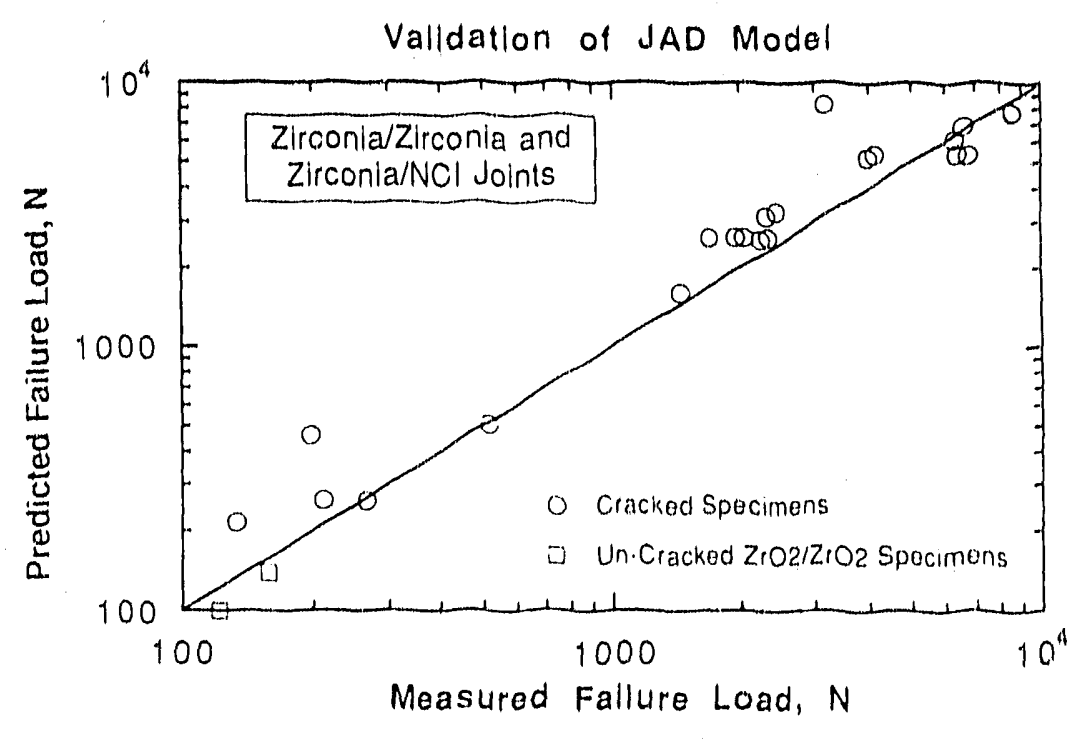

Figure 50. Results of validation analyses and testing with zirconia/zirconia and zirconia/NCI joints. The hend bars were used for preliminary validation and the disk specimens were used for final validation. 
In Table 12, the geometric data needed to calculate the failure loads are also displayed. Shown for each experiment, where applicable, are the joining temperature, the specimen width, $B$, and depth, $W$, the half-crack length, a, the radius of the disk. $R$, the angle between the loading points and the crack, $\phi$, the percent zirconia in the MASZ interlayer, and the calculated angle the assessment vector makes with the $\mathrm{P}_{\mathrm{r}}$-axis.

The comparisons between predicted and calculated failure loads are encouraging. The exceptions that appear are believed not to be due to errors in model calculations. Rather, we believe them to be the result of differences in failure path (for example, failure in the reaction zone of zirconia/zirconia joints fabricated at $1400 \mathrm{C}$ ) which could not be predicted a priori, and also degradation of the MASZ-67 interlayer in zirconia/zirconia joints. Note that the measured failure loads are consistently below the predicted failure loads for zirconia/zirconia joints fabricated using MASZ-67 interlayer. For these joints, if the results of preliminary validation are used to modify the $G_{c}$ of the interlayer, then better agreement is obtained in the final validation. The exceptions in Table 12 point out the need to evaluate the crack path as part of any preliminary investigations, and to include some form of the process parameters in the JAD model calculations.

Overall, the degree of correlation between predicted and measured failure loads of different joints and with different specimen geometries strengthens the validity of the joint design model. 


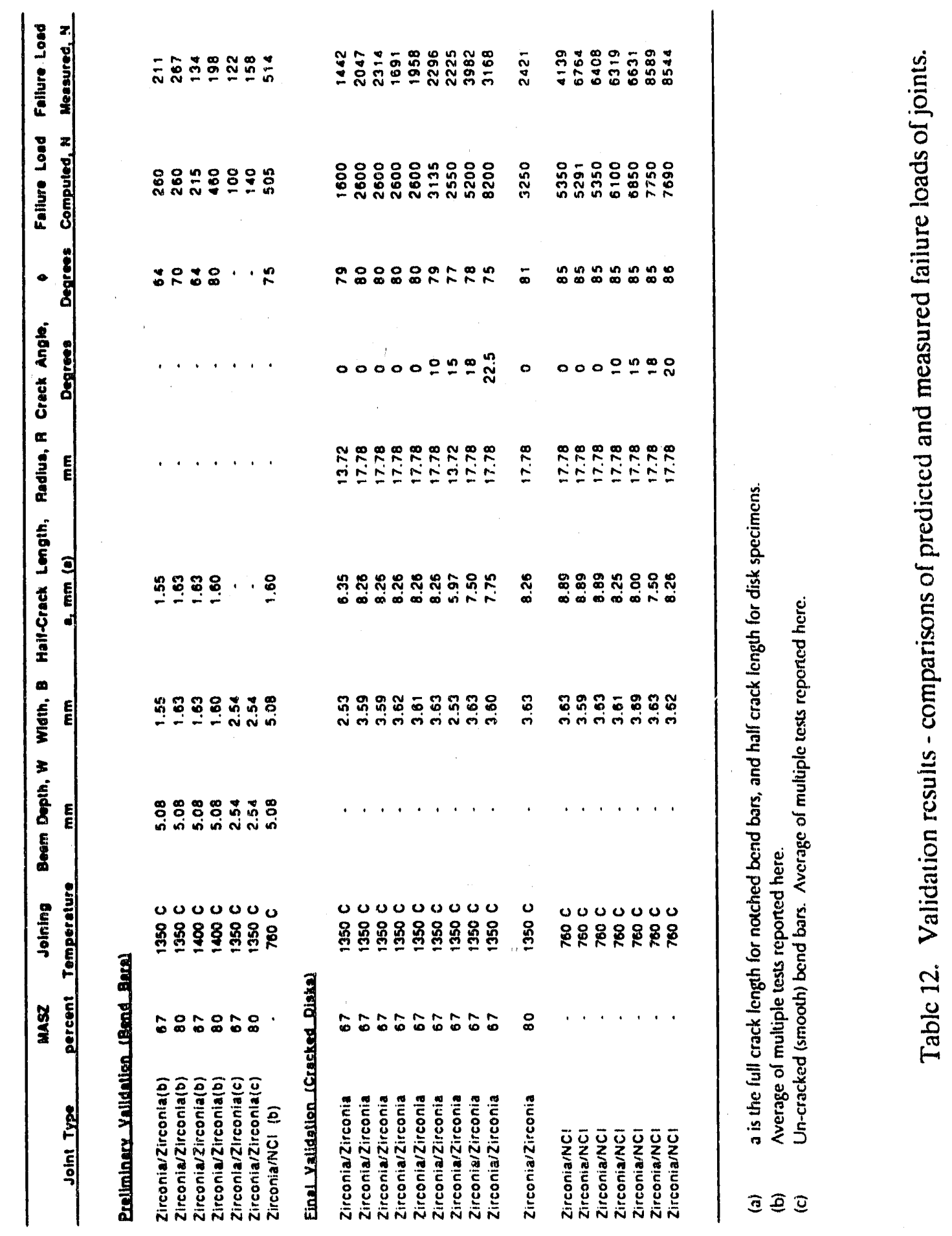




\subsection{CONCLUSIONS AND RECOMMENDATIONS}

The most significant accomplishment of the work described in the present report is the development of an engineering model applicable to design improvement and structural integrity assessment of ceramic/ceramic and metal/ceramic joints. A novel modeling approach was adopted which marries state-of-the-art knowledge in mechanics of material interfaces with engineering fracture mechanics concepts. This resulted in a model which provides a rational link between constituent material properties and oining process variables, and load carrying capacity of a joint. As shown in Figure 51, the JAD model can be used for (a) assessing a given joint's load carrying capacity and (b) designing improvement by systematically changing constituent properties and joining process variables.

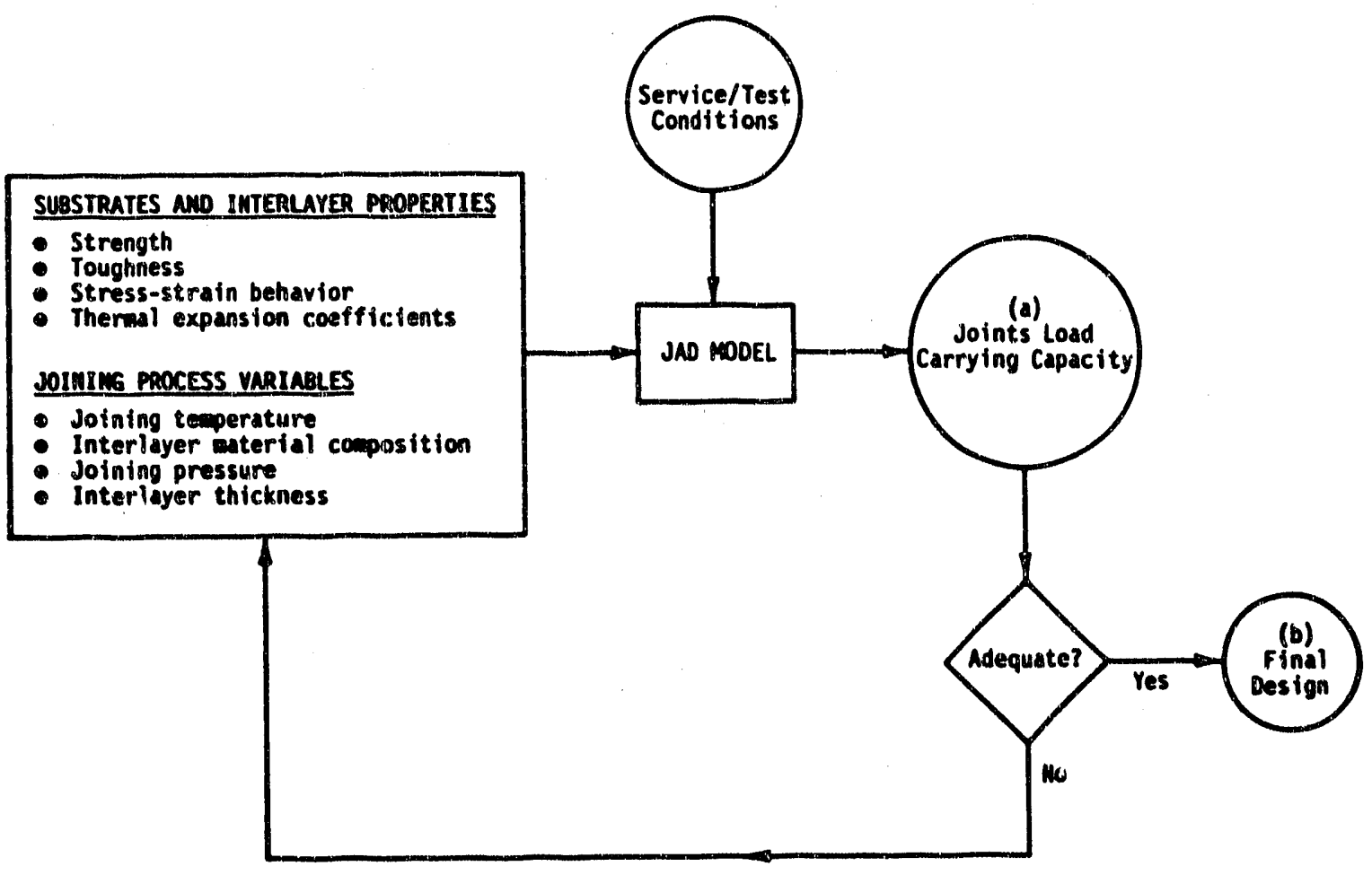

Figure 51. Role of JAD model: (A) structural integrity assessment and (b) joint design. 
Besides the analytical modeling effort, extensive laboratory experimentation was performed invulving fabrication and testing of zirconia/zirconia and $\mathrm{NCl} /$ zirconia joints. Remarkable success was achieved in fabricating zirconia/zirconia joints by a novel hot forging method. A versatile test specimen in the shape of a disk was introduced for characterizing joints. In addition to experiments on joints, which provided data for validating JAD model predictions, laboratory tests were performed to generate thermomechanical property data for each constituent material: zirconia, cast iron, braze and the interlayer material for zirconia/zirconia joints. These constituent property data were used as part of the input to the model.

The JAD model was validated by comparing predictions with the measured load carrying capacity of two significantly different joint configurations - the bend bar and the disk. The reasonably good agreement between predictions and measurements for both configurations indicates that the model is not geometry specific. Therefore, it would be useful in engineering applications involving other joint configurations.

Overall, the work represents a major step toward the development of an analytical design methodology for ceramic/ceramic and metal/ceramic joints. Nevertheless, the model does need additional validation and to be augmented to formulate a more generally useful joint design methodology.

Additional validation of the JAD model is most needed at elevated temperatures which are representative of engine operating conditions. Also, the model needs to be validated for crack sizes smaller than those used in the present work ani more representative of typical flaw sizes anticipated in as-fabricated joints. It would also be worthwhile to assess the accuracy of the JAD model predictions for joints between other metals and ceramic materials than those included in the present work. For this purpose, the recent experiments by GTE Laboratories, Inc. and the Norton Company involving silicon nitride and Inconel joints may provide the needed data.

In its current state of development, the JAD model is only applicable for joints subjected to quasi-static, monotonically increasing loads. In engine applications, a joint is more likely to experience conditions which may consist of load reversals as well as dwell periods giving rise to relatively low sustained loads. Thus, creep, fatigue and possible subcritical crack growth under such conditions may give rise to failure mechanisms not considered in the present work. We recommend that future research be directed toward augmenting the JAD model to include creep and fatigue considerations.

Finally, it is recommended that the JAD model should be formulated in a probabilistic analysis framework to more meaningfully address the issue of joint reliability. Anticipating at the beginning of the present work that a probabilistic design model would eventually be needed, the $J A D$ model was purposefully formulated in a manner such that its incorporation in a probabilistic analysis framework would be relatively straightforward. Because application of the JAD model does not require case by case finite element analyses, the model readily lends itself to practically useful probabilistic analyses which could be performed using a personal computer. In fact, the JAD model has already been implemented in a PC code which can be readily adapted for this purpose. 


\section{ACKNOWLEDGEMENTS}

The authors would like to acknowledge the support and contributions of a number of people who have been influential to the progress of this work.

Foremost, we would like to acknowledge Dr. M. Santella of Oak Ridge National Labjratories who was the technical monitor on the program. He gave encouragement, technical guidance, and laboratory assistance in using the active substrate brazing technique. We would also like to recognize Dr. D. R. Johnson of Oak Ridge National Laboratories whose clarification of the program goals was largely responsible for the final form of our joint assessment and design methodology.

Others who made substantial contributions to the work are Dr. Frank. S. Honecy of the Surface Science Branch, NASA Lewis Research Center, Cleveland, Ohio, who provided (gratis) the RF-sputtered titanium coatings on the zirconia billets used in the active substrate brazing work; Drs. K. Sorenson and R. Salzbrenner of Sandia National Laboratories who contributed the nodular cast iron; Professor C. F. Shih of Brown University for providing finite element solutions for zirconia/NCI disk specimens and for valuable advice on interface fracture mechanics; Dr. William Lee of Cambridge University, England, who assisted in the design and microstructural characterization of zirconia/nodular cast iron joints; Mr. Paul Held of Battelle who conducted the material characterization and validation experiments; Mr. Andrew Skidmore of Battelle who performed the microscopy; Mr. George Wall of Battelle who performed the high temperature validation experiments; Mr. Roger Beal of Battelle who joined the zirconia/zirconia disks by hot forging; Mr. John Hunt of the Edison Welding Institute who prepared many metallographic specimens; and Ms. Connie Keels of Battelle whose care and accuracy in manuscript preparation are evident in this report.

Research sponsored by the U.S. Department of Energy, Assistant Secretary for Conservation and Renewable Energy, Office of Transportation Technologies, as part of the Ceramic Technology Project of the Advanced Materials Development Program, under contract DE-AC05-84OR21400 with Martin Marietta Energy Systems, Inc. 


\section{REFERENCES}

1. C. F. Shih, V. Kumar, and M. D. German, "Studies on the Failure Assessment Diagram Using the Estimation Scheme and J-Controlled Crack Growth Approach", General Electric Company, TIS Report, (1981).

2. I. MIlne, et al, "Assessment of the Integrity of Structures Containing Defects", Central Electrify Generating Board Report, South Wester Region, CEGB, Bristol, U.K. (1978).

3. S. L. Swartz, B. S. Majumdar, and B. C. Mutsuddy, "Joining of Zirconia Ceramics", Proceedings of the 26th Automotive Technology Development Contractors Coordination Meeting, Dearborn, Michigan (1988).

4. S. L. Swartz, B. S. Majumdar, A. Skidmore, and B. C. Mutsuddy, "Joining of Zirconia Ceramics with a CaO-TiO $2-\mathrm{SiO}_{2}$ Interlayer”, Material Letters, Vol. 7, No. 11, (1989).

5. B. S. Majumdar, S. L. Swartz, and A. T. Hopper, "Zirconia-Zirconia Joints - Part I, Fabrication and Microstructural Characterization", Submitted to J. American Ceramic Society (1990).

6. B. S. Majumdar, J. Ahmad, and A. R. Rosenfield, “Zirconia-Zirconia Joints - Part II, Mechanical Characterization and Analysis, submitted to J. American Ceramic Society (1990).

7. C. Atkinson, R. E. Smelser, and J. Sanchez, "Combined Mode Fracture via the Cracked Brazilian Disk Test", International J. of Fracture, Vol. 18, No. 4, pp. 279-291 (1982).

8. A. G. Evans and J. W. Hutchinson, "Effects on Non-planarity of the Mixed Mode Fracture Resistance of Bimaterial Interfaces", to be published in Acta Metall. (1990). 
ORNL/SUb/87 -SB046/1

\section{INTERNAL DISTRIBUTION}

1-2. Central Research Library

3. Document Reference Section

4-5. Laboratory Records Department

6. Laboratory Records, ORNL RC

7. ORNL Patent Section

8-10. M\&C Records office

11. L. F. Allard, Jr.

12. L. D. Armstrong

13. P. F. Becher

14. R. F. Bernal

15. T. M. Besmann

16. P. J. Blau

17. A. Bleier

18. E. E. Bloom

19. K. W. Boling

20. R. A. Bradley

21. C. R. Brinkman

22. V. R. Bullington

23. R. S. Carlsmith

24. P. T. Carlson

25. G. M. Caton

26. S. J. Chang

27. R. H. Cooper, Jr.

28. B. L. Cox

29. D. F. Craig

30. S. A. David

31. J. H. DeVan

32. J. L. Ding

33. M. K. Ferber

34. F. M. Foust

35. W. Fulkerson

36. R. L. Graves

37. D. L. Greene

38. M. H. Harris

39. E. E. Hoffman

40. C. R. Hubbard

41. M. A. Janney
42. M. G. Jenkins

43. D. R. Johnson

44. W. F. Jones

45. D. Jos 7 in

46. R. R. Judkins

47. M. A. Karnitz

48. M. R. Kass

49-53. B. L. P. Keyes

54. H. D. Kinrey, Jr.

55. T. G. Kollie

56. K. C. Liu

57. E. L. Long, Jr.

58. W. D. Maniy

59. R. W. McCiung

60. D. J. McGuire

61. J. R. Merriman

62. D. L. Moses

63. T. A. Nolan

64. A. E. Pasto

65. J. L. Rich

66. C. R. Richmond

67. J M Robbins

68. M. L. Santella

69. A. C. Schaffhauser

70. S. Scott

71. G. M. Slaughter

72. E. J. Soderstrom

73. D. P. Stinton

74. R. W. Swindeman

75. V. J. Tennery

76. T. N. Tiegs

77. J. R. Weir, Jr.

78. B. H. West

79. F. W. Wiffen

80. S. G. Winslow

81. J. M. Wyrick

82. C. S. Yust 


\section{EXTERNAL DISTRIBUTION}

83. James H. Adair

University of Florida

Materials Science and

Engineering

317 MAE Bidg.

Gainesville, FL 32611-2066

84. Donald F. Adams

University of Wyoming

Mechanical Engineering

Department

P. 0. Box 3295

Laramie, WY 82071

85. Jalees Ahmad

AdTech Systems Research, Inc.

1342 North Fairfield Road

Dayton, OH 45432-2698

86. Yoshio Akimune

NISSAN Motor Co., Ltd.

Materials Research Laboratory

1 Natsushima-Cho

Yokosuke 237

JAPAN AIR MAIL

87. Mufit Akinc

Iowa State Univer:ity

322 Spedding Hall

Ames, IA 50011

88. IThan A. Aksay

University of Washington

Materials Science and Engineering

Department, FB-10

Seattle, WA 98195

89. R. G. Alexander

BASE

26 Malvern Close

Kettering Northants NN16 AJP

UNITED KJNGDOM AIR MAIL

90. Richard L. Allor

Ford Motor Company

Material Systems

Reliability Department.

20000 Rotunda Drive

P.0. Box 2053, Room S-2031

Dearborn, MI 48121-2053
91. Richard T. Alpaugh

U.S. Department of Energy

Advanced Propuision Division

CE-322, Forrestal Building

Washington, DC 20585

92. Joseph E. Amaral

Instron Corporation

Corporate Engineering Office

100 Royale Street

Canton, MA 02021

93. Edward M. Anderson

Aluminum Company of America

North American Industrial

Chemicals Division

P.0. Box 300

Bauxite, AR 72011

94. Norman C. Anderson

Ceradyne, Inc.

Ceramic-to-Metal Division

3169 Redhill Avenue

Costa Mesa, CA 92626

95. Don Anson

Battelle Collumbus Laboratories

Therma1 Power Systems

505 King Avenue

Columbus, OH 43201-2693

96. Thomas Arbanas

G.B.C. Materials Corporation

580 Monastery Drive

Latrobe, PA 15650-2698

97. Frank Armatis

3M Company

$3 M$ Center

Building 60-IN-01

St. PauT, MN 55144-1000

98. Everett B. Arnold

Detroit Diesel Corporation

Mechanical Systems Technology.

13400 Outer Drive, West.

Detroit, MI 48239-4001

99. Richard M. Arons

PA Consulting Group

279 Frinceton Road

Hightstown, MJ 08550 
100. Berti1 Aronsson

Sandvik $A B$

S-12680

Stockholm Lerkrogsvagen 19

SWEDEN AIR MAIL

101. Dennis Assanis University of Illinois

Department of Mechanical Engineering 1206 W. Green Street Urbana, IL 61801

102. William H. Atwell Dow Corning Corporation 3901 South Saginaw Road MS: 540

Midland, MI 48686-0995

103. V. S. Avva North Carolina A\&T State University

Department of Mechanical Engineering Greensboro, NC 27411

104. Patrick Badgley Adiabatics, Inc. 3385 Commerce Drive Columbus, IN 47201

105. Sunggi Baik Pohang Institute of Science \& Technology Department of Materials Science and Engineering P.O. Box 125

Pohang 790-600

KOREA AIR MAIL

105. John M. Bailey

Caterpillar, Inc.

Technical Center

Building L

P.0. Box 1875

Peoria, IL 61656-1875

107. Bob Baker

Ceradyne, Inc.

3169 Redhill Avenue

Costa Mesa, CA 92626
108. Frank Baker

Aluminum Company of America

Alcoa Technical Center

Alcoa Center, PA 15069

109. J. G. Baidoni

GTE Laboratories Inc.

40 Syivan Road

Waltham, MA 02254

110. Clifford P. Ballard

Allied-Signal, Inc.

Ceramics Program

P.0. Box 1021

Morristown, NJ 07962-1021

111. M. Balu

Amoco Performance Products Inc.

4500 McGinnis Ferry Road

Alpharetta, GA 30202

112. B. P. Bandyopadhyay

Toyohashi University of Technology

School of Production Systems Engineering

Tempaku-Cho Toyohashi 440

JAPAN AIR MAIL

113. P. M. Barnard

Ruston Gas Turbines Limited

Metallurgical Laboratory

P. 0. Box 1

Lincoln LN2 5DJ

ENGLAND AIR MAIL

114. Harold N. Barr

Hittman Corporation

9190 Red Branch Road

Columbia, MD 21045

115. Renald D. Bartoe

Vesuvius McDanel

510 Ninth Avenue

Box 560

Beaver Falls, PA 15010-Uะ:0

116. Donald M. Bartos

Dow Corning Corporation

Advanced Ceramics Program

Midl and, MI 48686-0995 
117. David L. Baty

Babcock \& Wilcox-LRC

P.0. Box 11165

Lynchburg, VA 24506-1165

118. Donald F. Baxter, Jr.

ASM Internetional

Advanced Materials and

Processes

Materials Park, OH 44073-0002

119. M. Brad Beardsiey

Caterpillar, Inc.

Advanced Materials Technology

Technical Center Bldg. E

P.O. Box 1875

Peorla, IL 61656-1875

120. Robert Beck

Teledyne CAE

Materials Engineering/Programs

1330 Laskey Road

P.0. Box 6971

Toledo, OH 43612

121. John C. Bel1

Shell Research Limited

Thornton Research Centre

P.0. Box 1

Chester, Chl 3SH

ENGLAND AIR MAIL

122. Albert H. Be11, III

General Motors Technical Center

30200 Mound Road

Engineering Building/W3 Turbine

Warren, MI AB090-9010

123. M. Bentele

Xamag, Inc.

259 Meiville Avenue

Fairfield, CT 06430

124. Larry D. Bentsen

BF Goodrich Company

R\&D Center

9921 Brecksville Road

Brecksville, OH 44141

125. Joseph C. Bentz

ENCERATEC

2525 Sandcrest Orive

Columbus, IN 47203
126. Louis Beregszazi

Defiance Precision Products

P.0. Drawer 428

Defiance, $\mathrm{OH} 43512$

127. Tom Bernecki

Northwestern Universit.y

BIRL

1801 Maple Avenue

Evanston, It 60201-3135

128. Charles F. Bersch

Institute for Defense Analyses

1801 North Beauregard Street

Alexandria, VA 22311

129. Ram Bhatt

NASA Lewis Research Center

21000 Brookpark Road

Clevel and, OH 44135

130. Deane I. Biehler

Caterpillar, Inc.

Engineering and Research Materials

Technical Center, Building $E$

P.0. Box 1875

Peoria, IL 61656-1875

131. John. W. Bjerhilie

Consolidated Natural Gas

Service Co., Inc.

Research Department

CNG Tower

Pittsburgh, PA 15222-3199

132. William D. Bjorndahl

TRW, Inc.

One Space Park

Building 01, Room 2040

Redondo Beach, CA 90278

133. Keith A. Blakely

Advanced Refractory Technologies, Inc.

699 Hertel Avenue

Buffa7o, NY 14207

134. Edward G. Blanchard

Netzsch Inc.

119 Pickering Way

Exton, PA 19341 
135. Keith Blandford

Boride Products, Inc.

2879 Aero Park Drive

Traverse City, MI 49684

136. Bruce Boardman

Deere and Company Technical

Center

3300 River Drive

Mol ine, IL. 61265

137. Russell Bockstedt

Hoechist Celanese Corporation

150 JFK Parkway

Short Hills, NJ 07078

138. M. Boehmer

DLR German Aerospace Research Establi ishment

Postfach 906058

D-5000 Koin 90

GERMANY AIR MAIL

139. Lawrence P. Boesch

EER Systems Corp.

1593 Spring Hi11 Road

Vienna, VA 22182-2239

140. Donald H. Boone

Boone \& Associates

2412 Cascade Drive

Wainut Creek, CA 94598-4313

141. Tom Booth

Allied-Signal Aerospace Company

AiResearch Los Angeles Division

2525 West 190th Street

Torrance, CA 90509-2960

142. Tibor Bornemisza

Sundstrand Power Systems

4400 Ruffin Road

San Diego, CA 92186-5757

143. J.A.M. Boulet

University of Tennessee

Department of Engineering Science and Mechanics 310 Perkins Hall

Knoxville, TN 37996-2030
144. H. Kent Bowen

Massachusetts Institute of Technology

77 Massachusetts Avenue

Room E40-434

Cambridge, MA 02139

145. Leslie J. Bowen

Materials Systems

53 Hillcrest-Road

Concord, MA 01742

146. Steven C. Boyce

Air Force Office of

Scientific Research

AFOSR/NA B1 dg. 410

Bolling AFB DC 20332-6448

147. Gary L. Boyd

CEC

400 Howell Avenue, No. 4

Warl and, WY 82401

148. Steve Bradley

UOP Research Center

50 East Algonquin Road

Des Plaines, IL 6D017-6187

149. Michael C. Brands

Cummins Engine Company, Inc.

P. 0. Box 3005

Mail Code 50179

Columbus, IN 47201

150. Raymond J. Bratton

Westinghouse Science and

Technology Center

1310 Beulah Road

Pittsburgh, PA 15235

151. John J. Brennan

United Technologies Corporation

Research Center

Silver Lane, MS: 24

East Hartford, CT 06108

152. Jeff D. Bright

Ceramatec, Inc.

2425 South 900 West

Salt Lake City, UT 84108 
153. Terrence K. Brog

Coors Ceramics Company

Corporate Development and

Technology

4545 McIntyre Street

Golden, CO 80403

154. Gunnar Broman

317 Fairlane Drive

Spartanburg, SC 29302

155. A1 Brown

High-Tech Materials Alert

P.0. Box 882

Dayton, NJ 08810

156. Jesse Brown

Virginia Polytechnic Institute and State University

Center for Advanced Ceramic Materials

Blacksburg, VA 24061-0256

157. Sherman D. Brown

University of Illinois

Materials Science and

Engineering Department

105 South Goodwin Avenue

204 Ceramics Building

Urbana, IL 61801

158. S. L. Bruner

Ceramatec, Inc.

2425 South 900 West

Salt Lake City, UT 84119

159. Adolfo Brusaferro

Keramont Corporation

4231 South Fremont Avenue

Tucson, AZ 85714

160. W. Bryzik

U.S. Army Tank Automotive Command

R\&D Center

Propulsion Systems Division

Warren, MI 48397-5000

161. S. T. Buljan

GTE Laboratories, Inc.

40 Sylvan Road

Wartham, MA 02254
162. S. J. Burden

GTE Valenite

1711 Thunderbird

Troy, MI 48084

163. Curt V. Burkland

AMERCOM, Inc.

8928 Fullbright Avenue

Chatsworth, CA 91311

164. B111 Bustamante

AMERCOM, Inc.

8928 Fuijbright Street

Chatsworth, CA 91311

165. Oral Buyukozturk

Massachusetts Institute of

Technology

77 Massachusetts Avenue

Room 1-280

Cambridge, MA 02139

166. David A. Calllet

Ethyl Corporation

451 Florida Street

Baton Rouge, LA 70801

167. Frederick J.Calnan

Heany Industries, Inc.

249 Briarwood Lane

P.0. Box 38

Scottsville, NY 14546

168. Roger Cannon

Rutgers University

Ceramics Department

P.0. Box 909

Piscataway, NJ 08855-0909

169. Scott Cannon

P.0. Box 567254

Atlanta, GA 30356

170. Harry W. Carpenter

19945 Acre Street

Northridge, CA 91324

171. David Carruthers

Kyocera Industrial Ceramics Company

P.0. Box 2279

Vancouver, WA 98668-2279 
172. Calvin H. Carter, Jr. Cree Research, Inc. 2810 Meridian Parkway Durham, NC 27713

173. J. David Casey

35 Atlant is Street West Roxbury, MA 02132

174. Jere G. Castor J. C. Enterprise 5078 North 83rd Street Scottsdale, AZ 85250

175. James D. Cawley Case Western Reserve University Materials Science and Engineering Department Cleveland, $\mathrm{OH} 44106$

176. Thomas C. Chadwick Den-Mat Corporation P.0. Box 1729 Santa Maria, CA 93456

177. Rona?d H. Chand Chand Kare Technical Ceramics 2 Coppage Drive Horcester, MA 01603

178. Robert E. Chaney EG\&G Idaho, Inc. Idaho National Engineering Laboratory

P.0. Box 1625

Idaho Falls, ID 83415-3525

179. Frank C. Chang

U.S. Army Materials Technology Laboratory AMTL-EM

405 Arsenal Street

Watertown, 02172

180. Robert M. Chapman

Allied-Signal Aerospace Company

1530 Wilson Boulevard, 10tb Floor

Ari ington, VA 22209
181. William Chapman

Willialls In:ternational Corporation 2280 Wist Maple Road Wail led Lake, MI 48390-0200

182. Charlie Chen LECO Corporation P.0. Box 211688 Augusta, GA 30917

183. Albert A. Chesnes U.S. Dlepartment of Energy Transpiortation Technologies CE-30, Forrestal Building, 6B-(1)94 Vashington, DC 20585

184. Kaiyin Chia

Carbolrundum Company

P.O. 1830x 832

Niagara Falls, NY 14302

185. Frank Childs

EG\&G Idaho, Inc.

Idaho National Engineering Laboratory

P.0. Box 1625

Idaho Falls, ID 83415-3527

186. William J. Chmura

Torrington Company

59 Field Street

Torrington, CT 06790-4942

187. Tsu-Wei Chou

University of Delaware

Center for Composite Materials

201 Spencer Laboratory

Newark, DE 19716

188. R. J. Christopher

Ricardo Consulting Engineers

Bridge Works

Shoreham-By-Sea West Sussex BN43 5FG

ENGLAND AIR MAIL

189. Joel P. Clark

Massachusetts Institute of Technology

Roism 8-409

Canbridge, MA 02139 
190. Giorgio Clarotti

Commission of the European Communities

DGXII-C3, $11075,1-53$; 200 Rue de la Loi

B-1049 Brussels BELGIUM AIR MAIL

191. W. J. Clegg

ICI Advanced Materials

P.0. Box 11

The Heath, Runcorn Cheshire

WA7 4QE

ENGLAND

AIR MAIL

192. Joseph Cleveland

GTE Products Corporation

Hawes Street

Towanda, PA 18848-0504

193. Gloria M. Collins

ASTM

1916 Race Street

Philadelphia, PA 19103

194. William C. Connors

Sundstrand Aviation Operations

Materials Science and

Engineering Department

4747 Harrison Avenue

P.0. Box 7002

Rockford, IL 61125-7002

195. John A. Coppola

Carborundum Company

P.0. Box 156

Niagara Falls, NY 14302

196. Normand D. Corbin

Norton Company

Advanced Ceramics

Goddard Road

Northboro, MA 01532-1545

197. Douglas Corey

Allied-Signal Aerospace

Company

2525 West 190th Street

MS: T52

Torrance, CA 90504-6099
198. Keith P. Costello

Chand/Kare Technical Ceramics

2 Coppage Drive

Worcester, MA 01603-1252

199. Ed L. Courtright

Pacific Northwest Laboratory

MS:K3-59

Richland, WA 99352

200. Anna Cox

Mitchell Market Reports

P.0. Box 23

Monmouth Gwent NP5 4YG

UNITED KINGDOM AIR MAIL

201. Thomas Coyle

Unocal Corporation

Unocal Science \& Technology Division

376 South Valencia Avenue

Brea, CA 92621

202. Art Cozens

Instron Corporation

3414 Snowden Avenue

Long Beach, CA 90808

203. Robert C. Craft

American Ceramic Society, Inc.

757 Brooksedge Plaza Drive Westerville, $\mathrm{OH} 43081$

204. Mark Crawford

New Technology Week

4604 Monterey Drive

Annandale, VA 22003

205. Richard A. Cree

Markets \& Products, Inc.

P.0. Box 14328

Col umbus, OH 43214-0328

206. Les Crittenden

Vesuvius McDanel

Box 560

Beaver Falls, PA 15010 
207. William J. Croft U.S. Army Materials Technology Laboratory 405 Arsenal Street Watertown, MA $\mathrm{C} 2172$

208. M. J. Cronin Mechanical Technology, Inc. 968 Albany-Shaker Road Latham, NY 12110

209. Gary M. Crosbie Ford Motor Company 1430 Culver Avenue S-2079, SÃL Building Dearborn, MI 48121-4036

210. Floyd W. Crouse, Jr. U.S. Department of Energy Morgantown Energy Technology Center Collins Ferry Road P.0. Box 880

Morgantown, Biv 26505

211. John Cuccio

Allied-Signal Aerospace Company

Garrett Auxiliary Power Division

P.O. Box 5227, MS: $1302-2 Q$

Phoenix, AZ 85010

212. Raymond Cutler Ceramatec, Inc. 2425 South 900 West

Salt Lake City, UT 84119

213. Charles D'Angelo GTE Laboratories, Inc. 40 Sylvan Road Waltham, MA 02154

214. Stephen C. Danforth Rutgers University Ceramic Engineering Department P.0. Box 909

Piscataway, NJ 08855-0909
215. Sankar Das Gupta Electrofuel Manufacturing Co., Ltd. 9 Hanna Avenue Toronto Ontario MGK-1W8 CANADA AIR MAIL

216. Charles Davis Sverdrup Technology, Inc., MSFC

620 Discovery Drive Huntsville, AL 35806

217. Frank Davis

Allied Signal Aerospace Co. 7550 Lucerne Dr. , \#203 Middleburg Heights, OH 44130

218. Robert F. Davis North Carolina State University Materials Engineering Department 229 Riddick Laboratory P.O. Box 7907

Raleigh, NC 27695

219. Thomas DeAngel is Carborundum Company Niagara Falls R\&D Center P.0. Box 832 Niagara Falls, NY 14302

220. George DeBell Ford Motor Company Material Systems Reliability Department 20000 Rotunda Drive P.0. Box 2053, Room S-2023 Dearborn, MI 48121-2053

221. Michael Deluca AMP-AKZO West Lane Aquebogue, NY 11931

222. Geraid L. Depoorter Colorado School of Mines Metallurgical and Materials Engineering Department Golden, $C O 80401$ 
223. J. F. DeRidder

Omni Electro Motive, Inc.,

12 Seely Hill Road

Newfield, NY 14867

224. Nick C. Dellow

Materials Technology

Publications

40 Sotheron Road

Watford Herts WDI 2QA

UNITED KINGDOM AIR MAIL

225. L. R. Dharani

University of Missouri-Rolla

224 M.E.

Rolla, MO 65401

226. Douglas A. Dickerson

Union Carbide Specialty

Powders

1555 Main Street

Indianapolis, IN 46224

227. John Dodsworth

Vesuvius Research \& Devel opment

Technical Ceramics Group

Box 560

Beaver Falls, PA 15010

228. B. Dogan

Institut fur Werkstofforschung

GKSS-Forschungszentrum

Geesthacht GmbH

Max-Planck-Strasse

D-2054 Geesthacht

GERMANY AIR MAIL

229. Jean-Marie Drapier

FN Moteurs S.A.

Material and Processing

B-4041 Milmort (Hersta1)

BELGIUM AIR MAIL

230. Kenneth C. Dreitlein

United Technologies

Research Center

Silver Lane

East Hartford, CT 06108
231. Robin A.L. Drew

McGill University

Department of Mining and

Metallurgical Engineering

3450 University Street

Montreal Quebec H3A 2A7

CANADA AIR MAIL

232. Winston H. Duckworth

BCL

Columbus Division

$505 \mathrm{King}$ Avenue

Columbus, $\mathrm{OH} \mathrm{43201-2693}$

233. Edmund M. Dunn

Texel Company

6 Third Street

Lexington, MA 02173

234. Bill Durako

Sundstrand Aviation Operations

Department 789-6

4747 Harrison Avenue

P.0. Box 7002

Rockford, IL 61125-7002

235. Ernest J. Duwell

212 Elm Street.

Hudson, WI 54016

236. Chuck J. Dziedzic

Coors Ceramics Company

Structural Products Group

17750 West 32nd Avenue

Golden, CO 80401

237. Robert J. Eagan

Sandia National Laboratories

Engimeered Materials \& Processes Center

Org 1700

P.0. Box 5800

Aibuquerque, NM 87185-5800

238. Jeffrey Eagleson

Lanxide Corporat in

1001 Connecticut avenue, N.W.

Was'sington, DC 20036 
239. Harry E. Eaton

United Technologies Corporation

Research Center

Silver Lane

East Hartford, CT 06108

240. Harvill C. Eaton

Louisiana State University

Office of Research and Economic Development

240 Thomas Boyd Hall

Baton Rouge, LA 70803

241. Christopher A. Ebel

Carborundum Company

Technology Division

P.0. Box 337

Niagara Falls, NY 14302

242. J. J. Eberhardt

U.S. Department of Energy

Office of Transportation

Materials

CE-34, Forrestal Building

Washington, DC 20585

243. Jim Edler

Eaton Corporation

26201 Northwestern Highway

P.0. Box 766

Southfield, MI 48037

244. William A. Ellingson

Argonne National Laboratory

Materials Science Technology

Division

9700 South Cass Avenue

Argonne, IL 60439

245. William S. Ellis

Machined Ceramics

629 N. Graham St.

N. Industrial Park

Bowling Green, KY 42101

246. Glen B. Engle

Nuclear \& Aerospace Materials Corporation

16716 Martincoit Road

Poway, CA 92064
247. Jeff Epstein

Ceramic Technologies, Inc.

2107 Jamara Lane

Houston, TX 77077

248. Kenneth A. Epstein

Dow Chemical U.S.A.

Ceramics and Advanced

Materials

800 Building

Midl and, MI 48667

249. Art Erdemir

Argonne National Laboratory

Materials and Components

Technology Division

9700 South Cass Avenue

Argonne, IL 60439

250. E. M. Erwin

Lubrizol Corporation

1819 East 225th Street

Euclid, OH 44117

251. Kenji Esaki

Toyota Technical Center

U.S.A., Inc.

2000 Town Center, Suite 500

Southfield, MI 48075

252. Jose L. Escal ante

Anglo-Mex-Tech. Inc.

3923 N.W. 24th Street

Miami, FL 33142

253. John N. Eustis

U.S. Department of Energy

Industrial Energy Efficiency

Division

CE-221, Forrestal Building

Washington, DC 20585

254. Robert C. Evans

NASA Lewis Research Center

Terrestrial Propulsion Office

21000 Brookpark Road, MS:86-6

Cleveland, $\mathrm{OH} 44135$

255. W. L. Everitt

Kyocera International, Inc.

8611 Balboa Avenue

San Diego, CA 92123 
256. Gordon Q. Evison 332 South Michigan Avenue Suite 1730

Chicago, IL 60604

257. John W. Fairbanks

U.S. Department of Energy Advanced Propulsion Division CE-322, Forrestal Building Washington, DC 20585

258. Tim Fawcett

Dow Chemical Company Central Research, Advanced Ceramics Laboratory 1776 Building Midland, MI 48674

259. Robert W. Fawley Sundstrand Power Systems Division of Sundstrand Corporation 4400 Ruffin Road P.0. Box 85757 San Diego, CA 92186-5757

260. John J. Fedorchak GTE Products Corporation Hawes Street Towanda, PA 18848-0504

261. Jeff T. Fenton Vista Chemical Company 900 Threadneedle Houston, TX 77079

262. Larry Ferrell Babcock \& Wilcox 01d Forest Road Lynchburg, VA 24505

263. Raymond R. Fessler BIRL

Industrial Research Lab 1801 Maple Avenue Evanston, IL 60201

264. Michelle Finch

E. I. DuPont de Nemours \& Company, Inc. Experimental Station Information Center E302/301 Wilmington, DE 19898

265. Arthur D. Fine United Technologies Corporation Pratt \& Whitney Aircraft 400. Main Street MS: $163-10$

East Hartford, CT 06108

266. Ross F. Firestone Ross Firestone Company 188 Mary Street Winnetka, IL 60093-1520

267. Sharon L. Fletcher Arthur D. Little, Inc. 15 Acorn Park Cambridge, MA 02140-2390

268. Thomas F. Foltz Textron Specialty Materials 2 Industrial Avenue Lowe 11, MA 01851

269. Renee G. Ford Materials and Processing Report P.0. Box 72 Harrison, NY 10528

270. John Formica Supermaterials 2020 Lakeside Avenue Cleveland, $\mathrm{OH} 44114$

271. Jennifer M. Fox Dyson Refractories Limited R\&D Laboratory

Owler Bar

Sheffield S17 3BJ

UNITED KINGDOM

AIR MAIL

272. Edwin Frame

Southwest Research Institute

Division 2

P.0. Drawer 28510

San Antonio, TX 78284

273. Armanet Francois

French Scientific Mission 4101 Reservoir Road, N.W. Washington DC 20007-2176

274. R. G. Frank Technology Assessment Group 10793 Bentley Pass Lane Lovel and, $\mathrm{OH} 45140$ 
275. David J. Franus

Forecast International

22 Commerce Road

Newtown, CT 06470

276. Marc R. Freedman

NASA Lewis Research Center

21000 Brookpark Road

MS: 49-3

Clevel and, OH 44135

277. Douglas Freitag

LTV Missiles Division

P.0. Box 650003

MS:WT-21

Dallas, TX 75265

278. Brian R.T. Frost

Argonne National Laboratory

9700 South Cass Avenue

Building 900

Argonne, IL 60439

279. Lawrence R. Frost

Instron Corporation

100 Royall Street

Canton, MA 02021

280. George A. Fryburg

Norton/TRW Ceramics

7A-4 Raymond Avenue

Salem, NH 03079

281. Xiren Fu

Shanghai Institute of Ceramics

Chinese Academy of Sciences

1295 Ding-xi Road

Shanghai 200050

CHINA AIR MAIL

282. John Gahimer

P.0. Box 1302

Dublin, OH 43017

283. J. P. Gallagher

University of Dayton Research Institute

300 College Park, JPC-250

Dayton, OH 45469-0120
284. Tom Garritano

University of Tennessee

Science Alliance

101 South College

Knoxville, TN 37996-1328

285. Joy A. Garwood

Norton Company

Advanced Ceramics

Goddard Road

Northboro, MA 01532-1545

286. H. Maury Gatewood

Reynolds Metals Company Corporate RAD

Fourth and Canal Streets

P.0. BoX 27003

Richmond, VA 23261

287. L. J. Gauckler

ETH-Zurich

Sonneggstrasse 5

CH-8092 Zurich 8092

SWITZERLAND

AIR MAIL

288. Peter A. Gaydos

Battelle Columbus Laboratories

$505 \mathrm{King}$ Avenue

Columbus, $\mathrm{OH} 43201$

289. George E. Gazza

U.S. Army Materials

Technology Laboratory

Ceramics Research Division

405 Arsenal Street

Watertown, MA 02172-0001

290. D. Gerster

CEA-DCOM

33 Rue De La Federation

Paris 75015

FRANCE AIR MAIL

291. John Ghinazzi

Coors Technical Ceramics Company

1100 Commerce Park Drive

Oak Ridge, TN 37830 
292. Robert Giddings

General Electric Company

Research Laboratory

P.0. Box 8

Schenectady, NY 12301

293. A. M. Glaeser

University of California

Materials Science and Mineral Engineering

Lawrence Berkeley Laboratory

Hearst Mining Building

Berkeley, CA 94720

294. Paul Glance

Concept Analysis

R\&D

950 Stephenson Highway

Dupont Automotive Development Building

Troy, MI 48007-7013

295. Joseph W. Glatz

Naval Air Propulsion Center

Systems Engineering Division

P.0. Box 7176, PE24

Trenton, NJ 08628

296. W. M. Goldberger

Superior Graphite Company

R\&D

2175 East Broad Street

Columbus, $\mathrm{OH} 43209$

297. Allan E. Goldman

U.S. Graphite, Inc.

907 West Outer Drive

Oak Ridge, TN 37830

298. Stephen T. Gonczy

Allied Signal Research

P.0. Box 5016

Des Plaines, IL 60017

299. Jeffrey M. Gonzales GTE Products Corporation

Hawes Street

Towanda, PA 18848-0504

300. Robert J. Gottschall

U.S. Department of Energy

ER-131, MS: G-236

Washington, DC 20545
301. Earl Graham

Cleveland State University

Department of Chemical Engineering

Euclid Avenue at

East 24th Street

Cleveland, $\mathrm{OH} 44115$

302. William A. Graham

Lanxide Carporation

P.0. BoX 6077

Newark, DE 19714-6077

303. Robert E. Green, Jr. Johns Hopkins University

Materials Science and Engineering Department

Baltimore, MD 21218

304. Lance Groseclose

General Motors Corporation

Allison Gas Turbine Division

P.O. Box 420, MS:W-5

Indianapolis, IN 46206

305. Mark F. Gruninger

Union Carbide Corporation

Specialty Powder Business

1555 Main Street

Indlanapol is, IN 46224

306. Ernst Guge 1

Cremer Forschungsinstitut GmbH\&CO.KG

Oesiauer Strasse 35

D-8633 Roedental 8633

GERMANY

AIR MAIL.

307. Donald L. Guile

Corning Glass Works

SP-DV-1-9

Corning, NY 14831

308. Bimleshwar P. Gupta

Solar Energy Research Institute

Mechanical and Industrial Technology Division

1617 Cole Boulevard

Golden, CO 80401 
309. John P. Gyekenyes i

NASA Lewis Research Center

21000 Brookpark Road, MS:6-1

Clevel and, OH 44135

310. Nabil S. Hakim

Detroit Diesel Corporation

13400 West Outer Drive

Detroit, MI 48239

311. Philip J. Haley

General Motors Corporation

Vehicular Engineering

P.0. Box 420, MS:T12A

Indianapolis, IN 46236

312. Judith Hall

Fiber Materials, Inc.

Biddeford Industrial Park

5 Morin Street

Biddeford, ME 04005

313. Y. Harada

IIT Research Institute

Nometalific Materials and Composites

10 West 35th Street

Chicago, IL 60616

314. R. A. Harmon

25 Schalren Drive

Latham, MY 12110

315. Amy Harmon-Barrett

Martin Marietta Laboratories

1450 South Rolling Road

Baltimore, MD 21227

316. Norman H. Harris

Hughes Atrcraft Company

P.0. Box 800520

Saugus, CA 91380-0520

317. Alan Hart

Dow Chemical Company

Advanced Ceramics Laboratory 1776 Building

Midl and, MI 48674
318. Pat E. Hart

Battelle Pacific Northwest Laboratories

Ceramics and Polymers

Development Section

P.0. Box 999

Richland, WA 99352

319. Stephen D. Hartline

Norton Company

Advanced Ceramics

Goddard Road

Northboro, MA 01532-1545

320. Michael H. Haselkorn

Caterpillar, Inc.

Engineering Research Materials

Technical Center, Building E

P.O. Box 1875

Peoria, IL 61656-1875

321. N. B. Havewala

Corning, Inc.

SP-PR-11

Corning, NY 14831

322. John Haygarth

Teledyne WAA Chang Albany

P.O. Box 460

Aibany, OR 97321

323. Norman L. Hecht

University of Dayton Research Institute 300 College Park

Dayton, OH 45469-0172

324. Peter W. Heitman

General Motors Corporation

Allison Gas Turbine Division

P.O. Box 420, MS: W-5

Indianapolis, IN 46206-0420

325. Robert W. Hendricks

Virginia Polytechnic Institute and State University

Materials Engineering Department

210 Holden Hall

B1 acksburg, VA 24061-0237 
326. Hynne Henley

Hertel Cutting Technologies, Inc. 1000 Clearview Court

Oak Ridge, TN 37830

327. Thomis L. Henson

GTE Products Corporation

Chemical \& Metallurgical

Division

Hawes Street

Towanda, PA 18848

328. Thomas P. Herbel1

MASA Lewis Research Center

21000 Brookpark Road

MS: 49-3

Cleveland, $\mathrm{OH} 44135$

329. Marlene Heroux

Rolls-Royce, Inc.

2849 Paces Ferry Road

Suite 450

At 1anta, GA 30339-3769

330. Robert L. Hershey

Science Management Corporation

1255 New Hampshire Ave., N.W.

Sujte 1033

Washington, DC 20036

331. Hendrik Heystek

Bureau of Mines

Tuscaloosa Research Center

P.0. Box L

University, AL 35486

332. Wallace C. Higgins

Norwal Uni imited

P.0. Box 1258

Alfred, NY 14802

333. Robert V. Hillery

GE Aircraft Engines

One Neumann Way, M.D. H85

Cincinnati, $\mathrm{OH} 45215$

334. Arthur Hindman

Instron Corporation

100 Royall Street

Canton, MA 02021
335. Jon Hines

American Ceramic Society, Inc.

757 Brooks dge Plaza Drive

Westervilla, $\mathrm{OH}$ 43081-6136

336. Hans Erich Hintermann

CSEM

Materials and Micromechanics Division

Rue Breguet- 2

Neuchatel 2000

SWITZERLAND AIR MAIL

337. Shinichi Hirano

Mazda IR\&D of North

America, Inc.

1203 Woodridge Avenue

Ann Arb Jr, MI 48105

338. Tommy Hiraoka

NGK Lockt', Inc.

1000 Town Center

Southfie]d, MI 48075

339. John M. Hobday

U.S. Department of Energy

Morgantown Energy Technology Center

Collins Ferry Road

P.0. Box 880

Morgantown, WV 26507

340. Greg Hoenes

Vista Chemical Company

900 Threadneedle

P.O. Box 19029

Houston, TX 77079-2990

341. Clarence Hoenig

Lawrence Livermore National Laboratory

P.0. Box 808, Mail Code L-369

Livermore, CA 94550

342. Thomas Hollstein

Fraunhofer-Institut fur Werkstoffmechanik IWM

Wohlerstrabe 11

D-7800 Freiburg

GERMANY AIR MAIL 
343. Richard Holt

National Research Council

of Canada

Structures and Materials Laboratory

Ottawa Ontario K1A OR6

CANADA AIR MAIL

344. Joseph Homeny

University of Illinois

Department of Materials Science and Engineering

105 South Goodwin Avenue

Ceramics Building

Urbana, IL 61801

345. A. T. Hopper

Battelle Columbus Laboratories

Metals and Ceramics Department

505 King Avenue

Columbus, OH 43201-2693

346. Michael Horgan

Materials Engineering Magazine

1100 Superior Avenue

Cleveland, OH 44114

347. Woodie Howe

Coors Technical Ceramics

Company

1100 Commerce Park Drive

Oak Ridge, TN 37830

348. Stephen M. Hsu

National Institute of

Standards and Technology

Gaithersburg, MD 20899

349. Hann S. Huang

Argonne National Laboratory

9700 South Cass Avenue

Argonne, IL 60439-4815

350. Gene Huber

Precision Ferrites : Ceramics

5576 Corporate Drive

Cypress, CA 90630

351. M. L. Huckabee

GTE Laboratories, Inc.

40 Sylvan Road

Waltham, MA 02254
352. Harold A. Huckins

Princeton Advanced

Technology, Inc.

56 Finley Road

Princeton, NJ 0.8540

353. Fred R. Huettic

Advanced Magnetics, Inc.

45 Corey Lane

Mendham, N- 07945

354. Bill Huffiman

Zircar

110 North Main Street

Florida, NY 10921

355. Brian K. Humphrey

Lubrizol Petroleum

Chemicals Co.

3000 Town Center, Suite 1340

Southfield, MI 48075-1201

356. Robert M. Humrick

Dylon Ceramic Technologies

3100 Edgehill Road

Clevel and Heights, $\mathrm{OH} 44118$

357. Lorretta Inglehart

National Science Foundation

Division of Materials Research

1800 "G" Street, N.W.,

Room 408

Washington, DC 20550

358. Michael S. Inoue

Kyocera International, Inc.

KII Library

8611 Balboa Avenue

San Diego, CA 92123-1580

359. Osama Jadaan

University of WisconsinPlatteville

General Engineering Division

1 University Plaza

Platteville, WI 53818

360. Curtis A. Johnson

General Electric Company Corporate R\&D

Room MB-187

P.0. Box 8

Schenectady, NY 12301 
361. Sylvia Johnson

SRI International

333 Ravenswood Avenue

Menlo Park, CA 94025

362. Thomas A. Johnson

Lanxide Corporation

1300 Marrows Road

P.0. Box 6077

Newark, DE 19714-6077

363. W. S. Johnson

Indiana University

One City Centre, Suite 200

Bloomington, IN 47405

364. Jill E. Jonkouski

U.S. Department of Energy

9800 South Cass Avenue

Argonne, IL 60439-4899

365. L. A. Joo

Great Lakes Research Corporation

P.0. Box 1031

Ei izabethton, TN 37643

366. A. D. Joseph

SPX Corporation

700 Terrace Point

Muskegon, MI 49443

367. Adam Jostsons

Australian Nuclear Science \& Technology Organization

Lucas Heights Research Laboratories

New Illawarra Road

Lucas Heights New South Wales

AUSTRALIA AIR MAIL

368. Matthew $K$. Juneau

Ethyl Corporation

451 Florida Street

Baton Rouge, LA 70801

369. Hartmut Kainer

Didier-Werke $A G$

Anlagentechnik Wiesbaden

Abraham-Lincoln-Str. 16

D-62 Wiesbaden

GERMANY AIR MAIL
370. Tom Kalamasz

Norton/TRW Ceramics

7A-4 Raymond Avenue

Salem, NH 03079

371. Lyle R. Kallenbach

Phillips Petroleum Company

RED

Mail Drop:123AL

Bartlesvilie, OK 74004

372. Nick Kamiya

Kyocera Industrial Ceramics Corporation

2700 River Road

Des Plaines, IL 60018

373. Roy Kamo

Adiabatics, Inc.

3385 Commerce Park Drive

Columbus, IN 47201

374. S. Kaing

GTE Laboratories, Inc.

40 Sy'lvan Road

Waltham, MA 02254

375. Chih-Chun Kan

Industrial Technology Research Institute

Materials Research

Laboratories

195 Chung-Hsing Road, Sec. 4

Chutung Hsinchu 31015 R.O.C.

TAIWAN AIR MAIL

376. Keith R. Karasek

All led-Signal, Inc.

Engineered Materials Research Center

50 East Algonquin Road

P.0. BoX 5016

Des Plaines, IL 60017-5016

377. Robert E. Kasse1

Ceradyne, Inc.

3169 Redhill Avenue

Costa Mesa, CA 92626

378. All an Katz

Wright Laboratory

Metals and Ceramics Division WL/MLLM

Wright-Patterson AFB, OH 45433 
379. R. Nathan Katz

Worcester Folytechnic Inst tute

Dept. of Mechanical Engineering

100 Institute Road

Worcester, MA 01609

380. Ted Kawaguchi

Tokai Carbon America, Inc.

375 Park Avenue, Sulte 3802

New York, NY 10152

381. Noritsugu Kawashima

TOSHIBA Corporation

Mechanical Engineering Laboratory

4-1 Ukishima-Cho

Kawasaki-Ku Kawasaki 210

JAPAN AIR MAIL

382. Lisa Kempfer

Penton Publishing

Materials Engineering

1100 Superior Avenue

Cleveland, $\mathrm{OH}$ 44114-2543

383. Frederick L. Kennard, III

General Motors Corporation

AC Rochester

Department 32-24, EB

1300 North Dort Highway

Flint, MI 48556

384. David 0. Kennedy

Lester B. Knight Cast Metals Inc.

549 West Randolph Street

Chicago, IL 60661

385. George Keros

Photon Physics

3175 Penobscot Building

Detroit, MI 48226

386. Pramod K. Khandelwal

General Motors Corporation

Allison Gas Turbine Division

P.O. Box 420, MS:W05

Indianapo Tis, IN 46206
387. Jim R. Kidwel1

Allied-Signal Aerospace Company

Garrett Auxiliary Power Division

P. 0. Box 5227

Phoenix, AZ 85010

388. Han J. Kim

GTE Laboratortes, Inc.

40 Sylvan Road

Wal tham, MA 02254

389. Shin Kim

Korea Institute of Machinery \& Metals

66 Sangnam-dong, Changwon

Kyungnam 641-010

KOREA AIR MAIL

390. W. C. King

Mack Truck, Z-41

1999 Pennsylvania Avenue

Hagerstown, MD 21740

391. Carol Kirkpatrick

MSE, Inc.

CDIF Technical Library

P.0. Box 3767

Butte, MT 59702

392. Tony Kirn

Caterpillar, Inc.

Defense Products Department, JB7

Peoria, IL 61629

393. James D. Kiser

NASA Lewis Research Center

21000 Brookpark Road, MS:49-3

Clevel and, $\mathrm{OH} 44135$

394. Max Klein

Gas Research Institute

Thermodynamics

8600 West Bryn Mawr Avenue

Chicago, IL 60631

395. Richard N. Kleiner

Coors Ceramics Company

4545 McIntyre Street

Golden, CO 80403 
396. Stanley J. K1 ima

NASA Lewis Research Center 21000 Brookpark Road

MS: $6-1$

Clevel and, $\mathrm{OH} 44135$

397. Chris E. Knapp

Norton Advanced Ceramics of Canada Ltd.

8001 Daly Street

Niagara Falls, Ontario L2G 6S2 CANADA AIR MAIL

398. Albert S. Kobayashi University of Washington Mechanical Engineering Department

MS: FU10

Seattle, WA 98195

399. Shigeki Kobayashi

Toyota Central Research Labs, Inc.

Nagakute Aichi 480-11

JAPAN AIR MAIL

400. Richard A. Kole

Z-Tech Corporation

8 Dow Road

BOW, NH 03304

401. E. Kostiner

University of Connecticut

Chemistry Department, U-60

Storrs, CT 06269-3060

402. Kenneth A. Kovaly

Technical Insights, Inc.

P.0. Box 1304

Fort Lee, NJ 07024-9967

403. Ralph G. Kraft

Spraying Systems Company

North Avenue at Schmale Road

Wheaton, IL 60189-7900

404. Saunders B. Kramer

U.S. Department of Energy Advanced Propulsion Division CE-322, Forrestal Building Washington, DC 20585
405. Arthur Kranish

Trends Publishing, Inc.

1079 National Press Building

Washington, DC 20045

406. A. S. Krieger

Radiation Science, Inc.

P.0. Box 293

Belmont, MA 02178

407. Pieter Krijgsman

Ceramic Design International Holding B.V.

P.0. Box 68

Hattem 8050-AB

THE NETHERLANDS AIR MAIL

408. Waltraud M. Kriven

University of Illinois

Materials Science and

Engineering Department

105 South Goodwin Avenue

Urbana, IL 61801

409. Edward J. Kubel, Jr.

ASM International Advanced

Materials \& Processes

Materials Park, OH 44073

410. Dave Kupperman

Argonne National Laboratory

9700 South Cass Avenue

Argonne, IL 60439

411. Oh-Hun Kwon

Norton Company

Advanced Ceramics

Goddard Road

Northboro, MA 01532-1545

412. W. J. Lackey

Georgia Institute of TechnoTogy

Materials Science and

Technology

Atlanta, GA 30332

413. Jai Lala

Tenmat Ltd.

40 Somers Road

Rugby Warwickshire CV22 7DH

ENGLAND AIR MAIL 
414. Hari S. Lamba

General Motors Corporation

Electro-Motive Division

9301 West 55th Street

LaGrange, IL 60525

415. Richard $L$. Landingham

Lawrence Liverwore National Laboratory

Ceramics, Corrosion, and

Thermochemistry

P.0. Box 808, L-369

Livermore, CA 94550

416. Charles J. Landry

Chand Kare Technical Ceramics

712 Flat Hill Road

Lumenburg, MA 01462

417. Manfred W. Langer

Volkswagen AG

Material Technology

3180 Wolfsburg 1

GERMANY AIR MAIL

418. James Lankford

Southwest Research Institute

Department of Materials

Sciences

6220 Culebra Road

San Antorio, TX 78228-0510

419. Staniey B. Lasday

Business News Publishing Co.

Manor Oak One

1910 Cochran Road, Suite 630

Pittsburgh, PA 15220

420. Mark S. Laser

Solar Turbines, Inc.

2211 Erie Street

San Diego, CA 92110

421. S. K. Lau

Carborundum Company

Technology Division

P.0. Box 832, B-100

Niagara Falls, NY 14302

422. Edward A. Lauder

Advanced Composite Materials Corporation

1525 South Buncombe Road

freer, SC 2955!-9209

423. J. Lawrence Lauderdale

Babcock \& Hilcox

Contract Research Division

1850 "K" Street, Suite 950

Washingtion, DC 20006

424. Harry A. Lawler

Carbiorundum Company

Technology Division

P.0. Box 832

Miagara Fal7s, MY 14302

425. Jean F. LeCostaouec

Textron Speciality Materials

2 Industrial Avenue

Lowe11, MA 01851

426. Benson P. Lee

Interscience, Inc.

9718 Lake Shore Boulevard

Cleveland, OH 44108

427. Burktrand I. Lee

Clenson University

Departarent of Ceramic Engineering

01 in Hall

Clemson, SC 29634-0907

428. June-Gunn Lee

KIST

Structural Ceramic Lab

P.0. B10x 131, Cheong-Ryang

Seoul 130-650

KOREA AIR MAIL

429. Ran-Rong Lee

Ceramics Process Systems

Corporation

155. Fortune Boulevard

Mitford, MA 01757

430. Stan Levine

MASA L.ewis Research Center

21000 Brookpark Road

MS: 49.3

Cieveland, OH 44135

431. ATain V. Levy

Laurence Berkeley Laboratory

Onf Cyclotron Road, MS:62-203

Berkeley, CA 94720 
432. Ai-Kang Li

Materials Research Laboratories, ITRI

195-5 Chung-Hsing Road, Sec. 4 Chutung Hsinchu 31015 R.O.C.

TAIWAN AIR MAIL

433. Winston H. Liang

Hong Kong Industrial Technology Centre Co. Ltd.

78 Tat Chee Avenue

4/F, HKPC Building

Howloon

HONG KONG AIR MAIL

434. Robert Licht

Norton Company

Advanced Ceramics

Goddard Road

Northboro, MA 01532-1545

435. E. Liliey

Norton Company

Advanced Ceramics

Goddard Road

Northboro, MA 01532-1545

436. Laura J. Lindberg

Allied-Signal Aerospace

Company

Garrett Fluid Systems Division

1300 West Warner

MS: 93-901-1207-4TT

P.0. Box 22200

Tempe, AZ 85284-2200

437. Leonard C. Lindgren

General Motors Corporation

Allison Gas Turbine Division

P.0. Box 420, Speed Code:T-20A

Indianapol is, IN 46206-0420

438. Hans A. Lindner

Cremer Forschungsinstitut GmbHaCO.KG

Oeslauer Strasse 35

D-8633 Rodenta 18866

GEPMANY

AIR MAIL
439. Ronald E. Loehman

Sandia National Laboratories

Chemistry Ceramics Department 1840

P.0. Box 5800

Aibuquerque, NM 87185

440. Jeffrey C. Logas

Winona State University

Composite Materials

Engineering

115 Pasteur Hall

Winona, MN 55987

441. Bill Long

Babcock Wilcox

P.0. Box 11165

Lynchburg, VA 24506

442. William D. Long

Wacker Chemicais (USA), Inc.

ESK Engineered Ceramics

50 Locust Avenue

New Canaan, CT 06840

443. L. A. Lott

EGeG Idaho, Inc.

Idaho National Engineering Laboratory

P.0. Box 1625

Idaho Falls, ID 83415-2209

444. Raouf 0. Loutfy

MER Corporation

7960 South Kolb Road

Tucson, AZ 85706

445. Gordon R. Love

Aluminum Company of America

Alcoa Technical Center

Alcoa Center, PA 15069

446. Lydia Luckevich

Ortech International

2395 Speakman Drive

Mississauga Ontario L5K 183

CANADA AIR MAIL. 
447. James W. MacBeth

Carborundum Company

Structural Ceramics Division

P.0. Box 1054

Niagara Falis, NY 14302

448. H. Maclaren

General Electric Company

Thomson Laboratory, Materials

Engineering 36807

1000 . Western Avenue

Lynn, MA 01910

449. George Maczura

Aluminum Company of America

Industrial Chemicals Division

670 One Allegheny Square

Pittsburgh, PA 15212

450. David Maginnis

Tinker AFB

OC-ALC/LIIRE

Tinker AFB OK 73145-5989

451. Frank Maginnis

Aspen Research, Inc.

220 Industrial Boulevard

Moore, OK 73160

452. Tai-il Mah

Universal Energy Systems, Inc.

Ceramics and Composites Research

4401 Dayton-Xenia Road

Dayton, $\mathrm{OH} 45432$

453. Kenneth M. Maillar

Barbour Stockwell Company

83 Linskey Way

Cambridge, MA 02142

454. Lorenzo Majno

Instron Corporation

100 Royal 1 Street

Canton, MA 02021

455. S. G. Malghan

Naitonal Institute of Standards and Technology

I-270 \& Elopper Road

Gaithersburg, MD 20899
456. Lars Malmrup

United Turbine AB

Box 13027

Malmo S-200 44

SWEDEN AIR MAIL

457. John Mangels

Ceradyne, Inc.

3169 Redhill Avenue

Costa Mesa,-CA 92626

458. Russell V. Mann

Matec Applied Sciences, Inc.

75 South Street

Hopkinton, MA 01748

459. Willitam R. Manning

Champion Aviation Products Division

old Norris Road

P.0. Box 686

Liberty, SC 29657

460. Ken Marnoch

Amercom, Inc.

8928 Fuilbright Avenue

Chatsworth, CA 91311

461. Robert A. Marra

Aluminum Company of America

Alcoa Technical Center

Advanced Ceramics Center - E

Alcoa Center, PA 15069

462. Chauncey L. Martin

3M Company

3M Center, Building 60-1N-01

St. PauT, MN 55144

463. Steven C. Martin

Advanced Refractory

Technologies, Inc.

699 Hertel Avenue

Buffalo, NY 14207

464. Kelly J. Mather

Williams International Corporation

2280 West Maple Road

P.0. Box 200

Walled Lake, MI 48088 
465. James P. Mathers

3M Company

$3 M$ Center

Building 201-3N-06

St. Paui, MN 55144

466. Marshall Mayer

Instron Corporation

3815 Presidential Parkway, Suite 100

Atianta, GA 30340

467. Ron Mayvilile

Arthur D. Little, Inc.

15-163 Acorn Park

Cambridge, MA 02140

468. F. N. Mazadarany

General Electric Company

Research Laboratory

Building K-1, Room MB-159

P.0. Box 8

Schenectady, NY 12301

469. James W. McCauley

Alfred University

NYS College of Ceramics

Binns-Merrill Hall

Alfred, NY 14802

470. Carolyn McCormick

Allied-Signal Aerospace Company

Garrett Auxiliary Power Division

Bldg. 1303-206

P.O. Box 5227, MS:9317-2

Phoenix, AZ 85010

471. Louis R. Mccreight

2763 San Ramon Drive

Rancho Palos Verdes, CA 90274

472. Colin F. McDonald

McDonald Thermal Engineering

1730 Castellana Road

La Jolla, CA 92037

473. B. J. McEntire

Morton Company, TRW Ceramics Goddard Road

Northboro, MA 01532-1545
474. Chuck McFadden

Coors Ceramics Company

600 9th Street

Golden, CO 80401

475. Henry McFadden

Magnetic Bearings, Inc.

Engineering Library

609 Rock Road

Radford, VA 24141

476. Thomas D. McGee

Iowa State University

Materials Science and

Engineering Department

110 Engineering Annex

Ames, IA 50011

477. Carol McGill

Corning Inc.

Sullivan Park, FR-02-08

Corning, NY 14831

478. T. C. McLaren

Cameron Forged Products Company

P.0. Box 1212

Houston, TX 77251-1212

479. James McLaughl in

Sundstrand Power Systems

4400 Ruffin Road

P.0. Box 85757

San Diego, CA 92186-5757

480. Arthur F. McLean

6225 North Camino Almonte

Tucson, AZ 85718

481. Matt McMonigie

U.S. Department of Energy

Improved Energy Productivity Division

Forrestal Building, CE-231

Washington, DC 20585

482. Dennis McMurtry

EG\&G Idaho, Inc.

Idaho National Engineering Laboratory

P.0. Box 1625

Idaho Falls, ID 83415 
483. D. B. Meadowcroft National Power Technology and Environmental Centre

Kelvin Avenue

Leatherhead Surrey KT22 7SE

ENGLAND AIR MAIL

484. Jo Meglen

11004 Birdfoot Court

Reston, VA 22091

485. Pankaj K. Mehrotra

Kennametal, Inc.

P.0. Box 639

Greensburg, PA 15601

486. Joseph J. Meindl

Reynolds International, Inc. 6603 West Broad Street

P.0. Box 27002

Richmond, VA 23261-7003

487. Michael D. Meiser

All ied-Signal Aerospace Company

Garrett Ceramic Components

Division

19800 South Van Ness Avenue

Torrance, CA 90509

488. George Messenger

National Research Council of Canada

Engine Laboratory

Building M-7

Ottawa Ontario KIA OR6

CANADA AIR MAIL

489. D. Messier

U.S. Army Materials Technology Laboratory

SLCMT-EMC

405 Arsenal Street

Watertown, M4 02172-0001

490. Gary L. Messing

Pennsyivania State University

Ceramic Science and Engineering Department

119 Steidle Building

University Park, PA 16802
491. Arthur G. Metcalfe

Arthur G. Metcalfe and

Associates, Inc.

2108 East 24th Street

National City, CA 91950

492. R. Metselaar

Eindhoven University

Centre for Technical Ceramics

P.O. Box 513

Eindhoven 5600 MB

THE NETHERLANDS

AIR MAIL

493. Nancy S. Meyers

U.S. Department of Energy

Transportation Technologies

CE-30, Forrestal Building 6B-094

Washington, DC 20585

494. David J. Michael

Harbison-Walker Refractories Company

P.0. Box 98037

Pittsburgh, PA 15227

495. Ken Michaels

Chrysier Motors Corporation

Ceramics Development Metallurgical Processes

P.0. Box 1118, CIMS: 418-17-09

Detroit, MI 48288

496. Bernd Miche1

Institute of Mechanics

Fracture and Micromechanics Department

P. 0. Box 408

D-9010 Chemnitz

GERMANY AIR MAIL

497. David E. Miles

Commission of the European Communities

rue de la Lot, 200

B-1049 Brusseis

BELGIUM AIR MAIL

498. John V. Milewski

Superkinetics, Inc.

P.0. Box 8029

Santa Fe, NM 87504 
499. Carl E. Miller

AC Rochester

1300 North Dort Highway, MS: 32-31

Engineering Building B

Flint, MI 48556

500. Mike Miller

McGraw-Hill Aviation Week

Performance Materials

1156 15th Street, N.W.

Washington, DC 20005

501. Charles W. Miller, Jr.

Centorr Furnaces/Vacuum Industries

542 Amherst Street

Nashua, NH 03063

502. R. Mininni

Enichem America

2000 Cornwall Road

Monmouth Junction, NJ 08852

503. Michele V. Mitchell

Allied-Signal Aerospace Company

Garrett Ceramic Components Division

19800 South Van Ness Avenue

Torrance, CA 90501-1149

504. Howard Mizuhara

GTE - WESGO

477 Harbor Boulevard

Beimont, CA 94002

505. Helen Moeller

Babcock \&ilcox

P.0. Box 11165

Lynchburg, VA 24506-1165

506. Francois R. Mollard

Metalworking Technology, Inc.

1450 Scalp Avenue

Johnstown, PA 15904

507. Phil Mooney

Panametrics

NDE Division

221 Crescent Street

Wal tham, MA 02254
508. Thomas Morel

Ricardo North America

645 Blackhawk Drive

Westmont, IL 60559

509. Geoffrey P. Morris

3M Company

3M Traffic Control Materials

Division

Bldg. 209-BW-10, 3M Center

St. PauT, MN 55144-1000

510. Jay A. Morrison

Rolls-Royce, Inc.

Engineering and Information Center, Overlook 1

2849 Paces Ferry Road, Suite 450

Atlanta, GA 30339-3769

511. Joel P. Moskowitz

Ceradyne, Inc.

3169 Redhill Avenue

Costa Mesa, CA 92626

512. Brij Moudgi1

University of Florida

Material Science and Engineering

Gainesville, FL 32611

513. Christoph J. Mueller

Sprechsaal Publishing Group

P.0. Box 2962, Mauer 2

D-8630 Coburg

GERMANY AIR MAIL

514. Thomas W. Mullan

Vapor Technologies Inc.

345 Route 17 South

Upper Saddle River, NJ 07458

515. M. K. Murthy

MKM Consultants International

10 Avoca Avenue, Unit 1906

Toronto Ontario M4T 2B7

CANADA AIR MAIL

516. Solomon Mustkant

TransCon Technologies, Inc.

Materials Science Engineering 1508 Waynesboro Road

Paolf, PA 19301 
517. David L. Mustoe

Custom Technical Ceramics

8041 West 1-70 Service Road, Unit 6

Arvada, CO 80002

518. Curtis V. Nakaishi

U.S. Department of Energy

Morgantown Energy Technology Center

Collins Ferry Road

P.0. Box 880

Morgantown, WV 26507-0880

519. Yoshio Nakamura

Faicera Research Institute 2-5-8 Hiyakun in-cho Shinjuku-Ko Tokyo JAPAN

AIR MAIL

520. K. S. Narasimhan Hoeganaes Corporation River Road

Riverton, NJ 08077

521. Samuel Natansohn

GTE Laboratories, Inc. 40 Sylvan Road

Wa7tham, MA 02254

522. Robert Naum

Applled Resources, Inc.

P.0. Box 241

Pittsford, NY 14534

523. Malcolm Naylor

Cummins Engine Company, Inc.

P.0. Box 3005, Mail Code 50183

Columbus, IN 47202-3005

524. Jeffrey Nei1

GTE Laboratories, Inc.

40 Sylvan Road

Wal tham, MA 02254

525. Fred A. Nichols

Argonne National Laboratory

9700 South Cass Avenue

MCT - Building 212

Argonne, IL 60439
526. H. Nickel

Furschungszentrum Jüelich (KFA)

P.0. Box 1913

Jüel ich 1-5170 BRD NRW

GERMANY AIR MAIL

527. Dale E. Niesz

Rutgers University

Center for Ceramic Research

P.0. Box 909

Piscataway, Nu 08855-0909

528. David M. Nissley

United Technologies Corporation

Pratt \& Whitney Aircraft

400 Main Street, MS: 163-10

East Hartford, CT 06108

529. Richard D. Nixdorf

ReMaxCo Technologies, Inc.

11317 Snyder Road

Knoxville, TN 37932

530. Bernard North

Kennametal, Inc.

P.0. Box 639

Greensburg, PA 15601

531. Bruce E. Novich

Ceramics Process Systems Corporation

155 Fortune Boulevard

Milford, MA 01757

532. Daniel Oblas

GTE Laboratories, Inc.

40 Sylvan Road

Waltham, MA 02254

533. Don Ohanehi

Magnet ic Bearings, Inc.

1908 Sussex Road

Blacksburg, VA 24060

534. Robert Orenstein

General Electric Company

55-112, River Road

Schenectady, NY 12345 
535. Norb Osborn

Aerodyne Dallas

151 Regal Row, Suite 120

Dallas, TX 75247

536. A. M. Paddick

BP International Limited

BP Research Centre, Main Library

Chertsey Road

Sunbury-on-Thames

Middlesex TW16 7LN

UNITED KINGDOM

AIR MAIL

537. Russe11 J. Page

Kanthal-Artcor

3001 Redhill Avenue, II-109

Costa Mesa, CA 92705

538. Richard Palicka

Cercom, Inc.

1960 Watson Way

Vista, CA 92083

539. Muktesh Paliwal

GTE Products Corporation

Hawes Street

Towanda, PA 18848

540. Joseph E. Palko

General Electric Company

55-113, River Road

Schenectady, NY 12345

541. Hayne Palmour, III

North Carolina Stiste University

Materials Science and Engineering Dept.

Raleigh, NC 27605-7905

542. Joseph N. Panzarino

Norton Company

Advanced Ceramics

Goddard Road

Northboro, MA 01532-1545

543. Pellegrino Papa

Corning Inc.

MP-WX-02-1

Corning, NY 14831
544. E. Beth Pardue

Technology for Energy

Corporation

One Energy Center

P.0. Box 22996

Knoxville, TN 37933-0996

545. Soon C. Park

3M Company

3M Center

Building 142-4N-02

P. O. Box 2963

St. Paut, MN 55144

546. Hartmut Paschke

Schott G1 aswerke

Christoph-Dorner-Strasse 29

D-8300 Landshut

GERMANY AIR MAIL.

547. Marina R. Pascucci

GTE Laboratories, Inc.

40 Sylvan Road

Waltham, MA 02254

548. James W. Patten

Cummins Engine Company, Inc.

Materials Engineering

P.0. Box 3005, Mail Code 50183

Columbus, IN 47202-3005

549. Robert A. Penty

Eastman Kodak Company

KAD/D73 - 35612

901 Elmgrove Road

Rochester, NY 14653

550. Robert W. Pepper

Textron Specialty Materials

2 Industrial Avenue

Lowe 11, MA 01851

551. Peter Perdue

Detroit Diesel Corporation

Research Advanced Development Group

13400 West Outer Drive, Speed Code A-07

Detroit, MI 48239-4001 
552. Bruce Peters

Dow Chemical Company

Butlding 52

Midland, MI 48667

553. John J. Petrovic

Los Al amos National Laboratory

Group MST-4, MS:6771

Los Alamos, NM 87545

554. Frederick S. Pettit

University of Pittsburgh

Pittsburgh, PA 15261

555. Ben A. Phillips

Phillips Engineering Company

721 Pleasant Street

St. Joseph, MI 49085

556. Richard C. Phoenix

Ohmtek, Inc.

2160 Liberty Drive

Niagara Falis, NY 14302

557. Bruce J. Pletka

Michigan Technological University

Metallurgical and Materials Engineering Department

Houghton, MI 49931

558. John P. Pollinger

Garrett Ceramic Components

19800 Van Ness Avenue

Torrance, CA 90501

559. P. Popper

High Technology Ceramics International Journal

22 Pembroke Drive

Westlands NewCastle-under-Lyme Staffs ST5 2 JN

ENGLAND AIR MAIL

560. F. Porz

Universitat Karlsruhe

Institut fur Keramik Im Maschinendau

Postfach 6980

D-7500 Karlsruhe

GERMANY AIR MAIL
561. Harry L. Potma

Royal Netherlands Embassy

Science and Technology

4200 Linnean Avenue, N.W.

Washington, DC 20008

562. Bob R. Powel1

General Motors Research

Laboratories

Metallurgy.Department

30500 Mound Road

Box 9055

Warren, MI 48090-9055

563. Stephen C. Pred

ICD Group, Inc.

1100 Valley Brook Avenue

Lyndhurst, NJ 07071

564. Karl M. Prewo

United Technologies Research Center

411 Silver Lane

MS: 24

East Hartford, CT 06108

565. Peter E. Price

Industrial Materials Technology, Inc.

P.0. Box 9565

Andover, MA 01810

566. Joseph M. Proud

GTE Laboratories, Inc.

Materials Science Laboratory

40 Syivan Road

Waltham, MA 02254

567. Vimal K. Pujari

Norton Company

Advanced Ceramics

Goddard Road

Northboro, MA 01532-1545

568. George Quinn

National Institute of

Standards and Technology

Ceramics Division, Bidg. 223

Gaithersburg, MD 20899 
569. Ramas V. Raman

Ceracon, Inc.

1101 North Market Boulevard, Suite 9

Sacramento, CA 95834

570. Charles F. Rapp

Owens Corning Fiberglass

2790 Columbus Road

Granville, OH 43023-1200

571. Dennis H. Readey

Colorado School of Mines

Department of Metallurgy and Materials Engineering Golden, CO 80401

572. Wilfred J. Rebello

PAR Enterprises, Inc.

12601 Clifton Hunt Lane

Ciffton, VA 22024

573. Harold Rechter

Chicago Fire Brick Company

R\&D

7531 South Ashl and Avenue

Chicago, IL 60620

574. Robert R. Reeber

U.S. Army Research Office

P.0. Box 12211

Research Triangle Park, NC 27709

575. K. L. Reifsnider

Virginta Polytechnic Institute and State University

Department of Engineering Science and Mechanics

Blacksburg, VA 24061

576. Paul E. Rempes

McDonnell Douglass Missle Systems Company

P.0. Box 516, Mail Code: 1066086

St. Louis, MO 63166-0516

577. Gopal S. Revankar John Deere Company Metals Research 3300 River Drive Moline, IL 61265
578. K. T. Rhee

Rutgers University

Mechanical Engineering

P.0. Box 909

Piscataway, NJ 08854

579. James Rhodes

Advanced Composite Materials

Corporation

1525 South Buncombe Road

Greer, SC 29651

580. Roy W. Rice

W. R. Grace and Company

7379 Route 32

Columbia, MO 21044

581. David W. Richerson

2093 East Delmont Drive

Salt Lake City, UT 84117

582. Tomas Richter

J. H. France Refractories

1944 Clarence Road

Snow Shoe, PA 16874

583. Michel Rigaud

Ecole Polytechnique

Campus Universite De Montreal

P.0. Box 6079, Station A

Montreal, P.Q Quebec H3C $3 A 7$

CANADA AIR MAIL

584. R. E. Riman

Rutgers University

Ceramics Engineering Department

P.0. Box 909

Piscataway, NJ 08855-0909

585. Barry Ringstrom

Superior Graphite Company

P.0. Box 2373

Smyrna, GA 30081

586. John E. Ritter

University of Massachusetts

Mechanical Engineering Department

Amherst, MA 01003 
587. Frank L. Roberge

Allied-Signal Aerospace
Company
Garrett Aux 17 tary Power
Division
P.O. Box 5227
Phoenix, AZ 85010

588. W. Eric Roberts Advanced Ceramic Technology, Inc. 990 " $F$ " Enterprise Stroet Orange, CA 92667

589. Martha Rohr U.S. Department of Energy DOE Oak Ridge Field Office Butlding $4500 \mathrm{~N}$ P.O. Box 2008, MS: 6269 Oak Ridge, TN 37831-6269

590. Y. G. Roman

TNO TPD Keramick

P.0. Box 595

Einhoven 5600 AN HOLLAND AIR MAIL

591. Mark D. Roos

Carborundum Company

P.0. Box 156

Niagara Falls, NY 14302

592. Michael Rossetti

Arthur D. Little, Inc.

15 Acorn Park

Cambridge, MA 01240

593. Barry R. Rossing

Lanxide Corporation

1300 Marrows Road

Newark, DE 19714-6077

594. Steven L. Rotz Lubrizol Corporation 29400 Lakel and Boulevard Wickliffe, OH 44092

595. Bruce Rubinger Global Competitiveness, Inc. One Devonshire Place, Suite 1011 Boston, MA 02109

596. Robert Ruh

Wright Laboratory

WL/MLLM

Wright-Patterson AFB, OH 45433

597. Robert J. Russe11

17 Highgate Road

Framingham, MA 01701

598. L. Will tam Sahley

Supermaterials Company

$24400 \mathrm{Highl}$ and Road

Richmond Hoights, OH 44143

599. Jon Salem

NASA Lewis Research Center

21000 Brookpark Center

Clevel and, $\mathrm{OH} 44135$

600. W. A. Sanders

NASA LeWis Research Center

21000 Brookpark Road,

MS : 49-3

Clevel and, $\mathrm{OH} 44135$

601. J Sankar

North Carolina A\&T State University

Department of Mechanical Engineering

Greensboro, NC 27411

602. Yasushit Sato

NGK Spark Plugs (U.S.A.), Inc.

1200 Business Center Drive, Suite 300

Mt. Prospect, IL 60056

603. Maxine L. Savitz

Allied-Signal Aerospace Company

Garrett Ceramic Components Division

19800 South Van Ness Avenue

Torrance, CA 90501

604. Ashok Saxena

Georgia Institute of

Technology

Materials Engineering

At1 anta, GA 30332-0245 
605. David W. Scanlon

Instron Corporation

100 Royall Street

Canton, MA 02021

606. Charles A. Schacht

Schacht Consulting Services

12 Holl and Road

Pittsburgh, PA 15235

607. James Schlente

All ted-Signal Aerospace Company

Garrett Auxillary Power Division

2739 East Washington Street

P.0. Box 5227, MS:1302-2P

Phoenix, AZ 85010

608. John C. Schneider

San Juan Technologies

P.0. Box 49326

Colorado Springs, CO 80949-9326

609. Gary Schnittgrund

Rocketdyne, BA05

6633 Canoga Avenue

Canoga Park, CA 91303

610. Mark Schomp

Lonza, Inc.

Corporate Headquarters

17-17 Route 208

Fair Lann, NJ 07410

611. Joop Schoonman

Delft University of Technology

Laboratory for Inorganic Chemistry

P.0. Box 5045

2600 GA Delft

THE NETHERLANDS

AIR MAIL.

612. John Schuldies

Industrial Ceramic Technology, Inc.

37 Enterprise Drive

Ann Arbor, MI 48103
613. Robert B. Schulz

U.S. Department of Energy

Office of Transportation

Materials

CE-34, Forrestal Building

Washington, DC 20585

614. Murray A. Schwartz

Materials Technology

Consulting, Inc.

30 Orchard Way, North

Potomac, MD 20854

615. Peter Schwarzkopf

SRI International

333 Ravenswood Avenue

Men1o Park, CA 94025

616. Thomas C. Schweizer

Princeton Economic

Research, Inc.

12300 Twinbrook Pkwy., Suite 650

Rockville, MD 20852

617. William T. Schwessinger

Multi-Arc Scientific

Coatings

1064 Chicago Road

Troy, MI 48083-4297

618. W. D. Scott

University of Washington

Materials Science Department

Mail Stop:FB10

Seattle, WA 98195

619. Nancy Scovilie

Thermo Electron Technologies

74 West Street

P.0. Box 9046

Wal tham, MA 02254-9046

620. Brian Seegmiller

Coors Ceramics Company

600 9th Street

Golden, CO 80401 
621. T. B. Selover

AICRE/DIPPR

3575 Traver Road

Shaker Heights, OH 44122

622. J. H. Selverian

GTE Laboratories, Inc.

40 Sylvan Road

Waltham, MA 02254

623. Charles E. Semler

Semler liaterials Services

4160 Mumford Court

Columbus, $\mathrm{OH} 43220$

624. Thomas Service

Service Engineering Laboratory

324 Wells Street

Greenfield, MA 01301

625. Kish Seth

Ethyl Corporation

R\&D Laboratories

P.0. Box 341

Baton Rouge, LA 70821

626. Karleen Seybold

Allied-Signal Aerospace Company

Garrett Auxiliary Power Division

P.0. Box 5227

Phoenix, AZ 85010

627. William J. Shack

Argonne National Laboratory

9700 South Cass Avenue

Billding 212

Argonne, IL 60439

628. Peter T. B. Shaffer

Technical Ceramics Laboratories, Inc. $4045 \mathrm{Nine} / \mathrm{McF}$ arl and Drive A] pharetta, GA 30201

629. Richard K. Shaltens NASA Lewis Research Center 21000 Brookpark Road, MS: $301-2$

Cleveland, $\mathrm{OH} 44135$
630. Robert S. Shane

238 Heinlock Road

Wynnewood, PA 19096

631. Daniel Shanefield

Rutgers University

Ceramics Engineering Department

P.0. Box 909

Piscataway,- NJ 08855-0909

632. Ravi Shankar

Chromalloy

Research and Technology Division

Blaisdell Road

Orangeburg, NY 10962

633. Terence Sheehan

Alpex Wheel Company

727 Berkley Street

New Milford, NJ 07646

634. Dinesh K. Shetty

University of Utah

304 EMRO, Dept. of Materials

Science and Engineering

Salt Lake City, UT $\mathbf{8 4 1 1 2}$

635. Masahide Shimizu

Ceramic Society of Japan

2-2-503 Takiyama 6-chome

Higash ikurume-Shi Tokyo 203

JAPAN AIR MAIL.

636. John Shipinski

Toyota Technical Center U.S.A., Inc.

Technical Research Department

2000 Town Center, Suite 500

Southfield, MI 48075

637. Thomas Shreves

Amertcan Ceramic Society, Inc.

Library

757 Brooksedge Plaza Drive

Westerville, OH 43081-2821

638. Jack D. Sibold

Coors Ceramics Company

Contracts for Corporate Technology

4545 McIntyre Street

Goiden, 6080403 
639. George H. Siege1

Point North Assoctates, Inc.

P.0. Box 907

Madison, NJ 07940

640. Richard silberglitt

Technology Assessment and Transfer, Inc.

133 Defense Highway, \#212

Annapolis, MD 21401

641. Mary Silverberg

Norton Company

Advanced Ceramics Library

Goddard Road

Northboro, MA 01532-1545

642. Gurpreet Singh

Department of the Navy

Internal Combustion \& Gas

Turbine Engine Division

Code 56×31

Washington, DC 20362-5101

643. Maurice J. Sinnott

University of Michigan

Chemical and Metallurgical Engineering

5106 IST Building

Ann Arbor, MI 48109-2099

644. John Skildum

3M Company

3M Center

Building 224-2S-25

St. Paul, MN 55144

645. David P. Smith

Hoskins, Rees \& Smith

1910 Cochran Road

Manor Oak II, Suite 658

Pittsburgh, PA 15220

646. Richard H. Smoak

Smoak \& Associates

3554 Hollyslope Road

Altadena, CA 91001-3923
647. Jay R. Smyth

Alited-Signal Aerospace Company

Garrett Auxiliary Power Division

2739 East Washington Street

P.0. Box 5227

MS: $93-173 / 1303-207$

Phoenix, AZ 85010

648. Edward A. Snajdr

Premier Refractories and Chemicals, Inc.

P.0. Box 392

Find 1 ay, $\mathrm{OH} 44815$

649. Rafa1 A. Sobotowski

British Petroleum Company

Technical Center, Broadway

3092 Broadway Avenue

Cleveland, $\mathrm{OH} 44115$

650. A. G. Solomah

SAC International Ltd.

1445 Bonhil1 Road, \#13

Mississauga Ontario L5T IV3

CANADA AIR MAIL

651. S. Somiya

Nishi Tokyo University

3-7-19 Soijo, Setagaya

Tokyo 157

JAPAN AIR MAIL

652. Boyd W. Sorenson

DuPont Lanxide Composites

1300 Marrows Road

P.0. Box 6077

Neward, DE 19707

653. Charles A. Sorrell

U.S. Department of Energy

Advanced Industrial Concepts Division

CE-232, Forrestal Building

Washington, DC 20585 
654. C. Spencer

EA Technology

Capenhurst Chester CHI 6ES

UNITED KINGDOM AIR MAIL

655. Allen Spizzo

Hercules, Inc.

Hercules Plaza

Wilaington, DE 19894

656. Richard M. Spriggs

Alfred University

Center for Advanced Ceramic Technology

Alfred, NY 14802

657. Charles Spuckler

MASA Lewis Research Center

21000 Brookpark Road

MS: 5-11

CTeveland, $\mathrm{OH}$ 44135-3191

658. M. Srinivasan

Material Solutions

P.0. Box 663

Grand Island, NY 14702-0663

659. Gordon L. Starr

Cummins Engine Company, Inc.

Design \& Technology

P.0. Box 3005

Mait Code 50182

Columbus, IN 47202-3005

660. Jim Stevenson

Windrock, Incorporated

154 Fairbanks Plaza

Oak Ridge, TN 37830

661. Tom Stillwagon

Allied-Signal Aerospace Company

Garrett Ceramic Components Division

19800 South Van Ness Avenue

Torrance, CA 90501

662. Harold L. Stocker

General Motors Corporation

Allison Gas Turbine Division P.0. Box 420

Indíanapo? is, In 46205
663. Paul D. Stone

Dow Chemical USA

1775 "Eye" Street, N.W., Suite 575

Washington, DC 20006

664. Roger S. Storm

Carborundum Company

Technology Division

P.0. Box 337

Niagara Falls, NY 14302-0337

1565. Peter A. Stranges

4 Chittenden Lane

Owings Mills, MD 21117

666. F. W. Stringei

Aero \& Industrial

Technology Ltd.

P.0. Box 46, Hood Top

Burniey Lancashire BB11 4BX

UNITED KINGDOM AIR MAIL

667. Thomas N. Strom

MASA Lewis Rese urch Center

21000 Brookpark Road

MS: 86-6

Clevel and, $\mathrm{OH} 44135$

668. M. F. Stroosnijder

Institute for Advanced

Materials

Joint Research Centre

21020 ॥spra (VA)

ITALY AIR MAIL

669. Karsten Styhr

30604 Gianado Drive

Rancho Palos Verdes, CA 90274

670. T. S. Sudarshan

Materials Modification, Inc. 2929-PI Eskridge Center

Fairfax, VA 22031

671. M. J. Sundaresan

University of Miami

Mechanical Engineering Department

P.O. Box 248294

Coral Gables, FL 33124 
672. Patrick L. Sutton

U.S. Department of Energy

Advanced Propulsion Division

CE-322, Forrestal Building

Washington, DC 20585

673. Willard H. Sutton

United Technologies

Corporation

Research Center, MS:24

Silver Lane

East Hartford, CT 06108

674. Ron Sviben

100 Indel Avenue

Rancocas, NJ 08073

675. J. J. Swab

U.S. Army Materials Technology Laboratory

Ceramics Research Division

SLCMT-EMC

405 Arsenal Street

Watertown, MA 02172

676. Robert E. Swanson

Metalworking Technology, Inc.

1450 Scalp Avenue

Johnstown, PA 15904

677. Scott L. Swartz

Battelle Columbus

Laboratories

Metals and Ceramics

505 King Avenue

Col umbus, OH 43201

678. Steve Szaruga

Air Force Wright Aeronautical Laboratory

Materials Directorate

UL/MLBC

Wright-Patterson

AFB, OH 45433-6533

679. Yo Tajima

NGK Spark Plug Company, Ltd.

NTK Technical Ceramic Division 2808 Iwasaki

Komaki-shi Aichi-ken 485

JAPAN AIR MAIL
680. Fred Teeter

5 Tra, ee Terrace

East Amherst, NY 14051

681. Monika O. Ten Eyck

Carborundum Company

Technology Division

P.0. Box 832

Niagara Falls, NY 14302

682. David F. Thompson

Corning Glass Works

SP-DV-02-1

Corning, NY 14831

683. Merle L. Thorpe

Hobart Tafa Technologies, Inc.

146 Pembroke Road

Concord, NH 03301

684. Eberhard Tiefenbacher

Daimler-Benz AG Abt. FIS

Mercedes-Strabe 136

Stuttgart 60

GERMANY AIR MAIL

685. T. Y. Tien

University of Michigan

Materials Science and Engineering Department

Dow Building

Ann Arbor, MI 48103

686. Julian M. Tishkoff

Air Force Office of Scientific Research

AFOSR/MA

Bolling AFB, DC 20332-6448

687. D. M. Tracey

Norton Company

Advanced Ceramics

Goddard Road

Northboro, 01532-1545

688. Dick Trippett

General Motors Corporation

Allison Gas Turbine Division

P.0. Box 420, MS:H-16

Indianapol is, IN 46206-0420 
689. L. J. Trostel, Jr.

Box 199

Princeton, MA 01541

690. W. T. Tucker

General Electric Company

Corporate RSD

Building K1-4C35

P.0. Box 8

Schenectady, NY 12301

691. Masanori Ueki

Nippon Steel Corporation

Central RED Bureau

1618 Ida

Nakahara-Ku Kawasaki 21]

JAPAN AIR MAIL

692. Filippo M. Ugolini

ATA Studio

Via Degli Scipioni, 268A

ROMA 00192

ITALY AIR MAIL

693. Donald L. Vaccari

Allison Gas Turbines

P.0. Box 420

Speed Code 549

Indianapol is, IN 46206-0420

694. Carl F. Van Conant

Boride Products, Inc.

2879 Aero Park Drive

Traverse City, MI 49684

695. Marcel H. Van De Voorde

Commission of the European Communities

Institute for Advanced Materials

Joint Research Centre

P.0. Box 2

1755 Z6 Petten

THE NETHERLANDS AIR MAIL

696. O. Van Der Biest

Katholieke Universiteit Leuven

Departement Metaalkunde en Toegepaste

de Croylaan 2

B-3030 Leuven

BELGIU⿴囗十 AIR MAIL
697. Michael Vannier

Washington University,

St. Louis

Mallinckrodt Institute of Radiology

510 South Kings Highway

St. Louts, MO 63110

698. Stan Venkatesan

Southern Coke \& Coal Corporation

P.0. Box 52383

Knoxville, TN 37950

699. V. Venkateswaran

Carborundum Company

Niagara Falls RQD Center

P.0. Box 832

Niagara Falls, NY 14302

700. Dennis Viechnicki

U.S. Army Materials Technology Laboratory

405 Arsenal Street

Watertown, MA 02172-0001

701. Ted Vojnovich

U.S. Department of Energy

Office of Energy Research, ER-42

Washington, DC 20585

702. John D. Volt

E. I. Dupont de Nemours Company, Inc.

P.0. Box 80262

Wilimington, DE 19880

703. John B. Wachtman

Rutgers University

Ceramics Department

P.0. Box 909

Piscataway, NJ 08855

704. Shigetaka Wada

Toyota Central Research Labs, Inc.

Nagakute Aichi 480-11

JAPAN AIR MAIL 
705. Janet Wade

Allied-Signal Aerospace Company

Garrett Auxiliary Power Division, Department 93-772

P.0. Box 5227, MS: 1303-2

Phoenix, AZ 85010

706. Richard L. Nagner

Ceramic Technologies, Inc.

537 Turtle Creek South Drive, Suite 240

Indi anapol is, IN 46227

707. J. Bruce Hagner, Jr.

Arizona State University

Center for Solid State Science

Tempe, AZ 85287-1704

708. Daniel J. Wahlen

Kohier, Co.

$444 \mathrm{Highland}$ Drive

Kohler, WI 53044

709. Ingrid Wahlgren

Royal Institute of Technology

Studsvik Library

S-611 82 Nykoping

SWEDEN AIR MAIL.

710. Ron H. Halecki

Allied-Signal Aerospace Company

Garrett Ceramic Components Division

19800 South Van Ness Avenue

Torrance, CA 90501

711. Michael S. Walsh

Vapor Technologies Inc.

2100 Central Avenue

Boulder, CO 80301

712. Chien-Min Wang

Industrial Technology Research Institute

Materials Research Laboratories 195 Chung-Hsing Road, Sec. 4 Chutung Hsinchu 31015 R.O.C. TAIWAN AIR MAIL.
713. Robert M. Washburn

ASMT

11203 Colima Road

Whittier, CA 90604

714. Gerald Q. Weaver

Carborundum Specialty Products

42 Linus Allain Avenue

Gardner, MA 01440-2478

715. Karen E. Weber

Detroit Diesel Corporation

Technology and Planning

13400 West Outer Drive

Detroit, MI 48239-40.01

716. R. W. Weeks

Argonne National Laboratory

MCT-212

9700 South Cass Avenue

Argonne, IL 60439

717. Ludwig Weiler

ASEA Brown Boveri AG

Corporate Research

Eppelheimer Str. 82

D-6900 Heidelberg

GERMANY AIR MAIL

718. James Wesse1

Dow Corning Corporation

1800 "Mw Street, N.W., Suite 325 South

Washington, DC 20036

719. Robert D. West

Therm Advanced Ceramics

P.0. Box 220

Ithaca, NY 14851

720. Themas J. Whalen

Ford Motor Company

26362 Harriet

Dearborn Heights, MI 48127

721. Ian A. White

Hoeganaes Corporation

River Road

Riverton, NJ 08077 
722. Alan Whitehead

General Electric Company

1 River Road, 55-111

schenectady, NY 12345

723. Sheldon M. Wiederhorn National Institute of

Standards and Technology Butiding 223, Room A329

Gaithersburg, MD 20899

724. John F. Wight

Alfred University

McMahon Building

Alfred, NY 14802

725. D. S. Wilkinson

McMaster University

Materials Science and

Engineering Department

1280 Main Street, Hest

Hamilton Ontario L.8S 4L7

CANADA AIR MAIL

726. James C. Williams

General Electric Company

Engineering Materials Technology Labs

One Neumann Hay

Mail Drop: H85

Cincinnat $i$, $O H$ 45215-6:01

727. Janette R. Williams

Kollmorgen Corporation

PCK Technology Division

150 Motor Parkway, 262

Hauppauge, AY 11788-5108

728. Steve J. Williams

RCG Hagler Bailly, Inc.

1530 Wi i son Boulevard, Suite 900

Arlington, VA 22209-2406

729. Craig A. Hillkens

Morton Company

Advanced Ceramics

Goddard Road

Northboro, MA 01532-1545
730. Roger R. Wills

TRW, Inc.

Valve Division

1455 East 185th Street

Cleveland, $\mathrm{OH} 44110$

731. David Gordon Wilson

Massachusetts Institute of Technology

Mechanical-Engineering Department

77 Massachusetts Avenue, Room 3-455

Cambridge, MA 02139

732. Matthew F. Winkler

Seaworthy Systems, Inc.

P.O. Box 965

Essex, CT 06426

733. Gerhard Winter

Hermann C. Starck Berl in GmbH, Werk Gosiar

P.O. Box 2540

D-3380 Gos 1 ar 3380

GERMANY AIR MAIL

734. W. L. Winterbottom

Ford Motor Company

Material Systems Reliability

Department

20000 Rotunda Drive

SRL, Room E-3182

P.0. Box 2053

Dearborn, MI 48121

735. David G. Wirth

Coors Ceramics Company

600 9th Street

Golden, CO 80401

736. Thomas J. Wissing

Eaton Corporation

Engineering \& Research Center

P.0. Box 766

Southfield, MI 48037

737. James C. Withers

MER Corporation

7960 South Kolb Road

Building $F$

Tucson, AZ 85706 
738. Dale E. Wittmer Southern Illinois University Mechanical Engineering Department Carbondale, IL 62901

739. Warren W. Wolf Owens Corning Fiberglass 2790 Columbus Road, Route 16 Granville, OH 43023

740. George W. Wolter Howmet Turbine Components Corporation Technical Center 699 Benston Road Whitehal1, MI 49461

741. James C. Wood NASA Lewis Research Center 21000 Brookpark Road MS : 86-6

Cleveland, $\mathrm{OH} 44135$

742. Marrill Wood LECO Corporation Augusta Division P.0. Box 211688 Augusta, GA 30917-1688

743. Wayne L. Worrell University of Pennsylvania Department of Materials Science and Engineering 3231 Walnut Street Philadelphia, PA 19104

744. John F. Wosinski Corning Inc. ME-2 E-5 HB Corning, NY 14830

745. Ian G. Wright Battelle Columbus Laboratories 505 King Avenue Columbus, $\mathrm{OH} 43201$

746. Ruth Wroe ERDC Metals \& Materials Industries Division Capenhurst Chester CHI 6ES ENGLAND AIR MAIL

747. Bernard J. Wrona Advanced Composite Materials Corporation 1525 South Buncombe Road Greer, SC 29651

748. Carl C. M. Wu Naval Research Laboratory Ceramic Branch, Code 6373 Washington, -DC 20375

749. John C. Wurst

University of Dayton Research Institute 300 College Park Dayton, OH 45469-0101

750. Neil Wyant

ARCH Development Corp. 9700 South Cass Avenue Butlding 202 Argonne, IL 60439

751. Roy Yamamoto Texaco Inc. P.0. Box 509 Beacon, HY 12508-0509

752. John Yamanis Allied-Signal, Inc. Ceramics Program P.0. Box 1021 Morristown, NJ 07962-1021

753. Harry C. Yeh All led-Signal Aerospace Company Garrett Ceramic Components Division 19800 South Van Ness Avenue Torrance, CA 90509

754. Hiroshi Yokoyama Hitachi Research Lab 4026 Kuji-Cho Hitachi-shi Ibaraki 319-12 JAPAN AIR MAIL

755. Thomas M. Yonushonis Cummins Engine Company, Inc. P.0. Box 3005 Mall Code 50183 Columbus, IN 47202-3005 
756. Thomas J. Yost

Corning, Inc.

Technical Products Division, Main P1 ant 21-1-2

Corning, NY 14831

757. Jong Yung

Sundstrand Aviation

Operations

Department 789-6

4747 Harrison Avenue

Rockford, IL 61125

758. A. L. Zadoks

Caterpillar Inc.

Techntcal Center, Building L

P.0. Box 1875

Peoria, IL 61656-1875

759. Avi Zangvil

University of Illinots

Materlals Research Laboratory

104 South Goodwin Avenue

Urbana, IL 61801

760. Charles H. Zenuk

Transtech

6529 East Calle Cavalier

Tucson, AZ 85715

761. Anne Marie Zerega

U.S. Department of Energy

Office of Energy Research, ER-42

Washington, DC 20585

762. Ken Z111mer

Applied Test Systems, Inc.

2571 Mt. Gallant Road

Rock Hill, SC 29730

763. Carl Zweben

General Electric Company

P.O. Box 8555, VFSC/V4019

Philadelphia, PA 19101

764. Klaus M. Zwilsky

National Research Council

Mational Materials

Advisory Board

2101 Constitution Avenue

Washington, DC 20418

765. Department of Energy

DOE Field Office, Oak Ridge

Assistant Manager for Energy

Research and Development

P.O. Box 2001

Oak Ridge, TN 37831-8501

766-775. Department of Energy

office of Scientific and

Technical Information

office of Information

Services

P.0. Box 62

Oak Ridge, TN 37831

For distribution by microfiche as shown in DOE/OSTI-4500, Distribution Category UC-332 (Ceramics/Advanced Materials). 

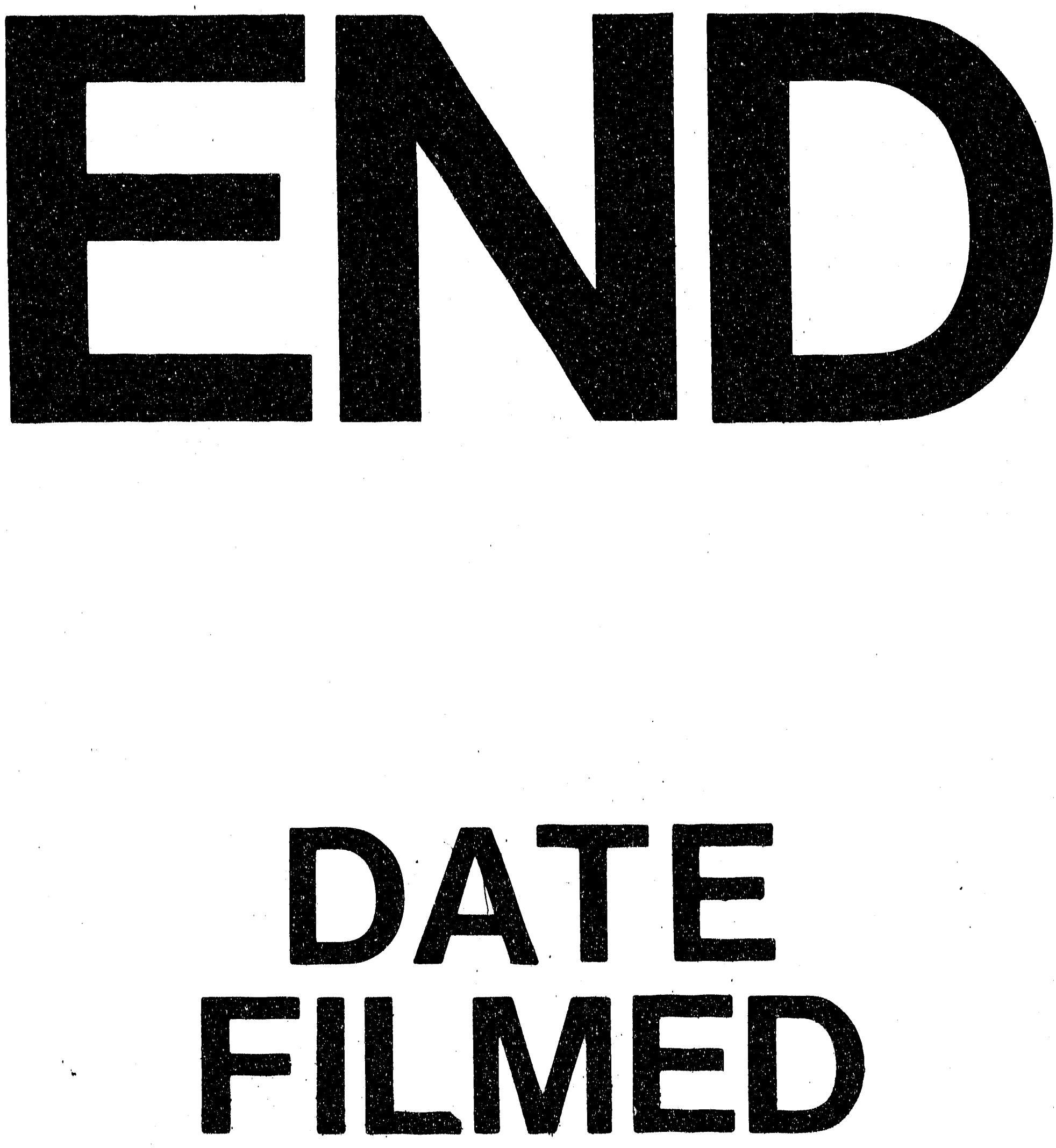

$=$

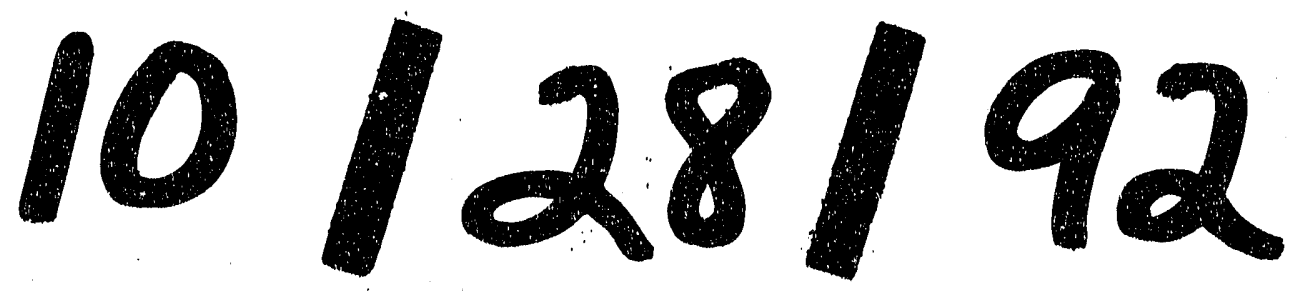


